\title{
Necessity and Proportionality and the Right of Self-Defence in International Law
}

Christopher O'Meara

Faculty of Laws, University College London

Submitted for the degree of PhD

27 July 2018 
I, Christopher O'Meara, confirm that the work presented in this thesis is my own. Where information has been derived from other sources, I confirm that this has been indicated in the thesis. 


\begin{abstract}
When states use force extraterritorially, they invariably claim a right of selfdefence. They also accept that its exercise is conditioned by the customary international law requirements of necessity and proportionality. To date, these requirements have received little attention. They are notorious for being normatively indeterminate and operationally complex. As a breach of either requirement transforms lawful acts of self-defence into unlawful uses of force, increased determinacy regarding their scope and substance is crucial to how international law constrains military force.
\end{abstract}

This thesis addresses this fact. It examines the conceptual meaning, content and practical application of necessity and proportionality as they relate to the right of self-defence following the adoption of the UN Charter. It provides a coherent and up-to-date description of the lex lata and an analytical framework to guide its operation and appraisal. It does this by undertaking the first comprehensive review of relevant jurisprudence, academic commentary and state practice from 1945 to date. Although the operation of necessity and proportionality is highly contextual, the result is a more determinate elaboration of international law that bridges theory and practice. This greater normative clarity strengthens the law's potential to exert a pull towards compliance.

Necessity determines whether defensive force may be used to respond to an armed attack, and where it must be directed. Proportionality governs how much total force is permissible. This thesis contends that the two requirements are conceptually distinct and must be applied in the foregoing order to avoid an insufficient 'catch-all' description of (il)legality. It also argues that necessity and proportionality must apply on an ongoing basis, throughout the duration of an armed conflict prompted by self-defence. This ensures that the purposes of self-defence are met, and nothing more, and that defensive force is not unduly disruptive to third party interests and international peace and security. 


\section{IMPACT STATEMENT}

As an original contribution to existing scholarship, this thesis constitutes a significant development of the academic understanding of international law relating to self-defence. Whilst confirming and updating the existing literature, it also confronts a number of conclusions made by authors in the field. It presents a coherent account of applicable theory, which includes a novel taxonomy that captures more accurately the operation of international law and provides a clearer explanation of the differences between often conflated concepts. It tackles deficiencies and gaps in existing knowledge and advances the subject in a methodologically rigorous fashion.

As well as undertaking a critical review of relevant jurisprudence and academic commentary, this thesis provides the first comprehensive review of state practice since 1945 relating to necessity and proportionality. This developed understanding of international law has significant practical utility beyond academia. For example, the analytical framework set out herein has the potential to benefit future jurisprudence. Should a claim of self-defence be bought before an international court or tribunal, it serves as a judicial guide to necessity and proportionality and the use of defensive force more generally. Moreover, this thesis constitutes a tool for states to justify and legitimate their actions and for other states and international organizations to review more effectively defensive action. It assists, therefore, with improved and more transparent decision-making, whilst operating to limit potential abuse by states that assert an overly broad right of self-defence.

This thesis also represents an important academic resource. Normatively, its arguments and conclusions provide a basis for how jus ad bellum scholars should view the right of self-defence and can develop it in the future. It provides a scholastic tool, therefore, for approaching some of the long-standing debates in the jus ad bellum relating to, inter alia, a right of self-defence against nonstate actors, responding to imminent armed attacks and whether there is a gravity threshold that triggers the right of states to defend themselves. A more 
coherent conception of necessity and proportionality allows for a novel way to tackle these controversial subjects and advance the literature on them.

This author intends to disseminate this work via workshops, seminars and conferences, as well as journal articles and blog posts. Engaging with policy makers and lawyers in governments and international organizations, in addition to military lawyers and non-governmental organizations, allows for academia and practice to be bridged in a meaningful and useful way. Such engagement will be on a national and international basis. This thesis clarifies the scope and content of a notoriously indeterminate area of international law and strengthens its potential to regulate how states use force in self-defence. Working with these key stakeholders allows this potential to be realised. 


\section{ACKNOWLEDGEMENTS}

Writing this thesis has been a transformative process. It has taken me from being a practising lawyer into the wonderful world of academia. This could not have happened without the support of an array of noteworthy people who deserve my sincere gratitude.

First and foremost, I owe so much to Dr Kimberley Trapp, my remarkable primary $\mathrm{PhD}$ supervisor. Dr Trapp has inspired me to be a scholar and an educator, and I am indebted to her for developing and refining my thinking, insisting on precision and for being a source of patient wisdom and friendly encouragement. I thank her for going the extra mile and being so generous with her time, for her unfailing good humour, passion for the project and beautifully detailed feedback. I am lucky indeed to have such a supportive guide and mentor.

I thank Professor Roger O'Keefe, my secondary PhD supervisor, for his frank and incisive comments, delivered with his unique style and valuable rigor. I am also grateful for the backing of my fellow PhD candidates and colleagues at University College London. I thank the Faculty of Laws for generously funding my research, and all the staff that have helped me along the way. Thanks to Dr Steven Vaughan for his guidance regarding structuring my thesis and emphasising its strengths, as well as his counsel for what comes after, namely finding that precious academic job.

My research has also benefitted from my time as a Visiting Researcher at the University of Leiden and at Harvard Law School. Throughout the months spent at these marvellous institutions, I spent many hours sharing my work with students, visitors and faculty members, all of whom have aided its progression. Amongst many others, I am grateful to Dr Erik Koppe, Professor Jack Goldsmith, Professor Ashley Deeks, and Professor Allan Rock.

I am immensely appreciative of the support of my family and friends, and for trying their very best to understand a little of 'what I do'. They have always 
wanted the very best for me and have been there to help me along my chosen path. Special mention goes to Dino Fontes and Claire Jervis who kindly offered to proofread sections of my thesis. I am thankful for their speedy review and attention to detail.

Last, but by no means least, I want to thank my husband, Mike. Mike spurred me on to return to university, and I am lucky to have had him by my side during these years of study. I am grateful for his encouragement and steadfast support (in every sense of that word!), for his patience, love and understanding, and for doing everything humanly possible to help me succeed. I would have not have undertaken this thesis without him, and I can never thank him enough. This thesis is dedicated to Mike. 


\section{TABLE OF CONTENTS}

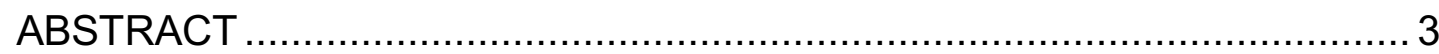

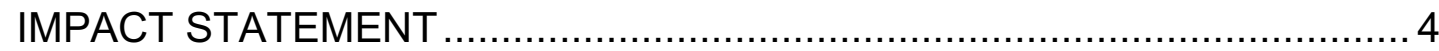

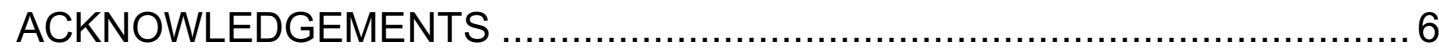

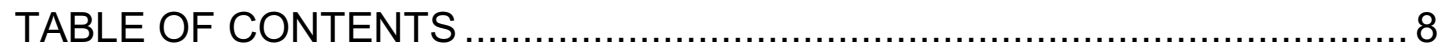

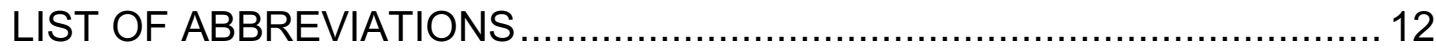

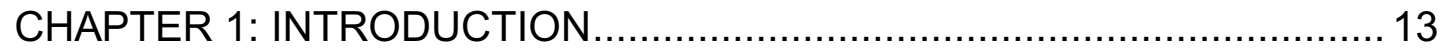

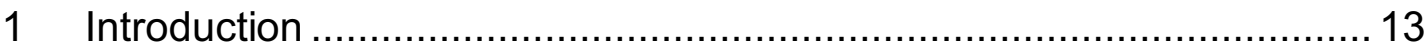

1.1 Context and provenance ......................................................... 13

$1.2 \quad$ Purpose of this thesis...................................................................... 18

1.2.1 Jurisprudence of the International Court of Justice 20

1.2.2 Scholarship 24

1.2.3 State Practice 25

1.3 Thesis structure, arguments and initial observations .................... 27

1.3.1 The nature and function of necessity and proportionality 28

1.3.2 The purposes of the right of self-defence 32

a) Halting, repelling or preventing an armed attack ....................... 32

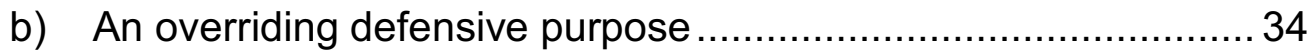

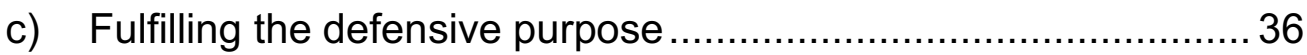

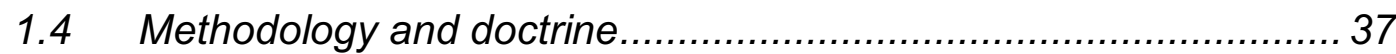

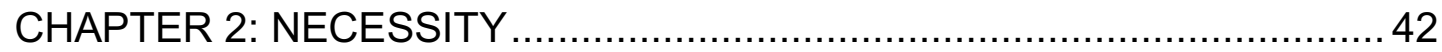

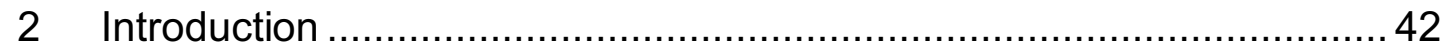

2.1 Necessity in other areas of international law............................... 43

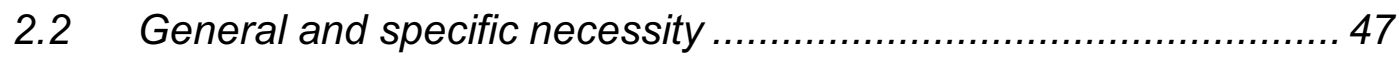

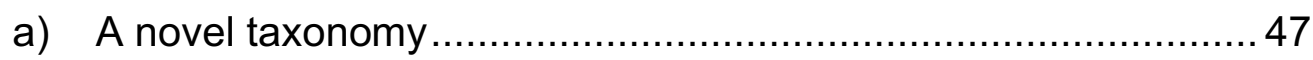

b) General and specific necessity and ICJ jurisprudence ............... 49 
c) General necessity, specific necessity and armed attack. .54

2.3 General necessity - other options open to a state .58

2.3.1 General principles

2.3.2 State practice

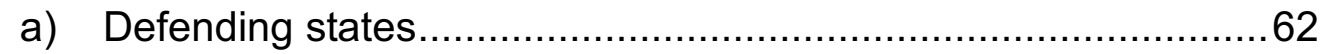

b) Reactions of other states .................................................66

c) Proving general necessity?........................................ 71

2.3.3 ICJ jurisprudence and alternative measures 73

2.3.4 A temporal distinction - ongoing, imminent and completed armed attacks

2.4 General necessity - imminence, immediacy and duration 78

2.4.1 The timing of the armed attack 79

a) Ongoing armed attacks................................................ 79

b) Imminent armed attacks .......................................... 81

c) Completed armed attacks. 89

2.4.2 The timing of the defending state's response to an armed attack 90

a) An immediate need to respond .......................................90

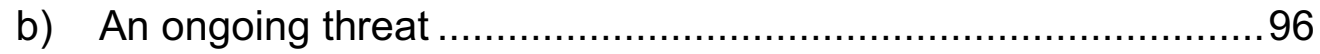

2.5 Specific necessity - targeting ........................................... 105

a) A JAB military target ............................................ 105

b) IHL and a JAB connection with the armed attack ................. 110

2.6 Conclusions......................................................... 116

CHAPTER 3: PROPORTIONALITY ............................................ 118

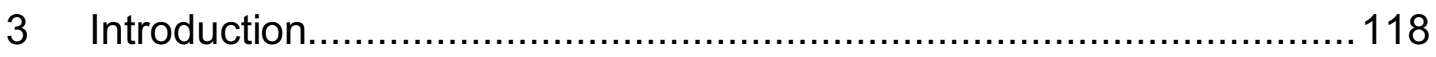

3.1 Proportionate to what? ............................................. 121

3.1.1 Quantitative or teleological proportionality? 122

a) Alternative models and academic opinion .......................... 123

b) State practice - consideration in abstract terms .................... 126

c) State practice - specific incidents and the quantitative model...130

d) State practice - specific incidents and the teleological model...134 
e) State practice - pleadings before the ICJ .......................... 139

f) ICJ jurisprudence ....................................................... 141

3.1.2 A mixed model of proportionality 148

3.2 Applying proportionality and identifying 'excessiveness'............ 152

3.2.1 Scale, nature, methods and means 154

3.2.2 Timing - a distinct element of proportionality? 158

$\begin{array}{ll}3.2 .3 \text { Geography } & 161\end{array}$

a) ICJ jurisprudence .................................................... 161

b) State practice ........................................................... 163

c) Principle and general application...................................... 165

3.2.4 Effect of the use of force on the defending and attacking states $\begin{array}{ll}\text { general considerations } & 167\end{array}$

a) The defending state........................................................ 167

b) The attacking state ...................................................... 168

$\begin{array}{ll}3.2 .5 \text { Civilian harm } & 169\end{array}$

3.2.6 Effect on third-party rights 176

a) General considerations and state responsibility ................... 176

b) Neutrality and former belligerent rights............................ 178

3.2.7 Effect on the environment 185

3.3 Proportionality, IHL and JAB necessity - overlaps and distinctions 188

3.3.1 JAB proportionality v. IHL proportionality 188

3.3.2 JAB proportionality $v$. JAB necessity 195

a) Proportionality and general necessity................................. 196

b) Proportionality and specific necessity............................... 197

3.4 Overall assessment and enduring application ........................ 201

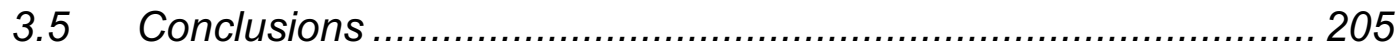

CHAPTER 4: NECESSITY AND PROPORTIONALITY AND ARMED

ATTACKS BY NON-STATE ACTORS ............................................. 207

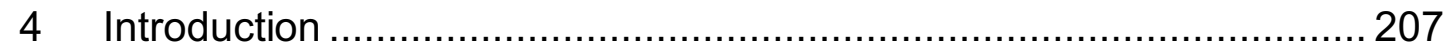

4.1 Necessity and armed attacks by NSAs ................................. 208 
4.1.1 The host state and alternative measures 208

4.1.2 'Unwilling or unable' 214

4.1.3 Targeting the host state - state practice 218

a) Operation Enduring Freedom …...................................... 218

b) Coalition action in Syria .................................................. 220

c) UNSC involvement - a limiting factor .............................235

4.1.4 NSA armed attacks - timing and imminence 238

a) Temporal duration of the right of self-defence .....................238

b) Imminence ................................................................. 240

4.2 Proportionality and armed attacks by NSAs ............................243

4.2.1 A more permissive response vis-à-vis terrorist NSAs 244

4.2.2 Geography 249

4.2.3 Effect on the host state and its citizens 252

a) General considerations............................................ 253

b) Coalition action in Syria ................................................ 258

4.3 Conclusions............................................................... 265

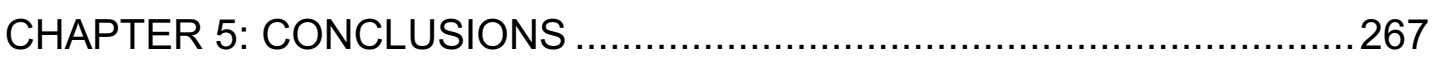

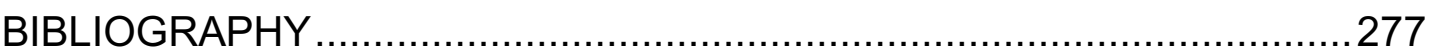




\section{LIST OF ABBREVIATIONS}

\begin{tabular}{|c|c|}
\hline ANC & African National Congress \\
\hline ARSIWA & $\begin{array}{l}\text { ILC Articles on Responsibility of States for Internationally } \\
\text { Wrongful Acts }\end{array}$ \\
\hline DPIH & Directly participating in hostilities \\
\hline EU & European Union \\
\hline ICJ & International Court of Justice \\
\hline ICRC & International Committee of the Red Cross \\
\hline $\mathrm{IHL}$ & International Humanitarian Law \\
\hline IIFFMCG & $\begin{array}{l}\text { Council of the European Union's Independent International Fact- } \\
\text { Finding Mission on the Conflict in Georgia }\end{array}$ \\
\hline ILC & International Law Commission \\
\hline JAB & Jus ad Bellum \\
\hline JUFIL & Journal on the Use of Force and International Law \\
\hline NAM & Non-Aligned Movement \\
\hline NATO & North Atlantic Treaty Organization \\
\hline NSA & Non-state actor \\
\hline UN & United Nations \\
\hline UNGA & United Nations General Assembly \\
\hline UNSC & United Nations Security Council \\
\hline UNYB & The Yearbook of the United Nations \\
\hline VJIL & Virginia Journal of International Law \\
\hline
\end{tabular}




\section{CHAPTER 1: INTRODUCTION}

\section{Introduction}

\subsection{Context and provenance}

The regulation of military force in international relations remains at the forefront of international concern and academic debate. States, the International Court of Justice ('ICJ', or the 'Court') and academic commentators have long ruminated over the meaning and scope of the prohibition of the threat or use of force contained in Article 2(4) UN Charter and the inherent right of individual and collective self-defence recognized by Article 51. ${ }^{1}$ States almost invariably invoke self-defence to justify using force extra-territorially, ${ }^{2}$ even in the most dubious of circumstances when their acts are subsequently condemned. Such 'ritual incantation' ${ }^{3}$ of the right is nearly universally accompanied, either explicitly or implicitly, by assertions that the purported defensive force is necessary or proportionate, or both. ${ }^{4}$ Whilst doubt will always exist regarding the extent to which international law can limit states using force, that they habitually justify their actions in law points to an acceptance that using force is subject to legal constraints. ${ }^{5}$ This topic lies, therefore, at the heart of preserving international peace and security.

The jus ad bellum ('JAB') rules pertaining to the exercise of the right of selfdefence remain a controversial and intensely debated topic and are often difficult to apply in practice. In particular, arguments persist over whether a

\footnotetext{
${ }^{1}$ Charter of the United Nations, 26 June 1945, 892 UNTS 119 ('UN Charter'). Art 2(4) prohibits the threat or use of force against the territorial integrity or political independence of any state, or in any other manner inconsistent with the purposes of the United Nations ('UN'). Art 51 affirms the inherent right of individual or collective self-defence if an armed attack occurs.

2 Schmitt (2002-2003) 543; Gray (2018) 121.

${ }^{3}$ Gray (2018) 125.

${ }^{4}$ Green (2009) 108-9, 208. This conclusion will be explored throughout this thesis. Implicit reference means that a state may not have used the words 'necessary' or 'proportionate', but has nevertheless referred to the content of either, or both, of these requirements when justifying or responding to claims of self-defence.

${ }^{5}$ Sands (2005) 179-80.
} 
threshold of violence is required before a right of self-defence arises, how the right operates in relation to armed attacks by non-state actors ('NSAs'), and temporal issues pertaining to anticipatory self-defence. ${ }^{6}$ Within this context, and as explored further below, it is universally recognized that for defensive force to be lawful, it must be both 'necessary' and 'proportionate'. Necessity and proportionality have been associated with the use of force long before the adoption of the UN Charter in 1945. They formed part of the just war tradition, stretching back centuries. ${ }^{7}$ Although they are not referenced in the UN Charter itself, they are still recognized as 'essential components' of the normative framework pertaining to the use of defensive force. ${ }^{8}$ They form the core of the contemporary right of self-defence. ${ }^{9}$

The requirements of necessity and proportionality are typically derived from the Caroline incident of 1837 . More specifically, their provenance is the ensuing correspondence between Mr Webster, the American Secretary of State, and Lord Ashburton, the British representative in Washington. ${ }^{10}$ The incident stemmed from the rebellion against British rule in Canada. The steamboat Caroline was being used to ship reinforcements and supplies from the USA to the rebels on Navy Island in British controlled Canada. To stop this,

\footnotetext{
${ }^{6}$ These issues are considered in the following Chapters.

${ }^{7}$ For an overview of necessity and proportionality in just war theory, and more generally prior to the adoption of the UN Charter, see Gardam (2004) 28-58.

${ }^{8}$ Institut de Droit International, Tenth Commission, Santiago Session, 27 October 2007, $<$ http://www.justitiaetpace.org/idiE/resolutionsE/2007 san 02 en.pdf> para 2.

${ }^{9}$ In Nicaragua, paras 176, 193, the ICJ confirmed that the UN Charter recognizes a 'natural' or 'inherent' pre-existing customary right of individual and collective self-defence, which has been 'confirmed and influenced by the Charter.' It recognized that the UN Charter does not regulate all aspects of the right, but operates alongside existing customary international law, including the requirements of necessity and proportionality. Ibid 176, 194. Whilst an argument can be made that the UN Charter and customary rules on the use of force and self-defence are not identical, the ICJ's approach in Nicaragua shows that it considers the two regimes to be largely equivalent. See Kress in Weller (2015) 568-69. The only difference that the Court has identified is the lack of a customary duty to report the exercise of the right of self-defence to the UNSC. Nicaragua, paras 181, 188, 200. Regarding the UN Charter requirements, see n 126. For a contrary judicial position, see Nicaragua, diss op Jennings, paras 7-15. This thesis proceeds on the basis, as per the prevailing view amongst commentators, that Art 51 excludes any pre-UN Charter customary right that is incompatible with the UN Charter.

10 See British and Foreign State Papers, 1841-1842, Vol. XXX, 193. On this incident generally, see Jennings (1938); Kearley (1999); Green (2006); Wood in Ruys and Corten (2018) 5-14.
} 
a British force entered American territory, boarded the Caroline, set it on fire and sent it over Niagara Falls. Two people were killed in the process. ${ }^{11}$

A number of defences were raised by the British to justify their actions. It is Webster's response to such justifications, and to the incident more generally, that informs the present enquiry. Regarding the necessity of a state's ability to act in self-defence, Webster famously proclaimed that this was limited to cases in which the 'necessity of that self-defense is instant, overwhelming, and leaving no choice of means and no moment for deliberation.'12 Supposing the necessity of the moment required action, Webster asserted that it would also be incumbent on a government purportedly acting in self-defence to show that it 'did nothing unreasonable or excessive; since the act, justified by the necessity of self-defence, must be limited by that necessity, and kept clearly within it.'13 These pronouncements are commonly referred to as the 'Webster formula' or the 'Caroline formula'. Lord Ashburton disagreed on the facts at issue but, in justifying the British action, he agreed with Webster's characterisation of self-defence and the applicable international law. ${ }^{14}$

The precedential value of the Caroline incident is questionable. Well known debates persist regarding the extent to which Webster's formula informs the application of necessity and proportionality to a modern, post UN Charter, right of self-defence. On the one hand, it is said that the Caroline incident changed self-defence from a political excuse to a legal doctrine. ${ }^{15}$ After all, the correspondence between Webster and the British ministers consistently refers to self-defence in legal terms. Ashburton described it as 'the first law of nature'

\footnotetext{
11 Jennings (1938) 84.

12 Letter from Mr Webster to Lord Ashburton (6 August 1842) British and Foreign State Papers, 1841-1842, Vol. XXX, 201. Webster was referring to earlier correspondence between him and Lord Ashburton's predecessor, Mr Fox. See Letter from Mr Webster to Mr Fox (24 April 1841) British and Foreign State Papers, 1840-1841, Vol. XXIX, 1126.

13 Ibid, 1138.

${ }^{14}$ Letter from Lord Ashburton to Mr Webster (28 July 1842) British and Foreign State Papers, 1841-1842, Vol. XXX, 195.

15 Jennings (1938) 82.
} 
and the 'great law of self-defence'. ${ }^{16}$ Along these lines, certain commentators continue to emphasize the Caroline's influence on the contemporary JAB. ${ }^{17}$

Others are more measured in their views. Gray notes how the episode has attained 'mythical authority'. ${ }^{18}$ Indeed, the particular factual matrix might be said to narrow its precedential application. Some scholars highlight that the British action was pre-emptive and that its potential purview might, therefore, be limited to anticipatory self-defence..$^{19}$ Others focus on the fact that the British were targeting rebels operating from American territory. As a result, the Webster formula is potentially limited to self-defence against NSAs operating from the territory of another state that is unable or unwilling to suppress them. ${ }^{20}$ Combining these two factors might further limit the Caroline precedent to a right of anticipatory action of an extra-territorial nature, against NSAs, both of which describe the incident. ${ }^{21}$ Moreover, the episode occurred in 1837, when international law did not outlaw the use of force. Any invocation of self-defence at that time had little substantive legal meaning. The incident may, therefore, be described as one of a state of necessity rather than self-defence. ${ }^{22}$ The correspondence further justifies a characterisation of the wider right of selfpreservation, or self-help..$^{23}$

\footnotetext{
${ }^{16}$ British and Foreign State Papers, 1841-1842, Vol. XXX, 196, 201.

17 E.g. Gardam (2004) 31; Gill (2006) 366-8; Wilmshurst (2006) ('The Chatham House Principles') 965.

${ }^{18}$ Gray (2008) 149.

${ }^{19}$ E.g. Bowett (1958) 188-9. Gill (2006) 366, emphasizes Caroline's particular relevance to such debate and Judge Schwebel in his dissenting opinion in Nicaragua (para 200) explicitly limits the Caroline formula in this manner. Cf Dinstein (2017) 225, asserting that there was nothing anticipatory about the British action against the Caroline. See also Gardam (2004) 149; Schmitt (2013) 64.

${ }^{20}$ Kearley (1999) 325, notes that this was the position taken by writers in the pre-UN Charter era and describes this as the proper context in which to apply the Caroline formula. He concludes, however, that the formula is commonly, though not universally, accepted as applying to all forms of self-defence. See Section 4.1.2 regarding the unwilling or unable doctrine.

${ }^{21}$ Green (2006) 444.

${ }^{22}$ Bowett (1958) 59-60, although he affirms that Webster's principles apply to both necessity and self-defence. The International Law Commission ('ILC') also characterises the incident in this way. Art 25 ILC Articles on Responsibility of States for Internationally Wrongful Acts, with Commentaries, UN Doc A/56/10 (2001) ('ARSIWA') Commentary, para 5. For a critique of this characterisation, and a conclusion that the incident is best characterised as an example of self-defence, see Paddeu (2018) 351-7.
}

${ }^{23}$ See Jennings (1938) 91-2. 
There is doubt, therefore, whether the Webster formula represented, at the time it was expressed, state practice pertaining to the right of self-defence..$^{24}$ Moreover, it is questionable whether it describes custom today. ${ }^{25}$ Whilst the ICJ has consistently confirmed necessity and proportionality as customary requirements, ${ }^{26}$ at no point has the majority referenced the Caroline incident or Webster's formula. ${ }^{27}$ However, we should not simply dismiss the Caroline incident as an out-dated distraction. ${ }^{28}$ Following World War II, the Nuremberg Tribunal cited Webster's formula with approval in the context of the necessity of anticipatory self-defence. ${ }^{29}$ Moreover, states occasionally refer to the Caroline incident as a precedent during the discussion, justification and condemnation of particular claims of self-defence, as well as when considering the genesis and nature of the right. ${ }^{30}$ They have relied on the incident generally, and Webster's formula in particular, to establish the conditions of necessity and proportionality in cases put before the ICJ. ${ }^{31}$ Furthermore, even if not referenced explicitly, states have also employed the wording of Webster's formula during deliberations of the UN Security Council ('UNSC'). ${ }^{32}$

These state practice examples are not all that common, but the Caroline incident endures as the locus classicus of international law pertaining to the

\footnotetext{
24 Gardam (2004) 42-4.

25 See generally Green (2006).

${ }^{26}$ See Section 1.2.1.

27 The only reference is found in Nicaragua, diss op Schwebel, para 200.

28 Green (2006) 449.

29 Judgment of the International Military Tribunal for the Trial of the German Major War Criminals, Nuremberg 1946 (1947) Vol I, 205, referring to 'preventative' action in foreign territory.

${ }^{30}$ E.g. UN Docs S/PV.1939 (1976) para 115 (Israel); S/PV.2250 (1980) para 40 (Iraq); S/PV.2282 (1981) paras 14-15 (Uganda); S/PV.2288 (1981) para 80 (Israel); USA State Department Legal Adviser Speech 2016, 239; UK Attorney General Speech 2017; Australian Attorney General Speech 2017.

${ }^{31}$ E.g. Nuclear Weapons, Note Verbale from the Embassy of Mexico, together with Written Statement of the Government of Mexico, 19 June 1995 (Nuclear Weapons, Mexican Note Verbale), para 63; Nuclear Weapons, Note Verbale from the Embassy of New Zealand, together with Written Statement of the Government of New Zealand, 20 June 1995 (Nuclear Weapons, New Zealand Note Verbale), 56; Oil Platforms, Memorial Submitted by the Islamic Republic of Iran, 8 June 1993, para 4.18; Armed Activities, Reply of the Democratic Republic of the Congo, 29 May 2002, para 3.159.

32 E.g. UN Docs S/PV.1024 (1962) para 110 (Ghana); S/PV.2148 (1979) para 10 (Egypt); S/PV.2283 (1981) para 148 (Sierra Leone); S/PV.2293 (1981) para 69 (Egypt); S/PV.3653 (1996) 15 (Egypt).
} 
right of self-defence. ${ }^{33}$ Its impact on the interpretation of the UN Charter and the development of customary international law, including necessity and proportionality, persists to this day ${ }^{34}$ Lex lata and the original Webster formula are not synonymous, but they have much in common. Jennings and Watts, for example, conclude that the 'basic elements of the right of self-defence were aptly set out in connection with the Caroline incident', ${ }^{35}$ and Gardam agrees that the Caroline incident 'encapsulates' the contemporary position. ${ }^{36}$ In Dinstein's words, the modern requirements may be 'distilled' from the yardsticks set by Webster. ${ }^{37}$ This thesis proceeds to employ the Webster formulation as the starting point for the examination and distillation of necessity and proportionality.

\subsection{Purpose of this thesis}

Necessity and proportionality are fundamental to the exercise of the right of self-defence. Yet, until now, they have not received the legal or normative attention that they deserve. This surprising gap might be because the operation of both requirements is highly contingent on the facts of each case, and that they are difficult to apply in practice. Also, proportionality appears in the JAB and International Humanitarian Law ('IHL'). ${ }^{38}$ The relationship between the requirement in each legal regime is complex, and states may prefer to rely on the clearer rules of $\mathrm{IHL}$ to explain and review putatively defensive actions. ${ }^{39}$ Judicial examination of necessity and proportionality has been light, and their meaning and importance as legal tools have not been fully explored in academic literature. As this Section illustrates, the focus of the ICJ and scholarship has instead been on the trigger of the right of self-defence

\footnotetext{
33 Jennings (1938) 92; Bowett (1958) 58.

${ }^{34}$ As noted, this thesis focuses on necessity and proportionality post adoption of the UN Charter. For a review of how these requirements were perceived following the Caroline incident and up until 1945, see Gardam (2004) 42-9.

35 Jennings and Watts (1996) 420.

${ }^{36}$ Gardam (2004) 148.

${ }^{37}$ Dinstein (2017) 249. Green (2006) 450, takes a similar view.

${ }^{38} \mathrm{IHL}$ is also known as the jus in bello and the laws of armed conflict. IHL is adopted for the purposes of this thesis.

${ }^{39}$ Gardam (2004) 20-4. These factors are considered further below and in subsequent Chapters. See in particular, Section 3.3.1.
} 
under Article 51 UN Charter, being the occurrence of an 'armed attack'. In contrast, states have placed great importance on necessity and proportionality when justifying and reviewing claims of self-defence, but have not typically clarified their understanding of them.

That the scope and content of necessity and proportionality remain normatively undetermined weakens the potential of international law to regulate when and how states use force. Such indeterminacy deprives states, courts, international organizations and scholars of the tools to guide decision making regarding constraining uses of force, to determine whether resort to force is lawful in the circumstances, and to guard against abuse of the right of self-defence. ${ }^{40}$ Necessity and proportionality, more fully understood and effectively applied, can be better employed by such bodies to review and regulate the exercise of a state's right of self-defence. Their application can also help solve some of the long-standing controversies described at the beginning of Section 1.1 that have been traditionally analysed within the ambit of the armed attack trigger.

The purpose of this thesis is to address this legal and normative gap. It seeks to answer two principal questions: a) what is the meaning, in both theory and practice, of the requirements of necessity and proportionality as they pertain to the right of self-defence following the adoption of the UN Charter, and b) how can a better understanding of these requirements be used in the future ${ }^{41}$ As an original contribution to the field, this thesis provides an up-to-date analytical framework of the current law. It does this by undertaking the first comprehensive review of the applicable jurisprudence, academic commentary and, most importantly, relevant state practice from 1945 until the present day. It provides, therefore, a robust and contemporary description of the lex lata. This enunciation of the law encompasses an exploration of the conceptual meaning of each requirement, explains the distinctions between them,

\footnotetext{
40 See generally Deeks (2012) regarding the benefits of increased normative determinacy.

${ }^{41}$ For an overview of their applicability to collective security and the powers of the UNSC under Chapter VII UN Charter, see e.g. Gardam (2004) 188-229. Responding in self-defence to an armed attack for the purposes of Article 51 is the only accepted ground for the lawful unilateral use of force in international law. This thesis will not consider the so called right of humanitarian intervention. For this author's views on that topic, see O'Meara (2017) ICLQ.
} 
confronts existing preconceptions and clarifies areas of controversy. This thesis ultimately presents a detailed understanding of these two requirements that bridges theory and practice.

Sections 1.2.1 to 1.2.3 proceed to elaborate on how necessity and proportionality are viewed by the ICJ, scholars and states. It expands on the existing deficiencies and gaps that this thesis seeks to redress.

\subsubsection{Jurisprudence of the International Court of Justice}

The ICJ's jurisprudence on self-defence provides an important, if limited, source of guidance for the present enquiry. The vast majority of disputes regarding self-defence claims do not reach the ICJ on the merits. ${ }^{42}$ To date, the Court has only dealt directly with the substantive rules of self-defence in five cases. Three were merits decisions: Nicaragua, Oil Platforms and Armed Activities. ${ }^{43}$ Two were advisory opinions: Nuclear Weapons and Palestinian Wall. ${ }^{44}$ In addition, the Court has touched upon claims pertaining to the use of force in a more limited fashion, the most obvious example being Corfu Channel, ${ }^{45}$ where the UK claimed to be acting pursuant to a more broadly understood right of 'self-help'. ${ }^{46}$

The five core self-defence cases offer varying degrees of insight. Whereas the majority in Nicaragua devoted much of their opinion to the law pertaining to self-defence, the Court in Palestinian Wall dismissed Israel's self-defence claim in a cursory two paragraphs. ${ }^{47}$ The cases have also tended to focus on

\footnotetext{
42 See generally Green (2009) 165-206.

${ }^{43}$ Military and Paramilitary Activities in and against Nicaragua (Nicaragua v US) (Merits) [1986] ICJ Rep 14 ('Nicaragua'); Case Concerning Oil Platforms (Iran v US) (Judgment) [2003] ICJ Rep 161 ('Oil Platforms'); Case Concerning Armed Activities on the Territory of the Congo (Democratic Republic of the Congo v Uganda) (Judgment) [2007] ICJ Rep 168 ('Armed Activities').

${ }^{44}$ Legality of the Threat or Use of Nuclear Weapons (Advisory Opinion) [1996] ICJ Rep 226 ('Nuclear Weapons'); Legal Consequences of the Construction of a Wall in the Occupied Palestinian Territories (Advisory Opinion) [2004] ICJ Rep 136 ('Palestinian Wall').

${ }^{45}$ Corfu Channel (United Kingdom v Albania) (Merits) [1949] ICJ Rep 4 ('Corfu Channel').

${ }^{46}$ Corfu Channel, Reply Submitted, Under the Order of the Court of 26th March 1948, by the Government of the UK of Great Britain and Northern Ireland, 284.

47 Paras 138-9.
} 
'armed attack', which the ICJ has clearly viewed as the most important element of the right. ${ }^{48}$ The Court has, however, emphasized the importance of necessity and proportionality in four of the five self-defence cases, ${ }^{49}$ and confirmed that they are rules of customary international law in three..$^{50} \mathrm{It}$ has also been clear that it requires rigid and objective adherence to these requirements. Whereas the defending state forms an initial unilateral view, the Court has strongly rejected the notion that the determination of necessity lies within the state's discretion, even where acting in good faith. Instead, it has stipulated that the test of necessity is 'strict and objective, leaving no room for any "measure of discretion". .51

The Court has nevertheless treated necessity and proportionality as subsidiary, or accessory, criteria. This is demonstrated by the limited amount of space it has devoted to them in its judgments. ${ }^{52}$ Furthermore, the Court has not sought to define necessity or proportionality in general or abstract terms, or to place them within a wider conceptual framework. Whilst it has been steadfast in affirming their application to claims of self-defence, therefore, it has offered only minimal insight into their content and meaning. This is perhaps understandable, given that no case has been determined on the basis of necessity and proportionality. Other than Nuclear Weapons, the legality of avowed acts of self-defence were decided on the basis that none of the respondent states was able to establish that it had been the victim of an armed

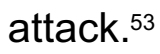

\footnotetext{
${ }^{48}$ See further Green (2009) 7, 23-62.

${ }^{49}$ Nicaragua, paras 176, 194, 237; Nuclear Weapons, paras 30, 41, 48; Oil Platforms, paras 43, 51, 73-7; Armed Activities, paras 147, 304.

50 Nicaragua, para 176; Nuclear Weapons, para 41; Oil Platforms, paras 73-7.

51 Oil Platforms, para 73. The Court presumably adopts the same approach for proportionality.

52 This is particularly noticeable in the contentious cases involving specific claims of selfdefence. In Nicaragua, the Court devoted only one paragraph (para 237) to considering necessity and proportionality. Its approach in Oil Platforms (see paras 74-7) and Armed Activities (see paras 147, 304) was likewise cursory. In the latter case, this was so despite the fact that both parties claimed a right of self-defence.

${ }^{53}$ For an overview of the ICJ jurisprudence on the use of force, see e.g. Green (2009); Gray in Tams and Sloan (2013) 237-61; Kress in Weller (2015) 561-604.
} 
This fact has not prevented the Court from making obiter dicta pronouncements that have often been confusing. For example, it has rightly confirmed an armed attack as the condition sine qua non of the right of selfdefence. ${ }^{54}$ Yet, it has also noted that, in the absence of an armed attack, strict compliance with the canons of necessity and proportionality will not render any purported defensive action lawful, and any breach of these additional prerequisites will constitute additional grounds of wrongfulness. ${ }^{55}$ It is difficult to fathom, however, how these latter comments have meaning. Absent an armed attack, the right of self-defence is not triggered, and any use of force will be unlawful. In these circumstances, necessity and proportionality are inapplicable and cannot complied with, nor breached. ${ }^{56}$ In addition, like states, the Court has sometimes been remiss in identifying whether its observations on necessity and proportionality relate to the JAB or to IHL. ${ }^{57}$ Certain judges may even be accused of conflating the two. In the course of his review of IHL proportionality in Nuclear Weapons, for example, Judge Schwebel refers to the UK's oral arguments. ${ }^{58}$ However, in the passage that he cites for support, the UK Attorney General is clearly presenting his views on JAB proportionality, not IHL proportionality. ${ }^{59}$

Such judicial comments obscure the meaning and operation of necessity and proportionality. As an armed attack was not established in any of the cases referred to above, the question of both necessity and proportionality was moot. It is unclear, therefore, why the Court has chosen to comment on them in the manner referred to in this and subsequent Sections. The circumstances of the cases might have incentivized the Court to speak out on these issues, but the need for clarity in the JAB requires that when it takes these opportunities, it does so diligently and with meaningful sufficiency. ${ }^{60}$ Its approach to necessity and proportionality appears particularly remiss given the overriding importance

\footnotetext{
${ }^{54}$ Nicaragua, para 237.

55 Ibid.

56 See Sections 1.3.1 and 1.3.2.

57 See Sections 1.2.3 and 3.3.2.

58 Nuclear Weapons, diss op Schwebel, para 25.

${ }^{59}$ Nuclear Weapons, Oral Proceedings, Verbatim Record, CR 95/34, 34.

60 See e.g. Oil Platforms diss op Simma, para 6; Armed Activities, diss op Simma, paras 8-9.
} 
that states place on them. As will be made clear, there is enough state practice for the Court to draw upon in order to clarify the content and operation of these requirements, but it has so far avoided doing this. It is both what the Court has said on necessity and proportionality, and what is has not said, therefore, that is the problem. ${ }^{61}$ This thesis seeks to address this issue and provide a critical and more nuanced review of the ICJ's jurisprudence.

The Court has offered some guidance, however, regarding how it approaches necessity and proportionality. In Nicaragua, it clearly dealt with the two requirements separately, first opining on the necessity of the USA's actions, before going on to assess whether they were also proportionate. ${ }^{62}$ In Oil Platforms, the Court likewise treated the two concepts as independent, and considered them in the same order. ${ }^{63}$ In Armed Activities, however, its approach was less structured. ${ }^{64}$ In line with Nicaragua and Oil Platforms, this thesis contends that necessity must be applied and assessed before proportionality. This order is crucial so that the true meaning and practical application of each requirement can be fully understood and realised in practice. ${ }^{65}$ On this basis, if a putative act of self-defence is unnecessary, it cannot be disproportionate or proportionate. It will simply be an unlawful use of force. If necessity is satisfied, however, an exercise of self-defence may be proportionate or disproportionate. The importance of the order of consideration and application of necessity and proportionality will be considered further in the Chapters 2 and 3.

Finally on the ICJ's jurisprudence, and as a general matter, the Court's examination of necessity and proportionality must be viewed with a degree of circumspection, and we should not draw conclusions that are too wide ranging. The small number of propositions made by the ICJ must be read in light of,

\footnotetext{
61 Ibid. Green (2009) 106, suggests that, for the most part, it is what the Court has not said that is the problem.

62 Nicaragua, para 237.

63 Oil Platforms, paras 76-7.

${ }^{64}$ Armed Activities, para 147.

65 This approach also finds support in the literature. E.g. Gardam (2004) 138-9; Green (2009) 89.
} 
and confined to, the particular facts of the case before it. We should also bear in mind the time that has passed since each judgment was rendered. The principal self-defence case, Nicaragua, is over 30 years old. The most recent, Armed Activities, was delivered over 12 years ago. This does not diminish the importance of these judgments, but rather sets their enduring legacy into context. These cases represent the law as understood by the majority of the ICJ at the relevant time and within the confines of the factual context presented to the Court. As Green notes, we must be cautious when assessing the jurisprudence and bear in mind these considerations and the fact that any judgment represents, at best, a 'freeze frame' of international law at a particular juncture. ${ }^{66}$

\subsubsection{Scholarship}

Academic commentary to date on necessity and proportionality has also been relatively light. Scholarship has focused instead on the controversies surrounding the ratione materiae, ratione temporis and ratione personae elements of the armed attack trigger. ${ }^{67}$ With limited notable exceptions, ${ }^{68}$ to the extent that necessity and proportionality have been considered, commentators have been selective with their analysis. They have tended to focus on individual incidents of self-defence and whether, typically as a matter of fact, they satisfy the two criteria. Whilst acknowledging their central function in the right of self-defence, they have not established a comprehensive analytical framework. Consideration of necessity and proportionality is often cursory, with a brief overview of their content, or remarks that are limited to noting the lack of academic examination of these requirements, their indeterminate nature, or that they require further analysis. ${ }^{69}$

\footnotetext{
${ }^{66}$ Green (2009) 24-5.

${ }^{67}$ These debates are well known, and the associated literature is vast. For an overview of the various issues, see e.g. Ruys (2010).

68 E.g. Gardam (2004); Tams in Van den Herik and Schrijver (2013) 373-421; Kretzmer (2013).

${ }^{69}$ E.g. Brownlie (1963) 261; Kress in Weller (2015) 586; Gray (2018) 159. See also Gardam (2004) 20.
} 
No previous work has attempted the breadth and depth of review of state practice of the present study, nor the conceptual analysis set out in the following Chapters. The paucity of scholarship on necessity and proportionality is perhaps a natural consequence of the complexities that surround them and the ICJ's focus on 'armed attack'. Proportionality has posed particular problems for scholars. Gardam noted this phenomenon back in 2004, in her book that is regarded as one of the most comprehensive reviews of necessity and proportionality..$^{70}$ Her work is an important contribution to the field, yet it takes us only so far. Gardam devotes only one chapter of her book to these requirements as they pertain to the right of self-defence, and her analysis is in need of updating, particularly in light of more recent state practice.

This thesis references a number of academics who have since contributed to a better understanding of necessity and proportionality, but there remains a lack of academic consideration and consensus regarding their meaning and application. The gap in the literature detracts from the potential of the JAB to evolve and respond to the issues that test it the most, such as the increasing militarisation of NSAs. This thesis seeks to contribute to remedying this position by bringing the scholarship up-to-date and offering a more rigorous approach to the subject. It advances the current theoretical understanding of necessity and proportionality by suggesting how academics may better conceive of these requirements, and adds to the existing knowledge via a comprehensive examination of state practice.

\subsubsection{State Practice}

As noted, states invariably invoke necessity and proportionality when seeking to justify claims of self-defence. Whilst occasionally recognizing that the concepts require further clarification and study, ${ }^{71}$ states almost universally accept that necessity and proportionality regulate their defensive actions. ${ }^{72}$

\footnotetext{
70 Gardam (2004) 155.

${ }^{71}$ E.g. UN Doc A/AC.134/SR.67-78 (1970) 83 (Iraq).

72 This is not without exception. During the negotiations of UNGA Res. 3314 (1974) ('Definition of Aggression'), for example, the representative of Ghana argued that the principle of
} 
This thesis reviews over 70 years' worth of state practice and identifies trends and themes that have not previously been explored. Whether in compliance or breach, state practice reveals that necessity and proportionality occupy a central, and often decisive, role in how states justify their own uses of force and assess the military actions of other states. ${ }^{73}$ We will see that states often resort to necessity and proportionality as the main, or only, factors to determine the legality of a particular action. In contrast to the position taken by the ICJ and scholars, therefore, states tend to avoid doctrinal debates over whether or not there has been an armed attack and, instead, turn to these requirements to regulate the exercise of self-defence..$^{74}$

That states focus on necessity and proportionality is the principal reason why this thesis is so important. Concentrating our attention on these requirements better represents how states view the right of self-defence, explain their actions and review the acts of other states. A more coherent and determinate conception of necessity and proportionality speaks directly to this fact and the practical operation of self-defence. As a novel contribution to the field, the current work further develops an academic understanding of the law, but in a way that is both practical and useful. The following analysis can assist defending states to form policies and reach decisions regarding resorting to self-defence, and to justify their actions to the international community. This thesis also operates to provide clearer restraints on that action by providing the means for other states, international organizations, courts and academics to monitor and appraise it more effectively.

\footnotetext{
proportionality, as it applied to self-defence, had 'no basis in modern jurisprudence'. Ibid, 86. The Syrian delegate was equally dismissive. Ibid, 87-8.

${ }^{73}$ Examples where states have expressly asserted that their actions are necessary and proportionate, as well as incidents where such criteria form the basis of reactions of other states and international organizations are referenced throughout this thesis.

${ }^{74}$ See e.g. Green (2009) 9, 108-9; Gray (2018) 163-4; Henderson (2018) 228-9. For example, in relation to necessity, the current debate regarding the legality of particular defensive action against NSAs revolves around the controversial unwilling or unable doctrine, as well as the notion of 'imminence'. See, respectively, Sections 4.1.2. and 2.4.1(b). Proportionality is often central in determining legality. Notable examples include Israel's (disproportionate) intervention into Lebanon 2006 and Turkey's (proportionate) Operation Sun in 2008. See in particular Section 3.2.5. Other examples are referenced in the following Chapters.
} 


\subsection{Thesis structure, arguments and initial observations}

Before moving to the detail of Chapters 2 to 4 , the remainder of this Section sets out some initial observations to frame the analysis and emphasize some of the further contributions that this thesis makes to the existing literature. This Section covers some substantive content, but it is primarily intended to act as an introductory guide for the reader to understand the fundamentals of necessity and proportionality and why they are so important to the right of selfdefence in international law. This first foray into the subject is developed in the subsequent Chapters. Section 1.4 explains this author's approach to methodology and doctrine.

Chapter 2 focuses on the meaning and content of necessity. It argues, for the first time, that there are two different 'types' of necessity. In so doing, this author proposes a novel taxonomy to distinguish between them. This distinction addresses, and better explains, the two principal and distinct concerns of this requirement that are reflected in state practice, ICJ jurisprudence and scholarship: a) is military force required at all in the circumstances (an issue of 'general necessity'); and b) if so, where must such force be directed (an issue of 'specific necessity')? Without general necessity, the applicability of both specific necessity and proportionality is moot. Drawing on core principles of $\mathrm{IHL}$, Chapter 2 provides a clearer and more workable understanding of necessity that highlights both the weaknesses in, and opportunities for, its operation.

Chapter 3 proceeds to examine proportionality. As with Chapter 2, it employs primary and secondary sources of international law to provide a coherent and granular realization of this requirement, and how it operates in practice. In particular, it offers a more nuanced analysis of the various factors and interests that inform the review of 'how much' force states may use in their defence, and whether other states will view such action as excessive. In so doing, Chapter 3 draws on the laws of state responsibility to consider how a diversity of interests are affected by the exercise of self-defence. It also has recourse to 
$\mathrm{IHL}$, exploring how it interacts with the $\mathrm{JAB}$, whilst remaining a distinct regime of international law.

Chapter 4 builds on the analysis of the previous Chapters by considering how necessity and proportionality are adapted to apply to defensive action against NSAs. With a particular focus on international terrorism, their utility and limitations are brought to the fore. Chapter 5 completes this thesis by setting out its conclusions and considerations for the future development of international law.

\subsubsection{The nature and function of necessity and proportionality}

Necessity and proportionality condition the exercise of the right of selfdefence. ${ }^{75}$ Necessity determines whether defensive force may be used to respond to an actual or imminent armed attack, and where it must be directed. Proportionality governs how much force is permissible. Once the availability of the right is triggered in response to an armed attack, these two requirements operate to restrain the scope of defensive action and ensure that it remains defensive. As Ago notes, 'the objective to be achieved by [self-defence], its raison d'être, is necessarily that of repelling an attack and preventing it from succeeding, and nothing else.' 76 Compliance with necessity and proportionality, therefore, indicates that the purposes of self-defence are achieved, and nothing beyond that. ${ }^{77}$ As guardians of the parameters of the right of self-defence, they are the 'touchstones' that ground such action in the principle of legality. ${ }^{78}$ Absent a clearer and more coherent realization of these requirements, states operate in a grey area of legal regulation.

Necessity and proportionality seek to strike a balance between the rights and interests of three different groups of actors. The first is the right of the

\footnotetext{
75 Nuclear Weapons, para 41.

${ }^{76}$ Ago (1980) para 119.

77 The purposes of self-defence are discussed further in Section 1.3.2.

78 Australian Attorney General Speech 2017.
} 
defending state to defend itself in the face of an armed attack. ${ }^{79}$ Second, is the right of the attacker to be protected from excessive defensive responses. ${ }^{80}$ Third, are the interests of other states and the wider international community. These latter interests include concern for civilian harm and the environment, as well as the operation of the collective security system. In this latter respect, necessity and proportionality function to contain the risk of escalating violence and instability. They thereby contribute to international peace and security, whilst reserving to the UNSC the primary responsibility for its long-term maintenance. These three classes of rights and interests are examined in the following Chapters.

As will be made clear, necessity and proportionality apply on an ongoing basis, throughout the duration of an armed conflict prompted by self-defence, and not just at its commencement. ${ }^{81}$ This enduring obligation is often overlooked in the literature, yet it is crucial to appreciating the potential of necessity and proportionality to restrain military action. The JAB regulates the use of force by states as a whole and its rules must be continually monitored and reviewed by states. Put simply, if the recourse to force is, or the continuing use of force becomes, unnecessary or disproportionate, it is not lawful self-defence and will breach Article 2(4) UN Charter. Therefore, either force must not be employed in the first place, or it must cease. ${ }^{82}$

\footnotetext{
${ }^{79} \mathrm{~A}$ 'defending state' is a state that is (or claims to be) the victim of an armed attack by another state or NSAs.

${ }^{80}$ An 'attacker' may be a state or NSAs, in each case, that have launched, or intend to launch, an armed attack against a defending state. See 2.4.1 regarding the timing of an armed attack and Chapter 4 regarding armed attacks by NSAs.

81 Greenwood (1983) 222-5; Gardam (2004) 155-6; Gazzini (2005) 146-7; Ruys (2010) 124. See in particular Sections 3.3.1 and 3.4.

${ }^{82} \mathrm{~A}$ distinction should be drawn between applying these rules and assessing compliance with them. Whilst necessity and proportionality apply to a defending state's actions on an enduring basis, and such state must continually monitor its own compliance with them, their ultimate review is likely to occur on a post facto basis. The full picture of putative defensive conduct is only likely to be available once over and the facts regarding its scope are made known (e.g. in debates before the UNSC or arising out of a fact-finding process). Unless such deliberations are during the course of a lengthy ongoing conflict, or set in the context of an enduring threat, therefore, an assessment of necessity and proportionality will typically occur as a retrospective exercise. See further Section 3.4.
} 
Necessity and proportionality have been described as two sides of the same coin. ${ }^{83}$ This characterization emphasizes that they are closely linked conceptually. In recognizing this relationship, Gray has suggested that an unnecessary use of force cannot be proportionate and if it is not proportionate, it is difficult to see how it can be necessary. ${ }^{84}$ This statement oversimplifies the relationship, yet exemplifies how the two requirements are sometimes referred to without due distinction. Their close connection means that they have often been equated by academics, ${ }^{85}$ and states. ${ }^{86}$ This thesis confronts this approach. As will be made clear in Chapters 2 and 3, they are in fact distinct and separate requirements of customary international law and must be applied as such. ${ }^{87}$

Given their close relationship, occasional conflation of the two concepts is perhaps inevitable. Yet, differentiating between them, and challenging assertions that seek to equate them, is important and not simply a question of semantics: 'Failure to distinguish between necessity and proportionality would seem to be one of the key factors contributing to the uncertainty surrounding both concepts.' ${ }^{88}$ The greater the determinacy of these rules, therefore, the greater the potential for states to comply with them. ${ }^{89}$ This compels us to consider specifically what it is about a use of force that is 'necessary' or 'unnecessary', 'proportionate' or 'disproportionate' and, therefore, lawful or unlawful. It is not enough to say that necessity amounts to the same thing as proportionality without further justification or explanation. Neither is it sufficient to conclude that an act satisfies or breaches either or both criteria, without considering first how the criteria apply and, crucially, in what order. ${ }^{90}$ This

\footnotetext{
${ }^{83}$ Ago (1980) para 121.

84 Gray (2018) 159.

85 See Section 2.2(a)

86 During discussions regarding the Definition of Aggression, for example, the USSR maintained that 'the word "necessary" contained the idea of proportionality.' UN Doc A/AC.134/SR.67-78, 91.

87 Greenwood (2011) para 26. Gray (2018) 159, questions, however, how far the two concepts can operate separately.

88 Tams in Van den Herik and Schrijver (2013) 377.

${ }^{89}$ Franck (1988) 713-25.

90 As noted in Section 1.2.1, this author contends that necessity must be considered and applied before proportionality.
} 
thesis seeks a clearer normative structure of each requirement, marking these distinctions to the fullest extent possible and applying them in the correct order. Only with such clarity can necessity and proportionality have proper meaning and be applied effectively in practice.

An investigation of necessity and proportionality has its limitations, however. The two are essentially abstract and flexible concepts that, as the following Chapters reveal, often incorporate equally indeterminate ideas of 'excessiveness' and 'reasonableness'. ${ }^{91}$ Their nature is also such that their potential to curb state action is very much context dependent. This means that establishing general rules for their application is challenging. Further, they are creatures of custom that, by its nature, will always be less precise and detailed than conventional law. ${ }^{92}$ These factors, together with competing views on the scope and purpose of self-defence, make them difficult to apply to an increasing diversity of situations in which the right of self-defence has been invoked. ${ }^{93}$

Despite these challenges, a thorough review of state practice, whilst demonstrating that the two requirements are applied flexibly, provides their core content and outer limits. In addition, a better theoretical grasp of necessity and proportionality helps us to understand and interpret that state practice and provides guidance on identifying potential objective characteristics. Compliance with necessity and proportionality is essentially contextual, but this thesis provides tools for states, scholars and courts to adopt a more coherent approach to appraising defensive action and mitigating its abuse. This strengthens the potential for international law to regulate when and how states resort to using force.

\footnotetext{
91 Green (2015) JUFIL 101.

92 This may be no bad thing. The necessary flexibility that this allows will also be discussed in the following Chapters.

93 Simma et al (2012) 1426.
} 


\subsubsection{The purposes of the right of self-defence}

a) Halting, repelling or preventing an armed attack

Compliance with necessity and proportionality guarantees that the purposes of self-defence are achieved, and nothing more. ${ }^{94}$ The result is a lawful use of force. Such compliance in turn depends on establishing the purposes of selfdefence. These purposes provide the benchmark against which adherence to the requirements of necessity and proportionality is gauged. ${ }^{95}$ This benchmark defines their content and scope. It answers the two questions that govern the present analysis: 'necessary to do what?' and 'proportionate to what?' There can be no meaningful deliberation of necessity and proportionality without concomitant consideration of these purposes. Whether a narrow or expansive view is adopted on this issue delineates the conceptual boundaries of these requirements.

The legitimate purposes of the right of self-defence remain highly controversial, however. ${ }^{96}$ Disagreements regarding how far a state may go to defend itself risks making an assessment of necessity and proportionality an overly subjective exercise, beholden to the position of the reviewer, be it a state, international organization or scholar. Even if subject to a later, objective review by a court (which is rare), continuing controversies mean that it may be very difficult to identify when the defensive purpose is fulfilled and, as a result, the exercise of the right of self-defence is exhausted. Many of these controversies are discussed in the following Chapters. One of the most notable is whether there exists the right of some form of anticipatory self-defence.

\footnotetext{
${ }^{94}$ Proportionality also ensures that third-party interests are not unduly disrupted. See Chapter 3.

${ }^{95}$ See Greenwood (2011) para 27.

${ }^{96}$ See e.g. Kress in Weller (2015) 586-7. Tams in Van den Herik and Schrijver (2013) 399401,419 , talks of a 'normative drift' of the legitimate aims of self-defence in the context of combatting terrorism. He notes that, in this context, states are subsuming far-reaching military goals under a broadly defined concept of self-defence. See Chapter 4.
} 
The ability to counter potential future threats that have not yet materialized is widely rejected by scholars and states alike, although the right of states to respond to 'imminent' armed attacks occupies a less clear position. ${ }^{97}$ However, there is certainly a growing academic consensus, particularly following the 11 September 2001 terrorist attacks against the USA ('9/11'), that supports such a right. State practice is inconclusive, but has followed this general trend ${ }^{98}$ If one accepts a limited right of pre-emptive self-defence against imminent armed attacks, then the purposes of the right of self-defence are to halt, repel or prevent an armed attack. However, such purposes, and the attendant analysis of both necessity and proportionality, change if one rejects this possibility. For commentators and states that deny any right of anticipatory self-defence, necessity and proportionality become much narrower concepts. This is because the purposes of self-defence are reduced to halting and repelling, and not preventing, an armed attack. As explored further below, the more limited the view of self-defence, therefore, the more circumscribing these requirements become.

Whilst the outer parameters of self-defence may be debated along these lines, the core purpose is not. A use of force in self-defence must be defensive in nature. Force going beyond halting, repelling or preventing an armed attack

\footnotetext{
${ }^{97}$ A distinction is to be made here between 'pre-emptive' and 'preventive' self-defence. See Ruys (2010) 250-4 for a general discussion of the terminology that this thesis adopts. 'Preemptive' self-defence refers to force employed to counter imminent armed attacks (see Section 2.4.1(b)). In contrast, 'preventive' self-defence refers to a use of force to counter possible future attacks that are not imminent. Instead, the threats are conjectural and have not yet materialized. This highly controversial notion is best represented by the so-called 'Bush Doctrine'. The National Security Strategy of the United States of America, September 2002, $<$ https://www.state.gov/documents/organization/63562.pdf $>, 15>$. It is almost universally rejected by scholars and is not generally accepted by states. See e.g. Ruys (2010) 322-4; Corten (2010) 441; Gray (2018) 248-53; Henderson (2018) 285-95. As a point of terminology, reference is sometimes made to 'pre-emptive' rather than 'preventive' self-defence. Whatever the chosen nomenclature, the point is that a right of self-defence against non-imminent armed attacks is generally regarded as unlawful.

98 See e.g. Bowett (1955-6) 131; Greenwood (2002) paras 22-4; The Chatham House Principles 967-9; Gill (2006) 362, 366; Ruys (2010) 324-42; Lubell in Weller (2015) 701; Green (2015) JUFIL, 105-6; Henderson (2018) 277. For recent explicit state assertions of this right, see e.g. USA State Department Legal Adviser Speech 2016, 239; UK Attorney General Speech 2017; Australian Attorney General Speech 2017. See also UN Doc A/59/2005 (2005) para 124. See further Section 2.4.1(b).
} 
will be either unnecessary or disproportionate and, ipso facto, unlawful. ${ }^{99}$ Yet, the reality beyond the pages of an academic text, or courtroom judgment, may not be so clear-cut. States do not confine themselves to the neat argot of 'halting, repelling or preventing' when discussing defence and their national security. They may employ other terms, including 'deterring' or 'discouraging' armed attacks. ${ }^{100}$ This language appears to take action beyond an immediate defensive purpose and into a more uncertain and distant future of possibilities. 'Deterrence', it may be argued, is an inherent part of punitive measures and cannot, therefore, be recognized as a legitimate motive for using force. ${ }^{101}$ Yet, an element of deterrence might in fact be considered by states to be an integral part of a defensive response. Instead of focusing on the label that might be employed to describe a particular act, the key factor that will determine the legality of a putatively defensive response is whether there is a continuing threat to a defending state and its actions are necessary and proportionate to counter that threat. ${ }^{102}$ This points to the existence of a legitimate defensive purpose.

\section{b) An overriding defensive purpose}

The existence of additional and even decisive motives, over and above selfdefence, does not deprive a state of the right to resort to self-defence, provided the conditions for an armed attack are met. ${ }^{103}$ Particular motives for taking military action, and the outcomes of such action do, however, relate to the issue of whether a purported defensive act is necessary and proportionate. For example, the appropriation of resources, changing a border, destroying state infrastructure, occupation and regime change are all possible results of purported defensive action. Whether these outcomes are a result of coincidence or design, the question is whether they are necessary and

\footnotetext{
${ }^{99}$ Defensive force can be necessary and proportionate, or necessary and disproportionate, but it cannot be unnecessary and proportionate, or unnecessary and disproportionate. See Section 3.3.2.

100 See further Section 2.4.2(b).

101 See Okimoto (2012) 64; Kretzmer (2013) 268.

102 See Section 2.4.2(b). The idea of a continuing threat is explored in subsequent Chapters.

${ }^{103}$ Nicaragua, para 127.
} 
proportionate to achieving a defensive purpose (viz halting, repelling or preventing an armed attack), not whether they are additional legitimate purposes of the right of self-defence itself.

Simma maintains that as long as defensive action 'visibly and credibly preserve[s] a primary repelling character it is immaterial if [a defending state] simultaneously harbours additional, but subordinate deterrent, retributive or even punitive motives when conducting them. ${ }^{104}$ Reference here to retribution and punishment is potentially troubling. Such terms are at odds with the notion of defence. Yet, as Dinstein notes, 'the motives driving States to action are usually multifaceted, and a tinge of retribution can probably be traced in every instance of response to force. ${ }^{105}$ This issue goes to the question of how far a state may go to protect itself. Ultimately, any motive or purpose beyond defence risks rendering ostensibly defensive action an unlawful armed reprisal. ${ }^{106}$

Corten argues that it is better to think of the 'main' or 'ultimate aim' of defensive action. Subordinate aims, such as overthrowing a government, are permitted, provided they are necessary to put an end to an armed attack. Such approach, Corten argues, best accords with Ago's reference to the 'raison d'être' of selfdefence. ${ }^{107}$ This account is logical. It recognizes that a state may pursue other subsidiary aims in exercising its right of self-defence, but requires such aims to be necessary and proportionate to halting, repelling or preventing an armed attack. Whilst it may not be easy to establish clear lines of distinction on this point, adding a potentially open-ended list of extra possible defensive aims risks rendering self-defence meaningless. The analytical framework set out in this thesis aims to assist with assessing adherence to an overriding defensive purpose.

\footnotetext{
104 Simma et al (2012) 1426-7.

105 Dinstein (2001) 199.

106 See Section 2.4.2.

107 Corten (2010) 484-5. See n 76.
} 


\section{c) Fulfilling the defensive purpose}

It is also important to consider what sort of action a defending state might be permitted to take to fulfil a defensive purpose that complies with the requirements of necessity and proportionality. As an example, it is logical to conclude that an armed attack that has succeeded in capturing territory can only be successfully defended against by repulsing the attacker and restoring that territory. A return to the territorial status quo ante bellum is the minimum legitimate defensive goal in such circumstances. However, it is clear that states can do more than this, while remaining within the bounds of necessity and proportionality. ${ }^{108}$ As Green notes, it may not be enough simply to expel the attacker from captured territory. A defending state's troops are not required to stop at the border and idly watch the attacker regroup and prepare a fresh attack. Steps may be taken to ensure there is no repeat occurrence. ${ }^{109}$ An example is Operation Desert Storm, being the coalition response in 1991 to Iraq's invasion of Kuwait. Forcing Iraq's withdrawal from Kuwait meant that the response was not restricted to the latter's territory. ${ }^{110}$

In terms of how much further a state may go beyond re-establishing the status quo ante bellum, therefore, it seems sensible to suggest that action taken that 'reasonably secures the state following an armed attack will be acceptable'. 111 An example is the 'protection zone' maintained by the British for five years around the Falkland Islands following the end of active hostilities arising out of Argentina's 1982 invasion. Given that Argentina had refused to proclaim a formal end to hostilities, excluding Argentine military aircraft and vessels from this area was probably a lawful defensive measure. ${ }^{112}$ This ability to reestablish and guarantee the security of the defending state can be sensibly interpreted as part of, or attendant to, halting, repelling or preventing an armed

\footnotetext{
108 Green (2015) JUFIL, 113. See also Gardam (2004) 156.

109 Green (2015) JUFIL, 114. See further Sections 2.4.1 and 2.4.2.

110 See e.g. Greenwood (1992); Wet in Ruys and Corten (2018) 456-68.

111 Green (2015) JUFIL, 114. Gardam (2004) 157, likewise acknowledges a right to 'restore the security of the State after an armed attack', suggesting the international response to 9/11 as an example.

112 Greenwood (1989) 276; Green (2015) JUFIL, 114. See further Section 3.2.6(b).
} 
attack. Without this ability, these purposes might not be achieved effectively and the threat to the defending state might subsist.

States are not permitted to protect 'perceived security interests', however. ${ }^{113}$ Any putative defensive action taken by a defending state must, therefore, relate to a distinct and identifiable threat. Furthermore, temporal considerations limit the extent to which states may claim a defensive necessity. This reflects the fact that self-defence is a temporary, emergency right. To be considered necessary, such acts must be aimed at provisionally guaranteeing the legitimate and immediate security of defending states. Once the threat has been successfully countered, the necessity of self-defence falls away. ${ }^{114}$ Beyond the immediate security needs of the defending state, 'the creation of permanent conditions of security seem to have been reserved by the international community as tasks to be performed collectively. ${ }^{\prime 115}$ An enduring solution to the situation is, therefore, to be provided by the collective security mechanisms of the UN Charter, with the UNSC at its head. These considerations are explored further in the following Chapters.

\subsection{Methodology and doctrine}

This thesis aims to provide a comprehensive review of the customary requirements of necessity and proportionality by undertaking an audit of relevant state practice and opinio juris since the signing of the UN Charter in 1945. ${ }^{116}$ The 'quest for custom' is not an exact science, however, ${ }^{117}$ and controversies abound regarding the identification of customary international

\footnotetext{
${ }^{113}$ Armed Activities, para 148. See also n 97 regarding preventive self-defence.

${ }^{114}$ See further Sections 2.4.1, 3.2.2 and 4.1.4.

${ }^{115}$ Cannizzaro (2006) 782.

${ }^{116}$ As a doctrinal matter, state practice and opinio juris are determinative of the existence and content of rules of customary international law. Art 38(1)(b) Statute of the International Court of Justice, 26 June 1945, 15 UNCIO 355 ('SICJ'); North Sea Continental Shelf Cases (Federal Republic of Germany/Denmark; Federal Republic of Germany/Netherlands) (Judgment) [1969] ICJ Rep 3, para 77; Nicaragua, paras 184, 186. General consistency of state practice is sufficient. Ibid, 186. Regarding the requisite amount, uniformity, representativity and duration of state practice, as well as the position of 'specially affected states', in each case regarding the JAB, see Ruys (2010) 44-51.

117 Ibid, 30.
} 
law. ${ }^{118}$ Eschewing a binary choice between an 'extensive' or 'restrictive' approach to determining custom, ${ }^{119}$ a balanced methodology is adopted herein that accords with the ICJ's jurisprudence on the identification of rules of customary international law. ${ }^{120}$ This approach examines both the words and deeds of states, ${ }^{121}$ with a focus on specific incidents where states have claimed, or can be taken to have used, force in putative self-defence. ${ }^{122}$ Such incidents have a central practical importance in the formation of customary international law, including in the area of self-defence. ${ }^{123}$ This is because they give rise to a form of dialogue comprising claims made by states using force in putative self-defence and counter-claims by other states in response. Any legal justifications embodied in these claims, together with any legal positions advanced in counterclaims, are capable of contributing to the affirmation or

\footnotetext{
118 The identification of customary JAB is a relatively under-theorized topic. For an overview of relevant issues, representing a range of opinion, see e.g. Cannizzaro and Palchetti (2005); Corten (2010) 4-49; Ruys (2010) 29-52; Van Steenberghe (2015); Talmon (2015); Gray (2018) 9-26. See further the work of the ILC on the identification of customary international law, <http://legal.un.org/ilc/guide/1 13.shtml>.

119 See Corten (2010) 5-27; Ruys (2010) 31-44. The so-called 'extensive approach', inter alia, prioritizes state practice (meaning the physical conduct of states in this instance), in particular that of powerful states. The so-called 'restrictive approach' focuses on opinio juris. This means that states must be convinced that their acts accord with a legal rule. It posits that all states equally contribute to customary formation. Whereas the former approach gives rise to accounts of the law that admit of uses of force in a wide range of circumstances, the latter adheres strictly to a broad prohibition on the use of force.

${ }^{120}$ See further Ruys (2010) 51-2; Corten (2010) 27-49.

121 A distinction between words and deeds is semantically convenient, but ontologically untenable. Both are acts of states. See further Ruys (2010) 31-44; n 129.

122 The right of self-defence may or may not be explicitly claimed by a state. Where it is, the veracity of the facts, and/or the legal position claimed, may be in doubt or contested. Yet, any invocation of the right and the reactions to it of other states furnish state practice and opinio juris. Whether or not a putative defending state's right of self-defence has lawfully been triggered, that state's enunciation of the international legal restraints to which it considers itself subject when exercising that right, along with other states' reactions to this, constitute state practice and opinio juris relevant to the content of the applicable customary rules. There is also value in examining cases where the facts speak to a claim of self-defence that could have been advanced but was not. Whilst the lack of an express legal justification means that the putative defending state's opinio juris might be absent, ensuing reactions from other states can be elucidating. The approach adopted, therefore, examines concrete examples where the right of self-defence is at issue and states have made their views known on the lawfulness of the purported exercise of that right.

${ }^{123}$ The importance of the incident-based approach to the examination of state practice and opinio juris has been highlighted by a number of scholars. See e.g. Reisman (1984); Wedgwood (2005) 52; Green (2009) 7-9; Ruys (2010) 34, 41.
} 
modification of the applicable rules of customary international law. ${ }^{124}$ They stand as important precedents, therefore, for its development. ${ }^{125}$

The following Chapters seek to establish the particular facts relating to these incidents, the action taken by the states involved, any legal claims advanced, and the corresponding reactions of other states. Where available, letters sent to or put before the UNSC, in accordance with the reporting obligation in Article 51 UN Charter, by states invoking the right of self-defence are the starting point in attempting to identify a legal justification for a particular use of force. ${ }^{126}$ Thereafter, the focus is on state practice and opinio juris in respect of specific incidents and the consideration by states of legal issues before the UNSC and the UN General Assembly ('UNGA'). ${ }^{127}$ Official statements made by, ${ }^{128}$ and to, other international bodies (such as NATO, the EU and the Arab League) are also cited, as are those made elsewhere, such as to the press, or before national parliaments. In addition, pleadings by states before international courts and tribunals have been a valuable source of opinio juris and state practice. ${ }^{129}$ These tend to contain more clearly articulated legal positions on

\footnotetext{
124 South West Africa Cases (Ethiopia v South Africa; Liberia v South Africa) (Judgment) [1966] ICJ Rep 6, para 49. Where a state using force has advanced no explicit legal claim to justify its actions, a legal justification might nevertheless be implicit in official statements and from the particular context. Ruys (2010) 36-7.

${ }^{125}$ Ruys and Corten (2018) 1-4.

${ }^{126}$ Art 51 UN Charter requires measures taken by states in the exercise of the right of selfdefence to be reported immediately to the UNSC.

${ }^{127}$ Statements made by states to the UNSC regarding particular incidents are important to the identification of state practice and opinio juris in the JAB. In respect of the UNSC's role in developing custom, a particular UNSC Resolution might constitute prima facie evidence of legality or illegality, but caution is needed. Statements made by members of the Council concerning the adoption of a Resolution, as well as the reactions of other states outside of its fifteen members, must also be accounted for when considering the customary position. See e.g. Ruys (2010) 39-41, 49. See further Gray (2018) 16-26, regarding the relative importance of the UNSC and the UNGA in developing the JAB. Insight is also gained by statements made in fora, such as the UNGA, that do not relate to particular incidents of self-defence, but rather engage in the abstract with legal issues relevant to the present study. Examples include statements made during the drafting of the Definition of Aggression. UNGA Resolutions, in particular states' votes on them, may also be used to establish state practice and opinio juris. See Nicaragua, para 188.

${ }^{128}$ As with the role of the UNSC and UNGA in developing custom, caution must be had regarding whether statements made by such organizations reflect the state practice and opinio juris of states. See $n 127$.

129 That such pleadings are generally regarded as state practice, see e.g. International Law Association, 'Statement of Principles Applicable to the Formation of General Customary International Law', Report of the Committee on Formation of Customary (General) International Law (2000) 14. See also Crawford et al (2013) 724.
} 
the part of states than may be provided to political organs such as the UNSC and in other diplomatic fora, where politics and law tend to be intermingled. ${ }^{130}$ With every declaration regarding an incident, great care has been taken to distinguish, where possible, legal from political or moral justifications advanced by the relevant state. ${ }^{131}$

Potential incidents run into the hundreds, however, and are varied in nature. ${ }^{132}$ They comprise uses of force accompanied by explicit claims by states of selfdefence, as well as uses of force where the right of self-defence is relied on implicitly or is arguable on the facts. It is simply not possible, however, to identify each and every invocation of the right of self-defence advanced since the signing of the UN Charter, let alone appraise them all, within the word limits of this thesis. States do not always comply with the Article 51 reporting obligation, ${ }^{133}$ and there is no official or definitive log of claims of self-defence that might facilitate this review. Furthermore, not all incidents provide insight into the law. This is particularly so where claims of self-defence illicit no response from other states and are not debated in the UNSC or other public fora. ${ }^{134}$

Whilst it is impossible to be exhaustive, this author has identified as many examples of the use of force in putative self-defence since 1945 as possible, in order to provide as comprehensive a picture as is possible of the current lex lata. The focus is on those incidents particularly pertinent to and instructive for this task. Examples that have generated the most discussion between states, particularly within the UNSC, have proved the most useful in establishing

\footnotetext{
130 Paddeu (2015) 118-9.

${ }^{131}$ As such, whilst the UNSC is relied upon for the present analysis, caution has been taken to discern from debates and resolutions any legal claims. This author is mindful of the need not to ascribe legal views to states that they themselves do not advance (per Nicaragua, para 207). As noted, however, such views might be implicit in statements made or from the particular context.

132 See, e.g. Green (2009) 3. This author's own research has identified well over two hundred potential incidents and recognizes that there are many more.

${ }^{133}$ For further details of this phenomenon, and on reporting more generally, see Green (2015) VJIL.

${ }^{134}$ Gray (2018) 16, notes, for example, that it used to be common for minor incidents to be referred to the UNSC and debated, but that this is no longer the case.
} 
states' positions on the customary restraints of necessity and proportionality. To avoid, as much as possible, the inherent deficiencies that selecting some incidents over others necessarily entails, ${ }^{135}$ the incidents cited are intended to be representative of a breadth and diversity of practice. They have been selected from over the entire period from 1945 to the present. Collectively, they constitute the practice of states from all continents and represent a spectrum of political, economic and legal systems, of levels of economic development, and so on. Such practice also covers the full range of 'types' of self-defence claims, encompassing traditional state-to-state violence, uses of force against NSAs and anticipatory action.

In the course of this review, legal significance must be inferred from primary materials and factual context, which necessarily involves a degree of personal judgement. ${ }^{136}$ Identifying relevant state practice and discerning opinio juris requires a measure of subjectivity. ${ }^{137}$ To avoid arbitrariness, this subjective element must be grounded in legal doctrine and theory and must take account of assessments of the evidence by systemically-recognized bodies and individuals. Our exploration of necessity and proportionality must, therefore, include a review of the jurisprudence of the ICJ, and of the writings of academic commentators. These constitute subsidiary sources for determining rules of international law, with the former carrying particular authority. ${ }^{138}$ Both not only help to establish an analytical framework that informs the author's review of the evidence, but also provide standards against which the cogency of the author's assessments of this evidence can be measured.

\footnotetext{
135 This includes any selection bias of the author. See Reisman (1984) 13-15.

${ }^{136}$ For example, states do not always invoke necessity and proportionality explicitly, instead alluding in more general terms to the content of these requirements. Where this is the case, it is indicated. As noted in Chapter 3, states may also invoke 'proportionality' without further explanation, not making it clear whether the reference is to JAB or to IHL, where the term is also used, to different ends.

137 See e.g. Corten (2010) 17-20; Talmon (2015).

${ }^{138}$ Art 38(1)(d) SICJ.
} 


\section{CHAPTER 2: NECESSITY}

\section{Introduction}

In the JAB, necessity acts as an immediate limitation on the use of defensive force. It is the first requirement that operates to condition a state's exercise of its right of self-defence. ${ }^{1}$ In response to an actual or imminent armed attack, it determines whether defensive force is required at all by way of a response, or whether peaceful alternatives will suffice. It also restricts where defensive force is to be directed. Only once these requirements are established can the proportionality of defensive action be considered. Necessity has been described as the more straightforward, or least problematic, of the two requirements. ${ }^{2}$ It is true that necessity is often clearly identifiable when states justify acts of self-defence and review force used by other states. Green has rightly noted, however, that it is a notoriously indeterminate concept. ${ }^{3}$ Indeed, on a conceptual level, necessity raises challenging questions that go to the heart of the right of self-defence and its exercise. These issues are rarely explored in the literature in a systematic and comprehensive manner. As such, it is a mistake to dismiss necessity as uncomplicated. There is much more to be said regarding its conceptual scope and its practical content. A clear exposition of these elements enables a delimitation of its parameters and its potential to limit or bar the use of military force.

In this Chapter, a distinction will first be made between necessity in the JAB and necessity in the laws of state responsibility and IHL. Highlighting the differences in the operation of necessity within these three regimes of international law helps to explain JAB necessity. It will be seen that, conceptually, there are in fact two types of JAB necessity. A novel taxonomy is, therefore, proposed to capture this separation, before moving on to parse

\footnotetext{
${ }^{1}$ In respect of the distinction between armed attack (as a trigger of the right) and necessity (as rule that conditions is exercise), see Section 2.2.

${ }^{2}$ Gardam (2004) 26; Akande and Liefländer (2013) 564.

${ }^{3}$ Green (2006) 450-1.
} 
Webster's formula in detail. This investigation encompasses consideration of whether peaceful alternatives are open to a defending state when faced with an actual or imminent armed attack. Temporal questions inherent in the concept of necessity are then reviewed, in particular whether a state has time to consider such alternatives. The issue of targeting completes the analysis.

\subsection{Necessity in other areas of international law}

Necessity is only relevant where a state has first been the victim of an armed attack. In this respect, it may be contrasted with a plea of necessity under the laws of state responsibility that do not require any prior act (wrongful or otherwise) on the part of the state against which the act of necessity is taken. ${ }^{4}$ Instead, pursuant to Article 25 ARSIWA, states may invoke necessity to preclude the wrongfulness of an act if it 'is the only way for the state to safeguard an essential interest against a grave and imminent peril'. ${ }^{5}$ Some scholars have suggested, therefore, that a plea of necessity might justify a use of defensive force on its own terms. They argue that, in certain circumstances, it might be elevated to an independent legal basis to use military force, akin to self-defence. ${ }^{6}$

Relying solely on a plea of necessity to excuse an otherwise illegal use of force faces significant problems however. Article 25 is drafted in the negative, thereby restricting its invocation and emphasising that states may only invoke it in exceptional circumstances. ${ }^{7}$ Whilst the existence of an armed attack might

\footnotetext{
${ }^{4}$ As a point of doctrine, this thesis adopts the position that self-defence is an independent right under the UN Charter. This means that the right is triggered on the terms of Art 51 UN Charter by an armed attack. It is not a responsive right that requires a prior breach of Art 2(4). A state exercising its right of self-defence recognized by Art 51 is not, 'even potentially', in breach of Art 2(4). Crawford (1999) para 298; Art 21 ARSIWA Commentary, para 1. The Art 2(4) prohibition on the use of force must be read, therefore, as incorporating the self-defence exception within its terms. Trapp (2015) 214-20. See also Paddeu (2015). Cf Ago (1980) paras $87-9$. See further $n 16$. See also Chapter 4 regarding the ability of NSAs to carry out armed attacks that are not attributable to a state.

${ }^{5}$ Art 25(1) ARSIWA and related Commentary. For further discussion of the distinction between necessity and self-defence, see Ago (1980) paras 82-124.

${ }^{6}$ See e.g. Laursen (2004); Vidmar (2017). For a general discussion (and rejection of) this argument, see Corten in Weller (2015) 863-7; Tsagourias (2010).

7 Gabčíkovo-Nagymaros Project (Hungary/Slovakia) (Judgment) [1997] ICJ Rep 7 ('Gabčíkovo-Nagymaros') para 51; Crawford (2013) 306-7.
} 
be said to satisfy this requirement, resorting to a plea of necessity is disbarred if the international obligation in question (being Article 2(4) UN Charter) excludes the possibility of its invocation. ${ }^{8}$ Accepting that Article 2(4) constitutes an absolute prohibition on the use of force, subject only to the explicit exceptions set out in the UN Charter, on its own terms Article 2(4) likely prevents wrongfulness preclusion on the basis of a separate plea of necessity. A fortiori if the Article 2(4) prohibition is jus cogens. ${ }^{9}$

A plea of necessity should not, therefore, be viewed as an independent justification that allows for the circumvention of the prohibition of the use of force. JAB necessity is a customary requirement that, whilst related to, is distinct from the laws of state responsibility. On this basis, a 'state of necessity' is a constituent element of the primary rule, being the right of self-defence recognized by Article 51 UN Charter. Such right accounts for the necessity criterion and, by implication, excludes the possibility of invoking a general 'state of necessity' as a circumstance precluding wrongfulness. ${ }^{10}$ As part of an existing primary rule of international law, therefore, there is no need to rely on a secondary rule of international law as a general excuse to use force. ${ }^{11}$

It could be argued, however, that a plea of necessity and the right of selfdefence affirmed by Article 51 UN Charter are not precisely co-extensive in respect of their relationship with the prohibition of the use of force. Situations

\footnotetext{
${ }^{8}$ Art 25(2)(a) ARSIWA.

${ }^{9}$ Art 26 ARSIWA denies a preclusion of wrongfulness where a jus cogens norm is violated. The Art 2(4) prohibition is often labelled by scholars as jus cogens (see e.g. Simma (1999) 3), although such characterisation is contested. In Nicaragua, para 190, the ICJ noted that the ILC and the USA (in its Memorial on the Merits in the case) characterised the prohibition on the use of force as jus cogens, but it has never ruled on this point. Questioning its peremptory status, see Green (2011).

${ }^{10}$ Art 25 ARSIWA Commentary, para 21, states that 'the plea of necessity is not intended to cover conduct which is in principle regulated by the primary obligations.' It gives the example of the doctrine of 'military necessity' in IHL as one that already takes into account the concept of necessity. Adopting this approach, Section 2.3 UK Ministry of Defence, The Manual of the Law of Armed Conflict (2005) ('UK Military Manual') concludes that necessity cannot be used to justify actions prohibited by law. This reasoning directly translates to the primary rules of the JAB. Note also that Art 55 ARSIWA expressly recognizes the rule of lex specialis by disapplying the ARSIWA 'where and to the extent that the conditions for the existence of an internationally wrongful act or the content or implementation of the international responsibility of a state are governed by special rules of international law.' This is also the case with the JAB rules governing the right of self-defence. See further Crawford (2013) 308.

11 See further Tsagourias (2016) 813-19; Paddeau (2017).
} 
might be said to exist where the right of self-defence is not triggered, but a plea of necessity may nevertheless excuse a use of force. ${ }^{12}$ Examples include the controversial right to employ putatively defensive force against NSAs on foreign territory, and anticipatory action to counter future armed attacks. ${ }^{13}$ On this logic, Article 25 ARSIWA has the potential to operate beyond the boundaries of self-defence, and UNSC authorisation, as an independent basis for using force. This position faces a significant hurdle, however. Necessity may not be invoked where the actions taken 'seriously impair an essential interest of the State or States towards which the obligation exists, or of the international community as a whole.' ${ }^{14}$ The interest relied on (being the right to take defensive action) must outweigh all other considerations, both individual and collective. ${ }^{15}$

The essential interests of sovereignty and territorial integrity would appear to preclude the operation of a plea of necessity in this context. Absent an established right of self-defence, these essential interests, which are legally protected by Article 2(4) UN Charter, will be violated by a use of force that is deployed in or against the territory of an aggressor state or, ${ }^{16}$ in the case of armed attacks by NSAs, a host state. ${ }^{17}$ Using force beyond the parameters of

\footnotetext{
12 E.g. Vidmar (2017) 305.

13 Ibid.

${ }^{14}$ Art 25(1)(b) ARSIWA.

15 Art 25 ARSIWA Commentary, para 17.

16 In an interstate context, these essential interests are not a barrier to a lawful exercise of self-defence covered by Art 51. An exercise of lawful self-defence against an aggressor state does not violate Art 2(4) (see n 4), and the incidental breaches of an aggressor state's sovereignty and territorial integrity (resulting from a lawful act of self-defence) are excused by operation of Art 21 ARSIWA. See Crawford (1999) para 298-9; Art 21 ARSIWA Commentary, para 2; Crawford (2013) 290; Paddeau (2017) 100-5. In such cases, self-defence has two functions. First, it operates as a primary right and as an exception to Art 2(4) UN Charter. Second, in respect of incidental breaches of certain other obligations, it operates as a secondary rule, precluding responsibility for an internationally wrongful act. See generally Crawford (2013) 290-2; Paddeu (2017).

${ }^{17}$ A 'host state' is a state from whose territory NSAs launch an armed attack, and in whose territory a defending state uses force in response to such armed attack. In respect of an exercise of self-defence against NSAs on the territory of a host state, the position of these essential interests of the host state is more complicated and controversial. Absent attribution of the armed attack to the host state, there are various potential justifications that might be argued to excuse the temporary breach of a host state's sovereignty and territorial integrity. Whilst disputed, all of these potential justifications rely on the lawful exercise of self-defence, rather than on a plea of necessity. They include the argument that lawful self-defence operates in the same way as the circumstance precluding wrongfulness of necessity, thereby excusing any breach of these Art 2(4) protected rights, even if the breach affects innocent third-party
} 
Article 51 also has wider negative implications for international peace and security, which is an essential interest of the international community as a whole. As such, a plea of necessity should not be regarded as precluding wrongfulness vis-à-vis the prohibition on the use of force of contained in Article 2(4). The use of defensive force forms part of that primary obligation and it operates solely under the auspices of the 'inherent' right recognized by Article 51 UN Charter. ${ }^{18}$

A distinction must also be drawn with the role of necessity in IHL. Within this legal regime, necessity is referred to as 'military necessity', which:

permits a state engaged in an armed conflict to use only that degree and kind of force, not otherwise prohibited by the law of armed conflict, that is required in order to achieve the legitimate purpose of the conflict, namely the complete or partial submission of the enemy at the earliest possible moment with the minimum expenditure of life and resources. ${ }^{19}$

Throughout the rules of IHL, military necessity works in conjunction with, and is balanced by, the principle of humanity. ${ }^{20}$ The function of necessity within this relationship is to permit the attainment of military objectives and, simultaneously, curb the potential excesses of war in the name of

states. Trapp (2015) 216-19. Another is where the host state is either unwilling to prevent its territory from being used as a base for NSAs or is unable to do so and is unwilling to cooperate by accepting assistance (thereby it is acquiescing). This conduct is itself a breach of Art 2(4), meaning that the host state cannot claim the protection of Art 2(4). Trapp (2015) 21920 , in the context of a responsive reading of Art 51 that requires a prior breach of Art 2(4) (although, as explained in $n 4$, this author does not adopt such a reading). A third is that the incidental breaches of a host state's sovereignty and territorial integrity (resulting from a lawful act of self-defence) are also excused by operation of Article 21 ARSIWA. Tsagourias (2016) 819-24; Paddeu (2017) 110-14. It is notable that the ILC explicitly leaves open the question of the effects of defensive force on other states. ARSIWA 21 Commentary, para 5. 'Lawful' self-defence requires compliance with the primary rules of Art 51 and customary international law, including the existence of an armed attack and adherence to the requirements of necessity and proportionality. It also implies compliance with obligations of 'total restraint', such as non-derogable human rights and 'intransgressible' rules of IHL, breaches of which may not be justified by operation of Art 21 ARSIWA. Art 21 ARSIWA Commentary, pars 3-4, 6; Crawford (2013) 291-2; Paddeu (2017) 104. See further Section 3.2.6 and Chapter 4.

${ }^{18}$ Crawford (2013) 290.

${ }^{19}$ Section 2.2 UK Military Manual.

20 'Humanity forbids the infliction of suffering, injury, or destruction not actually necessary for the accomplishment of legitimate military purposes.' Section 2.4 UK Military Manual. 
humanitarianism. The underlying purpose of military necessity, therefore, is not dissimilar to the operation of JAB necessity and proportionality. Both sets of rules seek to contain the use of military force. However, IHL and the JAB are separate and distinct regimes, with the former operating principally at the micro level, and the latter at the macro level. These distinctions and overlaps are explored below and in Chapter $3 .{ }^{21}$

\subsection{General and specific necessity}

\section{a) A novel taxonomy}

It was noted in Section 1.3.1 that necessity and proportionality are sometimes conflated by states and academics, and/or used interchangeably in a way that does not distinguish between them. Gray, is but one example. ${ }^{22}$ Corten's explanation of exclusive purpose, referred to in Section 1.3.2(b) is another. In his analysis, Corten asserts that necessity being said to have an exclusive purpose 'amounts to the same thing' as saying that a response is proportionate. ${ }^{23}$ Other examples are referenced in subsequent Sections. The challenge, therefore, is to see whether it is in fact possible, or even desirable, to distinguish clearly between necessity and proportionality, rather than employing them jointly or alternatively as a general description of illegality.

In exploring how far a state may go to defend itself, much may be gained by conceptual clarity that distinguishes between the two concepts. Separating them, and identifying their particular characteristics, renders them easier to apply in both principle and practice. In approaching this question, this author proposes that a novel taxonomy should be employed to describe necessity. This taxonomy is set out in the following paragraphs. Its purpose is to aid with constructing an analytical framework of necessity, and how such concept may

\footnotetext{
21 See in particular Sections 2.5 and 3.3.

22 Gray (2018) 159.

${ }^{23}$ Corten (2010) 484. In so doing, it is notable that Corten refers to analysis by Gardam (2004) 156 , regarding proportionality (not necessity).
} 
be compared to, and contrasted with, both proportionality and armed attack. ${ }^{24}$ It draws a clearer division between these concepts. Furthermore, the proposed taxonomy constitutes a tool to analyse and interpret state practice and expressions of opinio juris, as well as academic commentary and the ICJ's jurisprudence. ${ }^{25}$ This author uses it to capture and clarify what already exists in these primary and secondary sources of international law. The taxonomy is, therefore, derived from such sources. It reflects how states, courts and scholars refer to two distinct aspects of necessity, even if they do not articulate it in the terms set out below. It is submitted that this new approach to necessity is a lens through which we can better view the lex lata and lex ferenda.

The proposed taxonomy distinguishes between two 'types' of necessity. In response to an actual or imminent armed attack, the first type governs whether there is a necessity of some form of defensive response. In conditioning the exercise of the right, once triggered, it requires that i) there are no reasonable alternatives available to halt, repel or prevent that armed attack (i.e. force is the only reasonable way to resolve the particular situation), and/or ii) there is no time to pursue such alternatives. ${ }^{26}$ In such circumstances, we may conclude that there is a 'general necessity' of employing defensive force. Such conclusion is irrespective, at this point in time, of the means and methods of effecting that defensive response. Importantly, general necessity cannot be confused or conflated with proportionality. The two are conceptually distinct. ${ }^{27}$

In response to an actual or imminent armed attack, general necessity is, therefore, the first barrier that must be passed before a state may respond with force. Its absence means that there is no necessity of self-defence (at all) and any ensuing use of force will be unlawful. If, and only if, general necessity is established, the next question to be answered is whether the requirements of the second 'type' of necessity are also satisfied. This separate and distinct category of necessity relates to the specific acts that effect the right of self-

\footnotetext{
${ }^{24}$ On the distinction between necessity and armed attack, see Section 2.2(c).

${ }^{25}$ Regarding this taxonomy and the ICJ's jurisprudence, see Sections 2.2(b) and (c).

${ }^{26}$ These issues are covered in Sections 2.3 and 2.4 respectively.

27 This point is explored further in Section 3.3.2.
} 
defence. This concept of 'specific necessity' requires a rational connection between the force used and a defensive purpose. The nature of the targets chosen to fulfil such defensive purpose are determinative of this test. ${ }^{28}$

An example of specific necessity's operation is evident when considering deliberately targeting civilians. As non-military targets, they can have no connection with the armed attack. Their neutralisation or destruction can achieve no defensive purpose and suggests instead that a use of force has a punitive and, therefore, unlawful goal. ${ }^{29}$ Specific necessity perhaps explains references that, at first sight, sound like comments on proportionality. For example, it has been suggested that the size, duration and the target of the response are all relevant to proportionality..$^{30}$ Specific necessity is most closely related to proportionality, as it acts to constrain the defensive response to what is necessary to halt, repel or prevent an armed attack. ${ }^{31}$ In contrast, general necessity conditions the prima facie right to exercise defensive force, once that right has been triggered by an actual or imminent armed attack. These two forms of necessity capture, therefore, the two distinct questions that arise in state practice, scholarship and ICJ jurisprudence that are considered under the generic umbrella of 'necessity': i) can a state use force at all in the circumstances, and ii) if so, where must such force be directed?

\section{b) General and specific necessity and ICJ jurisprudence}

The distinction between the two types of necessity, although novel, is reflected in the ICJ's jurisprudence, ${ }^{32}$ and can be employed to analyse its reasoning more fully. Oil Platforms provides a clear example. In this case, the USA claimed a right of self-defence in respect of attacks on two vessels, which it attributed to Iran. The Court rejected this argument. It determined that neither

\footnotetext{
28 See Section 2.5 .

${ }^{29}$ See further Section 2.5. The fact that such targeting would breach IHL rules is a separate, albeit closely connected, issue.

30 Gray (2018) 159.

31 Okimoto (2012) 65, notes that this understanding of necessity is effectively identical to proportionality. See further Section 3.3.2.

32 Although, as noted, it is not expressed in these terms.
} 
the missile attack on the Sea Isle City, nor the mining of the USS Samuel B. Roberts, constituted armed attacks imputable to Iran. They did not, therefore, give rise to a right of self-defence on the part of the USA. ${ }^{33}$ Despite the absence of an armed attack, the Court nevertheless went on to consider necessity, concluding that the American response to both incidents was unnecessary. ${ }^{34}$ The distinctions clarified by the taxonomy proposed in Section 2.2(a) clearly appear in the majority's reasoning.

First, the Court did not opine explicitly on the prior question of the general necessity of the USA acting in self-defence in the particular circumstances. It did not say that the right of self-defence was, or was not, exercisable in general terms. It simply concluded that it could not be exercised against Iran. The issue of general necessity is nevertheless implicit in the judgment. In respect of its consideration of the mining of the USS Samuel B. Roberts, the Court recognized that the mining might be sufficient to 'bring into play' the right of self-defence, or at least it could not exclude that possibility. ${ }^{35}$ The basis for this conclusion appears to be that the act of mining might constitute an armed attack, which triggers the right of self-defence. However, also implicit in this statement is that general necessity, which conditions the exercise of the right once triggered, might also be satisfied. This is because, without general necessity, the right cannot be 'brought into play'.

The proposed taxonomy helps to draw out this factor of general necessity from the judgment and to highlight the contrast between it and specific necessity. It was specific necessity that was determinative of the Court's finding of a lack of 'necessity'. The Court concluded that, in the circumstances, the American response against Iran was not justifiable in response to an armed attack on the USA that could not conclusively be attributed to Iran. ${ }^{36}$ Moreover, the Court made it clear that it did not believe that the oil platforms were military targets. ${ }^{37}$

\footnotetext{
33 Oil Platforms, paras 61, 64, 72.

${ }^{34} \mathrm{Ibid}$, para 76. The Court also considered proportionality. See Section 3.1.1(f).

35 Ibid, para 72.

${ }^{36}$ Ibid (emphasis added). See further Section 2.5.

37 Ibid, para 76 .
} 
These are issues of specific necessity. The target of the defensive response is clearly distinct from whether there has there been an armed attack and, if so, whether prima facie there is a need to resort to force under the circumstances. Whilst not expressed in these terms, these distinctions are reflected in the Court's judgment.

This conceptual separation of the two constituent elements of necessity provides greater clarity regarding the Court's reasoning and conclusions. It sheds light on why the Court deemed the exercise of self-defence to be 'unnecessary' and what it requires for it to be necessary. It also helps us to interpret and critique the Court's analysis of whether or not the USA had first been the victim of an armed attack. The Court's analysis of the armed attack requirement on the one hand (being the trigger of the right) and necessity on the other (being the requirement that conditions its exercise) appear somewhat conflated. The Court's approach to the legality of the missile attack on the Sea Isle City was that the USA had to prove that it was the victim of an armed attack by Iran, such as to justify it using armed force in self-defence, ${ }^{38}$ and that the burden of proof had not been discharged. ${ }^{39}$ It took the same approach to determining the legality of the mining of the USS Samuel B. Roberts. ${ }^{40}$

For the majority, therefore, the identity of the attacker was an intrinsic part of establishing the existence of an armed attack. Such an approach is illogical. The fact of whether or not a state has been the victim of an armed attack is quite different from, and separate to, the question of identifying the attacker. The former does not require the latter to be confirmed for it to have factually occurred. ${ }^{41}$ For the purposes of a defensive response, it is submitted that the identity of the attacker is an important factor, but it relates to necessity. With respect to general necessity, the identity of the attacker informs whether any

\footnotetext{
${ }^{38} \mathrm{Ibid}$, para 57 (emphasis added).

$39 \mathrm{Ibid}$, para 61.

$40 \mathrm{lbid}$, paras $71-2$.

${ }^{41}$ This author adopts the position that the existence of an armed attack is essentially a factual, rather than normative, question. Whilst potentially subject to a de minimis gravity threshold (see Nicaragua, para 191), the identity of the attacker, whether it be a state or group of NSAs, is a separate question. See further $\mathrm{n} 57$ and accompanying text. Regarding the timing of an armed attack, see Section 2.4.1. See further Chapter 4 regarding armed attacks by NSAs.
} 
sort of military response is required, or whether the putative defending state can resolve the issue peacefully with the attacker, without resorting to force. ${ }^{42}$ For specific necessity, the identity of the attacker goes to the question of to what/whom any defensive force is to be directed. Following an armed attack, it is simply unnecessary for a state to defend itself against anything/anyone other than the attacker.

That the attack and the identity of the attacker are two separate factors is apparent in the Court's reasoning in Oil Platforms. In respect of the missile attack on the Sea Isle City, the Court insisted that, in looking at whether the missile attack was grave enough (for the purposes of the Nicaragua gravity threshold test), it was setting aside the question of attribution to Iran of the attack. ${ }^{43}$ This was also the case for the related incidents to which the USA alleged it was responding. ${ }^{44}$ In respect of the mining of the USS Samuel $B$. Roberts, the Court did not exclude the possibility that the mining of a single military vessel might be sufficient to give rise to the right of self-defence, but concluded, principally relying on the 'inconclusiveness of the evidence of Iran's responsibility', that there had not been an armed attack. ${ }^{45}$

In principle, therefore, the Court has recognized the distinction between the attack and its attribution to the perpetrator. However, it has treated both as separate parts of the armed attack trigger. It is submitted that the better view is that in response to an actual or imminent armed attack (complying with any gravity threshold), the next question is whether there is the necessity of some form of defensive response (which is an issue of general necessity). Only if this is satisfied does the question of where the defensive force should be directed arise (being an issue of specific necessity). Conceptually separating

\footnotetext{
42 E.g. via diplomatic resolution. See Section 2.3.

43 Oil Platforms, para 64.

${ }^{44}$ Part of the American case was that it had been the victim of a number of related attacks, of which the attack on the Sea Isle City had been the latest. Ibid, paras 61-4.

${ }^{45} \mathrm{Ibid}$, para 72.
} 
out the stages in this manner leads to a more accurate description of the factual and legal position.

Had the Court followed this approach, it might have determined that the USA had been the victim of an armed attack. This conclusion reflects the facts of the incident, namely the physical damage incurred, and the Court's comments regarding the mining of the USS Samuel $B$. Roberts. It could then have addressed the issue of attribution of the attacks to Iran and considered the availability of reasonable alternatives to force to resolve the dispute. Finally, absent such alternatives, it was in a position to consider whether the USA had properly directed its military response. Without attribution of the armed attacks to Iran, a decision based on specific necessity leads to the same result reached by the Court. However, the process described here would have led to a better reasoned and more transparent judgment. It would have enabled an appreciation of what elements of an armed attack and/or necessity were operative in, and determinative of, the Court's reasoning. It could have avoided much of the confusion that persists to this day regarding issues like the gravity threshold, attribution, and belligerent intent, ${ }^{46}$ and if and how they all relate to an armed attack. Moreover, following this process would have provided a clear and predictable framework to be adopted for deciding future judgments. Such framework could also have served as a decision-making tool for states when considering whether or not to resort to defensive force, how they explain their decisions, and how they review the actions of other states.

\footnotetext{
${ }^{46}$ The Court also appeared to require belligerent intent on the part of Iran when considering the existence of an armed attack. Oil Platforms, para 64. Previously in Nicaragua, para 231, the Court referred to 'possible motivations' relating to trans-border incursions allegedly carried out by Nicaragua. The Court did not go into any detail in either case or provide any support for this requirement in international law. Requiring aggressive intent to establish an armed attack is controversial. See e.g. Taft (2004) 302-3; Green (2008) 201-6; Gray (2018) 152; Henderson (2018) 214-16. It does, however, relate to the issue of the need to respond to unintended attacks, such as accidental incursions into territory, munitions going astray, or military personnel acting in error or beyond the scope of their orders. Requiring a hostile motive for an armed attack to have occurred might help to exclude forcible responses to such incidents of error or accident. However, this concern would be better addressed by considering intent as part of the general necessity calculus, rather than as a constituent part of an armed attack. This to ask whether there is prima facie need to resort to force in response to an attack that appears to be accidental or made in error, or whether alternative means would suffice to resolve the situation.
} 
c) General necessity, specific necessity and armed attack

As the above example and analysis highlights, distinguishing between specific and general necessity also helps to draw a line between both types of necessity and the prior armed attack trigger. This distinction requires further elaboration. Green suggests that, in the vast majority of situations, the requirements of an armed attack and of necessity are likely to condition a use of force in the same manner. This is because, it is argued, if one applies the Nicaragua standard of 'armed attack as a grave use of force', only in extreme cases (i.e. grave uses of force) may self-defence be exercised. The situation is the same on an understanding of necessity that limits defensive force to extreme cases, where such action is a last resort. The two requirements are, therefore, performing a similar function, which raises the question: 'if an armed attack is established, does this automatically prove necessity?' ${ }^{47}$ Green's response is that establishing an armed attack (amounting to a 'grave' use of force) is tantamount to establishing necessity in virtually all cases. ${ }^{48}$

It might be true that a state faced with a grave use of force easily establishes the defensive necessity that permits a forcible response. However, as Green notes, the Court has clearly recognized that 'armed attack' and 'necessity' are distinct concepts..$^{49}$ It has set out a two-stage test for assessing the lawfulness of self-defence, even if confusion may arise from the jurisprudence regarding how they are applied. First is the requirement of the armed attack. If (and only if) that triggering element is present may we proceed to the additional requirements that the defensive response is necessary and proportionate. ${ }^{50}$ Yet, Green rightly highlights that this distinction may not be so clear in state practice. States do not always employ this two-stage evaluation and may instead present the two concepts as part of the same legal claim. ${ }^{51}$

\footnotetext{
47 Green (2009) 135, 138.

48 Ibid.

49 Ibid, 138.

50 Nicaragua, para 194; Oil Platforms, para 51.

51 Green (2009) 135-6.
} 
Applying the concepts of general and specific necessity to this issue of coextensive operation of armed attack and necessity helps to draw a brighter line between them. This approach demonstrates that it is not just a conceptual possibility that an armed attack may not, in all cases, establish the necessity of responding to a 'grave use of force'. ${ }^{52}$ The answer, therefore, to the question of whether an established armed attack automatically proves necessity, is that it does not. ${ }^{53}$ First, we should not over-emphasize the 'most grave uses of force' description of an armed attack. The gravity threshold, to the extent it is accepted, is not generally regarded as being particularly high. As noted, the ICJ has suggested that the mining of a single military vessel might be enough to engage the right of self-defence. ${ }^{54}$ Regardless, whilst gravity is a factor that might determine the existence of an armed attack (if the Nicaragua gravity threshold is accepted), it does not inevitably establish general necessity.

As addressed in detail in Section 2.3, general necessity evaluates whether other reasonable options are open to the defending state to respond to an armed attack, before resorting to defensive force as a last resort. This assessment is context dependent and draws upon a number of factors, which may or may not include the gravity of the armed attack. Therefore, even if an armed attack is established (because a particular, undefined, threshold of violence has been surpassed), this does not automatically mean that there are no peaceful alternatives available to resolve the situation. An unintentional armed attack provides a cogent example. Factually, although this could surpass any gravity threshold, a peaceful resolution might suffice to resolve the issue, such as negotiations leading to reparations.

Therefore, considerations other than the gravity of an armed attack might determine whether there is a general necessary to resort to defensive force. One of the principal factors is timing. With fully completed armed attacks, for example, because they are factually over, there may be no need to rely on

\footnotetext{
52 Ibid, 138.

${ }^{53}$ For possible conflation of general necessity and imminence, however, see Section 2.4.1(b).

54 Oil Platforms, para 72.
} 
force where the situation may be resolved reasonably by other means..$^{55}$ The gravity of the attack could be irrelevant to this determination of general necessity. In situations where a state is facing an imminent armed attack, whether it has time to pursue peaceful alternatives is likely to govern the general necessity question. Addressing this timing issue is required in every case of an imminent armed attack, regardless of its gravity. ${ }^{56}$

The foregoing evaluation offers a clearer conceptual division between armed attack and general necessity. The gravity of an armed attack might factor in considering general necessity, but this calculation goes beyond questions relating purely to the level of force directed at a state and addresses concerns that are clearly distinct from the armed attack trigger that precedes it. If the Nicaragua gravity threshold is accepted, however, the result is that the severity of the armed attack potentially features in both the armed attack trigger and considerations of general necessity. This is redundant. If the right of selfdefence is not triggered until a particular level of force is surpassed, it is questionable whether a threshold requirement can also condition its exercise. It is doing no additional legal work in regulating the use of defensive force.

It is submitted, therefore, that an armed attack is better conceived of as a baseline factual trigger of a use, or threatened use, of military force that prima facie engages the right of self-defence. This would equate 'armed attack' in Article 51 UN Charter with 'use of force' in Article 2(4). ${ }^{57}$ If accepted, issues of gravity are confined to conditioning the exercise of the right. It determines if the exercise of self-defence is necessary and proportionate. Rather than gravity factoring in an ill-defined manner as part of the preceding armed attack trigger, it fits more naturally into the overall contextual assessment of both of

\footnotetext{
${ }^{55}$ See further Section 2.4.1(c).

${ }^{56}$ See further Section 2.4.1(b).

57 This author has written elsewhere regarding the gravity threshold controversy, whether there exists a gap between Arts 2(4) and 51, and how this might affect the rights of individual military personnel and their units to defend themselves. O'Meara (2017) JUFIL 289-98. On the gravity threshold issue more generally, see e.g. Green (2009) 111-46, 148-63; Ruys (2010) 139-57; Henderson (2018) 222-3. On how the gravity of the armed attack informs the proportionality of the response, see Chapter 3.
} 
these requirements. Drawing a clear line between armed attack and general necessity emphasizes this fact.

An even clearer distinction may be drawn between armed attack and specific necessity. Clearly, the latter concept is not performing the same function as the armed attack trigger, or general necessity. Specific necessity is not limiting force to cases where it is a last resort. Rather, once the right of self-defence is triggered, and established to be prima facie necessary, it limits defensive force to legitimate targets that enable the defending state to pursue a defensive purpose. It confines action to the pursuit of that aim. Therefore, parsing the concepts of armed attack and the two types of necessity helps to understand the function and content of these distinct and separate requirements. Even if the ICJ is not always so clear in applying these criteria, it is entirely correct from a conceptual perspective for the Court to have affirmed a two-stage test that distinguishes between armed attack and necessity.

In sum, following an armed attack, or in response to one that is imminent, general necessity determines whether force is the only way to resolve the situation. If it is, any force that goes beyond what is required to halt, repel or prevent that armed attack, is either an issue regarding specific necessity (because of the nature of the target) or an issue of proportionality (because the overall defensive response is excessive). ${ }^{58}$ This proposed distinction between two types of necessity identifies what is meant by references to 'necessity'. It may, therefore, be used as a tool to analyse the literature, judicial pronouncements, state practice and expressions of opinio juris. It also helps us to tease out the conceptual differences between armed attack, necessity and proportionality and to draw a clearer dividing line between them. This novel terminology and associated analytical approach are adopted throughout this thesis.

${ }^{58}$ See Sections 2.5 and Chapter 3 respectively. 


\subsection{General necessity - other options open to a state}

\subsubsection{General principles}

Assuming an armed attack has occurred, Webster's formula suggests that selfdefence is only available to a defending state if there is 'no choice of means'. Today, the common understanding amongst scholars of this element of necessity is that resorting to defensive force is exceptional. It is a measure of last resort, ${ }^{59}$ where the particular situation compelled a certain course of conduct. ${ }^{60}$ This means that there must not be any non-military alternative to using force. ${ }^{61}$ If a state can counter an actual or imminent armed attack by measures not involving armed force, it has no justification for using it. ${ }^{62}$ Under our novel taxonomy, this equates to the requirement of general necessity.

The general academic consensus is that necessity does not require a defending state to consider all peaceful alternatives open to it, and to pursue and exhaust them before acting with force to end or avert an armed attack. This is despite the general obligation under international law requiring peaceful settlement of disputes between nations. ${ }^{63}$ Whilst terminology varies amongst scholars, there is widespread agreement that the essence of necessity (to be understood as general necessity) is that states are only required to consider peaceable options that are practical and which are likely to be effective in averting a threat or bringing an attack to an end, or have a reasonable chance of so doing. ${ }^{64}$ This focus on the lack of effective alternatives recalls the writings

\footnotetext{
59 The Caroline incident occurred in a period where emerging state practice already contained the notion that war was a means of last resort. Brownlie (1963) 21-2. Regarding necessity as a principle of last resort in the just war tradition, see Ohlin and May (2016) 15-37.

60 Tams in Van den Herik and Schrijver (2013) 380.

${ }^{61}$ Ago (1980); Schachter (1984) 1635-7; The Chatham House Principles, 967; Dinstein (2017) 250-1; Gray (2018) 159. See also Nicaragua, diss op Schwebel, 201 and 204.

${ }^{62}$ Ago (1980) para 120.

${ }^{63}$ Arts 1(1), 2(3) and 33 UN Charter. See also the preamble to UNGA Res. 2625 (1970) ('Friendly Relations Declaration').

64 The Chatham House Principles, 967. That alternative measures must be effective, see Greenwood (1986-1987) 945; Lubell (2010) 45; Tams and Devaney (2012) 96; Bethlehem (2012) 775; Tams in Van den Herik and Schrijver (2013) 380; Henderson (2018) 230.
} 
of just war theorists, such as Vattel. ${ }^{65}$ It also echoes Webster's insistence that [i]t must be shown that that admonition or remonstrance to the persons on board the Caroline was impracticable, or would have been unavailing. ${ }^{\prime} 66$

An alternative to reliance on 'effectiveness' is a belief that general necessity 'merely requires that non-forceful measures be insufficient to address the situation. ${ }^{\prime}{ }^{67}$ The UK has explicitly adopted this view. ${ }^{68}$ Notions of the feasibility and effectiveness of alternative measures are echoed by others who maintain that, where peaceful means have been found wanting, or when they clearly would be futile, then force should be considered necessary. ${ }^{69}$ Green, noting this variant terminology, concludes that the contemporary Caroline requirement of last resort will be met where it would have been unreasonable to expect the defending state to attempt to deploy means other than force to resolve the situation. There must, therefore, be no reasonable choice of means available to the defending state in the particular circumstances..$^{70}$ Such a view has been expressed explicitly, for example, by Australia. ${ }^{71}$ It is also reflected, in general terms, in state practice relating to specific incidents of self-defence. ${ }^{72}$

A conception of general necessity that maintains force as a last resort, and where it is the only reasonable choice of means, is also reflected in the wider operation of the collective security system. Under Article 42 UN Charter, the UNSC may take forcible measures to maintain or restore international peace and security if it considers that non-forcible Article 41 measures 'would be

\footnotetext{
65 'Force (...) becomes necessary (...) when every other [mode] proves ineffectual.' Vattel (1797) Book III, Chapter III, para 25.

${ }^{66}$ Letter from Mr Webster to Mr Fox (24 April 1841) British and Foreign State Papers, 1840 1841, Vol. XXIX, 1138.

${ }^{67}$ Schmitt (2013) 62 (emphasis added). Elsewhere Schmitt has argued that necessity requires the absence of 'adequate' non-forceful options. Schmitt (2007-2008) 151.

${ }^{68}$ UK Attorney General Speech 2017, 10.

${ }^{69}$ Schachter (1991) 152; Dinstein (2017) 250-1 (citing Schachter). Dinstein also highlights that alternative means of redress must be 'practicable'. Ibid. Gill in Weller (2015) 743-4, acknowledges that necessity usually refers to the lack of 'feasible alternatives'.

70 Green (2006) 453, 455-6 (emphasis added). Focusing on the absence of a reasonable alternative, such that force is the only reasonable option of addressing an armed attack, is supported by other scholars. See Rodin (2002) 111; Taft (2004) 304; Gardam (2004) 26; Schmitt (2006) 151; Chatham House Principles, 967; Ruys (2010) 95; Tams and Devaney (2012) 96; Henderson (2018) 230.

${ }^{71}$ Australian Attorney General Speech 2017.

72 See Section 2.3.2.
} 
inadequate or have proved to be inadequate'. ${ }^{73}$ For the right of self-defence, this premise requires that peaceful options are actually available to the defending state. Availability might be determined by temporal considerations (see Section 2.4), as well as more practical considerations. The latter include whether diplomatic channels are open between an attacker and the defending state. In cases of armed attacks by states, it will be diplomacy (whether by the defending state or other members of the international community) that constitutes the primary alternative means of resolution. ${ }^{74}$ If the attackers are NSAs, however, the option of communicating with them in order to pursue a peaceful resolution takes on additional complications. This is particularly difficult if states consider the NSAs to be terrorists. ${ }^{75}$ In terms of the availability of dispute resolution, this assumes consent by both parties. In any event, recourse to an international court or tribunal is unlikely, on its own, to be effective in halting, repelling or preventing an armed attack. One may doubt whether this is a viable and reasonable alternative to defensive force, particularly in response to an ongoing armed attack.

Alternatively, states may look to the UNSC for resolution. Under Article 51 UN Charter, the right of self-defence remains unimpaired until the UNSC has taken 'necessary measures' to restore international peace and security. As and when this happens, the necessity of self-defence is removed, and any continuing use of force by a defending thereafter risks being characterised as punitive and unlawful. 'Necessary measures' are not defined in the UN Charter, although it is generally understood that the UNSC has the final say on this point. ${ }^{76}$ This Charter mechanism recognizes that self-defence is an exceptional emergency action, pending resolution via the collective security framework

\footnotetext{
${ }^{73}$ Whether necessity in this context is legally justiciable, is debatable. Gardam (2004) 7, 206. Analogies with the operation of the collective security system are not straightforward, and more general consideration of the application necessity and proportionality to Chapter VII UN Charter is beyond the scope of the present work. See Gardam (2004) 188-229.

${ }^{74}$ Lubell (2010) 45.

${ }^{75}$ See Chapter 4.

${ }^{76}$ See e.g. Gill in Weller (2015) 746-9; Gray (2018) 131-2. It is clear that not all measures taken by the UNSC will interfere with self-defence. UNSC action may be complimentary to its exercise, and the UNSC may also choose to affirm the right. This happened, for example, after Iraq's invasion of Kuwait in 1990 (UNSC Res 661 (1990)) and the 9/11 attacks in 2001 (UNSC Res 1368 (2001); UNSC Res 1373 (2001)).
} 
with the UNSC at its head. For the right of self-defence to be terminated by reason of lack of necessity, however, the UNSC must take adequate and effective action to restore international peace and security. ${ }^{77}$ Where the UNSC fails to act, or where states fail to abide by its resolutions, the necessity of a response prima facie persists. ${ }^{78}$

If the availability of reasonable alternatives is established, then the summation of scholastic opinion places emphasis on whether non-military responses are, or will be, feasible and effective to address the situation. On this academic evaluation, therefore, general necessity requires that a defending state shows that eitheri) it has resorted to peaceful measures before using defensive force (and they have failed), or ii) peaceful measures are unfeasible and/or, on their own, they will be ineffective to halt, repel or prevent an armed attack. In relation to the latter point, it should be stressed that general necessity requires that force be needed as a response, but it does not demand that force be the only response. Military action may be combined with non-forceful measures such as diplomacy, economic sanctions, or law enforcement. ${ }^{79}$ The point is that force may only be used either on its own, or in combination with non-forceful measures, if the latter are unfeasible and/or will be ineffective if used exclusively. The focus is, therefore, on the availability of real alternatives.

The existing literature sets out the broad premise of general necessity and alternative measures, but not the complete picture. For example, there is no consensus, or much discussion, amongst scholars of how unlikely to succeed

\footnotetext{
77 See e.g. Halbertsam (1996); Gill in Weller (2015) 746-9; Dinsetin (2017) 255-8. The UNSC might, for example, order a ceasefire, a withdrawal of forces, a cessation of hostilities and so forth. Such binding decrees remove the necessity of self-defence where they succeed in restoring international peace and security. Ibid. That the UNSC must take adequate and effective action to restore international peace and security before the right of self-defence is terminated is confirmed by the drafting history of the UN Charter. Halbertsam (1996) 240-8.

${ }^{78}$ For example, the UK explained the necessity of self-defence against Argentina's invasion of the Falkland Islands by reference to Argentina's refusal to comply with UNSC Res 502 (1982). The Resolution had demanded an immediate cessation of hostilities and an immediate withdrawal of all Argentine forces from the Islands. The UK, therefore, justified its enduring and unimpaired right of self-defence by the fact that the Resolution had failed to be effective in maintaining international peace and security. UN Doc S/15025 (1982) 2. See further (1982) 53 BYIL, 543, 548, 551-2.

${ }^{79}$ Schmitt (2013) 62.
} 
alternative courses of action need to be before defensive armed force becomes a permissible option. More fundamentally, the summation set out in the preceding paragraphs does not fully explain the nuances of the role of alternatives to force in state practice. The review in the next Section shows that the importance of peaceful alternatives in determining the legality or otherwise of purported defensive force is highly contextual. Indeed, they may not factor at all in either the justification for, or review of, military action.

\subsubsection{State practice}

State practice affirms the aforementioned presumption that self-defence, by virtue of general necessity, is a measure of last resort. However, states have yet to provide a consistent approach to what this means in practice, beyond a general proposition. The following analysis shows that there is no consistent practice regarding what role alternative measures play in respect of particular incidents involving claims of self-defence. Such practice is varied and very context specific. Neither is there consensus amongst states regarding what they might require by way of alternatives, i.e. what constitute reasonable substitutes to force. The availability of peaceful measures is viewed by states as evidence of whether the resort to force is reasonable in the circumstances (i.e. that general necessity is satisfied). Yet, whether or not such measures are pursued or adopted does not appear to be determinative of their view of the legality of military action. There is no requirement on states, therefore, to prove general necessity. ${ }^{80}$

\section{a) Defending states}

States that are the objects of purported defensive force might highlight, by way of protest, that alternatives to force were open to the putative defending state. The DRC adopted this approach when it argued its case in Armed Activities. ${ }^{81}$ Likewise, in respect of the 1981 Osiraq incident discussed in detail below, Iraq

\footnotetext{
${ }^{80}$ Corten in Weller (2015) 872, argues that an attacked state is not obliged to prove that it has exhausted all peaceful means before reacting in self-defence.

${ }^{81}$ Armed Activities, Memorial of the Democratic Republic of the Congo, July 2000, para 5.29.
} 
argued that Israel had effective multilateral and bilateral recourses available to it in order to avoid any perceived threat. ${ }^{82}$ Yet, such states have a natural selfinterest in highlighting the existence of alternatives to the force directed against them. In contrast to references to alternatives made by defending states (which are self-limiting and, therefore, carry particular evidentiary weight), such protestations have much less probative value in determining what states require as a matter of law when seeking to establish general necessity.

Defending states might vigorously assert their right of self-defence, yet they accept that the exercise of such right is conditioned. In seeking to justify their defensive acts, they will often refer to peaceful alternatives being unavailable or futile. In the early post-UN Charter period, for example, Tunisia claimed a right of self-defence against France and attempted to expel French troops stationed on its territory. ${ }^{83}$ It stressed before the UNSC that it did everything in its power to avoid aggravating the situation and tried every method of reaching an amicable agreement, before resorting to self-defence. ${ }^{84}$ This included repeatedly requesting the French government over a period of two years to settle the issue of their troops, direct negotiation and the use of good offices. ${ }^{85}$ Likewise, during the Six Day War in 1967, Israel emphasized how it had waited for a peaceful settlement before resorting to force, claiming it only resorted to military means at the point at which there was no alternative. ${ }^{86}$

In 1986, South Africa faced criticism for its armed intervention in Zambia, Zimbabwe and Botswana, ostensibly aimed at African National Congress ('ANC') targets operating in those countries. ${ }^{87}$ South Africa claimed a right of

\footnotetext{
82 UN Doc A/36/PV.52 (1981) para 24.

83 UN Doc S/3951 (1958). France also claimed a right of self-defence, in respect of alleged Algerian NSA attacks against it originating from Tunisian territory. UN Doc S/3954 (1958). See further (1958) UNYB 77-9. This is an example, therefore, of both states claiming a right of self-defence on the basis of disputed facts. What is instructive here, is Tunisia's recourse to the language of alternative measures to justify its defensive action as a 'no choice of means' measure of last resort.

84 UN Doc S/PV.819 (1958) paras 22, 65.

$85 \mathrm{Ibid}$, paras $58,65$.

${ }^{86}$ UN Doc S/PV.1348 (1967) paras 176-8. On this incident generally, see Quigley in Ruys and Corten (2018) 131-42.

${ }^{87}$ See generally Kwakwa (1986).
} 
self-defence, ${ }^{88}$ emphasising not only that it had repeatedly warned Zambia, Zimbabwe and Botswana that the continued 'harbouring of terrorists' would result in a response against the threat emanating from their territory, but also that such states had rejected a South African offer to set up a 'joint mechanism' to negotiate an end to cross-border incursions by the ANC. ${ }^{89}$ Its justification in this incident echoed previous action against the ANC operating in foreign territory. ${ }^{90}$ The military action was action was broadly condemned, however. ${ }^{91}$ It was deemed to be particularly objectionable because it took place at the same time that mechanisms were available, and being used, to resolve peacefully the issues at hand. ${ }^{92}$ These included efforts by the Commonwealth at mediations and negotiations between the four states involved. ${ }^{93}$ For all sides, therefore, the potential for peaceful resolution was a focal point for assessing the necessity of self-defence, even though there was general disagreement that defensive force was genuinely being used as a last resort.

When the USA invaded Panama in 1989, it justified its actions, inter alia, by claiming to act in self-defence following aggression against American forces. ${ }^{94}$ In so doing, it referred to repeated prior attempts to deal with the Noriega government, including diplomacy and negotiations, all of which it had exhausted. ${ }^{95}$ In 1993, the USA maintained this approach when it claimed a right of self-defence to justify its strikes against the Iraqi Intelligence Service's ('IIS') headquarters in Baghdad in response to the failed attempt to

\footnotetext{
88 UN Doc S/PV.2684 (1986) 27-30.

$89 \mathrm{Ibid}, 22,24-6$. Warnings by defending states to states supposedly harbouring terrorists is a common theme where self-defence is invoked to justify force against NSAs operating in foreign territory. See Chapter 4.

90 In action taken the previous year against the ANC in Angola, South Africa pointed to previous failed attempts at peaceful resolution and to Angola's persistent harbouring of terrorists on its territory. This, it said, justified the necessity of its actions. UN Doc S/PV.2597 (1985) paras 58-60.

${ }^{91}$ Kwakwa (1986) 429-32.

92 Ibid, 432.

${ }^{93}$ See e.g. UN Doc S/PV.2685 (1986) 5 (Australia); 7 (USA).

94 'Deployment of United States Forces to Panama', Communication from the President of the United States, House Doc. 101-127, 101st Congress, 2nd Session (1990); UN Doc S/PV.2899 (1989) 31. On this incident generally, see Henkin (1991); Tsagourias in Ruys and Corten (2018) 426-38.

95 UN Doc S/PV.2899 (1989) 31, 36. The American action was widely condemned, however, and its claim of self-defence is controversial. See UN Docs S/PV.2899 (1989); S/PV.2900 (1989). See further Henkin (1991) 306; Tsagourias in Ruys and Corten (2018) 429-32.
} 
assassinate former President George HW Bush and Iraq's 'continuing threat to United States nationals. ${ }^{96}$ In so doing, the USA emphasized that there was no reasonable prospect that diplomatic initiatives or economic measures would suffice to counter the threat. As a last resort, therefore, it used force to respond to the attempted attack and the threat of further attacks. ${ }^{97}$

The USA also referred to the exhaustion of diplomatic efforts when it carried out strikes against Iraq in 1998, ${ }^{98}$ and argued that there were no peaceful diplomatic alternatives to using force when justifying the necessity of its actions before the ICJ in Oil Platforms. ${ }^{99}$ These are but a few examples of practice. References to a prior failure or unavailability of diplomacy or negotiation are fairly common in justifications of self-defence. ${ }^{100}$ They are often included explicitly in reports to the UNSC. ${ }^{101}$ Most recently, in the context of combatting NSAs, the USA has publicly affirmed that the necessity of resorting to selfdefence only arises when 'measures short of force have been exhausted or are inadequate to address the threat'. ${ }^{102}$ In the same context, the UK likewise confirmed that resort to forces is always a last resort, to be used where alternatives are insufficient or unavailable. ${ }^{103}$ Australia has concurred, noting that necessity is satisfied where force is the only reasonable option. ${ }^{104}$

The above incidents and public statements exemplify how defending states may refer to alternatives to force when seeking to establish the general necessity of resorting to self-defence (even if not expressed in those precise terms). Such states justify their actions as a genuine need to use force as a

\footnotetext{
${ }^{96}$ UN Doc S/26003 (1993). On this incident generally, see Kritsiotis (1996); Starski in in Ruys and Corten (2018) 504-26.

${ }^{97}$ UN Doc S/26003 (1993).

${ }^{98}$ UN Doc S/1998/1181 (1998).

99 Oil Platforms, Counter-Memorial and Counter-Claim submitted by the United States of America, 23 June 1997, paras 4.23-4.26.

100 Green (2006) 454.

101 E.g. UN Docs S/18728 (1987); S/19106 (1987); S/1995/87 (1995); S/1997/603 (1997); S/1998/827 (1998); S/1999/134 (1999); S/1999/304 (1999); S/2001/472 (2001); S/2008/21 (2008); S/2012/252 (2012).

102 USA State Department Legal Adviser Speech 2016, 241. The USA regards this view as an application of the unwilling or unable doctrine. See Section 4.1.2.

103 UK Attorney General Speech 2017, 1, 10, 13.

${ }^{104}$ Australian Attorney General Speech 2017.
} 
last resort. Whilst not always explicit, it seems inherent in these justifications that the states concerned viewed their forceful acts as the only reasonable option in the circumstances. Alternatives, such as diplomacy or negotiation, were expressed to be exhausted or insufficient to address the situation at hand. These assertions are made in the course of legal claims of self-defence. It might be concluded, therefore, that states consider themselves legally bound to contemplate, or explore, these alternatives before using force, rather than making such pronouncements out of political or moral expediency. ${ }^{105}$

However, defending states do not always consider alternatives before resorting to force. Context is key. When faced with an ongoing armed attack, for example, it would be unreasonable for states to employ peaceful options by way of a response, instead of using defensive force. The timing of the armed attack is determinative of general necessity in such cases. ${ }^{106}$ Furthermore, state practice, in particular since $9 / 11$, indicates that defending states are much less likely to explore, or have recourse to, peaceful alternatives before resorting to force against NSA armed attacks in the context of transnational terrorism. ${ }^{107}$ The importance of the particular circumstances is also highlighted by the reactions of other states to claims of self-defence.

\section{b) Reactions of other states}

Other states, in criticising or condemning a purported use of defensive force by defending states, often employ the medium of peaceful alternatives to comment upon the legality of self-defence. This might be in ambiguous or general terms, however, without detailed engagement with the facts or legal

\footnotetext{
105 Gardam (2004) 155, maintains that states regard themselves as under a 'continuing obligation' to endeavor to settle their differences by peaceful means'. Therefore, '[d]epending on the circumstances, a failure to acknowledge peaceful overtures could transform a legitimate response in self-defence into an aggressive use of force.' See also Gazzini (2005) 147. Whether or not Gardam considers this to be a legal, as opposed to a moral, obligation based on state practice is unclear. However, if such overtures constitute an option to resolve the situation in an effective manner then, as a matter of general principle, it would be difficult to maintain that a use of force continues to be necessary.

${ }^{106}$ See further Sections 2.3.4 and 2.4.1.

107 Peaceful alternatives vis-à-vis the NSAs themselves, as well as the role of the host state, are explored in Section 4.1.1.
} 
justifications advanced by defending states. For example, in response to the American strikes in 1993 against the IIS headquarters in Baghdad, China simply maintained that disputes between countries should be settled through 'peaceful means of dialogue and consultation', and that they did not endorse action that might intensify tension in the region, including the use of force. ${ }^{108}$ Moreover, references to alternatives to force are typically only one of a number of reasons for negative reactions by other states. The context of the particular incident usually provides additional grounds for such responses.

During the 1956 Suez crisis for instance, Yugoslavia maintained that rather than using military force in Egyptian territory, Israel should have availed itself of the 'armistice machinery' to deal with the fedayeen raids against it. ${ }^{109}$ This comment was made, however, in the context of general concern for peace in the Middle East and Israel's pattern of behaviour. This consisted of 'a policy of largescale armed reprisals against its neighbours', as well as the view that Israel had flouted UNSC Resolutions and ignored its UN Charter obligations. ${ }^{110}$ Therefore, wider factual and political factors, beyond resort to peaceful alternatives, informed the response to Israel's action.

This trend continues. In respect of the 1967 Six Day War, Zambia proclaimed before the UNGA that Israel should have had recourse to the UN, before resorting to what it labelled as aggressive action against Egypt. ${ }^{111}$ The factual and legal analysis relating to this incident is debated, however, and concern over preventive military action and accusations of Israeli aggression dominated the reactions of other states. ${ }^{112}$ When Israel claimed a right of selfdefence against terrorist armed attacks in 1972, resulting in incursions into Lebanon, ${ }^{113}$ Argentina asserted that, as a general matter, the principle of 'need' meant that there must be no alternative to using force and Israel had breached

\footnotetext{
108 UN Doc S/PV.3245 (1993) 21. See the equally ambiguous statement presented on behalf of the Non-Aligned Movement ('NAM') members of the UNSC relating to the same incident. Ibid, 16-17 (Cape Verde).

109 UN Doc S/PV.748 (1956) para 22.

110 Ibid (1956) para 21.

111 UN Doc A/PV.1538 (1967) para 84.

112 See Quigley in Ruys and Corten (2018) 131-42.

113 UN Doc S/10550 (1972).
} 
this requirement. ${ }^{114}$ Argentina's negative reaction was also based, however, on the disproportionality of the Israeli response, the view that it was punitive, and concerns regarding stability in the Middle East. ${ }^{115}$

Israel was further criticized for acting during ongoing, and increasingly productive, negotiations before its raid into Uganda over the Entebbe hostage crisis of $1976 .{ }^{116}$ Yet, these concerns regarding recourse to alternatives were again comingled with doubts regarding whether Israel had been the subject of an armed attack, controversy over the right to protect nationals abroad and unease over how best to respond to international terrorism and hijacking. ${ }^{117}$ When it launched air strikes on the PLO headquarters in Tunis in 1985, Israel again faced criticism for not pursuing peaceful settlement. ${ }^{118}$ Whilst Israel insisted that no other remedies were available to combat the PLO, the perpetrators of the terrorist attacks that had prompted the raid had had in fact been arrested. ${ }^{119}$ Furthermore, states were generally scathing of Israel's actions, which were condemned by the UNSC as an act of 'armed aggression'. ${ }^{120}$

Perhaps the best-known example involving Israel, was its airstrike on an Iraqi nuclear facility in Osiraq in $1981 .{ }^{121}$ Israel justified its actions as an act of selfdefence in response to a threat of 'nuclear obliteration', claiming that the facility was designed to produce atomic bombs that Iraq would use to target Israel. ${ }^{122}$ Israel argued that that they were required to strike the nuclear reactor before it went 'hot'. ${ }^{123}$ In terms of the necessity of that action and peaceful alternatives, Israel asserted that it had tried unsuccessfully to have the threat removed by

\footnotetext{
114 UN Doc S/PV.1644 (1972) paras 25, 28. The reference to 'need' here, is understood as referring to general necessity.

$115 \mathrm{Ibid}$, paras 28-31. Regarding proportionality, see section 3.1.1(b).

${ }^{116}$ On this incident generally, see Kress and Nussberger in Ruys and Corten (2018) 220-33.

117 E.g. UN Docs S/PV.1940 (1976) para 35 (Guinea); para 120 (Sweden); S/PV.1941 (1976) para 102 (Tanzania); S/PV.1942 (1976) paras 144-6 (India); S/PV.1943 (1976) paras 18, 22 (Libya). See further (1976) UNYB 315-20.

118 E.g. UN Doc S/PV.2611 (1985) 38 (Turkey).

119 UN Doc S/PV.2611 (1985) para 40 (Turkey); para 69 (Israel).

120 UNSC Res 573 (1985) para 1.

121 On this incident generally, see Ruys in Ruys and Corten (2018) 329-41.

122 UN Doc S/14510 (1981); UN Doc S/PV.2280 (1981) paras 58-9.

123 UN Doc S/PV.2280 (1981) para 95.
} 
diplomacy, which left it with no choice but to remove the 'mortal danger' using force. ${ }^{124}$ It highlighted that Iraq had rejected UN efforts at peaceful settlement and had ignored relevant UNSC Resolutions. ${ }^{125}$ Therefore, Israel had acted only after 'the usual international procedures and avenues had proved futile' and 'the diplomatic clock had run out'. ${ }^{126}$

States, at least implicitly, universally rejected this no choice of means justification. All states intervening in the UNSC debates explicitly condemned Israel's attack, with many characterising is at as act of aggression. ${ }^{127}$ Japan noted the recent IAEA inspection of the facility and the assurance regarding applicable safeguards given by the IAEA. In its view, '[i]f, in spite of that assurance, Israel suspected that Iraq intended to produce atomic bombs, it should (...) have sought to settle the matter by peaceful means, for example by submitting it to IAEA for consideration.' ${ }^{228}$ The Philippines likewise highlighted the availability to Israel of recourse to 'appropriate international bodies'. ${ }^{129}$ Sierra Leone agreed with the need to resort to peaceful alternatives, in particular by Israel seeking protection from the UNSC. ${ }^{130}$

Significantly, the USA stood with those states condemning the Israeli airstrikes. ${ }^{131}$ Its judgement that such acts had violated the UN Charter was 'based solely on the conviction that Israel had failed to exhaust peaceful means'. ${ }^{132}$ Given the usually close relationship between Israel and the USA, the negative American reaction to its staunch ally is exceptionally strong evidence of illegality. ${ }^{133}$ This is further reflected in the reactions of the UNSC and the UNGA. In the unanimously adopted UNSC Resolution 487, the former

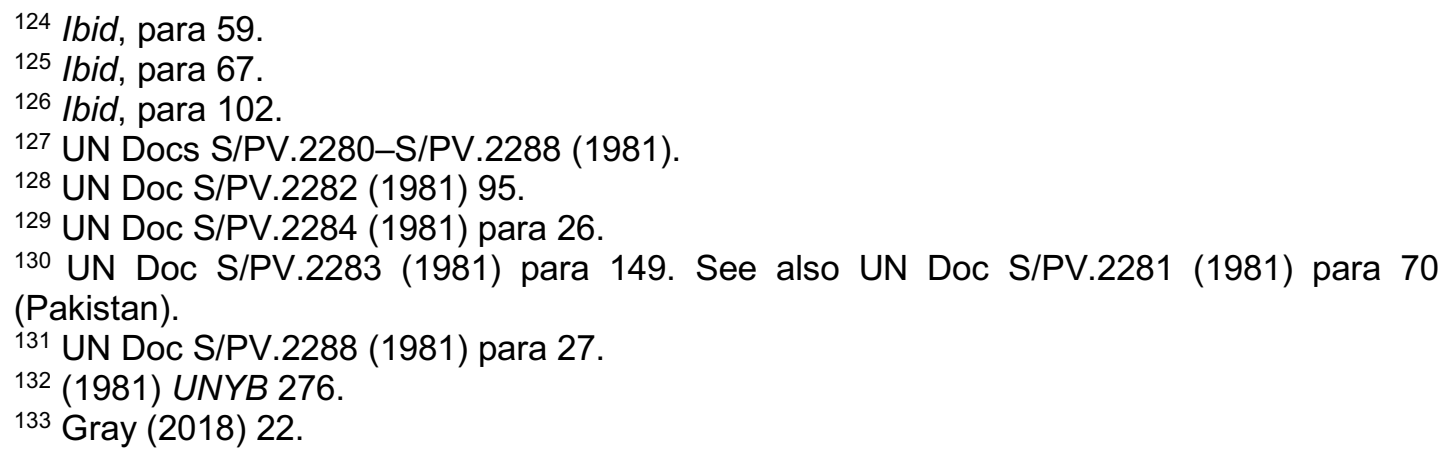


condemned Israel's military action as a clear violation of the UN Charter. ${ }^{134}$ The latter followed suit by condemning Israel's aggression. ${ }^{135}$

The Osiraq incident suggests that alternative measures might be placed at the forefront of the debate regarding the legality of purported defensive action. Their importance must be viewed in light of the particular context, however. It is clear from the UNSC debates that states were concerned by a number of factors, inter alia, the general impact of Israel's action on regional instability, the Middle East peace process, the issue of non-proliferation of nuclear weapons and the right to develop nuclear technology for peaceful purposes. Of central importance was Israel's attempt to justify its actions on the basis of preventive self-defence, rather than by way of a response to an actual or imminent armed attack. ${ }^{136}$ State concern over such 'pre-emptive' or 'preventive' action (both terms were employed) was readily apparent during the UNSC consideration of the incident and it formed an integral part of the censure of Israel. ${ }^{137}$ As such, the focus on peaceful alternatives and the issue of 'no choice of means' should be viewed in the light of the broader discussion concerning a putative right of anticipatory self-defence, and the dangers surrounding the potential for its abuse. This context strongly influenced states' assessment of this particular incident. ${ }^{138}$

Israel should not be singled out for special criticism, however. Its allies have also been censured for not pursing alternatives to force. For example, during discussions in the UNSC that followed the USA's claim of self-defence to justify its airstrikes against Libya in 1986, ${ }^{139}$ Ghana was trenchant in its criticism of

\footnotetext{
134 UNSC Res 487 (1981).

135 UNGA Res. 36/27 (1981).

${ }^{136}$ Israel never claimed to be responding to an imminent armed attack, but rather to prevent a potential future threat arising by virtue of Iraq developing nuclear weapons. See e.g. UN Docs S/14510 (1981); S/PV.2280 (1981) 92-6; S/PV.2288 (1981) 60. See further Sections 1.3.2(a) and 2.4.1(b); Ruys in Ruys and Corten (2018) 332-4.

137 UN Docs S/PV.2280 (1981)-S/PV.2288 (1981).

138 See Ruys (2010) 97, 280-7. The impact of the timing of an armed attack on the importance of alterative measures is explored further in Section 2.4.1.

139 UN Docs S/17938 (1986); S/17990 (1986). For commentary on this controversial, and widely condemned, incident, see Greenwood (1986-1987); Kamto in Ruys and Corten (2018) 408-25.
} 
the American action, noting that it 'did not bother to exhaust the provisions and arrangements set forth in the Charter for settling disputes." ${ }^{140}$ Yet, this came after the delegate had first expressed doubt regarding whether the USA had been the victim of an armed attack and over attribution to Libya. ${ }^{141}$ Whilst the need to settle disputes peacefully, therefore, was part of the Ghanaian denunciation, the failure to pursue alternatives was not itself determinative, but rather part of a package of a number of arguably more important rationales.

\section{c) Proving general necessity?}

A review of state practice provides a mixed account. States might justify their acts by reference, in whole or in part, to the absence of reasonable alternatives to force, but this is not always the case. Peaceful resolution is not invariably sought and a failure to negotiate does not automatically lead to an act being condemned as unnecessary. ${ }^{142}$ The American-led action against the Taliban in response to 9/11 and Coalition action against Daesh in Syria stand as recent examples. ${ }^{143}$ Other states may also reference alternative measures when responding negatively to acts of putative self-defence, but this is not a consistent or uniform response.

Where they are referred to, alternatives are often remarked upon in abstract terms. Whereas defending states' justificatory statements might implicitly allude to force being the only reasonable option, other states tend not to touch upon how effective or reasonable such alternatives might be. Rather, general concern is expressed that defending states should, or could, have tried peaceful alternatives. Moreover, the previous Section highlights that the role and importance of alternatives is highly contextual. If they are mentioned by other states, a lack of recourse to them tends to be one of a number of (potentially more important) reasons for criticism or condemnation. It is difficult to identify a case where there is a general consensus amongst states that the

\footnotetext{
140 UN Doc S/PV.2680 (1986) 33-5.

141 Ibid, 32-5.

142 Green (2009) 81.

143 See Section 4.1.1.
} 
sole reason for condemnation was that the necessity of using force was absent because reasonable alternatives to force were available to resolve a situation. The American statement in respect of the Osiraq incident is a rare exception.

Furthermore, in those cases where alternatives are adduced, either by way of justification (by defending states) or critique (by other states), there is no indication by such states that the need to consider or pursue them stems from a legal obligation. An exercise of good faith, political expediency, or a combination of all these things could likewise account for such comments. The firmest conclusion that may, therefore, be drawn regarding state practice is that the resort, or otherwise, to peaceful alternatives is not determinative of the legality of a purported use of defensive force. Defending states are not required to prove that general necessity is established because of an absence of a reasonable alternative. Instead, states view the resort to peaceful alternatives as desirable and as constituting evidence of whether or not there was a true necessity to employ force defensively and to continue to do so. Whilst failing to pursue reasonable alternatives to force might point to a lack of general necessity, on its own, such failure is unlikely to abrogate a determination of necessity.

Ultimately, general necessity will be established where there is a reasonable need to respond with force. ${ }^{144}$ How much other states will credit a defending state's subjective evaluation of the necessity of resorting to force is contingent on the surrounding circumstances. It also depends on what other JAB considerations are pertinent to assessing whether there has been a lawful recourse to self-defence. Peaceful alternatives are likely to be the focus of greater scrutiny in cases involving claims of anticipatory self-defence, but it might be the more fundamental issue of the existence and content of the right of such anticipatory action that is determinative. The Osiraq incident serves as a good example. Conversely, alternatives will be of less importance in respect of ongoing armed attacks, where there is no time to consider other options,

\footnotetext{
144 See Green (2016) 456.
} 
and where the necessity of self-defence is likely to be established per se. ${ }^{145} \mathrm{In}$ respect of action against NSAs in the context of international terrorism, recourse to alternative means plays a different role. As will be seen in Chapter 4 , rather than negotiation or other peaceful dispute resolution mechanisms, the focus is instead on the primacy of host state action to combat the terrorist threat.

\subsubsection{ICJ jurisprudence and alternative measures}

Whilst the ICJ's consideration of necessity and proportionality has been cursory, guidance may be found in its jurisprudence regarding the need for defending states to pursue alternative measures. Starting with Nicaragua, it is notable that the Court did not require the USA to have exhausted all peaceful means of resolution before resorting to the use of force. Nor did it censure the USA for this omission. Instead, as discussed in Section 2.4.2, the Court went directly to the issue of the timing (or 'immediacy') of the USA's putative defensive acts in order to reach its decision on necessity. The fact that the majority preferred to focus on temporal considerations and avoid consideration of alternative measures is notable. It accords with the state practice set out in the preceding Section that the option of alternative measures is not necessarily the determinant of legality, particularly where temporal issues are the focal point of the incident.

In contrast, Judge Schwebel did spend time in his dissent ruminating over whether the USA should have pursued peaceful alternatives. His comments represent the most extensive judicial review of the topic and raise some interesting issues regarding the interplay between forceful and non-forceful responses. For Judge Schwebel, the necessity of the USA's actions against Nicaragua turned on whether there were available to the USA 'peaceful means of realizing the ends which it has sought to achieve by forceful measures. ${ }^{1} 46$ $\mathrm{He}$ began his analysis with the position of the victim state, El Salvador. $\mathrm{He}$

\footnotetext{
145 See Sections 2.3.4 and 2.4.1(a).

146 Nicaragua, diss op Schwebel, para 201.
} 
quickly accepted the necessity of El Salvador's recourse to defensive force, rather than limiting itself to peaceful negotiations, given that it faced an ongoing large-scale insurgency. ${ }^{147}$

He proceeded to explain why the American response in the purported collective self-defence of El Salvador was also necessary. In so doing, he highlighted how the USA had mounted serious bilateral efforts to settle its dispute with Nicaragua peacefully, and only when they had failed had it resorted to armed force. ${ }^{148} \mathrm{He}$ noted that, before employing such force, an argument might be maintained that the USA should have first exhausted the multilateral means of peaceful settlement open to it, notably those of the Organization of American States and the UN. ${ }^{149}$ Interestingly, however, Judge Schwebel did not conclude that failure to exhaust these multilateral alternatives abrogated the necessity of the American action. Implicitly, this was because the failure was mitigated by the peaceful measures taken by the USA on both a bilateral and multilateral basis to try and resolve the situation, whilst it was also involved in its armed activities. ${ }^{150}$ He thereby explicitly recognized that the USA was employing both forceful and non-forceful means at the same time.

We must exercise caution regarding how much weight we give to Judge Schwebel's observations on recourse to peaceful measure of resolution, but there are number of observations to be made. ${ }^{151}$ His approach reflects the general premise stated in Sections 2.3.1 and 2.3.2 that, where they constitute a reasonable alternative to force, states are expected to pursue peaceful means of resolution, before resorting to force. This is subject to a number of caveats, however. First, his comments might be confined to states acting in

\footnotetext{
147 Ibid, para 202. See further Section 2.4.1(a).

148 Ibid, paras 203, 209.

149 Ibid, para 204.

150 These included maintaining diplomatic relations with Nicaragua and showing a readiness to negotiate a resolution whilst its support for the contras was underway. Ibid, para 205.

151 His conclusions regarding alternatives are part of a dissenting opinion. They are also tightly tied up with his response to the particular facts and his view of the justifiability of necessity per se. See ibid, para 206. Judge Schwebel denied that the necessity of the USA's actions was justiciable but felt bound to express a judgment. Ibid, paras 69-77, 201.
} 
collective self-defence of an ally that is the direct victim of an armed attack. For the victims of an ongoing armed attack, he waives this expectation completely, and the necessity for them to act in self-defence appears to be established per se. Arguably, the determinative factor is timing, i.e. the immediate need of the direct victim of an armed attack to respond to force with force. Such need is not shared by the other state acting in collective selfdefence. ${ }^{152}$

Second, resorting to force does not require the exhaustion of peaceful alternatives. He clearly recognizes that defensive force can be employed at the same time that peaceful resolution is sought. Attempting negotiation, or seizing the UNSC of the matter, does not ipso facto deny the necessity of exercising self-defence. This accords with the notion that peaceful alternatives, and action taken by the UNSC, must provide an effective resolution (i.e. force is not the only reasonable option in such circumstances). ${ }^{153}$ Ultimately, necessity may 'turn on' the availability of reasonable alternatives to the USA to achieve its goals, but there is no suggestion in Judge Schwebel's opinion that positive international law requires the pursuit or exhaustion of peaceful means to the exclusion of exercising selfdefence. The implication is that both individual and collective self-defence are necessary in the face of an ongoing armed attack until such time as the (concomitant) resort to alternatives, on their own, are effective to resolve the situation. On this basis, his judgment essentially boils down to what action is reasonable in the circumstances. ${ }^{154}$ This is both logical and accords with the conclusions set out in Sections 2.3.1 and 2.3.2.

\footnotetext{
152 See Section 2.4.1(a). In addition, Judge Schwebel is responding here to the majority's judgment that the actions of the USA were unnecessary. As such, it is perhaps understandable that he goes into much greater detail regarding the American response, given that he is attempting to justify that their actions were necessary.

153 It is clear from Judge Schwebel's dissent that such alternatives would need to be effective in resolving the situation. Ibid, paras 203-4.

154 'In circumstances where an aggressor State cannot be persuaded to cease its aggressive intervention, it is not unreasonable to seek to force the aggressor State to cease its aggressive intervention.' Ibid, para 203 (emphasis added).
} 
In Oil Platforms, the ICJ considered in some detail the issue of necessity. Significantly, however, it did not expressly refer to peaceful alternatives. Instead, rather than focusing on this issue of general necessity, it devoted its scrutiny to specific necessity. This comprised consideration of the nature of the targets chosen by the USA in the course of their putative acts of selfdefence, being a number of Iranian oil platforms. The Court did not view these as legitimate military targets, which rendered using force against them unnecessary. ${ }^{155}$ The Court followed this approach in Armed Activities. In this case, the DRC argued that Uganda's defensive action was unnecessary. This was based on the fact that the latter had used force without first resorting to peaceful means of resolution, even though it had time to do so. ${ }^{156}$ The Court did not address this fact however. Instead, as with Oil Platforms, it focused on specific necessity. It based its finding that the defensive force was unnecessary (and disproportionate) on the nature of the targets selected by Uganda. ${ }^{157}$

These three cases are the only examples where the ICJ has condemned a state for an unnecessary use of force that it attempted to justify by claiming self-defence. ${ }^{158}$ Whilst not indisputable, the Court's approach to general necessity suggests that it will not require states to prove that they have pursued or exhausted alternatives to force in order to establish such claim. ${ }^{159}$ This accords with the state practice examined in Section 2.3.2. The Court's examination of necessity has been contingent on the facts surrounding the particular use of force, however. The context has determined if the Court

\footnotetext{
155 Oil Platforms, paras 74-6. Targeting is covered in Sections 2.5 and 3.3.

${ }^{156}$ Armed Activities, Memorial of The Democratic Republic of the Congo, July 2000, para 5.28; Reply of The Democratic Republic of the Congo, May 2002, para 3.159; Oral Arguments of Professor Pierre Klein, CR 2005/3, 12 April 2005, 41-2 (para 4), 43-5 (paras 9-16).

${ }^{157}$ Armed Activities, para 147. This is likewise covered further in Section 2.5.

158 The Court did not raise the issue in Corfu Channel. In Nuclear Weapons, whilst the Court made general pronouncements regarding the use of force, necessity and alternative measures were not part of its reasoning. In Palestinian Wall, the ICJ limited its pronouncements on the right of self-defence to one paragraph (para 139). At no point did it refer to alternative measures.

159 This point has not been necessary to determine any case to date, and it is not explicit in the judgments, but it is clearly implied by the fact that the majorities have never addressed this factor when considering other aspects of necessity. It is also implicit in Judge Schwebel's dissent in Nicaragua, which did consider alternatives.
} 
focuses on whether the resort to any form of force was reasonable in the circumstances (viz Nicaragua, in particular, regarding the timing of the USA's actions), or whether such force was appropriately directed (viz Oil Platforms and Armed Activities). Whilst not a picture of clarity, this broadly accords with the taxonomy adopted in this thesis of, respectively, general and specific necessity. Whilst this thesis argues that necessity should be considered strictly in this order, the context of the case appears to have led the Court to focus on one or the other, depending on the most obvious or pertinent facts.

\subsubsection{A temporal distinction - ongoing, imminent and completed armed attacks}

Temporal considerations are central to the question of whether it is reasonable for a defending state to resort to other options not involving the use of force. Timing appears determinative to Webster's assertion that a state must in fact have 'no choice of means'. He maintained that:

'[i]t must be shown that admonition or remonstrance to the persons on board the Caroline was impracticable, or would have been unavailing (...) that it would not have been enough to seize and detain the vessel; but that there was a necessity, present and inevitable, for attacking her in the darkness of the night'. '160

Webster's assertion that peaceful means must first be explored is, therefore, based on elements of i) reasonableness (viz availability and effectiveness of alternative means) and ii) considerations of timing (viz a 'present and inevitable' necessity). This relationship between reasonableness and timing is best explored by distinguishing between ongoing, imminent and completed armed attacks. This distinction, as a determinant of general necessity, will be discussed in the next Section, together with general considerations of how timing relates to the exercise of self-defence.

${ }^{160}$ British and Foreign State Papers, 1840-1841, Vol. XXIX, 1138 (emphasis added). 


\subsection{General necessity - imminence, immediacy and duration}

Modern weaponry and delivery systems, coupled with the rise of international terrorism and attacks by NSAs, have increasingly highlighted the complexities surrounding the temporal element of the right of self-defence. ${ }^{161}$ Timing is pivotal to whether or not a defensive riposte is necessary. It is the chronology of events that establishes if there is a genuine situation of emergency and a pressing need for a state to resort to force at the expense of nonviolent means of settlement. This is a question of general necessity.

The genesis of some form of temporal limitation on the right of self-defence is also typically derived from Webster's assertion that the necessity of selfdefence must be 'instant, overwhelming, and leaving (...) no moment for deliberation. ${ }^{162}$ The timing elements of Webster's formula elicit much debate amongst scholars and, seemingly, great confusion. This is understandable, given that Webster's statement can be read as pertaining to the timing of the armed attack, or the defensive response, or both. In addition, temporal considerations are often mooted in very broad terms. References to 'instancy', 'immediacy' and 'imminence' are sometimes used without distinction and/or conflated with other considerations that mean a clear view of the timing element is lost. ${ }^{163}$ Some even question whether necessity places any temporal restraints on the use of defensive force at all. ${ }^{164}$

Temporal issues should be considered in relation to two aspects of the right of self-defence. The first is the armed attack and whether it is ongoing, completed, or will occur at some point in the future. Whilst the timing of the armed attack is typically examined in terms of when the right of self-defence is triggered, it also plays a central role in the factual context that determines

\footnotetext{
${ }^{161}$ For a general discussion of these issues and the ratione temporis element of the right of self-defence, see Ruys (2010) 250-367; Green (2015) JUFIL.

162 Letter from Mr Webster to Lord Ashburton (6 August 1842) British and Foreign State Papers, 1841-1842, Vol. XXX, 201.

${ }^{163}$ See e.g. Gardam (2004) 148-55. See further below in this Section.

164 E.g. Kress in Weller (2015) 587. Gardam (2004) in contrast maintains that, arguably, 'instancy' (or immediacy) is the only element of the Caroline formula that needs to be satisfied.
} 
whether the right of self-defence is exercisable. As explored in Section 2.4.1, this is an issue of general necessity, which responds to the timing of the armed attack. Most controversially, the prospect of future armed attacks engages the issue of anticipatory self-defence and considerations of 'imminence'. The second aspect is the timing of the defending state's response to an armed attack. This factors in the general necessity calculus by considering how long it takes a defending state to respond in self-defence. It engages the notion of 'immediacy'. Immediacy is sometimes stipulated as a third precondition, in addition to the requirements of necessity and proportionality. ${ }^{165}$ However, as will be made clear in Section 2.4.2, immediacy is most naturally analysed as part of general necessity. The ICJ has adopted this approach, rather than recognizing it as a distinct and separate criterion. ${ }^{166}$ Many of the leading JAB scholars also contemplate necessity along these lines. ${ }^{167}$ As such, the issue of timing of both the armed attack and the defensive response is essential to our understanding of general necessity.

\subsubsection{The timing of the armed attack}

As noted in the preceding Section, the timing of an armed attack bears heavily on whether it is reasonable for a putative defending state to pursue other options not involving the use of force. In order to explain this relationship, and how it alters with the time available, the following analysis distinguishes between ongoing, imminent and completed armed attacks.

\section{a) Ongoing armed attacks}

Ongoing armed attacks pose few conceptual complexities regarding recourse to alternative measures. This author adopts Schachter's contention that, where a state is under current armed attack, the necessity of self-defence is established per se, irrespective of probabilities as to the effectiveness of

\footnotetext{
165 E.g. Ago (1980) para 122; Dinstein (2017) 252, 287-8; Gill in Weller (2015) 743-5.

${ }^{166}$ Nicaragua, para 237. The ICJ adopted the same approach in the context of necessity as a circumstance precluding wrongfulness. Gabčíkovo-Nagymaros, para 54. This is discussed further in Section 2.4.1(b).

${ }^{167}$ E.g. The Chatham House Principles, 967; Ruys (2010) 99-108; Green (2015) JUFIL, 108.
} 
peaceful settlement. ${ }^{168}$ This is to be read as satisfying general necessity under this thesis' adopted taxonomy. Along similar lines, other authors maintain that necessity will usually be satisfied in such circumstances, or there exists a strong presumption of necessity. ${ }^{169}$ That the general necessity of using armed force to repel an ongoing attack is automatically established is reflected in state practice. ${ }^{170}$ Examples include the UK's response to the Argentinian invasion of the Falklands Islands in 1982, ${ }^{171}$ and Israel's intervention in Lebanon in 2006. ${ }^{172}$ A more recent case, in the context of combatting NSAs, is the ongoing Coalition action in Syria. ${ }^{173}$

The presumption in favour of general necessity being established in the case of ongoing armed attacks is entirely logical. In such instances, there exists a present and exigent need for a state to protect itself and its citizens by using force, without time to consider other options. It is unreasonable to expect a state to forego its right of forcible response in favour of a peaceful alternative, and there is nothing in the UN Charter or state practice to suggest otherwise. ${ }^{174}$ International law does not oblige a state to turn the other cheek when it is faced with continuing military violence. Until the UNSC acts effectively, or a peaceful resolution is otherwise found, defending states retain the option to respond to current force with force. Whether or not the defending state chooses to exercise that option is a separate question. Yet, to require a state to attempt

\footnotetext{
${ }^{168}$ Schachter (1991) 152. See further Section 2.3.3 and consideration of Judge Schwebel's dissent in Nicaragua.

169 E.g. Dinstein (2005) 237; Green (2006) 455; Lubell (2010) 43, 45; Akande and Liefländer (2013) 564; Tams in Van den Herik and Schrijver (2013) 417; Henderson (2018) 230. For further consideration by this author of this issue and related academic opinion, see O'Meara (2017) JUFIL, in particular 301-4.

170 This general proposition is subject to satisfaction of any required gravity threshold.

171 See Section 2.4.2(b).

172 See in particular Section 3.2.5.

173 This latter example is more controversial, however. See Section 4.1.

174 This conclusion mirrors the operation of the collective security system. The UN Charter does not require the UNSC to exhaust peaceful means before relying on force to maintain or restore international peace and security. Art 42 allows the UNSC to deploy force where nonforcible Art 41 measures would be inadequate or have proved to be inadequate. It explicitly recognizes, therefore, that force might be the appropriate response, even if viewed as a measure of last resort.
} 
peaceful methods of resolution, instead of using defensive force, is to abrogate the right of self-defence. ${ }^{175}$

\section{b) Imminent armed attacks}

As noted in Section 1.3.2(a), the right to respond to armed attacks that are imminent is disputed, but is assumed for present purposes. Undoubtedly, general necessity takes on additional significance regarding state responses to such armed attacks. ${ }^{176}$ The fact that they occur in the future places emphasis on peaceful alternatives to force and whether resorting to them is reasonable in the circumstances. As the Chatham House Principles explain it:

[n]ecessity is a threshold and the criterion of imminence can be seen to be an aspect of it, inasmuch as it requires that there be no time to pursue non-forcible measures with a reasonable chance of averting or stopping the attack. ${ }^{177}$

The analysis set out in Section 2.3.2 and in this Section suggests that states will consider peaceful ways to resolve a situation up until the point that the opportunity to defend themselves effectively is lost. Ultimately, general necessity will be determined by whether, in the particular circumstances, selfdefence was a reasonable choice to counter the future threat. This raises the further question of whether the trigger for the right of self-defence (being armed attacks that are 'imminent') and the conditioning of its exercise (being general necessity) are equated in this context. This potential is explored further below.

Aside from the issue of recognizing, or not, a general right to respond to imminent armed attacks, the greater difficulty with considering whether states have the time to consider or resort to other options when faced with such a

\footnotetext{
175 There is nothing to prevent a defending state pursuing peaceful means of settlement in addition to using force to respond to an ongoing armed attack. See generally Ruys (2010) 250-367.

${ }^{176}$ Ago (1980) para 120. Ago's reference to 'preventative' self-defence is expressed by him to include self-defence in relation to imminent attacks.

177 The Chatham House Principles, 967. This is understood as a reference to general necessity.
} 
threat is the lack of consensus regarding the meaning of imminence. The ICJ has not expressed its view on this topic, ${ }^{178}$ and there has been a relative paucity of consideration by scholars. ${ }^{179}$ In recent years, the USA, the UK and Australia have set out their understandings of imminence. Their positions remain open to varying interpretations and have raised as many questions as answers. ${ }^{180}$ However, as rare and explicit examples of state practice, they serve as important indicators of the possible meanings of imminence and the relationship such concept has with general necessity and the trigger of the right of self-defence. ${ }^{181}$

Each of these three states explicitly adopted Bethlehem's 'Principle 8' amongst the factors that they take into account when considering imminence:

Whether an armed attack may be regarded as "imminent" will fall to be assessed by reference to all relevant circumstances, including (a) the nature and immediacy of the threat, (b) the probability of an attack, (c) whether the anticipated attack is part of a concerted pattern of continuing armed activity, (d) the likely scale of the attack and the injury, loss, or damage likely to result therefrom in the absence of mitigating action, and (e) the likelihood that there will be other opportunities to undertake effective action in self-defense that may be expected to cause less serious collateral injury, loss, or damage. ${ }^{182}$

\footnotetext{
178 In Nicaragua, para 194, as the parties did not raise the issue of 'the imminent threat of an armed attack', the Court declined to express a view on the issue. This approach was followed in Armed Activities, para 143.

179 Notable exceptions include Bethlehem (2012) and Lubell in Weller (2015) 697-719. See also Akande and Liefländer (2013) 564-5.

${ }^{180}$ For comments representing a variety of views on these examples of state practice, see e.g. Lederman (4 and 11 April 2016); Deeks (2016); Hakimi (2017); Haque (January and May 2017); Milanovic (2017); Green (2017); Henderson (2018) 297-307.

${ }^{181}$ States seldom make such general statements about their understanding of international law. It potentially limits their right of action. The examples set out in this Section are, therefore, valuable (if not entirely coherent) examples of state practice.

182 Bethlehem (2012) 775-6, Principle 8. Bethlehem's Principle 8 is formed from detailed discussions with a number of state representatives with relevant operational experience. $\mathrm{He}$ describes these factors as indicative, rather than exhaustive, of imminence. Ibid, 773-4.
} 
It is not clear how these factors relate to each other, or whether they carry equal or differing weights. ${ }^{183}$ Yet, this formulation, and its adoption by the three states concerned, reflects the commonly held understanding that a temporal element is inherent in imminence. Bethlehem's characterisation encapsulates this by reference to the 'immediacy of the threat' and the 'other opportunities to undertake effective action'. Caution must be taken in approaching the issue of timing, however. The UK Attorney General, for instance, considers that '[i]mminence was described in the Caroline case as a threatened attack which was 'instant, overwhelming, leaving no choice of means, and no moment of deliberation." 184 This is incorrect. Imminence is not referred to at all in Webster's formula. Moreover, Webster refers to the necessity of self-defence being instant and overwhelming, not the armed attack. ${ }^{185}$ On both conceptions, however, timing plays a central role in determining imminence.

Focusing solely on the temporal element of Webster's formulation and his requirement that there be 'no moment for deliberation' suggests that, to be imminent, an armed attack must be just about to happen. Lubell emphasizes this temporal aspect, arguing that an imminent armed attack 'must be an impending attack over which there is a reasonable level of certainty that it will occur in the foreseeable future', and the threat must be 'specific and identifiable'. ${ }^{186}$ This latter requirement rightly draws a line between (potentially lawful) pre-emptive self-defence and (almost certainly) unlawful preventive self-defence. ${ }^{187}$ On the temporal aspect, Lubell notes that an armed attack may be imminent, but self-defence is not necessary where non-forcible alternatives are available, or where the action by the UNSC precludes the need for defensive action. ${ }^{188}$ This logic reduces imminence to a question of the timing

\footnotetext{
${ }^{183}$ Hakimi (2017).

184 UK Attorney General Speech 2017, 8.

185 Letter from Mr Webster to Lord Ashburton (6 August 1842) British and Foreign State Papers, 1841-1842, Vol. XXX, 201.

186 Lubell in Weller (2015) 702-5, 718. Whilst offering one of the few comprehensive reviews of imminence, Lubell describes it as a separate, third requirement for measuring defensive action, in addition to necessity and proportionality. This minority position is not generally shared by scholars, nor in the state practice referred to herein from the USA, UK and Australia. This Section explains why imminence is better understood as part of general necessity.

187 See Section 1.3.2(a).

188 Lubell in Weller (2015) 699-700.
} 
of a specifically identified future attack. Yet, imminence is commonly understood to involve additional components. As will be made clear, it is the interrelationship between a number of factors that blurs the line between imminence forming part of the armed attack trigger, and imminence inhering in the contextual determination of general necessity.

Bethlehem's Principle 8, the positions of the USA, the UK and Australia, and a weight of academic opinion all indicate that the timing of the armed attack is important, but imminence also depends on other factors that relate to the wider circumstances of the threat. Henderson calls this 'contextual imminence'. ${ }^{189}$ Ago believed that 'a State acting in self-defence (...) acts in response to an imminent danger - which must (...) be serious, immediate and incapable of being countered by other means.' 190 On the account of imminence endorsed by these scholars and states, whilst the temporal proximity of the attack is highly relevant, the nature of the threat and the prospect of nonviolent alternatives also feature. If this account is accepted, contrary to Lubell's position, where alternative measures are available and, on their own, are effective to prevent the attack from happening then, ipso facto, such attack is not truly imminent. The general necessity of self-defence will also be absent.

To develop this proposition further, Akande and Liefländer likewise suggest that imminence 'describes a certain pressing quality that a threat must have for anticipatory self-defense to be lawful'. This involves an assessment of the type of attack threatened, its likelihood of occurring, its gravity and timing. ${ }^{191}$

\footnotetext{
189 Henderson (2018) 297-307. See also The Chatham House Principles, 967; Schrijver and Van den Herik (2010) ('The Leiden Policy Recommendations') 543. On the UK's position, see further House of Commons, House of Lords, Joint Committee on Human Rights, 'The Government's Policy on the Use of Drones for Targeted Killing: Government Response to the Committee's Second Report of Session 2015-16', Fourth Report of Session 2016-17, HC 747, HL Paper 49, para 14.

${ }_{190}$ Ago (1980) para 88.

191 Akande and Liefländer (2013) 564-5. The authors highlight, however, that it is unclear how these four elements of imminence interrelate or whether they are independent. For example, is a low probability of threat permissible where the gravity of the threat is severe? Conversely, where a threat is mild, is there a requirement of a higher probability that the attack will occur? The position is unsettled. Ibid 565. See further The Leiden Policy Recommendations, 543. See also Milanovic (2017), concluding that imminence in the JAB is not really a temporal criterion, but a certainty/likelihood criterion.
} 
Most noteworthy, is the fact that they deny that imminence contains an independent temporal requirement. ${ }^{192}$ Positing that the temporal aspect of imminence acts on its own to bar self-defence is to potentially deny a right of self-defence in the face of a highly probable and severe threat, whose realization may be temporally remote, but where there will be no future opportunity to eliminate the threat. ${ }^{193}$ The ICJ adopted this approach to timing in the context of necessity as a circumstance precluding wrongfulness. ${ }^{194}$ The Court recognized that whilst imminence is traditionally understood as temporal immediacy or proximity, it does not establish an independent temporal requirement. Following this reasoning, manifest peril more distant in time may still be deemed to be imminent, allowing for a response. 195

This general approach accords with the idea, presented by a number of scholars, of a last 'window of opportunity' to respond effectively to an anticipated armed attack. It also reflects imminence as espoused in Bethlehem's Principle 8 and the positions of the USA, the UK and Australia. By this standard:

a State may act in anticipatory self-defence against an armed attack (...) when the attacker is clearly committed to launching an armed attack and the victim State will lose its opportunity to effectively defend itself unless it acts. In other words, it may act anticipatorily only during the last window of opportunity to defend itself against an armed attack that is forthcoming. ${ }^{196}$

On this construction of imminence, temporal considerations are important, but they do not act as an independent injunction against defensive action where

\footnotetext{
192 Akande and Liefländer (2013) 565; Lederman (11 April 2016).

193 Akande and Liefländer (2013) 565.

194 Gabčíkovo-Nagymaros, para 51.

195 Lubell in Weller (2015) 703, cautions against transposing this precedent from the laws of state responsibility into the $\mathrm{JAB}$ and delinking immediacy from imminence. The analysis in this Section suggests, however, that the JAB position may not be so different.

196 Schmitt (2013) 64. See also Lowe (2005) 192; The Chatham House Principles, 967-8; The Leiden Policy Recommendations, 543; Kress in Weller (2015) 710-13.
} 
the threat is sufficiently probable and severe. ${ }^{197}$ Rather, timing constitutes one of a number of contextual indicators. It interacts with considerations of the likelihood of a specifically identified future attack, its nature and gravity to determine how long a state has to respond to defend itself effectively before it is too late.

Controversially, it is suggested that the window of opportunity may present itself immediately before the attack in question or, in some cases, long before it occurs. ${ }^{198} \mathrm{~A}$ right to resort to a military response well in advance of the anticipated attack is potentially problematic. The potential risk of states abusing the right of self-defence in such circumstances is obvious. Timing is not to be ignored, however. Temporal factors have a 'heavy impact' on the possibility of making accurate predictions pertaining to the future threat. ${ }^{199}$ The further into the future the timeline goes, the harder it will be for states to justify that an attack is identifiable and/or probable and that there exists a genuine state of 'irreversible emergency' that necessitates the resort to defensive military force at a particular point in time. ${ }^{200}$ This hurdle tempers the risk of abuse. More time means that more variables will need to factor in a defending state's decision making. These include the possibility of the attacker reversing its course of action (such as delaying the attack or not launching it at all), alternative peaceful measures being effective to resolve the dispute, or the UNSC taking action to render the resort to defensive force unnecessary. The longer the period between the imminent armed attack and the response, the

\footnotetext{
197 Akande and Liefländer (2013) 565. Regarding the level of certainty that should be required before states may respond to imminent armed attacks, Green argues that it is illogical and impossible to require absolute certainty of the attack, but the degree of uncertainty can only increase the further into the future a state is looking to assess a threat to it. Green (2015) JUFIL, 105. Lubell in Weller (2015) 713-16, 718, concludes that a reasonable level of certainty is required. As with all claims of self-defence, lawfulness relies on a good faith assessment of all the circumstances, based on credible information and capable of objective assessment. The Chatham House Principles 970. See also USA State Department Legal Adviser Speech 2016, 239; UK Attorney General Speech 2017, 17; Australian Attorney General Speech 2017. In respect of imminent armed attacks, the need for the defending state to articulate clearly its justifications for taking defensive action is particularly important given the uncertainties inherent in responding to a future armed attack.

198 Schmitt (2013) 64.

199 Akande and Liefländer (2013) 565.

200 The authors of The Chatham House Principles, 967-8, maintain that there 'must exist a circumstance of irreversible emergency' to be able to respond to an armed attack that is imminent.
} 
more pressure there will be on the potential victim state to resolve the matter peacefully. ${ }^{201}$

The window of opportunity is not, therefore, thrown wide open to countering non-specific perceived threats, taking states towards an unlawful right of preventive self-defence. ${ }^{202}$ The UK Attorney General in particular appears to recognize this fact. He made it clear that the UK's position regarding imminence relates to an identified and direct threat to the UK, and does not countenance a right to respond to remote threats that have not yet materialized. ${ }^{203}$ He likewise accepted in respect of each exercise of selfdefence that it is crucial for the UK to ask whether there is anything else it can credibly do to prevent an attack. ${ }^{204}$ The Australian Attorney General expressly agrees with the UK position, ${ }^{205}$ and the USA appears to take a similar approach. ${ }^{206}$ These states ostensibly acknowledge the dangers of an overly broad interpretation of self-defence and, at least verbally, have responded to that danger by recognizing the limitations on anticipatory responses.

If the preceding analysis rightly characterizes how states and scholars conceive of imminence, a circularity between imminence and general necessity is revealed. A summation of the UK's understanding of imminence clearly reveals this overlap: is action against an identifiable threat necessary now, ${ }^{207}$ before the last clear opportunity to take action disappears, ${ }^{208}$ or are effective alternatives to force available? ${ }^{209}$ Imminence and general necessity are, accordingly, conflated. ${ }^{210}$ This blurs the bright line previously emphasized

\footnotetext{
201 Gardam (2004) 150-1. See also The Chatham House Principles, 967; Dinstein (2017) 252.

202 See Section 1.3.2(a).

203 UK Attorney General Speech 2017, 13, 19.

204 Ibid, 16.

${ }^{205}$ Australian Attorney General Speech 2017.

206 The USA State Department Legal Adviser Speech references actual or imminent armed attacks, as opposed to less certain threats that have not materialized, and which are characteristic of preventive self-defence. Bethlehem (2016) certainly understands this to be the USA's position and a departure from the previous 'Bush doctrine'. See Section 1.3.2(a).

207 UK Attorney General Speech 2017, 16.

$208 \mathrm{Ibid}, 7,8$.

${ }^{209} \mathrm{Ibid}, 10,13,16,20$. This is stated to include potential action against NSAs by a host state. See Section 4.1.1.

210 Haque (January 2017), reaching the same conclusion. See also the UK's All Party Parliamentary Group on Drones Inquiry Report (2018) 36-7.
} 
in this thesis between the trigger for the right of self-defence (being armed attacks, in this case that that are imminent) and the conditioning of its exercise (being general necessity)..211

On the one hand, this conclusion emphasizes the ambiguities of Bethlehem's Principle 8 and the three states' expositions of necessity, imminence and selfdefence more broadly. States should further clarify their understanding of these concepts. On the other hand, whilst rendering the term essentially nugatory, the forgoing account of imminence captures the substance of general necessity and how states conceive of the need to respond to future armed attacks based on the particular circumstances. It reveals how contextually sensitive general necessity is, with temporal considerations representing but one factor in its determination. Akande and Liefländer describe the bottom line of imminence: '[w]hat is really at stake us whether some sort of self-defence action is demonstrably necessary'. ${ }^{212}$ It is not, therefore, that the armed attack must be 'imminent' in any legally significant and independent sense but, as per Webster's formula, there must be a pressing need to resort to self-defence in the particular circumstances. ${ }^{213}$

If states have indeed adopted this position, the term 'imminence' simply describes the type of future armed attack that triggers a lawful defensive response today. ${ }^{214}$ In response to such attacks, Bethlehem's Principle 8 and the last window of opportunity construction of imminence allow for defensive force to meet offensive force, based on context. On the account set out in the preceding Sections of this Chapter, it is the satisfaction of general necessity that gives rise to this ability. On these terms, general necessity provides the defending state with a degree of flexibility and the means to protect itself,

\footnotetext{
211 See Section 2.2(c).

${ }^{212}$ Akande and Liefländer (2013) 565 (emphasis added).

${ }^{213}$ This general position is likewise reflected in the timing of the defending state's response to an armed attack. See Section 2.4.2.

${ }^{214}$ Milanovic (2017), also concluding that the approach to imminence described here looks very much like necessity. See also Lederman's comments in the same blog post. The Chatham House Principles, 967-8, also recognize this close, if not fully conflated, relationship. The authors maintain that ' $[\mathrm{t}] \mathrm{he}$ criterion of imminence is closely related to the requirement of necessity', and necessity may 'determine imminence'.
} 
rather than having to sit idly by and suffer an attack. It takes into account the wider circumstances, but also requires that the defending state is suffering a situation of genuine irreversible emergency, consisting of a need to respond forcibly at a particular time to an identifiable future armed attack. If a defending state can demonstrate that it used force when it did, because failure to do so would have deprived it of the ability to defend itself effectively, on the preceding analysis, general necessity will be satisfied.

\section{c) Completed armed attacks}

Completed armed attacks raise their own complexities. Factually, determining if and when an armed attack has ended might prove difficult in the circumstances. Conceptually, it helps to make a distinction between three types of completed armed attacks: i) fully completed armed attacks, ii) completed armed attacks resulting in occupation, and ii) self-contained armed attacks, where further armed attacks are imminent. In the first case, where the attack is a one-off, the lack of emergency negates the 'present and inevitable' necessity of using defensive force that Webster required. There is no pressing need to halt, repel or prevent an armed attack, meaning there is no general necessity of self-defence. Rather, the emphasis switches to non-forcible options to resolve the issue and seek redress. Any force used to respond to such armed attacks that are fully complete risks being characterised as an unlawful armed reprisal. ${ }^{215}$

Where completed armed attacks result in the occupation of territory, the legal analysis is more nuanced. Arguably, occupation equates to an ongoing armed attack, thereby retaining the general necessity of defensive force to recapture it. ${ }^{216}$ It would be unrealistic in such circumstances for a defending state, faced with continuing hostility (as evidenced by the factor of occupation), to forego its right of self-defence in favour of negotiation. The threat to it subsists. In Oil

\footnotetext{
215 See Section 2.4.2.

216 See e.g. Gill in Weller (2015) 745; Corten (2012) 486. Aust (2010) 229, agrees that using force to retake unlawfully captured territory is a lawful exercise of self-defence. See also Dinstein (2017) 230; Kretzmer (2013) 250.
} 
Platforms, Iran emphasized this distinction between fully completed armed attacks, and those that continue by virtue of occupation. ${ }^{217}$ On this understanding, a use of force by the defending state amounts to repelling an armed attack and is, therefore, in keeping with the purposes of self-defence. ${ }^{218}$ Finally, there are armed attacks that might appear completed and selfcontained but are in fact part of a series of armed attacks. In such instances, the defending state also faces a current threat. ${ }^{219}$ The general necessity analysis is largely one of anticipatory self-defence, however, as discussed in Section 2.4.1(b). The operative question is whether or not a new attack is imminent. If not, then the armed attack is fully completed. Where the current threat, comprising past and imminent armed attacks, is no more, the prima facie general necessity of self-defence is also absent. The focus must then switch to peaceful options of resolution.

\subsubsection{The timing of the defending state's response to an armed attack}

a) An immediate need to respond

General necessity not only takes account of the timing of the armed attack, but also the timing of the defensive response to such attack. Like imminence, this element of necessity is traditionally derived from Webster's insistence that defensive force must be shown to be 'instant, overwhelming, leaving (...) no moment for deliberation. ${ }^{220}$ This temporal element is, therefore, often referred to as the 'immediacy' requirement. Before we look at 'how immediate' a response must be, it is important to appreciate the function of a temporal link between attack and defence in determining the legality of the latter.

\footnotetext{
217 'In the case of the invasion of another State's territory, in principle an attack still exists as long as the occupation continues. But in cases of single armed attacks (as distinguished from a general situation of armed conflict), the attack is terminated when the incident is over.' Oil Platforms, Reply and Defence to Counter-Claim submitted by the Islamic Republic of Iran, 10 March 1999, para 7.47.

${ }^{218}$ See further Section 2.4.2(b).

219 Ibid.

${ }^{220}$ Letter from Mr Webster to Lord Ashburton (6 August 1842) British and Foreign State Papers, 1841-1842, Vol. XXX, 201.
} 
Understanding the theory informs how we view the relevant state practice and jurisprudence on this point.

Establishing a temporal limitation on a state's defensive reaction retains the principle that self-defence is an emergency response. Therefore, any act of self-defence should, in principle, be temporally proximate to the peril faced. As with imminence, if there is no genuine irreversible emergency, there may be a 'moment for deliberation' and no 'instant' and 'overwhelming' need for a response. Absent a new casus belli, an undue delay in responding to an armed attack indicates that, in the circumstances, there was no general necessity of self-defence. A temporal link, therefore, avoids the right of self-defence being used to respond to attacks long passed. It seeks to counter concerns that the response was in fact in retaliation or punishment. Accordingly, this timing element is crucial to distinguish lawful acts of self-defence from unlawful armed reprisals.

Armed reprisals are punitive rather than protective in nature. ' $T$ They seek to impose reparation for the harm done, or to compel a satisfactory settlement of the dispute created by the initial illegal act, or to compel the delinquent state to abide by the law in the future.'221 The ICJ has confirmed that international law prohibits armed reprisals. ${ }^{222}$ This is likewise reflected in the Friendly Relations Declaration. ${ }^{223} \mathrm{~A}$ defining feature of reprisals is that they take place after the armed attack. Those commentators that reject their legality rely on this fact to highlight that, by their nature, they can only ever be punitive, rather than defensive or protective. ${ }^{224}$ However, depending on the particular facts and timing of the response, the dividing line between acts that seek to protect and

\footnotetext{
${ }^{221}$ Bowett (1972) 3. For further analysis of the timing of defensive action and the controversies that surround the distinction between defensive acts and reprisals, see e.g. Schachter (1984) 1638; Dinstein (2017) 264-75; Corten (2010) 485-7; Gardam (2004) 148-55; Darcy in Weller (2015) Chapter 40; Henderson (2018) 240-7.

222 Corfu Channel, para 38; Nuclear Weapons, para 46.

${ }^{223}$ Friendly Relations Declaration, para 1.

224 Bowett (1972) 3.
} 
those that punish may be hard to draw. Defending states may be faced with a real challenge to satisfy the demands of such distinction.

Nevertheless, the need for a defending state to respond within a certain timeframe is clearly reflected in the ICJ's jurisprudence. In Nicaragua, the Court's determination that purported defensive measures taken by the USA were unnecessary was primarily determined by the fact that such measures were taken several months after the major offensive of the armed opposition against the Government of El Salvador had been completely repulsed. ${ }^{225}$ The extent of the time lag between the purported armed attack and the claimed act of self-defence was, therefore, determinative of the majority's opinion. Possible permissible time limits for defensive responses were not indicated in the judgment, however. Where the Court draws the line between lawful selfdefence and unlawful reprisal remains unclear.

Returning to Webster's formula for possible answers, on one interpretation it appears to require that military resistance to an armed attack should take place immediately, i.e. while the attack is still in process, and not after it has ended. ${ }^{226}$ Such a strict view of immediacy does find limited support in state practice. For example, in responding to Israel's claimed acts of self-defence against terrorists acting from Lebanese territory in 1972,227 Argentina was forthright in stating:

It is necessary that such [defensive] measures be indispensable and immediate; there must be no alternative and no time must pass in deliberating or reflecting on the desirability of a reaction. This means that the reaction must immediately follow the illegal attack. ${ }^{228}$

\footnotetext{
225 Nicaragua, para 237.

${ }^{226}$ Ago (1980) para 122

227 UN Doc S/10550 (1972).

228 UN Doc S/PV.1644 (1972) para 25.
} 
However, whilst 'immediacy' may be a convenient label, taking this as a literal requirement for a defending state's response is revealed in state practice to be too narrow and inflexible.

Whilst general necessity requires that the defensive response be made close in time to the armed attack, this temporal link is to be interpreted reasonably. No precise limit can be fixed. ${ }^{229}$ The best contemporary understanding amongst academics of immediacy is that a state acting in self-defence must do so within a reasonable timeframe, without unduly postponing the taking of measures. ${ }^{230}$ This understanding of immediacy is reflected in state practice. It reveals that the particular context will determine how quickly a defending state is in a position to respond. Relevant factors include the need to gather intelligence, the geographical locale of an attack, the level of military preparedness of the defending state, the need for internal constitutional permissions to use force and to consult and engage allies, and so forth. Many of these elements are necessary to ensure an adequate defence may be mounted and may therefore militate against an instantaneous response. It shows that states may need to prepare, before taking defensive action.

In response to the UK raid on the Harib Fort in 1964, for example, Iraq condemned the UK's acts based, in part, on the fact that a day had passed before the UK responded to the alleged attacks against the Federation of South Arabia. ${ }^{231}$ The UK justified its actions, inter alia, on the basis that its attack on Harib Fort was carefully planned and required approved at a high level by the British Government. Such approval and planning ensured that only those responsible for the alleged terror campaign were involved in the attack, and that civilians were not affected. ${ }^{232}$ Iraq's criticism was but one of a number of reasons for the widespread negative reaction to the British raid, ${ }^{233}$ but the

\footnotetext{
${ }^{229}$ Ruys (2010) 99.

230 Schachter (1985) 292; Gardam (2004) 150; Dinstein (2017) 252; Schmitt (2013) 65; Gill in Weller (2015) 745. Franck (2001) 840, argues that '[t]he assertion that self-defense requires "immediate" action comes from a misunderstanding of the Caroline decision, which deals only with anticipatory self-defense.'

231 UN Doc S/PV.1107 (1964) 17.

232 UN Doc S/PV.1109 (1964) paras 23-4.

${ }^{233}$ See e.g. Sections $2.5(\mathrm{~b})$ and 3.1.1(c) and (d).
} 
UK's stance exemplifies the fact that states may assert that they may not be in a position to respond 'immediately' in any strict sense of the word, and may assert justifiable reasons for the delay (even if not accepted by other states).

Other state practice more clearly demonstrates that the immediacy requirement must be viewed flexibly. In 1993, America took over two months to respond to the attempted assassination of former President George HW Bush and what it described as an enduring threat to the USA. ${ }^{234}$ It justified such delay on the need to confirm responsibility for the attempt before a response was made. This included a meticulous and exhaustive investigation of the incident to establish the facts, thereby ensuring that there was no rush to judgement before action was taken. ${ }^{235}$ The delay was not noted by any state during consideration of the incident by the UNSC. ${ }^{236}$ Indeed, the American action, justified as a lawful act of self-defence, was broadly supported. ${ }^{237} \mathrm{New}$ Zealand went so far as expressing its appreciation for the fact that the USA promptly informed the Security Council of the action it had taken. ${ }^{238}$ Likewise, a delay of two weeks between attack and defence was not a factor in the review by states of the USA's strikes against Afghanistan and Sudan in response to the 1998 African embassy bombings, attributed by the USA to AlQaeda. ${ }^{239}$

The insistence that states have a right to reflect, investigate and confirm both that they have been attacked and by whom, before responding against carefully selected targets, was reiterated again by the USA before the ICJ in Oil Platforms. ${ }^{240}$ It saw the need to take care over ensuring an appropriate

\footnotetext{
${ }^{234}$ See Section 2.3.2(a).

235 UN Doc S/PV.3245 (1993) 3.

236 UN Doc S/PV.3245 (1993).

237 Ibid, 13 (France); 16 (Japan); 18 (Hungary); 19-20 (UK); 21-2 (Russia); 23 (New Zealand); 24 (Spain). This incident comprised a completed armed attack that was unlikely to be repeated. The claim of self-defence is questionable, therefore. It might be better characterised as a reprisal, being punitive rather than defensive in nature. See e.g. Kritsiotis (1996) 175; Ruys (2010) 107-8; Gray (2018) 205; Starski in Ruys and Corten (2018) 523-6.

238 UN Doc S/PV.3245 (1993) 23.

239 UN Doc S/1998/780. On this incident generally, see Cannizzaro and Rasi in Ruys and Corten (2018) 541-51.

${ }^{240}$ Counter-Memorial and Counter-Claim submitted by the United States of America, 23 June 1997, paras 4.37-4.39.
} 
response, rather than using force instantly and without reflection, to be paramount, as requiring an 'instantaneous response could dramatically increase the risk of disproportionate damage. ${ }^{241}$ Given the analysis set out in the rest of thesis, including the purposes of self-defence and the requirements related to targeting and proportionality generally, this conclusion and approach to immediacy is entirely proper. Rash defensive action risks breaching both necessity and proportionality.

In his dissent in Nicaragua, Judge Schwebel appeared to take judicial note of this fact. He emphasized the efforts that the USA had made for more than a year in assisting El Salvador to suppress the insurgency within its own borders and by diplomatic representations to the government of Nicaragua, both of which had proved to be insufficient to quell the insurgency. Under these circumstances, Judge Schwebel concluded that it was not unreasonable for the USA to decide that the exertion of armed force was necessary. ${ }^{242}$ Whilst the majority in Nicaragua decided the case on a different appreciation of the facts, Judge Schwebel's views highlight the importance of assessing the temporal element of immediacy in conjunction with other relevant factors. Together, they will determine whether the purpose of the response is indeed defensive. His dissent also exemplifies how alternative measures to force factor into an appreciation of reasonableness. The longer the period between attack and response, the greater the pressure there will be on the defending state to resolve the issue by peaceful means, ${ }^{243}$ but pursuing such means should not, ipso facto, defeat the right of self-defence. If a defending state makes genuine attempts to settle the dispute amicably, but such attempts prove unproductive, it should not be faulted for losing time unduly before employing its armed forces in a defensive response..$^{244}$

As a general proposition, therefore, the greater the time-lapse between attack and riposte, the higher the likelihood that the latter will be characterised as an

\footnotetext{
$241 \mathrm{Ibid}$, paras 4.37, 4.39.

242 Nicaragua, diss op, para 203.

243 Gardam (2004) 150-1.

244 Dinstein (2017) 252. See also Ruys (2010) 100.
} 
unlawful reprisal. However, assessing the reasonableness of the time period and determining where to draw the line between necessary and unnecessary defensive responses is not governed solely by how many days or months have elapsed since the attack. As with determining imminence, establishing what is a sufficiently proximate timeframe in the circumstances is highly contextual. A reasonable conclusion on the basis of the preceding analysis and state practice is that, so long as the defending state takes action to defend itself in a reasonable timeframe and without undue delay, the right of self-defence will not be forfeited. ${ }^{245}$ Immediacy is a flexible concept such that there must be an immediate need to respond, but not that there must necessarily be an immediate response. ${ }^{246}$ Such an approach to self-defence is particularly persuasive when we consider whether a state is facing an ongoing threat when it responds to an armed attack militarily.

\section{b) An ongoing threat}

Whether general necessity is satisfied is ultimately determined by whether a defending state is facing an ongoing threat when it resorts to self-defence. This is best explained if we again consider the distinction between ongoing, completed and imminent armed attacks referred to in Section 2.4.1. The risk that a response might be characterised as an unlawful armed reprisal principally arises in respect of armed attacks that appear to be fully complete. ${ }^{247}$ In such cases, even if a response might be viewed as 'immediate', it is likely to be unnecessary, given the absence of a current threat. Completed armed attacks resulting in occupation or the capture of (parts of) territory are different, however. In this instance, as explored in 2.4.2(a) in general terms, it

\footnotetext{
245 Gill in Weller (2015) 745.

${ }^{246}$ Green (2006) 471. See also Ruys (2010) 100. This conclusion was also reflected, for example, by Mexico in its pleading before the ICJ in Nuclear Weapons. 'The right of selfdefense is actualized only when the need for defense is immediate and overwhelming' (emphasis added). Nuclear Weapons, Note Verbale from the Embassy of Mexico, together with Written Statement of the Government of Mexico, 19 June 1995, 57.

${ }^{247}$ For imminent armed attacks, as they have not yet happened, the question of immediacy and the fear of armed reprisals are not relevant. Unless imminent armed attacks form part of a series of armed attacks (see below), it is difficult to see how a response to a future attack could be characterised as a reprisal. The timing of the response to imminent armed attacks instead forms part of the window of opportunity discussed in Section 2.4.1(b).
} 
may not always possible for a defending state to take immediate action to defend itself and recover that territory. Where a state is not in a position promptly to resist invasion, provided that it does act to repel it as soon as it is able, or as soon as all attempts to secure a peaceful withdrawal have failed, such action will still be considered lawful self-defence. ${ }^{248}$ This is because the factor of occupied territory allows a state to treat such situation as an ongoing armed attack, which maintains the general necessity of defensive action. ${ }^{249}$

The most obvious example is the 1982 Falkland Islands conflict. In this incident, a delay of approximately three weeks between the Argentine invasion and the commencement of active military operations by the UK against Argentina was widely seen as an acceptable time delay. ${ }^{250}$ For some, the factor of continuing occupation of the Islands by Argentina accounts for the UK's continuing right of self-defence. ${ }^{251}$ Also relevant to when the response could be mounted is the geographical location of the Islands, and the time needed to assemble and put in place an adequate military force to mount an effective response. ${ }^{252}$ That the British Cabinet met on the same day as the invasion to agree to dispatch a task force to regain the Islands might, by itself, constitute an immediate response..$^{253}$

Whatever the particular reason, a lack of 'immediate' action was not raised during the UNSC debates and it was relatively uncontroversial that the UK retained its right of self-defence for some time after the initial attack and occupation. ${ }^{254}$ Also notable from this incident is that the British did not consider themselves under a legal obligation to pursue peaceable alternatives during this period, even if attempts for a peaceful settlement were in fact made. Instead, they felt their right to act in self-defence would have justified a 'purely

\footnotetext{
248 Higgins (1994) 241.

249 See Section 2.4.1(c).

250 Levitin (1986) 638; Ruys (2010) 102; Green (2015) JUFIL, 109; Henderson (2018) 231. For an overview of the conflict, including timing and the reactions of the international community, see (1982) UNYB 1320-47. See also Henry in Ruys and Corten (2018) 361-78.

${ }^{251}$ Myer and White (2002) 8. See also Section 2.4.1(c).

252 Higgins (1994) 241; Green (2015) JUFIL, 109; Henderson (2018) 231.

${ }^{253}$ Levitin (1986) 638.

${ }^{254}$ Gardam (2004) 151.
} 
military policy'. ${ }^{255}$ The fact of continuing occupation may account for this belief. The British state practice, and widespread acceptance of it, indicates that where there is an ongoing armed attack, whilst aiming for a peaceful settlement might be desirable as an additional policy option, it does not deny a military response. The 1990-1 Gulf War might also point to the acceptability of a delayed response to an armed attack. A period of approximately five months elapsed between the invasion by Iraq of Kuwait in August 1990 and the commencement of Operation Desert Storm in January 1991.256

Turning to self-contained armed attacks, where further armed attacks are imminent, different considerations apply. Where a defending state is subjected to a series of armed attacks, Ago argues that the immediacy of a response should be judged against the threat considered as a whole. ${ }^{257}$ It would be inimical to the purpose of self-defence to require that a state waits for the next armed attack before reacting, ${ }^{258}$ or to require that it react immediately to each armed attack. ${ }^{259}$ Ultimately, immediacy requires that the defensive riposte be aimed at behaviour that is still current, even if the material effects of its latest manifestation have already disappeared. ${ }^{260}$ This logic encompasses the prospective element of general necessity, whilst at the same time recognizing that a state may go no further than responding to an immediate protective need.

Self-defence is only permissible to prevent further armed attacks on this basis when a state has good reason to expect a series of armed attacks from the same source and retaliation serves as a deterrent or protective action against

\footnotetext{
255 'Falkland Islands: Negotiations for a Peaceful Settlement' White Paper, London, 21 May 1982, para 3.

${ }^{256}$ This incident might be cited in support of the flexibility of the immediacy criterion in the case of self-defence against ongoing armed attacks constituted by the occupation of territory (Kuwait was continually occupied during this period). However, its precedential value is obscured. This is because of the controversy over whether the incident stands as an example of self-defence and/or UNSC authorisation to use force. See Section 3.1.1(d).

257 Ago (1980) para 122.

${ }^{258}$ Argued by the US in Oil Platforms. Rejoinder of the United States, para 5.33.

${ }^{259}$ Corten (2010) 486. See more generally Gardam (2004) 148-55.

${ }^{260}$ Corten (2010) 487.
} 
those armed attacks. ${ }^{261}$ References to an ongoing or persisting 'threat' should, therefore, be understood on this basis. In such cases, however, the purpose of self-defence must remain clearly apparent at all times. In terms of looking at events cumulatively, the need to respond to the prospect of imminent armed attacks makes the purpose preventative. Force against a new attack is permissible, however, provided that it remains defensive rather than punitive in nature and is not a reprisal for revenge or as a penalty or a 'lesson'. ${ }^{262}$

For Ruys, there must be 'convincing proof' of further attacks, after the last attack has factually ended. Only in such cases may self-defence be relied upon to 'impede' further attacks. ${ }^{263}$ Where this conclusion regarding a campaign or series of attacks is not reasonable, however, in light of the circumstances prevailing at the time, any further use of force is liable to be characterised as mere retaliation rather than self-defence. ${ }^{264}$ In addition, such a right should not be understood as stretching to counter unspecified future attacks. This would indicate an unlawful exercise of preventive self-defence. ${ }^{265}$

Looking at a series of attacks as a whole and combining completed armed attacks with imminent armed attacks so as to collectively amount to an ongoing threat is interesting conceptually. It is sometimes referred to as the accumulation of events theory of self-defence, and may be equated to an ongoing armed attack. ${ }^{266}$ Ago's view that the immediacy of a response should be judged against the 'threat considered as a whole' is based on the

\footnotetext{
261 Schachter (1991) 154. Greenwood (2002) para 26, likewise recognizes that necessary and proportionate force extends to preventing the reoccurrence of a threat. Taft (2004) 295, argues that the right of self-defence 'allows States to deter armed attacks that would otherwise occur and to discourage further armed attacks.' Ruys (2010) 123 argues that, in 'exceptional circumstances', necessity and proportionality allow for the halting and repelling of 'successive and interlinked armed attacks' and the preventing of their reoccurrence.

262 Schachter (1991) 154. See also Corten in Weller (2015) 873.

${ }^{263}$ Ruys (2010) 102.

${ }^{264}$ Schmitt (2013) 66.

265 See Section 1.3.2(a).

${ }^{266}$ See e.g. Kress in Weller (2015) 588; Gray (2018) 164-5. The ICJ has, in principle, accepted that a number of small-scale uses off force, individually falling below the level of an armed attack, may be accrued such that, collectively, they amount to an armed attack. This is most clearly seen in Oil Platforms, para 64. See also the implicit acceptance of this principle in Nicaragua, para 231; Armed Activities para 146. For further analysis and examples of state practice see, e.g. Green (2009) 42-4; Ruys (2010) 168-75; Henderson (2018) 224-6.
} 
assumption that an armed attack has already occurred. As such, it has been argued that it should be distinguished from a purely pre-emptive or preventive justification of action. ${ }^{267}$ Claims of 'pure' anticipatory self-defence are, in any event, rare. In practice, states tend to invoke the need to respond to future armed attacks when they have already been the victim of a previous one. ${ }^{268}$ This point is also reflected in Bethlehem's Principle 8, which considers whether the anticipated imminent armed attack is part of a 'concerted pattern of continuing armed activity'. ${ }^{269}$

In such circumstances, absent ongoing hostilities, it is only the prospect of an imminent armed attack that keeps the threat current, thereby maintaining the general necessity of self-defence. This is logically assumed, given the widespread rejection of any right of preventive self-defence. ${ }^{270}$ Without the threat of an imminent armed attack, any prior armed attack would simply be complete, and the general necessity of self-defence would come to an end. With a series of armed attacks, therefore, the analysis largely depends on that related to imminent armed attacks. This fact should help to assuage the fear that adoption of the accumulation of events theory does away with the immediacy requirement and risks becoming an open-ended licence to use force. ${ }^{271}$ In such cases, the real relevance of the prior armed attack is that it might be strongly indicative of further attacks in the near future. As a matter of principle, therefore, this links imminence with immediacy and returns us to the window of opportunity analysis referred to in Section 2.4.1(b).

This analysis is reflected, for example, in Iran's arguments before the ICJ in Oil Platforms. Iran recognized that self-defence may be required in response to previous armed attacks where 'the victim State has experienced a series of attacks, and apprehends further attacks, so that the measures taken, although taken after the last actual attack are designed to protect the State against

\footnotetext{
267 Ruys (2010) 102.

268 See ibid, 342-3; Lederman (4 and 11 April 2016); Milanovic (2017).

269 See Section 2.4.1(b).

270 See Section 1.3.2(a). See also Greenwood (1986-1987) 946.

271 Tams (2009) 389-90.
} 
future attacks. ${ }^{272}$ It went on to stress that such a view of self-defence had been rightly rejected in the UNSC, because:

the apprehended future attacks, if not imminent, are hypothetical; and in any event the measures tend to be designed to "teach a lesson", to inflict retribution and to deter only by demonstrating that aggression does not pay. 273

The ICJ determined that the American attacks were unnecessary, ${ }^{274}$ but did not offer a view on the issue of immediacy, or the right to respond to a continuing threat. Rather, the Court's verdict was based largely on the lack of a proven armed attack and the nature of the USA's choice of targets. ${ }^{275}$ However, Iran's stance on the right to respond to a series of attacks is interesting. ${ }^{276}$ First, it encapsulates the belief that future threats must be imminent, which accords with this author's analysis above. In addition, Iran's view is consistent with the proposition that a clear defensive purpose must be apparent in the response. This reflects the aforementioned position that retributive acts will be viewed as unlawful acts of reprisal.

Other state practice provides support for the notion that, once an armed attack has occurred, further anticipated attacks may be prevented. During the Gulf of Tonkin incident in 1964, the USA claimed a right of self-defence to 'deter future aggression' by North Vietnam against its naval units following previous alleged

\footnotetext{
272 Oil Platforms, Memorial submitted by the Islamic Republic of Iran, 8 June 1993, para 4.33. $273 \mathrm{Ibid}$. It should also be noted that it took a strict review on the question of immediacy in relation to completed armed attacks: 'But in cases of single armed attacks (...) the attack is terminated when the incident is over. In such a case the subsequent use of counter-force constitutes a reprisal and not an exercise of self-defence.' Oil Platforms, Reply and Defence to Counter-Claim submitted by the Islamic Republic of Iran, 10 March 1999, para 7.47. The USA, in response, argued that this position rendered the right of self-defence 'illusory' and insisted that it had the right to respond to remove continuing threats to its security. Oil Platforms, Counter-Memorial and Counter-Claim submitted by the United States of America, 23 June 1997, paras 4.27-4.29.

274 Oil Platforms, para 76.

275 Ruys (2010) 106. See Section 2.5.

${ }^{276}$ As the object of force, however, Iran's views on self-defence have less probative value and should be approached with caution. See Section 2.3.2(a).
} 
attacks whilst operating in international waters. ${ }^{277}$ In support of the American action, the UK stated that the repeated nature of the attacks, and their mounting scale, permitted the USA to take action to prevent their recurrence. ${ }^{278}$ Preventive action, in these circumstances, was viewed by the UK as being essential to the right of self-defence. ${ }^{279}$ The general principle that self-defence was allowed to 'discourage and prevent further violence' was repeated by the UK in supporting the USA's claim of self-defence against an 'ongoing pattern' of Libyan-sponsored terrorist attacks in 1986. ${ }^{280}$ Similar support was given to the USA when it targeted the IIS headquarters in 1993, with the stated aim of deterring further acts of aggression. ${ }^{281}$

The right to prevent and/or deter the continuation of further attacks has, therefore, often been claimed by states. Other examples include Israel's action in Lebanon in 1975, ${ }^{282}$ South Africa' incursions into Lesotho in $1982,{ }^{283}$ and Iran's claim of self-defence against terrorists operating from Iraq. ${ }^{284}$ As Ruys notes, whilst several of these cited interventions received criticism or even condemnation by states, 'negative reactions were generally related to factual circumstances and other aspects of the incidents concerned and should therefore not be read as a principled rejection of post facto defensive measures. ${ }^{2} 25$

More recent state practice, most notably in the context of the response to transnational terrorism, points to an increased willingness of states to accept more expansive defensive action to counter further threats from the same source. Israel, in defending its action against Hezbollah in Lebanon in 2006,

\footnotetext{
277 UN Doc S/PV.1140 (1964) 44-5. On this incident generally, see Guilfoyle in Ruys and Corten (2018) 108-17.

278 Ibid, 78.

279 Ibid.

280 UN Doc S/17990 (1986).

281 E.g. UN Doc S/PV.3245 (1993) 6; 17 (Brazil); 19-20 (Hungary); 21-2 (UK). The USA repeated this aim following the 1998 African embassy bombings. UN Doc S/1998/780 (1998). 282 UN Doc S/PV.1859 (1975) para 119.

283 UN Doc S/PV.2409 (1982) paras 146-7. On this incident generally, see Reinold in Ruys and Corten (2018) 379-84.

284 UN Doc S/1999/781(1999) 2.

${ }^{285}$ Ruys (2010) 103-4.
} 
referred to the necessity of removing the 'overall threat' faced by a state, meaning that 'the right of self-defense includes not only acts taken to prevent the immediate threat, but also to prevent subsequent attacks. ${ }^{2}{ }^{28}$ In 2008 , in response to repeated violence from the PKK, the Turkish military explained that their resulting Operation Sun was to 'prevent the region from being a permanent and safe base for the terrorists. ${ }^{287} \mathrm{~A}$ clearer example occurred after 9/11.288 In justifying its actions, the USA referred to the 'ongoing threat' against it. It maintained that their actions, which were designed to prevent and deter further attacks, were in accordance with the inherent right of individual and collective self-defence. ${ }^{289}$ The UK, along similar lines, asserted that their defensive response to $9 / 11$ was designed to avert the continuing threat of attacks from the same source. ${ }^{2} 90$

It is noteworthy that the British opinion regarding this incident is that the combination of past attacks, current capabilities and ongoing and future aims amounted to a current threat that gave rise to a right of self-defence. That the 9/11 attacks were factually complete, and the defensive response did not occur until several weeks afterwards, appeared irrelevant to this determination. It also seemed to play no part in the wider assessment of the general necessity of the response. The UNSC recognized and reaffirmed the right to self-defence in the circumstances, ${ }^{291}$ and the characterisation of lawful self-defence was not generally questioned by states. To the contrary, the ensuing Operation

\footnotetext{
286 'Responding to Hizbullah attacks from Lebanon: Issues of proportionality', Israel Ministry of Foreign Affairs, 25 July 2006, <http://www.mfa.gov.il/MFA/Aboutlsrael/State/Law/Pages/Responding\%20to\%20Hizbullah\% 20 attacks $\% 20$ from $\% 20$ Lebanon-

\%20lssues\%20of\%20proportionality\%20July\%202006.aspx>. Israel's actions were nevertheless deemed to be disproportionate. See Section 3.2.5.

287 'Turkey Says t Has Sent Ground Troops Into Iraq', New York Times, 22 February 2008, $<$ http://www.nytimes.com/2008/02/22/world/middleeast/22iraq.html>. On this incident generally, see Ruys (2008); Trapp in Ruys and Corten (2018) 689-701. Whilst Turkey did not report its actions to the UNSC as self-defence under Art 51 UN Charter, Prime Minister Erdogan publicly justified Turkish action on this basis. 'Iraq Moves to Dissuade Turkey from Raids' The New York Times, 17 October 2007, <www.nytimes.com/2007/10/17/world/europe/17turkey.html>.

288 On this incident generally, see Byers in Ruys and Corten (2018) 625-38. See further Section 4.1.3(a).

289 UN Doc S/2001/946 (2001).

290 UN Doc S/2001/947 (2001).

291 UNSC Res 1368 (2001); 1373 (2001).
} 
Enduring Freedom received almost universal support from the international community. 292

Ruys concludes on the basis of state practice up to 2010 that if a state has been subject to a series of armed attacks, and if there is a considerable likelihood that more attacks will imminently follow, then self-defence is not automatically excluded. This, he argues, is logical, since otherwise states 'would have little defence against consecutive pin-prick attacks whereby opposing forces withdraw immediately after having carried out an attack. ${ }^{293}$ This logic is inescapable, and remains applicable today, especially in the context of armed attacks by NSAs deemed to be terrorists (see Chapter 4). Sporadic, but often devastating, attacks, possibly across a number of geographical locales, may well occur under the umbrella of a continuing threat comprised of past and imminent armed attacks. The most recent state practice relating to the international community's response to Daesh reinforces the proposition that states have a lawful right to respond to such a continuing threat. ${ }^{294}$ The issue, however, in this context is the risk of states abusing the right of self-defence. Section 4.1.4(b) examines the worrying prospect of an enduring defensive response based on a notion of 'permanent imminence', which keeps the general necessity of self-defence rolling on indefinitely. ${ }^{295}$

\footnotetext{
292 The reports to the UNSC by the US and the UK of their actions in self-defence were followed by others: UN Docs S/2001/1005 (2001) (Canada); S/2001/1103 (2001) (France); S/2001/1104 (2001) (Australia); S/2001/1127 (2001) (Germany); S/2001/1171 (2001) (The Netherlands); S/2001/1193 (2001) (New Zealand); S/2002/275 (2002) (Poland). The European Union declared its full solidarity with the United States of America and its wholehearted support for the action that is being taken in self-defence and in conformity with the Charter of the United Nations'. UN Doc S/2001/967 (2001). NATO also offered its full support, invoking the right of collective self-defence pursuant to Art 5 Washington Treaty for the first time in its history. (2001) 41 ILM 1267, 1268. The Organization of American States followed suit, also invoking collective self-defence. (2001) 41 ILM 1270, 1273. Support was furthermore expressed by Russia, China, Norway, Mexico, Egypt and others. See further Murphy (2002) 244-6, 248; Ruys (2010) 436-7; Byers in Ruys and Corten (2018) 628-31.

${ }^{293}$ Ruys (2010) 106.

${ }^{294}$ Daesh is known by a number of names, including 'the so-called Islamic State', 'ISIL' and 'ISIS'. This thesis adopts the former nomenclature.

295 See also Tams in Van den Herik and Schrijver (2013) 399-401, suggesting that state practice might point to a right of states to respond to non-imminent attacks, in cases where the 'fear of future attacks' seems genuine.
} 


\subsection{Specific necessity - targeting}

Necessity also relates to the target of defensive action. In the review that follows, it will be seen that states, scholars and the ICJ typically treat targeting as a distinct element of the necessity calculus. This issue of where defensive force must be directed is considered separately to the prior general necessity question of whether there is a prima facie need for a putative defending state to resort to force at all. To reflect this distinction, this thesis refers to targeting as an issue of specific necessity. ${ }^{296}$ However, it is also true that states, scholars and the ICJ sometimes consider targeting alternatively, or cumulatively, within the rubric of proportionality. ${ }^{297}$ This inconsistent narrative provides a mixed doctrinal picture. The following analysis seeks to provide, therefore, greater conceptual clarity to avoid a catch-all depiction of unlawfulness. Further analytical work distinguishes between general necessity, specific necessity and proportionality, and explains where the issue of targeting is best situated.

\section{a) A JAB military target}

Oil Platforms is the case in which, relatively speaking, the ICJ has most carefully and explicitly considered the application of necessity and proportionality to issues of targeting. ${ }^{298}$ In it, the Court stated that the USA 'must also show that its actions were necessary and proportional to the armed attack made on it, and that the platforms were a legitimate military target open to attack in the exercise of self-defence. ${ }^{299}$ This language might suggest that the Court considers the nature of the target to stand alongside necessity and proportionality as an additional determinant of legality. Later in its judgment, however, the Court rejected the USA's assertions that the oil platforms they attacked in purported self-defence performed a military function. On the basis of that determination, the Court concluded that the American attacks were not

\footnotetext{
296 See Section 2.2 .

${ }^{297}$ E.g. In the context of the Iran/Iraq War 1980-88, Iraq appeared to link not targeting civilians to the requirements of proportionality. UN Doc S/PV.2250 (1980) para 40. Other examples are referenced in this Section.

${ }^{298}$ See Sections 3.1.1(f) and 3.3.2(b) for further analysis.

299 Oil Platforms, para 51 (emphasis added).
} 
necessary to respond to either the missile attack on the Sea Isle City or the mining of the USS Samuel B. Roberts. ${ }^{300}$ As such, the Court's view that the nature of the target must be military appears to form part of the necessity analysis, rather than being an independent requirement.

The Court has been less explicit in its other relevant jurisprudence. In Nicaragua, it concluded that the American attacks on Nicaraguan ports and oil installations were not proportionate. ${ }^{301}$ This statement might implicitly refer to the nature of the target, or not. The Court does not go into any details, and its account of proportionality is unclear. ${ }^{302}$ In Nuclear Weapons, the Court held that 'States must take environmental considerations into account when assessing what is necessary and proportionate in the pursuit of legitimate military objectives.' ${ }^{303}$ Again, it provided no detail. In Armed Activities, the Court simply observed that the taking of airports and towns many hundreds of kilometres from Uganda's border was not necessary or proportionate. ${ }^{304} \mathrm{It}$ provided no breakdown of this conclusion.

Other than Oil Platforms, the ICJ did not explain in any of these cases how or why the issue of targeting was (or could be) relevant to either (or both) necessity or proportionality. Perhaps the Nuclear Weapons and Armed Activities recourse to 'necessity and/or proportionality' is the ICJ's own 'ritual incantation' 305 that generally denotes illegality. States and scholars sometimes follow this approach. Under the taxonomy adopted in this thesis, it is submitted that targeting is better understood as an element of specific necessity rather than proportionality. There are three main reasons for this conclusion.

First, as noted in Section 1.3.1, necessity must be addressed before proportionality can be considered. Second, it is difficult to argue from the

\footnotetext{
$300 \mathrm{lbid}$, paras $74-7$.

301 Nicaragua, para 237.

302 See Section 3.1.1(f).

${ }^{303}$ Nuclear Weapons, para 30. Whilst the Court's reference to 'legitimate military objectives' could be interpreted as an IHL issue, the Court is clearly referring here to the right of selfdefence and JAB necessity and proportionality. Regarding proportionality, see Section 3.2.7. ${ }^{304}$ Armed Activities, para 147.

305 Gray (2018) 125.
} 
position of principle or state practice that deliberately targeting a non-military target can be necessary to halt, repel or prevent an armed attack. ${ }^{306}$ Using force against a civilian target might also be regarded as excessive and, therefore, disproportionate, ${ }^{307}$ but this conclusion is essentially meaningless. This is because the necessity hurdle must be overcome before proportionality can be considered, and specific necessity incorporates the issue of targeting (as per Oil Platforms and the state practice referred to below). Therefore, also considering targeting within a proportionality assessment serves no additional legal function. Third, as explored in Chapter 3, the approach of the ICJ, scholars and states to proportionality reveals that proportionality is concerned with whether a defending state's overall defensive response is excessive. Proportionality looks at outcomes. These comprise the cumulative effects of self-defence, not each individual targeting decision. 308 Proportionality, therefore, plays a very different role to specific necessity, and the two are conceptually distinct.

The consequence of this analysis is that where specific necessity is not satisfied, an act of targeting will be unlawful. It cannot, therefore, also be disproportionate. Where targeting does satisfy specific necessity, it may nevertheless breach JAB proportionality. ${ }^{309}$ This latter conclusion is not due to the nature of the target, however, but the consequential effects of the defensive conduct. An example that helps to reveal this distinction between specific necessity and proportionality on the issue of targeting, is the sinking of the Argentine cruiser General Belgrano by a British submarine during the 1982 Falklands War. Gardam suggests it as an instance of state practice that

\footnotetext{
${ }^{306}$ In terms of state practice in support, see e.g. Sections 2.5(b) and the concern regarding civilian harm reflected in state practice in Section 3.2.5. This assumes that civilians are not directly participating in hostilities ('DPIH') for the purposes of $\mathrm{IHL}$, and that civilian objects are not being used for military purposes. Where a civilian is DPIH and/or where a civilian object is being used for military purposes they are potentially targetable under the rules of IHL. Where, in each case, there is also a connection with the armed attack, it would be also potentially possible to establish the JAB specific necessity of targeting them. See further Sections 2.5(b) and 3.3.2(b).

307 Green and Waters (2015) 12, for example, suggest that it is unlikely that a direct attack on a civilian target will be anything other than excessive when measured against a defensive need.

${ }^{308}$ See in particular Sections 3.3.1 and 3.3.2.

309 This may be the case even if such acts are IHL compliant. See Section 3.3.1.
} 
supports the notion that proportionally may act to limit attacks on military targets. ${ }^{310} \mathrm{Her}$ analysis can also be read, however, as referring to specific necessity. ${ }^{311}$ The key factor to note in this incident was the loss of life: over three hundred men were killed, far exceeding the total casualties on both sides up to that date. ${ }^{312}$ The act resulted in much international criticism, and reasonable arguments may be presented on either side regarding its proportionality. ${ }^{313}$ Crucially, however, the review of the proportionality of this episode is framed in terms of whether the British action was an unjustifiable escalation of the conflict. ${ }^{314} \mathrm{It}$ is tied to the effect on the wider context and the overall defensive response. ${ }^{315} \mathrm{It}$ is submitted, therefore, that the issue for proportionality is whether damaging or destroying a legitimate military target (for the purposes of both IHL and JAB specific necessity) takes a defending state's conduct, to be viewed as a whole, beyond a defensive purpose. Is it 'excessive' (to quote Webster)? ${ }^{316}$

Distinguishing between necessity and proportionality when considering targeting, including the need to apply the former first, is prima facie reflected in Oil Platforms. The Court first considered whether targeting the oil platforms was a necessary act of self-defence. Focusing on the non-military nature of the oil platforms, it concluded that it was not. ${ }^{317}$ The Court, therefore, expressly connects the nature of target to the necessity of the response. It then

\footnotetext{
${ }^{310}$ Gardam (2005) 171-2.

311 'At the time of the attack, the General Belgrano was outside of the total exclusion zone declared by the UK and appeared to pose no immediate threat.' Ibid, 171. This suggests a lack of connection with the ongoing armed attack and, therefore, an absence of defensive purpose in targeting it. See further Section 2.5(b).

312 See Greenwood (1989) 279.

${ }^{313}$ Greenwood (1989) 279, concludes: 'On balance, it is thought that the sinking was lawful, but the terms in which it is debated, and the intensity of that debate, show that the concept of self-defence may impose serious restrictions upon the right of a State to attack what, in terms of the jus in bello, is a legitimate military target'. Gardam (2005) 172, notes that the international criticism was not so much based on legal criteria, but rather that the British attack was somehow dishonourable.

${ }^{314}$ Greenwood (1989) 279. Gardam (2005) 171, also recognizes the issue of escalation in her comments on proportionality.

${ }^{315}$ Escalation may affect other interests, e.g. international peace and security, the rights of other states, the environment and so forth, that factor in whether self-defence is proportionate. See Section 3.2.

${ }^{316}$ See generally Chapter 3.

317 Oil Platforms, para 76.
} 
proceeded to consider proportionality as a subsequent, and separate, issue.$^{318}$ In so doing, it stated that the American response to the attack on Sea Isle City might, 'had the Court found that it was necessary in response to (...) an armed attack committed by Iran, have been considered proportionate' 319 This approach reflects the logic that a finding of proportionality (and disproportionality) can only flow from a conclusion that a use of defensive force is first necessary. It also confirms that the operation of both requirements relies on the existence of a defensive purpose. Without necessity, there is no defensive purpose against which proportionality can be gauged. There is only an unlawful use of force.

The Court proceeded to muddy the conceptual waters, however. Despite, and contrary to, the aforementioned logic and its approach to the attack on Sea Isle City, the Court adopted a different approach to proportionality and the mining of the USS Samuel B. Roberts. The Court concluded that the American response in this case, despite being unnecessary, was also disproportionate. ${ }^{320}$ Given the foregoing analysis, in the absence of necessity, it is not clear why the Court chose to opine on proportionality. The propriety of such comments is questionable. Furthermore, they are insufficient in setting out the basis on which the Court held that proportionality might have been satisfied in the former case and not the latter. However, its finding of disproportionality of the response to the mining of the USS Samuel B. Roberts does provide some clues to how it distinguishes between necessity and proportionality. Its view is clearly coloured by the effects of the overall American response, which consisted of a wider campaign that went beyond the reaction to the mining alone. ${ }^{321}$ This focus on the overall defensive response reflects the analysis referred to above regarding how proportionality operates, in contrast to specific necessity.

\footnotetext{
318 Ibid, paras 76-7.

319 Ibid, para 77 (emphasis added).

320 Ibid.

321 Ibid. For further details of the response and the ensuing proportionality analysis, see Section 3.1.1(f).
} 
The general rule that self-defence is limited to military targets finds support in state practice, where claims of self-defence and responses thereto have focused on this issue. ${ }^{322}$ An example includes the Israeli strike on the Osiraq reactor in 1981. In justifying its claim of self-defence, Israel insisted that the nuclear reactor was a legitimate military target. This characterization was greeted with scepticism in the UNSC, however. The fact that states instead regarded the reactor as civilian in nature provided one of the basis for the widespread condemnation of the Israeli action. ${ }^{323}$ Another instance is South Africa's justification of its purported defensive action in Zambia, Zimbabwe and Botswana in 1986 on the basis that it was limited to ANC targets, with great care taken not to involve local civilians. ${ }^{324}$ Similar claims appear consistently in the context of fighting international terrorism. ${ }^{325}$ One of the bases for condemnation of this particular action, however, was that the targets chosen were not connected to hostile acts, despite South Africa's assertions to the contrary. ${ }^{326}$ Tanzania specifically referred to this fact in rejecting the claim of self-defence. ${ }^{327}$ Under this thesis' proposed taxonomy, this is interpreted as a lack of JAB specific necessity. ${ }^{328}$ The following Section develops this analysis.

\section{b) IHL and a JAB connection with the armed attack}

In $\mathrm{IHL}$, it has long been established that targeting is limited to 'military objectives', with the corollary being that civilians and civilian objects must not be the object of attack. ${ }^{329}$ These targeting rules impose a continuous obligation on those who plan or decide upon an attack to evaluate whether or not

\footnotetext{
322 Section 2.5(b) provides examples of state practice that both confirm, and go beyond this general premise, suggesting a need for a connection between a military target and an armed attack.

${ }^{323}$ E.g. UN Docs S/PV.2280 (1981) paras 71-92 (Israel); para 147 (Algeria); S/PV.2284 (1981) 77 (Syria); S/PV.2285 (1981) para 29 (Cuba). See further Section 2.3.2(b).

${ }^{324}$ UN Doc S/PV.2684 (1986) 26-7.

${ }^{325}$ See Sections 2.5(b), 4.1, 4.2.3.

326 See e.g. Kwakwa (1987) 440.

327 UN Doc S/PV.2684 (1986) 44-5. Green (2006) 478, describes the military target issue as determinative of Tanzania's conclusion.

328 Green and Waters (2015) 13, interpret Tanzania's words as a lack of necessity and proportionality under the JAB.

${ }^{329}$ Arts 48, 51(2) and 52(2) AP1. This prohibition is an uncontroversial principle of customary international law. Rule 1 of The International Committee of the Red Cross ('ICRC') Study on Customary IHL, <https://ihl-databases.icrc.org/customary-ihl/eng/docs/home>.
} 
something is a military objective, and to cancel or suspend such attack if it becomes apparent that the objective is not military, if it is protected, or it would violate the IHL rules of proportionality. ${ }^{330} \mathrm{How}$, and to what extent, IHL and the $\mathrm{JAB}$ interrelate on this topic is, therefore, directly relevant to the present enquiry.

Green and Waters rightly note that IHL has primacy in the area of targeting and will generally be the 'first point of call' in relation to such decisions. They argue, however, that limitations on targeting also form part of the customary rules of necessity and proportionality in the JAB. On their view, therefore, IHL and the JAB impose broadly equivalent parallel, but cumulative, obligations. ${ }^{331}$ The ensuing review reflects this general premise. There is also wider academic support for the idea that non-military targeting will fall foul of JAB necessity, in addition to IHL. ${ }^{332}$ The Council of the European Union's Independent International Fact-Finding Mission on the Conflict in Georgia ('IIFFMCG') likewise adopted this position in its review of the 2008 conflict in Georgia. 333 This point also seems to have been recognized, at least to a degree, by Webster who took the view that it is necessary to show that there had been an attempt to discriminate between the innocent and the guilty. ${ }^{334}$

\footnotetext{
${ }^{330}$ Arts 52(2) and 57(2)(b) Protocol Additional to the Geneva Conventions, 12 August 1949, and Relating to the Protection of Victims of International Armed Conflicts, 8 June 1977, 1125 UNTS 3 ('API').

331 Green and Waters (2015) 6-7, 9-11, 13-25. In so doing, Green and Waters do not argue that custom contains specific stand-alone targeting limitations, but that the restrictions inherent in JAB necessity and proportionality regulate the choice of targets. They accept that, in the majority of cases the targeting rules will apply in tandem and will be substantively identical, with certain limited exceptions. Such concurrent application principle is in line with the ICJ's decision in Nuclear Weapons, which is discussed in Section 3.3.1. See generally Section 3.3 for further discussion of proportionality and targeting.

332 Greenwood (1989) 278-9; Gardam (2004) 171-2; Corten (2010) 488; Ruys (2010) 108-10. These commentators also maintain that targeting is limited by proportionality.

333 IIFFMCG Report, Vol II, September 2009 ('IIFFMCG Report'), <http://www.mpil.de/files/pdf4/IIFFMCG Volume II1.pdf>, 272. The IIFFMCG's adopted methodology vis-à-vis the JAB has been criticised, however. See e.g. Henderson and Green (2010). On this incident generally, see Gray in Ruys and Corten (2018) 712-28.

${ }^{334}$ Letter from Mr Webster to Mr Fox (24 April 1841) British and Foreign State Papers, 18401841, Vol. XXIX, 1138. Although, Green and Waters (2015) 10, note that Webster did not go so far as to claim that actions taken in self-defence must always be directed against military targets.
} 
This dual application of IHL and the JAB raises the question of whether a 'military target' under the JAB is identical to a 'military objective' under IHL. For the present consideration of JAB necessity, there are clear distinctions to be drawn. As noted, the generalities of the JAB, based on the principles set out in this Section, should not be directly equated with the specific provisions of $\mathrm{IHL}$. Yet, drawing on the principles of IHL helps to explore what the ICJ and states (for which, see further below) consider is targetable under the JAB. Under IHL, to constitute a targetable 'military objective', objects by their nature, location, purpose or use must make an effective contribution to military action. In addition, their total or partial destruction, capture or neutralization, in the circumstances ruling at the time, must offer a definite 'military advantage'. ${ }^{335}$ This definition provides a logical starting point regarding how we might conceive of the military activities that the Court in Oil Platforms considered necessary for targeting purposes. ${ }^{336}$ Like the IHL position on targeting, this JAB approach requires a connection with hostile activities.

Yet, whilst compliance (in broad terms at least) with this IHL definition of 'military objective' might be necessary to constitute a 'military target' for the purposes of the $J A B$, it is not sufficient to establish legality under the latter regime. There is an obvious additional JAB requirement for targeting in the context of defensive action. Whereas the target of self-defence must have some military connection, whether or not precisely equating to an IHL 'military objective', not any military target will suffice. Its destruction, capture or neutralization must also be connected with the force to be repelled. There must be a defensive purpose to the act. For the $J A B$, therefore, defensive force should in principle be directed against the source of the armed attack(s). ${ }^{337}$

A general JAB targeting precept that requires a connection between attack and defence is entirely logical and is in keeping with the approach taken by the ICJ

\footnotetext{
${ }^{335}$ Art 52(2) AP1. See generally Oeter in Fleck (2013) 166-87.

336 Oil Platforms, para 76.

${ }^{337}$ Ruys (2010) 108-9. Cannizzaro in Clapham and Gaeta (2014) 346, notes along similar lines that necessity secures the existence of a 'functional link' between military action and defensive purpose.
} 
in Oil Platforms ${ }^{338}$ Destroying, capturing or neutralizing military objectives (for the purposes of $\mathrm{IHL}$ ) connected with the armed attack (making them JAB military targets) clearly points to a prima facie defensive purpose. Conversely, other states may rightly question the JAB necessity of a defending state targeting $\mathrm{IHL}$-compliant military objectives of the attacker that are not related directly to the current threat that it faces. Depending on the circumstances, it would be difficult for a defending state to establish that destroying or neutralizing such military objectives carries with it a defensive purpose. ${ }^{339}$ In this respect, we should recall that self-defence is a temporary right that enables a defending state to counter a situation of emergency and address its immediate defensive needs. It is not designed to address longer-term security issues, which are reserved for the collective security mechanisms of the UN Charter. ${ }^{340}$ The JAB therefore overlays an additional and concurrent obligation on defending states when selecting targets. $\mathrm{IHL}$ and the JAB operate separately, but in tandem, to regulate targeting. The rules of both regimes must be complied with on a continuous basis to ensure that defensive action is lawful. ${ }^{341}$

State practice ostensibly reflects the dual application of IHL and JAB. The difficulty, however, in assessing this practice is that states do not tend to refer to the source of the targeting obligations incumbent upon them. For instance, Iran argued before the ICJ in Oil Platforms that 'self-defence must be addressed to the right target - to the source of the threat'. ${ }^{442}$ Whether or not

\footnotetext{
${ }^{338}$ Specific necessity requires that the defending state only targets the attacker. See Section 2.2. The analysis in this Section takes that general proposition one step further. The Court in Oil Platforms, para 77, also criticized the USA for attacking a 'target of opportunity', which might suggest that it requires a connection between the target and the purported threat to the state taking military action against it.

${ }^{339}$ From an IHL perspective, destroying, capturing or neutralizing a military objective during a defensive operation that is not connected with an armed attack is unlikely to offer a 'military advantage'. Whilst the application of IHL does not rely on the lawfulness under the JAB of a state resorting to armed force (thereby ensuring equal application of $\mathrm{IHL}$ to belligerents), it is influenced by its reasons for doing so. The overall (defensive) purpose of the action will, therefore, define the military advantage. Absent such advantage, a military objective is not targetable under IHL. See further Oeter in Fleck (2013) 175-7; Section 3.3.1.

340 See Section 1.3.2(c) and also Section 2.4.2 regarding deterring future threats.

${ }^{341}$ The joint and separate application of the JAB and IHL is discussed further in Sections 3.3 and 3.4.

342 Oil Platforms, Memorial submitted by the Islamic Republic of Iran, 8 June 1993, para 4.25.
} 
Iran clearly identified such requirement as forming part of the proportionality or necessity requirement, or both, is not clear, however. ${ }^{343}$ What is clear, is that it viewed force used against targets that had no direct connection with the armed attacks as being punitive or retaliatory acts, thereby constituting reprisals. ${ }^{344}$ This logic is compelling and Iran's comments clearly relate to the JAB. The following incidents of practice likewise comprise claims of self-defence and also indicate that targeting obligations fall under the purview of the JAB.

For example, the UK defended its targeting of the Harib Fort in 1964 by reference to its military nature and the fact that it was a centre for subversion and aggression against the South Arabian Federation. ${ }^{345}$ Czechoslovakia rejected the British claim of self-defence. Yet, by pointing to the object of its response as having no connection with the alleged raids to which the UK claimed to be responding, it appeared nevertheless to confirm the requirement of a nexus. ${ }^{346}$ Iraq also adopted this position. It noted that the destruction of the Harib Fort, which was a military barracks for ground forces, provided no protection against the aerial attacks that had prompted the British raid. ${ }^{347}$ The UK's position is more recently reflected in the UK Military Manual, which not only recognizes that the JAB may limit the choice of targets, but also suggests that such target must have a connection to the armed attack, or risk unjustifiably escalating the conflict. ${ }^{348}$

\footnotetext{
${ }^{343}$ Iran purported to argue this point under the rubric of proportionality, making reference to the ICJ's dictum in Nicaragua regarding the American mining of the Nicaraguan ports and the attacks on ports, oil installations, etc. Ibid, paras 4.22-5. However, its reasoning also reflects an appreciation of specific necessity and/or conflates the two. This is apparent in Iran's statement that '[t]he Court [in Nicaragua] regarded such attacks as unable to meet the criterion of necessity because they could not be proportionate to the aid provided to the armed opposition inside El Salvador by Nicaragua. In other words, the mining, attacks on ports and selected installations were the wrong target. The measures could not therefore be proportionate and limited to the necessities of the case.' Ibid, para 4.25.

344 Ibid, para 4.38.

345 UN Docs S/PV.1106 (1964) paras 54-5; S/PV.1108 (1964) para 112; S/PV.1109 (1964) para 30.

346 UN Doc S/PV.1110 (1964) para 24.

347 UN Doc S/PV.1109 (1964) para 57.

${ }^{348}$ Section 2.8.1 UK Military Manual. It is interesting that the UK's position that self-defence might limit the choice of targets and weaponry is linked with the risk of conflict escalation. It is, perhaps, for this reason that the UK's position on these issues is placed in a section dealing with JAB proportionality, rather than necessity. See further Section 3.3.2.
} 
Likewise in 1964, the USA defended its actions against North Vietnamese torpedo boats and support facilities in the Gulf of Tonkin, on the basis that such action was limited to targets against which they had been forced to defend themselves. ${ }^{349}$ It provided a similar justification for it acts during the Vietnam War in 1972,350 and when it bombed Libya in $1986 .{ }^{351}$ In 1993, the USA also justified its targeting of the IIS headquarters in Baghdad on the basis that it was 'a target directly linked to the operation against President Bush. ${ }^{352}$ When targeting NSAs operating in foreign territory, defending states, in justifying claims of self-defence, will typically assert that their action is limited to the terrorists responsible for the armed attacks and to military targets. At the same time, they maintain that they are not targeting civilians or the host state. This was the case for Operation Sun in 2008,353 Operation Enduring Freedom in $9 / 11,{ }^{354}$ Coalition action in Syria, ${ }^{355}$ and is a general theme within state practice pertaining to the so-called 'unwilling or unable' debate. ${ }^{356}$

Other state reactions to purported acts of self-defence likewise support the premise that targets should be military and connected with the armed attack. For example, in respect of Turkey's Operation Sun in 2008, states emphasized the need for Turkey to limit its action to PKK targets. ${ }^{357}$ Israeli interventions in and against Lebanon over the years are similarly expositive. In 1968 the UNSC's condemnation of Israel's attack on Beirut airport was largely based on the lack of any connection between the airport and the prior attack on an Israeli aircraft. 358 In 1972, the UNSC condemned 'the repeated attacks of Israeli

\footnotetext{
349 UN Doc S/PV.1140 (1964) para 44.

350 Office of the Legal Adviser (1972) 837.

351 UN Doc S/PV.2674 (1986) 13, 14-15.

352 UN Doc S/PV.3245 (1993) 6. As noted, whilst this claim of self-defence is contestable, the fact that the defending state felt bound to justify it actions by pointing to the nexus between attack and defence is instructive.

353 UN Doc A/HRC/7/G/15 (2008) 1

${ }^{354}$ E.g. UN Docs A/56/PV.44 (2001) 9, 11, 27; S/2001/94 (2001).

${ }^{355}$ See Sections 4.1.3(b), 4.2.3.

${ }^{356}$ See Section 4.1.2.

357 E.g. 'EU Presidency Statement on the Military Action Undertaken by Turkey in Iraqi 25 February 2008, $<$ www.eu2008.si/en/News and Documents/CFSP Statements/February/0225MZZturkey.ht $\mathrm{ml}>$; Ruys (2008) 362-3.

358 UNSC Res 262 (1968); (1968) UNYB 228-232. See further Gray (2018) 203.
} 
forces on Lebanese territory and population'. 359 In 1982, it condemned 'Israeli incursions into Beirut', reaffirming 'the rights of the civilian populations' and repudiating 'all acts of violence against those populations'. ${ }^{360}$ Israel's operation against Hezbollah in Lebanon in 2006 is also elucidating on this point. Israel attempted to vindicate its action on the basis that it was concentrating its response on Hezbollah strongholds, positions and infrastructure. ${ }^{361}$ Whilst this was regarded with general scepticism, it is another example of a state attempting to establish a claim of self-defence by justifying its targeting decisions by reference to their connection with the armed attacks. ${ }^{362}$

\subsection{Conclusions}

Although not expressed using the taxonomy proposed in this Chapter, general and specific necessity are clearly reflected in state practice, ICJ jurisprudence and scholarship. A review of these sources reveals that necessity relates to two distinct questions. The first is whether, following an armed attack, any form of military force is required to resolve the issue, or peaceful alternatives suffice (general necessity). If force is the only reasonable response in the circumstances, the subsequent question is where such force must be aimed so as to be capable of achieving a defensive purpose (specific necessity). Proportionality assesses the overall outcomes of the decision to use force in self-defence.

States undoubtedly consider an exercise of self-defence to be a measure of last resort. Yet, general necessity is revealed to be highly contextually sensitive. A putative defending state might seek to justify a claim of selfdefence by pointing to the lack of reasonable alternatives to force to establish

\footnotetext{
359 UNSC Res 316 (1972).

360 UNSC Res 520 (1982).

361 UN Doc S/PV.5489 (2006) 6.

362 The principle source of state criticism and condemnation of this action was not based on explicit pronouncements that might be regarded as pertaining to specific necessity. Whilst great concern was expressed by states and international organizations regarding the nature of Israel's targeting of civilian infrastructure, states focused on the cumulative consequences of such actions. It was the overall effect of the Israeli response, therefore, that led to a general consensus that it was disproportionate. See Section 3.2.5.
} 
general necessity. However, the specific facts of the case will ultimately determine whether other states deem the resort to self-defence to be reasonable in the circumstances. The availability and pursuit of peaceful alternatives might feature in this this review and count as evidence of general necessity. However, they might not appear at all in either the justification or review of claims of self-defence. Where they are noted, the issue of peaceful alternatives is unlikely to be the sole determinant of legality. Other factors will tend to govern the final conclusion, such as the timing of the armed attack, its likelihood and gravity, the nature of the relationship between the defending state and the aggressor, the relevant history between the two and whether the threat is current and likely to persist. Additional factors pertain to armed attacks by terrorist NSAs. ${ }^{363}$

State practice, ICJ jurisprudence and scholarship suggest that a review of the legality of self-defence will ultimately rest on whether it was reasonable for a state to resort to self-defence in the circumstances. This raises questions over the ability of general necessity to restrain the use of defensive force, especially in the context of armed attacks against terrorist NSAs. In such cases in particular, general necessity is revealed to be a weak limitation on state action. In contrast, specific necessity operates as a clear restriction on the exercise of the right of self-defence. Requiring that force is limited to military targets connected with the actual or imminent armed attack, it ensures that their neutralisation or destruction is confined to a defensive purpose. A lack of this nexus suggests that a use of force is punitive and, therefore, unlawful. In this way, the JAB overlays onto $\mathrm{IHL}$ additional targeting rules that determine whether the exercise of self-defence is lawful.

\footnotetext{
363 See Chapter 4.
} 


\section{CHAPTER 3: PROPORTIONALITY}

\section{Introduction}

At its core, proportionality is a relatively straightforward concept: it is a prohibition against excess. ${ }^{1}$ Its role is to limit permitted harm done to others. ${ }^{2}$ Yet, identifying its content and outer conceptual boundaries, and applying them to specific incidents of self-defence, is more complex than with necessity. ${ }^{3}$ Flexibility is required. This is partly due to debates amongst scholars and states regarding the scope of self-defence. Most importantly, however, identifying from state practice the elements that make up the proportionality calculus is challenging. States' views on proportionality are frequently hard to interpret and may be too closely tied up with political considerations to permit a clear distillation of firm legal principles. States or UN bodies 'tend to use the phrase 'proportionality' indiscriminately, basing it on a gut feeling of when something was 'over the top", ${ }^{4}$ or 'excessive'. 5 Furthermore, proportionality is a limiting factor in both the JAB and $\mathrm{IHL}$, and it is often unclear whether states are referring to either, or both, regimes when commenting on specific incidents. This is despite the fact that the meanings and purposes of proportionality are markedly different in each of these bodies of law. ${ }^{6}$

This latter uncertainty might be due to states relying on $\mathrm{IHL}$, rather than the $\mathrm{JAB}$, to regulate the use of defensive force, once necessity has been established. ${ }^{7}$ The concern might also be that fully engaging with the JAB

\footnotetext{
${ }^{1}$ Tams and Devaney (2012) 106. See also Schmitt in Breau and Jachec-Neale (2006) 293, making the same argument for IHL proportionality.

${ }^{2}$ Higgins (1994) 230.

${ }^{3}$ This is particularly so with respect to armed attacks by NSAs in the context of international terrorism. See Section 4.2.

${ }^{4}$ Lubell (2013) 3.

${ }^{5}$ States and scholars often refer to 'excessive' when considering proportionality. Examples are referred to throughout this Chapter.

${ }^{6}$ See Section 3.3.1.

${ }^{7}$ See Section 3.4. Regarding the interaction between the two regimes, see Sections 2.5 and 3.3.
} 
requirements puts defending states at a disadvantage vis-à-vis the attacker because of the potential limitation the JAB imposes on the former's acts of selfdefence. ${ }^{8}$ The position has not been helped by the ICJ's jurisprudence. As this Chapter explains, the Court has provided confused and contradictory guidance regarding both the standard against which proportionality is to be measured and how the requirement is to be applied to specific cases. ${ }^{9}$ Despite these difficulties, an analysis of proportionality involving a critical review of state practice, case law and theory does bear fruit. The requirement's specific limitations remain to be developed through further state practice, but its core meaning is readily identifiable and meaningful conclusions regarding its content may be drawn.

As with necessity, the natural starting point for a review of proportionality is the Caroline incident. ${ }^{10}$ Supposing the necessity of the moment requires defensive action, Webster asserted that it would also be incumbent on a government purportedly acting in self-defence to show that it 'did nothing unreasonable or excessive; since the act, justified by the necessity of self-defence, must be limited by that necessity, and kept clearly within it." ${ }^{\prime 11}$ This is the genesis of the modern requirement that, following an armed attack, and where necessity (both general and specific) is established, the use of defensive force must also be proportionate. Whilst necessity determines whether force may be used to respond to an actual or imminent armed attack, and where it must be directed, proportionality governs how much force is permissible. It is proportionality, therefore, that seeks to prevent a state from acting excessively, beyond a

\footnotetext{
${ }^{8}$ Gardam (2004) 23-4; Green (2006) 457. The argument is that the defending state is put under an unfair burden by its obligation to comply with the JAB, which the attacker (if it is a state) has already breached and may, therefore, be disinclined to follow. During the negotiations on the Definition of Aggression, for example, a number of states expressed reservations that the inclusion of proportionality in the definition would put the defender at a disadvantage to the benefit of the attacker. UN Doc A/AC.134/SR.67-78 (1970) 85-6 (USSR); 86-7 (Ghana); 87 (Syria). Regardless of whether this is true empirically, this theoretical imbalance of obligations is countered by a better understanding of proportionality as set out in this Chapter. As will be seen, states have leeway to defend themselves effectively, provided that they do not act excessively.

${ }^{9}$ See in particular Sections 3.1.1(f) and 3.3.2(b).

${ }^{10}$ See Section 1.1.

${ }^{11}$ Letter from Mr Webster to Mr Fox (24 April 1841) British and Foreign State Papers, 1840 1841, Vol. XXIX, 1138.
} 
defensive purpose..$^{12}$ It restricts conflict from escalating in an ever-increasing cycle of violence and minimizes disruption to third parties and the international community. ${ }^{13}$ How proportionality is applied to achieve these aims, and what may count as 'excessive', is explored in the following Sections.

Proportionality's role is not universally viewed in this manner, however. Certain academics propose that proportionality forms part of the trigger of the right of self-defence, rather than conditioning the exercise of the right once it is triggered. ${ }^{14}$ Such an approach harkens back to just war theory, whereby proportionality was part of determining whether force was initially warranted. ${ }^{15}$ This minority view is difficult to reconcile with the ICJ's jurisprudence and principle. In Nicaragua, the Court clearly associates proportionality with the exercise of the right once it has arisen, rather than whether or not the right is available in the first place. ${ }^{16}$ The sine qua non for the right of self-defence is an armed attack. ${ }^{17}$ To assert that proportionality also relates to whether the right is triggered, rather than conditioning the response, unnecessarily conflates proportionality with an armed attack.

Adopting the ICJ's approach, it remains the case that Webster's exposition of proportionality should be taken as a starting, rather than an end point. On its own terms, it does not fully represent the complexities of how proportionality operates to moderate a defensive military response. Most importantly, as set out in the next Section, proportionality requires that defensive force is evaluated in relation to, or balanced against, a particular standard. What this standard should be, whilst perhaps implicit in Webster's formulation, requires much greater explicit elaboration. Therefore, the first part of this Chapter considers how proportionality applies to the right of self-defence, providing an answer to the operative question: 'proportionate to what?' The examination will

\footnotetext{
12 Greenwood (1989) 274.

${ }^{13}$ Greenwood, ibid, 278, argues that proportionality is concerned with the preservation of international order and the minimization of the use of force. See also Blank (2017) 14.

${ }^{14}$ E.g. Wedgwood (1992) 59-61, suggesting that proportionality is a strategic doctrine governing not only how a state employs force, but also whether it may do so.

${ }^{15}$ See e.g. Gardam (2004) 35-6.

${ }^{16}$ Nicaragua, paras 194, 237.

17 Ibid, para 237.
} 
continue to how proportionality operates in practice and what factors indicate whether or not states acting in purported self-defence have complied with the requirement.

As will be seen, the devil is in the detail. Assessing proportionality is even more context dependant than necessity. This is due to the nature and number of the variables inherent in a conceptual understanding of proportionality and that relate to its application to specific incidents. Establishing a 'magical template' that is applicable to all defensive action is not possible. ${ }^{18}$ Yet, just because something cannot be defined with absolute precision does not mean that 'anything goes'. States do employ proportionality as a marker of legality, and its use should be more coherent in the future, once proportionality is more clearly understood. As with necessity, much more can be said about this requirement than is currently available in the literature and jurisprudence.

\subsection{Proportionate to what?}

Proportionality is often understood as balancing two principal variables, although the reality is more complex. ${ }^{19}$ The first variable relates to the defending state's response to an armed attack. This might be described as the defensive 'action' or 'act', ${ }^{20}$ the defensive 'force', ${ }^{21}$ or the defensive 'operation'. ${ }^{22}$ The ICJ has likewise referred to purported defensive 'measures', 'activities', 'actions' and 'operations'. ${ }^{23}$ Such references prima facie pertain to the defending state's physical response, i.e. what the defending state is doing in pursuit of its defensive right. More accurately, however, it is better to view this variable as also including the effect of such defensive response. ${ }^{24}$

\footnotetext{
18 Ruys (2010) 110; Gardam (2004) 21-2.

19 Section 3.2 sets out how this balancing act, rather than being a purely binary exercise, accounts for a number of additional factors that go to whether a defensive act is excessive.

20 E.g. Lubell (2010) 64.

21 E.g. Green (2006) 45; Trapp (2007) 146.

22 E.g. Steenberghe (2012) 115.

${ }^{23}$ E.g. Nicaragua, paras 176, 237; Oil Platforms, paras 43, 51, 77; Armed Activities, paras 112, 118, 120.

24 Proportionality constrains the 'scale and effects of defensive action.' Ruys (2010) 110; Henderson (2018) 234. These are in fact two distinct variables. Whilst the scale of the force
} 
That the defensive action, and its consequences, together form the first variable is clear from state practice. As explored below, states tend to focus on (dis)proportionality in terms of the consequences of self-defence, most notably collateral civilian harm. The ICJ also considers the consequential harm, rather than just the defensive acts themselves. In Nuclear Weapons, the Court noted the potential environmental damage caused by the use of nuclear weapons when considering necessity and proportionality. ${ }^{25}$ In Oil Platforms, it concluded that the American response to the mining of a single military vessel, the USS Samuel B. Roberts, was disproportionate. This was framed in terms of the overall effect of the American response on Iran's military and civilian infrastructure and apparatus. ${ }^{26}$ Therefore, whilst the first variable comprises the defensive acts and their outcomes, identifying the second variable is more complicated. The standard against which defensive force and its effects are to be measured (i.e. answering the question: 'proportionate to what?'), is the focus of the debate.

\subsubsection{Quantitative or teleological proportionality?}

There are two principal analytical approaches that are proposed by academics to identify the second variable. They can also be discerned in the ICJ's reasoning and state practice. This Section begins by reviewing these two alternatives and the related scholarship and ICJ jurisprudence. A review of specific incidents of self-defence reveals a mixed approach in the practice of states.

may well be related to its effects, this will not always be so. For example, an intense bombardment of one isolated target may result in its destruction but have little other consequential effects. Likewise, a targeted use of limited force may result in much greater harm depending on the nature of the target (e.g. targeting an arms depot, resulting in a larger blast radius, or if a large number of civilians were in or nearby the target).

${ }^{25}$ Nuclear Weapons, paras 30-1. See further Section 3.2.7. The effects of nuclear weapons more generally were the focus of great attention in the separate and dissenting opinions. See especially the dissent of Judge Weeramantry, paras 102-72.

${ }^{26}$ Oil Platforms, para 77. See Section 3.1.1(f). 


\section{a) Alternative models and academic opinion}

The first option is a quantitative understanding of proportionality that focuses on the relationship between the armed attack and the defensive response. A purely quantitative approach requires an equivalence or parity of scale and/or means between attack and defence, i.e. the response must be proportionate to the act that provoked it. ${ }^{27}$ This 'tit for tat' or 'eye for an eye' conception of proportionality might better be described as 'armed attack proportionality', given that this is the variable against which the defensive force is being measured. However, it is generally referred to as 'quantitative proportionality', as it also seeks to balance the amount of harm suffered, or anticipated, by each side to the conflict. It dictates that the armed attack and the defence be commensurate in terms of relative injury, i.e. casualties and damaged incurred. ${ }^{28}$

The quantitative model therefore balances offensive kinetic force (and its outcomes) against defensive kinetic force (and its outcomes). ${ }^{29} \mathrm{~A}$ distinction should, however, be made between the 'quantitative model' described here and 'material factors' that form part of establishing a quantitative balance. Material factors typically include harm to civilians and civilian objects, as well as other material damage arising from uses of force. The subsequent analysis reveals that material factors are often referenced by states when considering proportionality. However, it does not necessarily follow that the quantitative model as a whole is being relied upon as the determinant of legality in such cases. This distinction between 'material factors' and the 'quantitative model' is explored further in the following Sections.

\footnotetext{
${ }^{27}$ Kretzmer (2013) 238. See also Dinstein (211) 262, who asserts that, in the case of 'on-thespot reactions' and 'defensive armed reprisals,' proportionality points at a symmetry or approximation of scale and effects between the armed attack and defensive response. See Section 3.4, however, regarding his approach to 'defensive wars'.

${ }^{28}$ Tams in Van den Herik and Schrijver (2013) 389, argues that proportionality is 'a prohibition against measures that are excessive in relation to the injury expected from the attack.'

${ }^{29}$ This assumes that the force involved is physical. Self-defence against cyber attacks is beyond the scope of the present enquiry.
} 
The second option is a teleological interpretation of proportionality. This model adopts a functional approach that is tied to the defensive needs of the defending state. ${ }^{30}$ It may also be described as the 'means-end' test, measuring as it does the defensive force (the means) against the legitimate ends of using that force (being the purposes of self-defence). ${ }^{31}$ Ago, in an often-quoted passage, explains teleological proportionality as follows:

The requirement of the proportionality of the action taken in self-defence (...) concerns the relationship between that action and its purpose, namely - and this can never be repeated too often - that of halting and repelling the attack or even, in so far as preventive self-defence is recognized, of preventing it from occurring. It would be mistaken, however, to think that there must be proportionality between the conduct constituting the armed attack and the opposing conduct. The action needed to halt and repulse the attack may well have to assume dimensions disproportionate to those of the attack suffered. What matters in this respect is the result to be achieved by the "defensive" action, and not the forms, substance and strength of the action itself. ${ }^{32}$

The majority of academic opinion favours this teleological model, requiring as it does a balance between the defensive responsive and a defensive purpose or necessity, i.e. halting, repelling or preventing an armed attack. ${ }^{33}$ This model

\footnotetext{
30 Ruys (2010) 112.

${ }^{31}$ Kretzmer (2013) 239.

32 Ago (1980) para 121. See also Lauterpacht (1968) 64.

33 Waldock (1951) 464; Brownlie (1963) 434; Higgins (1994) 231-2 (subject to the caveat noted above); Alexandrov (1996) 167; Akande (1998) 191; Taft (2004) 305; Gardam (2004) 142, 156-62; Cassese, La Charte des Nations Unies (2005) 1333; The Chatham House Principles, 969; Zimmermann (2007) 117, 123; Corten (2010) 470, 488-91; Ruys (2010) 945; Lubell (2010) 65-6; Greenwood (2011) para 27; Van Steenberghe (2012), 113, 115; Okimoto (2012) 64; Schmitt (2013) 62; Nolte (2013) 284; Tams in Van den Herik and Schrijver (2013) 388-9; Cannizzaro in Clapham and Gaeta (2014) 345-6; Green (2015) JUFIL, 101; Gill in Weller (2015) 744; Gray (2018) 159. Not all scholars cited here accept a right of anticipatory self-defence. Whilst 'halting' and 'repelling' are generally accepted as legitimate goals of self-defence, these commentators do not necessarily subscribe to the notion that a future armed attack may be 'prevented'. However, all the scholars referred to adopt a teleological understanding of proportionality, i.e. the notion that self-defence is limited by what is proportionate to the defensive objective and not by the requirement of strict equivalence of scale and/or means between the armed attack and resulting defence. See also Rodin (2002) 114-15; Taft (2004) 305; Simma et al (2012) 1426.
} 
encapsulates Webster's assertion that defensive acts must not be 'unreasonable or excessive' and must be limited by the necessity that gave rise to them. ${ }^{34}$ As such, defensive kinetic force (and its outcomes) is balanced against a defensive purpose, not only against offensive kinetic force (and its outcomes), as per the quantitative model.

Some commentators, in referencing this teleological model, paraphrase it as measuring proportionality against the 'threat' posed to the defending state. For example, Greenwood asserted in the lead up to the second Iraq war that:

'[i]f Iraq did pose such an immediate threat then, in my opinion, military action against Iraq for the purpose of dealing with that threat would be lawful. The degree of force used would have to be proportionate to the threat and no more than necessary to deal with that threat (including preventing a recurrence of the threat). ${ }^{35}$

This reference to 'threat' indicates one of the immediate advantages of the teleological model, which is its flexibility. This model avoids a purely retrospective view of proportionality that focuses solely on the completed armed attack. Rather than the only benchmark for proportionality being the harm already inflicted, a teleological appreciation of proportionality also accounts for the potential need to counter ongoing and imminent armed attacks. ${ }^{36}$ By encapsulating the total threat to the defending state comprising past, present and (potentially) future armed attacks, ${ }^{37}$ this model accepts a possible quantitative imbalance between the defensive response and the armed attack that immediately prompted such response. Without this ability, states would be limited to only responding to past events, rather than having

\footnotetext{
${ }^{34}$ See Section 1.1.

${ }^{35}$ Greenwood (2002) para 26. Whilst Greenwood's position on legality in this particular case is questionable, his statement of the law pertaining to self-defence more generally is widely supported. In terms of 'preventing a recurrence of the threat', see Section 2.4.2(b). Brownlie (1963) 261, 264, likewise discusses proportionality in relation to the 'threat' faced. Such formulation still assesses proportionality by reference to the goal that the defending state is entitled to seek to achieve. Greenwood (2011) 26-7. Greenwood states these goals as including halting and repelling an armed attack and recovering occupied territory.

${ }^{36}$ This is the position, for example, of the UK. See Section 3.1.1(b).

${ }^{37}$ See Section 2.4.2(b) regarding the 'accumulation of events' theory.
} 
the flexibility to counter threats that are both current and which may be reasonably anticipated. A teleological approach takes 'due account of the future-looking character of self-defence measures and of the characterization, in Article 51, of self-defence as an 'inherent right'. ${ }^{38}$

These two models might be presented as alternatives, although a review of state practice and opinio juris reveals a mixed picture. Depending on the context, states variously refer to the quantitative and/or teleological models of proportionality, as well material factors such as civilian harm that may speak to both.

b) State practice - consideration in abstract terms

When states reference proportionality in abstract terms, the variable against which they measure this requirement is sometimes unclear. In response to Israeli incursions into Lebanon in $1972,{ }^{39}$ for example, the representative of Argentina offered their view on the general meaning of proportionality:

the measures adopted in self-defence must be of a similar nature or reasonably in keeping with the means used in the illegal act against which action is being taken. Any use of force on a considerably larger scale or on a scale which goes beyond the events or the provocative circumstances obviously exceeds the general framework of self-defence and is considered illegal in accordance with the uses and practices of the law. 40

This comment, which refers to commensurability of the nature, means and scale of the attack and response, offers little insight into how this approach operates in practice. The reference to the 'general framework of self-defence' might also be interpreted as a reference to the overall governing principle that force must be defensive in nature. This might suggest that any finding of

\footnotetext{
${ }^{38}$ Tams in Van den Herik and Schrijver (2013) 388.

39 See Section 3.1.1(c).

40 UN Doc S/PV.1644 (1972) para 26.
} 
unlawfulness of a use of force is ultimately tied to the purpose of the right. Argentina's statement can be read, therefore, as supporting either model of proportionality, or both.

During the UNGA's deliberations over the Definition of Aggression, the proportionality of self-defence was also referenced by a number of delegates. Discussing the right in abstract terms, some states noted that an exercise of self-defence should be proportionate to the armed attack. ${ }^{41}$ Others clearly rejected the need for an exact balance between the two. ${ }^{42}$ Whilst there was no detailed discussion, a number of states did express concern regarding incorporating proportionality into the Definition of Aggression because of perceived benefits this would offer to the attacking state. In particular, on what appears to be a reference to the quantitative model, the view was that this would unduly restrict the victim state's choice of weapons and the scale of the defensive response..$^{43}$

The DRC representative initially expressed the view that 'the act of selfdefence must be proportionate to the armed attack which gave rise to it', ${ }^{44}$ again alluding to the quantitative model. He went on to say, however, that proportionality 'required the victim State to use only that amount of force necessary to halt the armed attack' and only when the defensive objective had been achieved would the right of self-defence end. ${ }^{45}$ Other representatives adopted this ultimately teleological model, albeit that there was no extended consideration of its content. ${ }^{46}$ These debates represent, therefore, an inconsistency among states in characterising a proportionate defensive response in broad conceptual terms.

\footnotetext{
${ }^{41}$ UN Doc A/AC.134/SR.52-66 (1970) 43 (Turkey); 61 (Yugoslavia); 88 (Madagascar); 91 (Cyprus).

42 E.g. UN Doc A/AC.134/SR.67-78 (1970) 83 (Iraq); 88 (Guyana).

43 Ibid, 85 (USSR); 86 (Ghana); 87 (Syria).

44 Ibid, 81.

45 UN Doc A/AC.134/SR.67-78 (1970) 81, 90.

46 Ibid, 83 (Iraq); 84, 117 (UK); 89 (Italy). See also UN Doc A/AC.134/SR.52-66 (1970) 53 (Ecuador).
} 
The DRC's comments referred to in the preceding paragraph exemplify how a state might set out both alternative models of proportionality, whilst ultimately tying proportionality to the defensive needs of the state. This is not uncommon. When states combine models, however, difficulties arise as to the proper meaning and application of proportionality. In 2004, for example, the UK Attorney General offered his thoughts on proportionality. On the topic of selfdefence in response to imminent armed attacks, Lord Goldsmith stated that 'the force used must be proportionate to the threat faced and must be limited to what is necessary to deal with the threat. ${ }^{37}$ Prima facie, therefore, the UK's position on proportionality refers to both the quantitative and teleological models.

The first thing to note is that the reference to 'threat' could be interpreted narrowly, i.e. equating it to an individual armed attack that has already occurred. Alternatively, it could be interpreted broadly, such that 'threat' encompasses the wider circumstances, potentially including past, ongoing and imminent armed attacks. ${ }^{48}$ The latter option appears to be the understanding of the current UK Attorney General. ${ }^{49}$ Whether we interpret 'threat' narrowly or broadly, however, there arises a possible dichotomy. This is where it is not possible for a defensive response to be proportionate to both the armed attacks(s) and the defensive necessity, as this formulation appears to require. As noted above, achieving a defensive aim (i.e. removing the totality of the threat posed by accumulating past, ongoing and imminent armed attacks) might necessarily require an amount of defensive force that exceeds the armed attack that prompted it.

\footnotetext{
47 Hansard, HL Deb 21 April 2004, vol 660 col 370 (emphasis added). Along similar lines, Cassese, International Law (2005) 355, suggests that the defending state 'must use an amount of force strictly necessary to repel the attack and proportional to the force used by the aggressor.' Elsewhere, however, Cassese links the lawfulness of self-defence solely to achieving the defensive necessity. Cassese, La Charte des Nations Unies (2005) 1333.

${ }^{48}$ Given that Lord Goldsmith clearly refers to 'armed attack' and 'attack' as distinct concepts throughout his speech, the broad interpretation of 'threat' is the most likely option. Ibid.

${ }^{49}$ UK Attorney General Speech 2017, 7, 19-20, clearly setting out a view of self-defence where proportionality is measured against a 'threat' that includes imminent armed attacks.
} 
Reading Lord Goldsmith's opinion as being cumulative of quantitative and teleological proportionality should be avoided. Understanding it this way effectively renders the purposive element irrelevant and makes the requirement of quantitative equivalence determinative. His reference to the defensive necessity suggests that this is not his intention. To the contrary, his (and his current successor's) reference to the need to 'deal with the threat' suggests that the purposive element is the overriding concern. This conclusion is also reflected in the UK Military Manual, ${ }^{50}$ and the UK practice referred to in the following Sections.

A more recent example of such 'dual reference' in the context of general considerations of proportionality is found in the 2017 Australian Attorney's speech regarding imminent armed attacks. In it, he initially appears to adopt the quantitative model: 'Proportionality (...) acts as a restraint to ensure that any use of force in self-defence corresponds to the gravity of the imminent attack sought to be repelled.' ${ }^{51} \mathrm{He}$ goes on to explain, however, that proportionality is designed to ensure that 'an imminent armed attack cannot be used as a pretext to engage in a wider act of aggression', before proceeding to quote Webster that defending states must do 'nothing unreasonable or excessive, since the act justified by the necessity of self-defense, must be limited by that necessity, and kept clearly within it. ${ }^{52}$ The latter two references, whilst not unequivocal, appear to relate to a defensive purpose. This interpretation is supported by references in his speech to self-defence serving a protective function. ${ }^{53}$ These examples demonstrate that states may generally adopt either, or both, models of proportionality. In order to avoid confusion, however, states should be careful in how they express their understanding of this requirement. ${ }^{54}$

\footnotetext{
50 Sections 2.8, 13.2 UK Military Manual.

51 Australian Attorney General Speech 2017.

52 Ibid.

53 Ibid.

${ }^{54}$ As noted in Section 2.4.1(b), states rarely make such general statements about their understanding of international law. The examples set out in this Section are, therefore, also valuable (if not entirely coherent) examples of state practice.
} 
c) State practice - specific incidents and the quantitative model

State practice and opinio juris in the context of specific incidents of purported self-defence also reference both models of proportionality, as well as material factors. Starting with examples of allusions to the quantitative model, China labelled Israeli action during the 1956 Suez crisis as disproportionate to the 'wrongs' suffered by Israel, without elaborating further. ${ }^{55}$ This was presumably a reference to attacks by the Egyptian Fedayeen, however, to which Israel claimed to be acting in self-defence.$^{56} \mathrm{~A}$ number of states also concluded that the British raid on the Harib Fort in Yemen in 1964 was out of proportion to the acts that provoked it. The Ivory Coast pointed to the fact that British action had resulted in the loss of twenty-five lives and caused extensive material damage, which was not in any way commensurate with the death of two camels, which had supposedly prompted the British raid. ${ }^{57}$ These references could be characterised as reliance on the quantitative model. Notably, however, this appears to be a case of marked asymmetry between attack and defence, based on both the scale and effects of the British action. Other states based their criticism on a lack of defensive purpose, however. ${ }^{58}$

In 1968, the USA decried Israel's attack on Beirut airport in response to prior attacks against Israeli civilian aircraft as entirely disproportionate in magnitude to the act that preceded it. ${ }^{59}$ The Americans understood disproportionality to be based on the degree of the destruction involved, and on the nature of the attack as compared to the purported act of self-defence. Whereas the former comprised acts of two individual terrorists, the latter was carried out by a

\footnotetext{
${ }^{55}$ UN Doc S/PV.749 (1956) para 133.

56 Ibid, para 33.

${ }^{57}$ UN Doc S/PV.1108 (1964) paras 32, 35 (Morocco); paras 48-50 (Ivory Coast). This was denied by the British, who insisted that they were responding in defence of the South Arabia Federation to a series of attacks from Yemeni territory and were also acting to prevent further attacks from the same source. UN Doc S/PV.1109 (1964) paras 2-45.

${ }^{58}$ See Section 3.1.1(d).

59 UN Doc S/PV.1460 (1968) para 73. The US employed the same language in the same year regarding Israeli anti-terrorist action in Jordan. UN Docs S/PV.1402 (1968) para 5; S/PV.1407 (1968) para 7. In the same incident, Senegal expressed the view that self-defence had to be 'by means proportionate to those used by the aggressor [in its attack]'. UN Doc S/PV.1436 (1968) para 132.
} 
sizeable military force operating under government orders. Regardless of this disparity, however, it is clear that the Americans viewed such action as being devoid of any justification whatsoever, disproportionate or not. ${ }^{60}$ The British concern meanwhile was over the 'scale and intensity' of the Israeli action, without referencing the particular nature of it. ${ }^{61}$

Prima facie, the reference by both states to such material factors as comparative harm and the nature, scale and intensity of the force deployed by Israel may indicate reliance on the quantitative model of proportionality. They highlight the disparity between attack and defence. Likewise, American concern over Israeli action against NSAs in Lebanon in 1970 appeared to rest on the scale and effects of the Israeli actions, the latter constituting the accompanying loss of life and destruction of property. ${ }^{62}$ However, it is not clear that the quantitative model was determinative in these incidents. The disparity in material factors could likewise speak to a lack of a defensive purpose. Moreover, states are not necessarily consistent over time in how they view proportionality. Even if the quantitative model informed the American response to these latter incidents, the USA has also explicitly adopted the teleological model of proportionality. This is evident in its claim of self-defence during the Vietnam War, ${ }^{63}$ in its pleadings before the ICJ ${ }^{64}$ and to justify its most recent actions against Daesh in Syria. ${ }^{65}$ The UK has also adopted the teleological model to justify its own actions. ${ }^{66}$

In 1972 Israel claimed a right of self-defence to justify its incursions into Lebanon in response to purported terrorist attacks by the PLO. ${ }^{67}$ The attacks had been on a relatively small scale, resulting in eight injuries and three deaths. In contrast, the Israeli response constituted a large-scale military

\footnotetext{
60 UN Doc S/PV.1460 (1968) para 73.

$61 \mathrm{lbid}$, para 81. The UK did not specifically refer to proportionality, although such comments clearly indicate concerns regarding this requirement.

62 UN Doc S/PV.1460 (1968) para 91.

63 Office of the Legal Adviser (1972) 837.

${ }^{64}$ See Section 3.1.1(e).

65 UN Doc S/2014/695 (2014).

${ }^{66}$ See Sections 3.1.1(b), (d) and (e).

67 UN Doc S/10550 (1972).
} 
operation comprising ground troops, tanks, aerial bombardments and artillery fire. It caused a number of deaths and substantial material harm. ${ }^{68}$ In the ensuing UNSC debates, states condemned Israel's action as disproportionate to the alleged terrorist acts that preceded them. ${ }^{69}$ Sudan labelled them unequal and disproportionate..$^{70}$ The UK confined itself to expressing concern over the unjustifiable scale of Israel's military response..$^{71}$ The means and scale of the Israeli action, and its effects were the focus of discontent, suggesting a reliance on the quantitative model. Yet, this is again an example of manifest asymmetry between attack and defence. Furthermore, reference to these material factors were clearly combined with wider concerns over peace in the Middle East.

In respect of Israel's strike on the PLO headquarters in Tunis in $1985,{ }^{72}$ Thailand's conclusion that it was disproportionate rested on the disparity in the numbers of casualties on both sides. ${ }^{73}$ However, whilst this factor was raised, it is clear that Thailand would have condemned Israel's actions in any event, based on the unjustified violation of Tunisia's sovereignty and territorial integrity. ${ }^{74}$ This was reflective of the general scepticism levied at Israel's response. The striking disparity between (high) Palestinian casualties and (low) Israeli casualties, coupled with widespread damage to civilian infrastructure and a dire humanitarian situation, is also a feature of concern regarding Israel's interventions in Gaza in 2008-9 and 2014. These material factors featured in a number of states' conclusions that such action was

\footnotetext{
68 Ibid; UN Doc S/PV.1644 (1972) paras 8-14 (Lebanon); 19-22 (Argentina).

${ }^{69}$ E.g. UN Docs S/PV.1643 (1972) para 20 (Lebanon); para 166 (Belgium); S/PV.1644 (1972) para 142 (Italy). See also UN Doc S/PV.1650 (1972) para 10 (France).

70 UN Doc S/PV.1644 (1972) para 210.

71 UN Doc S/PV.1643 (1972) para 134. The UK likewise referred to the 'scale' of Israeli action, highlighting concern over civilian casualties, when denouncing as unjustified Israeli against PLO targets in Lebanon in 1981. UN Doc S/PV.2293 (1981) paras 47, 49.

72 On this incident generally, see Pobjie et al in Ruys and Corten (2018) 395-402.

73 UN Doc S/PV.2611 (1985) para 44. They noted that whilst 15 Israelis were killed, over 60 lives were lost in Tunisia as a result of the Israeli response. The UK (ibid, para 111) also concluded that the raid was disproportionate. Again, however, this was within the context of a general rejection of the necessity of the Israeli action. Indonesia (UN Doc S/PV.2615 (1985) para 60) took a similar position. Israel, in defence of its actions, stated that it was necessary not only to count past victims in the proportionality calculus, but also potential future victims if 'this nerve-centre of terror is allowed to operate undisturbed.' Ibid, para 194.

74 UN Doc S/PV.2611 (1985) para 44.
} 
disproportionate. ${ }^{75}$ The relative scale of the military action and resulting civilian harm were also apparent in the general condemnation of Israeli's incursions into Lebanon in $1982,{ }^{76}$ and 2006. ${ }^{77}$ Material factors, in particular relative civilian harm, are clearly present in each of these examples as indicators of disproportionality. However, this does not equate to states requiring a strict adherence to the quantitative model, meaning parity between attack and defence. In respect of the 2006 invasion, for example, states tended to view material harm to Lebanon as indicative of Israel acting beyond a defensive purpose, thereby pointing to an overriding reliance on the teleological model. ${ }^{78}$

Other incidents might serve as precedents for recourse to the quantitative model of proportionality, at least in part. In support of the American strike on the IIS headquarters in Baghdad in 1993, France noted that it was 'proportionate to the action of the Iraqi secret service. ${ }^{19}$ The facts of the case do not support a conclusion of equivalence, however. In terms of methods, the foiled attempt on President Bush's life consisted of a car-bomb and other explosives, whereas the American response was the launch of twenty-three Tomahawk cruise missiles. ${ }^{80}$ On relative scale and casualties, this is much more difficult. The American President was not killed, although the potential damage that could have been caused by the bomb was considerable. ${ }^{81}$ The American response, however, resulted in the almost complete destruction of the IIS headquarters, at least three civilian deaths, civilian injury and the destruction of property. ${ }^{82}$ It is notable, therefore, that France's approval of the

\footnotetext{
${ }^{75}$ E.g. UN Docs S/PV.6060 (2009) 3 (UN Secretary General); 9 (South Africa); 9 (France); 10 (Indonesia); 13-14 (Vietnam); 15 (Burkina Faso); 16 (Costa Rica); 17 (Belgium); 18 (Egypt); S/PV.6061 (2009) 10 (Turkey); 14 (Austria); 15 (Vietnam). Regarding the 2014 Israeli action, deemed by most states to be disproportionate for the same reasons, see generally UN Doc S/PV.7222 (2014). See further Gray (2018) 230-1.

${ }^{76}$ E.g. UN Doc S/PV.2374 (1982) paras 35-6 (Ireland).

${ }^{77}$ See Sections 3.1.1(d) and 3.2.5.

${ }^{78}$ See Section 3.2.5.

${ }^{79}$ E.g., UN Doc S/PV.3245 (1993) 13.

80 Ibid, 3-9; 'U.S. Strikes Iraq for Plot to Kill Bush', Washington Post, 217 June 1993, $<$ http://www.washingtonpost.com/wp-srv/inat//longterm/iraq/timeline/062793.htm>.

81 UN Doc S/PV.3245 (1993) 5.

82 'U.S. Strikes Iraq for Plot to Kill Bush', Washington Post, 217 June 1993, $<$ http://www.washingtonpost.com/wp-srv/inat//longterm/iraq/timeline/062793.htm>. The numbers and details of civilian harm very. See e.g. Starski in Ruys and Corten (2018) 504, 522-3.
} 
American action was also closely tied to the need to combat terrorism and was set against a background of the desire by the international community to moderate Iraq's behaviour and to induce it to fulfil its international obligations. ${ }^{83}$

State practice reveals that material factors, most notably civilian harm, will influence conclusions regarding the (dis)proportionality of self-defence. States do focus on quantitative balance or imbalance, and may refer specifically to the nature, means and/or scale of the attack and response, in addition to the outcomes (i.e. relative harm). Such references are not consistent, however, and may be oblique. They also tend to factor most clearly in cases of clear and manifest asymmetry. This naturally raises questions regarding whether the forcible action has a defensive purpose. In any event, and as a general rule, states have approached the issue of equivalence flexibly and have not required an exact balance between attack and defence. ${ }^{84}$ They may have assessed proportionality by reference to a series of attacks and not just the armed attack that immediately preceded the defensive response, ${ }^{85}$ and material factors may constitute one of several justifications for determining the lawfulness of a particular act. As discussed further below, whilst states may point to equivalence, or lack thereof, between attack and defence, it is rarely the sole, or even primary, determinant of legality. Moreover, as will become clear in the next Section, pursuing a defensive aim may take precedence over considerations of quantitative equivalence, particularly in the context of combatting NSAs.

d) State practice - specific incidents and the teleological model

Reference to the teleological model of proportionality is also found in the practice and opinio juris of states. During the conflict between India and Pakistan over Kashmir in 1947-1948, Pakistan asserted that it did not do more than the 'very least' to 'hold the line' and protect its security against India. ${ }^{86}$

\footnotetext{
83 UN Doc S/PV.3245 (1993) 13-14

${ }^{84}$ Ruys (2010) 116.

85 Ibid.

86 UN Doc S/PV.464 (1950) 29.
} 
Whist not expressed in clear legal terms, its position appears to be that it was responding with a degree of force required to defend itself, and nothing beyond that. ${ }^{87}$ In the same conflict, sporadic activities of Pathan tribesmen (allegedly directed by Pakistan) resulted in a full-scale response by India's regular army, denoting quantitate imbalance, but appearing to advance a defensive purpose. ${ }^{88}$ The UNSC implicitly accepted India's action. ${ }^{89}$

The UK has also shown preference for the teleological mode. It defended its raid on the Harib Fort in Yemen in 1964, inter alia, on the basis that it was proportionate to a defensive aim. ${ }^{90}$ The UK's acts were widely condemned, however, and were deplored by the UNSC. ${ }^{91}$ During the 1982 Falkland Islands conflict, the UK Prime Minister did not refer specifically to the requirements of necessity and proportionality, but was nevertheless clear in describing the UK's response pursuant to Article 51 UN Charter as being 'measured and controlled' and 'consistent with achieving our objective'. ${ }^{92}$ The objectives, in line with demands from the UNSC, were ending the occupation and withdrawal of all Argentine troops from the Islands. ${ }^{93}$ Despite a number of controversies pertaining to the British response, most notably the sinking of the General Belgrano, ${ }^{94}$ it is noteworthy when considering the UK's 'objective' that the British military action was generally regarded as proportionate to securing its defensive goal, and was regarded as an incident of lawful self-defence. ${ }^{95}$ The UK's approach was repeated in relation to the first Gulf conflict of 1991. It defended the proportionality of coalition measures taken in collective selfdefence of Kuwait under the auspices of UNSC authority, insisting that the

\footnotetext{
${ }^{87}$ Green (2006) 458. Caution should be taken with examining this incident. Pakistan did not invoke self-defence to the UNSC until two years after the conflict began and was criticized by India for this omission. UN Doc S/PV.466 (1950) 4. Self-defence is, nevertheless, the most obvious implication of Pakistan's position. See also Green (2005) VJIL, 597-8.

${ }^{88}$ Green (2006) 458.

89 UNSC Res 47 (1948), requiring a Pakistani withdrawal from Kashmir, whilst allowing India to remain. Green (2006) 458.

90 UN Doc S/PV.1109 (1964) 30-1.

91 UNSC Res 5650 (1964).

92 Hansard, HC Deb 29 April 1982, vol 22 col 980.

93 UNSC Res 502 (1982). See further (1982) 53 BYIL, 538-40. See also Section 2.8.2 UK Military Manual noting the same under the heading of JAB proportionality.

${ }^{94}$ See Section 2.5(a).

${ }^{95}$ E.g. Levitin (1986) 638; Green (2006) 459.
} 
force used corresponded to the aim of liberating Kuwait. ${ }^{96}$ This view was generally consistent with the forceful response taken by the coalition to achieve compliance with the UNSC resolutions that preceded it. ${ }^{97}$ Proportionality was, therefore, tied to the purpose of repelling the Iraqi attack and securing the withdrawal of Iraqi forces from Kuwait.

In contrast, but likewise adopting a teleological model of proportionality, Panama condemned Russia's intervention in Georgia in 2008. This was also on the basis that it exceeded the stated defensive aim (of protecting Russian citizens and peacekeeping forces) and was, therefore, disproportionate. ${ }^{98}$ France meanwhile, appeared to focus simply on the civilian harm in Georgia in reaching its conclusion that Russian actions were 'brutal and disproportionate'. ${ }^{99}$ The IIFFMCG, however, also adopted the teleological approach in reviewing the conflict, with civilian harm acting as an indicator of whether or not a defensive purpose was exceeded. It concluded that Russia's actions were neither necessary nor proportionate. ${ }^{100}$

State action against NSAs often favours a teleological approach to proportionately. For example, Egypt linked proportionality to a defensive purpose to support its view that Israel's intervention in Lebanon in 1996 was an act of aggression. ${ }^{101}$ Iran's claim to be operating against terrorist bases in Iraq in 1999 has already been noted. In its report to the UNSC, Iran explicitly

\footnotetext{
${ }^{96}$ UN Doc S/PV.2977 (Part II) (1991) 73. The UK also stated that achieving this aim took account of the military capacity of Iraq. See further Section 3.2.1.

${ }^{97}$ Gardam (2004) 159. Whether this case should be rightly characterised as an incident of self-defence and/or UNSC authorisation to use force, however, is debatable. Its precedential value is, therefore, obscured. The USA claimed a right of individual and collective self-defence, which it reported to the UNSC. UN Doc S/21492 (1990). The UK followed suit. UN Doc S/21501 (1990). This right was affirmed by the UNSC. UNSC Res 661 (1990). The UNSC later authorised 'all necessary means' to respond to the invasion. UNSC Res 678 (1990). See e.g. Gardam (2004) 151; Ruys (2010) 101; Dinstein (2017) 323-7; de Wet in Ruys and Corten $456-68$.

98 UN Doc S/PV.5953 (2008) 15. Russia meanwhile offered a quantitative understanding of proportionality to justify its actions, coupled with a teleological elaboration of it: 'the use of force by the Russian side is strictly proportionate to the scale of the attack and pursues no other goal but to protect the Russian [peacekeepers and citizens] and to prevent future armed attacks against them.' UN Doc S/2008/545 (2008).

99 UN Doc S/PV.5961 (2008) 6.

100 IIFFMCG Report, 248-9, 272-5.

101 UN Doc S/PV.3653 (1996) 14.
} 
defended the proportionality of its actions by reference to the defensive aim of responding to past armed attacks and preventing repetition. ${ }^{102}$ It adopted the same approach in 2001. ${ }^{103}$

Israel's attacks on Hezbollah in Lebanon in 2006 also constitute an important case study of proportionality, both in terms of how states conceive of its general conceptual meaning and its granular content. This incident is discussed in detail in Section 3.2.5. For present purposes, it is notable that Russia's concern was framed in the following terms: 'the scale of [Israel's] use of force, the casualties and the destruction demonstrate that the actions stated for achieving this purpose go far beyond a counterterrorist operation.' 104 Whilst proportionality was not specifically referenced, this statement implicitly reflects Russia's teleological conception of this requirement, with material quantitative imbalance indicating a lack of defensive purpose. Qatar's attitude was the same. It remarked on the extent of civilian targets in reaching its conclusion that Israel's action had gone beyond a stated defensive objective. ${ }^{105}$ Although differing on the proportionality of its actions on the facts, Israel adopted this model to defend its actions: 'the proportionality of a response to an attack is to be measured not in regard to the specific attack suffered by a state but in regard to what is necessary to remove the overall threat. ${ }^{\prime 106}$ This reflected its prior justification when it acted to rescue its nationals in Uganda in 1976. The Israeli representative insisted that ' $t$ ] he means used were the minimum necessary to fulfil that purpose, as is laid down in international law. ${ }^{107}$

\footnotetext{
102 UN Doc S/1999/781(1999) 2.

103 UN Doc S/2001/381 (2001) 1.

104 UN Doc S/PV.5493 (Resumption 1) (2006) 2.

105 UN Doc S/PV.5493 (2006) 14.

106 'Responding to Hizbullah attacks from Lebanon: Issues of proportionality', Israel Ministry of Foreign Affairs, 25 July 2006, <http://www.mfa.gov.il/MFA/Aboutlsrael/State/Law/Pages/Responding\%20to\%20Hizbullah\% 20attacks\%20from\%20Lebanon\%20lssues\%20of\%20proportionality\%20July\%202006.aspx>.

107 UN Doc S/PV.1939 (1976) 121. Israel did not explicitly reference proportionality, but this is implicit in the statement and from the context. This claim of self-defence is dubious (see e.g. Gray (2018) 39), but the putative defending state expresses its actions to be bound by the requirement of a defensive purpose.
} 
The scale of the 2006 Israel invasion, and its effect on the civilian population, meant that the quantitative imbalance between the attack and defence (i.e. civilian harm on both sides) was particularly stark. States emphasized these material factors, although the general consensus amongst them was that the Israeli action went well beyond the defensive purpose of countering Hezbollah. It was regarded as excessive and punitive. ${ }^{108}$ In contrast, in response to Turkey's 2008 Operation Sun, the EU warned against a disproportionate military response. It called upon Turkey 'to limit its military activities to those which are absolutely necessary for achieving its main purpose - the protection of the Turkish population from terrorism.' ${ }^{109}$ The statement is ambiguous. It talks of 'protection' rather than 'self-defence' and does not explicitly engage with legality. Yet, the clear implication is that the lawfulness (or, at least, the acceptability) of the Turkish operation was conditioned on Turkey not exceeding a defensive purpose. Moreover, whilst the Turkish intervention was quantitatively greatly in excess of the PKK attacks that preceded it, the international community did not condemn it. ${ }^{110}$ Instead, an overarching teleological approach appears to lead to a conclusion that Turkey's actions were an act of proportionate self-defence. ${ }^{111}$

The most recent state practice in response to international terrorism also reveals a clear overarching teleological approach to proportionality. In this context, purported defensive action taken by states against NSAs labelled as terrorists will often be greatly in excess of the armed attack(s) that preceded it. Such a response may contain far-reaching aims over and above repulsing ongoing armed attacks or preventing imminent ones. This may stretch to removing a de facto government such as the Taliban, or the total destruction

\footnotetext{
108 See Section 3.2.5.

109 'EU Presidency Statement on the Military Action Undertaken by Turkey in Iraqi Territory', 25 February 2008 , $<$ www.eu2008.si/en/News and Documents/CFSP Statements/February/0225MZZturkey.ht $\mathrm{ml}>$.

$\frac{110}{110}$ The PKK's cross-border raids were on a small scale, albeit resulting in Turkish casualties. The eventual Turkish response, in contrast, consisted of the deployment of several thousand troops, aerial assaults and artillery support. For details, see Ruys (2008) 334-5, 362.

111 Ibid, especially 362-3; Tams in Van den Herik and Schrijver (2013) 396. See also Trapp in Ruys and Corten (2018) 700.
} 
of NSA terrorist organizations like Al-Qaeda and Daesh. Such action may constitute manifest quantitative imbalance between attack and defence. Yet, it is accepted by a large number of states. That such action might be proportionate to a defensive purpose has also received implicit support from the UNSC (e.g. in the form of UNSC Resolution 2249). These conclusions, and the applicable state practice are covered in detail in Chapter 4 .

\section{e) State practice - pleadings before the ICJ}

States have referred to both models of proportionality in their pleadings before the ICJ, whilst expressing a preference for the teleological model. In Nuclear Weapons, France explicitly relied on Ago's teleological characterisation set out in Section 3.1.1(a), stating that necessity and proportionality required that measures of response to an attack be adjusted to the defensive aim. ${ }^{112}$ In line with the practice referred to in the previous Sections, the UK's position in this case was that a proportionate response related to the 'threat posed to the victim State', referring to the need for the victim to be able to 'defend himself and reverse the aggression'. It insisted that '[a] decision to use nuclear weapons would only be taken in extreme cases and on the basis of the ultimate duty of a State to defend its people and their homeland. '113 Proportionality was to be judged, therefore, by balancing it against a defensive purpose. New Zealand, implicitly, took the same approach. It insisted that defensive acts be proportionate to the 'danger' that they are designed to meet. ${ }^{114}$ San Marino, meanwhile, argued that self-defence must be proportionate to the 'provocation' or the 'offence', ${ }^{115}$ which might be understood as the preceding armed attack. Mexico also asserted an apparently quantitative understanding to ensure that defensive acts are not 'excessive'. ${ }^{116}$ However, it drew on the ILC's work on

\footnotetext{
112 Nuclear Weapons, Oral Proceedings, Verbatim Record, CR 95/23, 66.

${ }_{113}$ Nuclear Weapons, Oral Proceedings, Verbatim Record, CR 95/34, 34.

${ }^{114}$ Nuclear Weapons, New Zealand Note Verbale, 55. Such 'danger' appears to consist of both actual and imminent armed attacks, and a right of self-defence to prevent the latter is explicitly asserted. Ibid, para 56. Ipso facto, a response to the cumulative 'danger' might include a quantitatively greater amount of force than the immediately preceding armed attack. This suggests a teleological approach.

115 Nuclear Weapons, Oral Proceedings, Verbatim Record, CR 95/31, 20-1.

116 'The right of self-defense is (...) considered legal when proportional to the armed attack that gave rise to such defense.' Nuclear Weapons, Mexican Note Verbale, paras 57-8.
} 
state responsibility to justify this position, rather than the JAB, which obscures its analysis. ${ }^{117}$ India referenced both models of proportionality in the alternative. ${ }^{118}$

In Oil Platforms, Iran also implicitly relied on Ago, appearing to accept a teleological model of proportionality that related to the needs of protection rather than the scale of the attack'. ${ }^{119}$ This understanding was made more explicit when it drew a distinction between lawful self-defence and unlawful reprisals. The difference, it was stated, was a disproportionate use of force, being excessive in relation to a protective need. ${ }^{120}$ Intriguingly, however, Iran later relied on the quantitative standard in its Reply:

It is an uncontroversial requirement of self-defence that counter-force must not be excessive in relation to the first use of force. This means that the damage done by the counter-force must be commensurate with or generally comparable to that caused by the first use of force. ${ }^{121}$

It is not clear from the pleadings why it switched models. It might have been to highlight the 'gross lack of balance' between the damage caused by the alleged attacks on the USA and the harm that the USA inflicted in response. ${ }^{122}$ The scale of the imbalance was reflected in the Court's observations on proportionality. ${ }^{123}$ It perhaps refers, therefore, to a belief that a manifest lack of symmetry between attack and defence is indicative of teleological disproportionality. The USA certainly understood Iran's position on

\footnotetext{
117 Ibid, para 58. The ICJ has also adopted this approach. See Section 3.1.1(f).

118 [A]ny use of force in self-defence has to be proportional to the means and ends involved or to the original wrongful use of force.' Nuclear Weapons, Letter from the Ambassador of India, together with Written Statement of the Government of India, 20 June 1995, 3.

119 Oil Platforms, Memorial submitted by the Islamic Republic of Iran, 8 June 1993, paras 4.213.

120 Ibid, para 4.34.

121 Oil Platforms, Reply and Defence to Counter-Claim submitted by the Islamic Republic of Iran, 10 March 1999, para 7.62.

122 Ibid, para 7.63.

${ }^{123}$ See Section 3.1.1(f).
} 
proportionality to be teleological, and explicitly agreed with this approach by, inter alia, also citing Ago's formulation. ${ }^{124}$

In Palestinian Wall, whilst many states were as dismissive of Israel's claim of self-defence as the Court, some did engage with necessity and proportionality. Palestine, for example, in asserting that defensive force must be 'proportional to the actual or imminent harm', ${ }^{125}$ appeared to adopt a mixed model, going beyond equivalence of attack and defence to encompassing the prospective need to avoid future harm. Indonesia, Malaysia, South Africa and Cuba, meanwhile, all clearly presented an understanding of proportionality linked to a defensive purpose. ${ }^{126}$ Lastly, in Armed Activities, the DRC was another state to expressly rely on Ago's teleological model. ${ }^{127}$ Uganda disagreed with the DRC's conclusions on the facts, although it likewise adopted this approach to proportionality, insisting that its actions were 'directly related to [its] defensive objectives'. ${ }^{128}$

\section{f) ICJ jurisprudence}

The quantitative model of proportionality prima facie dominates the reasoning of the ICJ. However, it goes too far to represent this as the Court's definitive approach to this issue. A firm and coherent line of reasoning is not reflected in the jurisprudence. In Nicaragua, the Court stated that 'self-defence would warrant only measures which are proportional to the armed attack and

\footnotetext{
124 Oil Platforms, Counter-Memorial and Counter-Claim submitted by the United States of America, 23 June 1997, para 4.32; Oil Platforms, Rejoinder submitted by the United States of America, 23 March 2001, paras 5.48-5.51. The USA reported to the UNSC that its defensive response was 'necessary and proportionate to the threat posed by (...) hostile Iranian actions' (emphasis added). UN Doc S/19791 (1988).

125 Palestinian Wall, Written Statement Submitted by Palestine, 29 January 2004, paras 530, 533.

${ }^{126}$ Palestinian Wall, Written Statement submitted by the Government of the Republic of Indonesia, 30 January 2004, para 5; Palestinian Wall, Written Statement of Malaysia, 30 January 2004, para 151; Palestinian Wall, Written Statement Submitted by the Government of the Republic of South Africa, 30 January 2004, paras 36, 38, 59; Palestinian Wall, Written Statement of the Republic of Cuba, 30 January 2004, 6.

${ }^{127}$ Armed Activities, Memorial of the Democratic Republic of the Congo, July 2000, paras 5.26-5.31; Armed Activities, Reply of the Democratic Republic of the Congo, 29 May 2002, paras 3.159-3.160.

${ }^{128}$ Armed Activities, Rejoinder submitted by the Republic of Uganda, 6 December 2002, paras 289-90.
} 
necessary to respond to it'. ${ }^{129}$ The majorities adopted this approach in Oil Platforms and Armed Activities, although they did not go into further detail in either case. ${ }^{130} \mathrm{~A}$ further examination of Nicaragua demonstrates that the Court's understanding of proportionality is not so straightforwardly quantitative. Whilst the issue of proportionality was moot in this case, ${ }^{131}$ the Court opined that:

Whatever uncertainty may exist as to the exact scale of the aid received by the Salvadorian armed opposition from Nicaragua, it is clear that [the United States' purported defensive conduct] could not have been proportionate to that aid. ${ }^{132}$

The balance the Court is striking in this paragraph is not between the armed attack and the purported defensive force, including their respective outcomes. Instead, it is between wrongful conduct (being action not sufficient to reach the scale of gravity required by the Court for an armed attack) and purported defensive force. There is, therefore, a disconnect between what the Court says it is doing and what it is actually doing.

Balancing wrongful conduct against measures adopted by a state in response to such conduct, and requiring a degree of equivalence, points more clearly to the operation of countermeasures than to claims of self-defence. It is generally accepted that countermeasure must be proportionate to the act that provoked them, ${ }^{133}$ an approach clearly followed by the ICJ in Gabčíkovo-Nagymaros. ${ }^{134}$ Whilst the Court stipulates in Nicaragua that it is balancing attack and defence, therefore, this is not so. By balancing instead wrongful conduct against

\footnotetext{
129 Nicaragua, para 176 (emphasis added).

130 Oil Platforms, para 77; Armed Activities, para 147.

131 The Court had decided that the provision of any aid by Nicaragua to the insurgents in $\mathrm{El}$ Salvador could not constitute an armed attack, thereby justifying an invocation of collective self-defence. Nicaragua, para 230.

132 Ibid, para 237 (emphasis added). For the Court's summary of the American's putative defensive conduct, see paras 80,81 and 86.

133 See Art 51 ARSIWA and related Commentary.

134 Gabčíkovo-Nagymaros, para 85.
} 
defensive force, it adopts an approach to proportionality that conflates selfdefence with countermeasures.

To add to this confusion, it is possible to interpret the Court's focus on this issue as pertaining to the provision of the aid, rather than the aid in and of itself. On this basis, the majority may be understood as referring not to equivalence between the aid given and the American response, but rather whether the action taken by the USA was commensurate to the goal of stopping that aid. ${ }^{135}$ If so, this is a teleological appreciation of proportionality, not a quantitative one. It suggests that the Court is measuring the application of purported defensive force against a particular purpose

It is notable that Judge Higgins, in her separate opinion in Nuclear Weapons, offered the following interpretation of the majority's opinion in Nicaragua:

the Court already made clear that the concept of proportionality in selfdefence limits a response to what is needed to reply to an attack. This is consistent with the approach of Professor Ago (...) that the concept of proportionality referred to was that which was proportionate to repelling the attack, and not a requirement of symmetry between the mode of the initial attack and the mode of response. ${ }^{136}$

In endorsing Ago's position, ${ }^{137}$ Judge Higgins rejects reliance on a purely quantitative model of proportionality. In so doing, she espouses a reading of the Nicaragua judgment that is unsupportive of the notion that proportionality requires equivalence between attack and defence. This reading of the majority opinion follows Judge Schwebel's approach in his dissent in Nicaragua, where he also quoted Ago. ${ }^{138}$ The ICJ's approach in Nicaragua is not, therefore, as clear-cut as it may initially seem. In addition to the confusion as to which variables the Court is balancing (in contrast to those it says it is balancing),

\footnotetext{
135 Gardam (2004) 158; Green (2009) 92.

136 Nuclear Weapons, diss op Higgins, para 5.

137 See Section 3.1.1(a).

138 Nicaragua, diss op Schwebel, para 212.
} 
there is scope to interpret its view of proportionality as one that is not reflective of a purely quantitative model. The jurisprudence also potentially takes account of the need to pursue a defensive purpose.

Judge Higgins' reading of Nicaragua is also implicit in the majority's opinion in Nuclear Weapons. Following an expansive review of international law, including consideration of necessity and proportionality, the Court could not reach a 'definitive conclusion as to the legality or illegality of the use of nuclear weapons by a State in an extreme circumstance of self-defence, in which its very survival would be at stake.' ${ }^{139}$ The Court's view, therefore, that the 'proportionality principle may thus not in itself exclude the use of nuclear weapons in self-defence in all circumstances' 140 is expressed in relation to the defensive need of the state, i.e. countering an existential threat. That survival is the overarching purpose of self-defence was explicitly recognized by the Court as a 'fundamental right of every State', ${ }^{141}$ thereby tying the right more generally to its purpose. It was this purpose that appeared to be ultimately decisive in respect of the question put to the Court. Judge Weeramantry adopted the same approach in his dissent. He likewise quoted Ago's teleological appreciation of proportionality, by implication endorsing it. ${ }^{142}$ In terms of the ICJ's more recent jurisprudence, Judge Kooijmans also chose to measure proportionality against a defensive purpose in his separate opinion in Armed Activities. ${ }^{143}$

Oil Platforms exemplifies the uncertainties regarding the Court's account of proportionality. Putting aside once again the general propriety of the Court's

\footnotetext{
${ }^{139}$ Nuclear Weapons, paras 41-4, 97, 105(E). The latter paragraph, being the operative part of the dispositif, was passed seven votes to seven, with the President's casting vote. This fact, and the number of separate and dissenting opinions, demonstrate the deep division within the Court on this highly controversial issue.

140 Ibid, para 42.

$141 \mathrm{lbid}$, para 96.

142 Ibid, diss op Weeramantry, paras 392-3.

143 '[Uganda's] actions moreover were grossly disproportionate to the professed aim of securing Uganda's border from armed attacks by anti-Ugandan rebel movements.' Armed Activities, sep op Kooijmans, para 34.
} 
observations on this issue ${ }^{144}$ its application of the requirement leaves much to be desired. The majority distinguished between the American response to the missile attack on the Sea Isle City, ${ }^{145}$ and its response to the mining of the USS Samuel B. Roberts. ${ }^{146}$ In respect of the former, the Court concluded that, had it found the American attack to be necessary, it could potentially have been proportionate. ${ }^{147}$ In contrast, the response to the latter incident could not be proportionate. ${ }^{148}$ The result is that the damage or destruction of oil platforms in response to a missile attack on a single merchant vessel may have been proportionate, whilst the damage and destruction of oil platforms in response to the mining of a single military vessel was disproportionate. The Court offered no reasons for this distinction.

Given that the USA's actions in each case were essentially of the same character, and both were responses to an attack on a single vessel, it is difficult to see why the Court viewed only one as potentially proportionate. ${ }^{149}$ Material factors alone (i.e. focusing solely on relative harm) appear not to be the reason. The Court accepted that the missile attack on the Sea Isle City caused damage to the ship and injury to six crewmembers. ${ }^{150}$ The mining of the USS Samuel B. Roberts resulted in the injury to ten American sailors, one seriously, and the ship was severely damaged. ${ }^{151}$ Prima facie, therefore, the harm to the

\footnotetext{
${ }^{144}$ As noted, in addition to finding an absence of an armed attack, the Court considered both responses by the USA to be unnecessary. Oil Platforms, paras $61,64,72,76$. Proportionality is, therefore, irrelevant.

${ }^{145}$ The USA attacked the Reshadat offshore oil production installation. One platform was almost completely destroyed and another severely damaged. Ibid, para 47.

${ }^{146}$ The USA attacked the Nasr and Salman oil complexes. The former was nearly destroyed and the latter severely damaged. Ibid, paras 65-6. These attacks were part of the wider American response, codenamed Operation Praying Mantis, which was not at issue before the Court. This operation involved, inter alia, the destruction of two Iranian frigates and a number of other naval vessels and aircraft, in addition to the destruction of the two oil complexes that were the subject of the dispute. Ibid, paras 68,77 .

147 Ibid, para 77.

$148 \mathrm{Ibid}$. Whilst the Court was clearly concerned with the overall reaction of the USA, this conclusion regarding disproportionality was expressed to be so regardless of whether the attacks on the Salman and Nasr platforms were considered in isolation, or as part of Operation Praying Mantis.

149 Green (2009) 87.

150 Oil Platforms, para 52. For further details of the alleged damage caused, see Oil Platforms, Counter-Memorial and Counter-Claim submitted by the United States of America, 23 June 1997, para 1.65 .

151 UN Doc S/19791(1988). These facts appear to be accepted by the Court. Oil Platforms, para 67 . The Court, at para 77, later characterised the damage as severe. For further details
} 
military vessel seems to be greater than that of the civilian vessel. Despite this disparity, the Court downplayed the damage to the USS Samuel B. Roberts. In commentating on the disproportionality of the USA's actions against the Iranian oil platforms, the Court places importance on the fact that the USS Samuel B. Roberts was 'a single United States warship, which was severely damaged but not sunk, and without loss of life'. ${ }^{152}$ This appears to be a comment on the marked asymmetry between attack and defence and the fact that the American response had a punitive feel to it. This points to an overarching teleological approach to proportionality. ${ }^{153}$

The difference in treatment by the Court of the two incidents might relate to the means of attack, i.e. by a missile or mine. ${ }^{154}$ This would make the governing factor the nature of the weapon used in the armed attack that, as explored in Section 3.2.1, should not of itself be viewed as determinative of proportionality. If the Court's reasoning pertaining to weapons is that mines are inherently indiscriminate, meaning that USS Samuel B. Roberts could not have been the intended target, ${ }^{155}$ then it is difficult to see how this pertains to proportionality. Logically, this pertains to general and specific necessity, i.e. did the USA need to respond at all if it was not the intended victim and, if so, to where should that response be directed? Alternatively, the Court might have made the distinction it did based on the nature of the object of the attack. In this case, an attack on a merchant vessel, being a civilian object, might be deemed by the Court to be qualitatively different to an attack on a military vessel. ${ }^{156} Y$ Yet, it was the attack on the USS Samuel B. Roberts, and the not the Sea Isle City, that was treated by the Court as being the most grave, with the potential of

of the alleged damage caused, see Oil Platforms, Counter-Memorial and Counter-Claim submitted by the United States of America, 23 June 1997, para 1.105.

152 Oil Platforms, para 77.

153 Simple asymmetry on its own would suggest a conclusion on proportionality based solely on the quantitative model. It is the factor of marked asymmetry in this incident that emphasizes the purpose element.

154 Laursen (2004) 152-3, for example, appears to assume that the means of attack plays a role in distinguishing the two approaches.

155 This is perhaps discernable in the Court's determination that the USA had not been the victim of an armed attack by Iran. Oil Platforms, para 61.

156 See Green (2009) 87-8. 
constituting an armed attack. ${ }^{157}$ Whether the distinction regarding proportionality is justifiable, therefore, is arguable. The Court may be criticized for not setting out the basis on which it makes it. ${ }^{158}$

Reaching firm inferences from the jurisprudence is, therefore, problematic. The ICJ's reasoning lacks clarity and consistency as to whether it regards proportionality as a quantitative and/or teleological exercise. The relationship between the armed attack and the defensive response certainly forms part of the limited commentary in the cases that have come before the Court. To what extent asymmetry between material factors will be determinative in future cases, and what other elements might be relevant to an assessment of proportionality, is uncertain.

It is also worth noting that the Court has so far adopted an analysis that is purely retrospective, focusing on the harm already inflicted. In contrast, the state practice discussed throughout this thesis is generally not confined to a purely retrospective view. Instead, states tend to adopt instead a prospective approach that accounts for the overall threat it is facing. The ICJ's approach reflects, therefore, the specific facts of the cases put before it. The result is that there is no evident judicial framework or abstract realisation of proportionality that might be readily applied to other cases with different facts. Perhaps all that may be said regarding the Court's general approach to proportionality thus far is that it is inclined to recognize the possibility that a defensive response is disproportionate if its intensity is in excess of the gravity of the armed attack. ${ }^{159}$

\footnotetext{
${ }^{157}$ The attack on the Sea Isle City, even taken together with other incidents cited by the USA, did not constitute an armed attack. Oil Platforms, para 64. In contrast, with regards to the USS Samuel B. Roberts, the Court accepted that mining a single military vessel may be sufficient to constitute an armed attack. Ibid, 72 .

158 Green (2009) 88.

159 Kress in Weller (2015) 590.
} 


\subsubsection{A mixed model of proportionality}

The foregoing analysis shows that understanding proportionality is not simply a matter of adopting one model to the complete exclusion of the other. The quantitative and teleological models both appear, in a somewhat inconsistent narrative, in state practice, ICJ jurisprudence and scholarship. This has led some commentators to conclude that there is a dual aspect to proportionality. ${ }^{160}$ Whilst there is debate regarding which model dominates, some also conclude that state practice suggests that the primary determinant of legality is the defensive purpose to be achieved. ${ }^{161}$ This latter conclusion certainly reflects the dominant feature of state practice, but the final picture is more nuanced. As the next Section shows, proportionality operates in a way that goes beyond consideration of just the quantitative and teleological models. There is more than a dual aspect to its operation.

It is clear, however, that states do not commonly rely on a purely quantitative model. They do not require precise equivalence between an armed attack and self-defence in terms of the nature, scale or means of the action taken, or their respective outcomes. ${ }^{162}$ Material factors such as civilian harm are typically referenced, but this does not equate to the adoption of the quantitative model to the exclusion of other considerations, such as achieving a defensive purpose. This is entirely logical. An approach to proportionality that measures it exclusively on the basis of quantitative equivalence faces significant limitations.

The deficiencies are largely practical and relate to what degree of equivalence is required and how it is to be evaluated. One might argue that, in cases of minor, one-off skirmishes, the quantitative model is simple and intuitively

160 E.g. Green (2009) 95; Cannizzaro (2006) 784; Ruys (2010) 116; Gill in Weller (2015) 744. See also Arts 4-5 San Remo Manual on International Law Applicable to Armed Conflicts at Sea, 12 June 1994, <https://ihl-databases.icrc.org/ihl/INTRO/560?OpenDocument> ('San Remo Manual').

161 E.g. Green (2009) 95; Van Steenberghe (2010) 205-7. See also Cannizzaro (2006) 784; Gill in Weller (2015) 744. Cf Ruys (2010) 117.

162 See further Section 3.2.1. Even the state practice referred to in Section 3.1.1(c) does not point to such equivalence. 
logical. Higgins notes, for example, that in respect of such incidents it is easy to see that the response must be proportionate to the harm inflicted. ${ }^{1163}$ On this basis, deploying a nuclear weapon in response to a raid across a border would be disproportionate. ${ }^{164}$ That much seems obvious. Yet, absent extreme asymmetry, it is not clear how quantitative equivalence should be measured, particularly in terms of effects. Whether it comes down to tallying up harm on either side in a mathematical fashion or involves another more complex quantification of injury is uncertain. How is one to place a value on dissimilar entities that have been damaged or destroyed on either side, and at what point does approximate equivalence turn into disproportionality? It seems impossible to draw a line that is conceptually meaningful.

Employing only a quantitative model to establish if and when force becomes unacceptable points to arbitrariness. It also potentially deprives the state of the means to pursue to conclusion the goal of its inherent right. ${ }^{165}$ In fact, limiting a defensive response to quantitative equivalence might give rise to further armed attacks. This is because the danger posed by the attacker is not necessarily countered in a way that ensures enduring peace. Ultimately, Higgins does accept that pursuing a legitimate defensive objective may mean that force is proportionate 'even though it is a more severe use of force than any single prior incident might have seemed to have warranted it. ${ }^{\prime} 166$ This reflects the fact that states tend to be more flexible in their appraisals, often including a retrospective and prospective appreciation that encompasses past, ongoing and (potentially) imminent armed attacks. ${ }^{167}$ This approach is particularly notable in state practice relating to self-defence against NSAs, where defending states do not limit their defence quantitatively to completed armed attack(s) and the resulting harm. Their defensive responses invariably

\footnotetext{
163 Higgins (1994) 231.

164 Ibid.

165 See further Cannizzaro in Clapham and Gaeta (2014) 345-6.

166 Higgins (1994) 232. See further Schmitt in Breau and Jachec-Neale (2006) 293, highlighting similar issues in assessing $\mathrm{IHL}$ proportionality.

${ }^{167}$ Ruys (2010) 116.
} 
encompass a prospective element and are calibrated to counter the entirety of the perceived threat. ${ }^{168}$

When defending states face a continuing threat over a period of time from the same source, greater flexibility is required for assessing the proportionality of defensive responses, potentially allowing for the deployment of force on a larger scale to the immediately preceding armed attack. This is reflected in the state practice referred to in Section 3.1.1 and Chapter 4. In such circumstances, there is potentially a greater need to tackle the source of the attacks itself. In extreme cases, the result might be the total military defeat of the attacking state, or the removal of its governing regime. ${ }^{169}$ Assessing proportionality in such cases will naturally involve a greater number of factors, even if the armed attack and its effects are the starting point. ${ }^{170}$

The state practice reviewed in Section 3.1.1 suggests, however, that there must be a rational connection between the outcomes of the attack and the defence. ${ }^{171}$ Manifest asymmetry may indicate an excessive reaction. Civilian harm appears from state practice to be the most important indicator of such excessiveness. ${ }^{172}$ Yet, whilst marked quantitative asymmetry in civilian harm might, as an independent factor, constitute disproportionality for some states, there is no significant body of practice where such quantitative imbalance alone has led to a determination of illegality. ${ }^{173}$ As noted above, such material factors, in and of themselves, cannot be tallied up in any meaningful manner so as to be determinative of proportionality. Rather, marked quantitative asymmetry will tend to act as an indicator of a lack of a defensive purpose (e.g.

\footnotetext{
168 See Chapter 4.

${ }^{169}$ Ruys (2010) 116-17. Overthrowing a government would only be considered proportionate in those extreme and very rare cases where this was the only way to achieve the defensive aim. Corten (2010) 285. See further Section 4.1.3 regarding Operation Enduring Freedom and the removal of the Taliban. This controversial prospect is also embodied, for example, in the contrasting opinions over whether the removal of Cambodia's Khmer Rouge by Vietnam in 1978 was a proportionate act of self-defence. See e.g. Franck (2001) 150; Fox in Ruys and Corten (2018) 251.

170 See Section 3.2 .

${ }^{171}$ This is to be contrasted to the connection between the armed attack and the target of the defensive response, which is an issue for specific necessity. See Sections 2.5 and 3.3.2.

172 See Sections 3.2.5 and 4.2.3.

${ }^{173}$ See Section 3.1.1(c).
} 
Israel's invasion of Lebanon in 2006). Such material factors, therefore, also speak to the teleological model of proportionality. When defensive action is greatly in excess of the armed attack and harm caused by it, absent a satisfactory justification, it risks being characterised as punitive and unlawful. Likewise, and conversely, states, courts and international bodies may point to quantitative equivalence in order to assist with establishing a defensive purpose. ${ }^{174}$ Material factors are, therefore, clearly important to appraising selfdefence, but the ultimate governing factor is typically whether or not a defensive purpose is objectively identifiable.

It is this overriding teleological approach to proportionality that is the predominant feature of the scholarship, jurisprudence and, most importantly, state practice analysed in Section 3.1.1. Adherence to this model, may even excuse manifest asymmetry between attack and defence (e.g. Operation Sun in 2008 and the ongoing Coalition action against Daesh in Syria). ${ }^{175}$ The injury incurred, or expected, from an armed attack is certainly an important part of the equation, but it is best thought of as offering a prima facie guideline to establishing a proportionate defensive response. Therefore, whilst it might be true that a response that is disproportionate in scale to the initial attack is likely to be disproportionate to the goal of abating that attack, ${ }^{176}$ this will not always be so. Proportionality should not be thought of as limiting defensive action to that which is less than necessary to remove the threat. ${ }^{177}$ We must, therefore, be careful in assuming that the 'primary determinant' of proportionality is the

\footnotetext{
174 In Oil Platforms, for example, whilst the USA favoured the teleological model, the summation of its position was that 'it is clear that the U.S. actions were proportionate responses in self-defense to the Iranian armed attacks and continuing threat of hostile action.' Oil Platforms, Rejoinder submitted by the United States of America, 23 March 2001, para 5.51. 175 That other states largely appear to accept quantitative asymmetry in these incidents, see Sections 3.1.1(d) and 4.1.3(b).

176 Green (2009) 94-5.

177 Greenwood (2011) para 28, gives an example of territory captured by a surprise attack employing a limited use of force. Where the attacker goes on to reinforce its position, the defending state will be required to employ a far greater degree of force to reverse the situation. To prohibit it from doing so would be to reward the attacker and place the victim state in an unreasonable disadvantage. Greenwood asserts that there is no indication that international law requires such an unjust conclusion. Proportionality must therefore allow the defending state to reverse the effects of the armed attack.
} 
nature and gravity of the armed attack. ${ }^{178}$ This approach risks placing undue emphasis on this particular aspect of the quantitative model at the expense of pursuing the defensive right to which proportionality speaks. Doing so may lead to hasty conclusions regarding the proportionate or disproportionate nature of a particular act.

Assessing proportionality primarily by reference to the defensive need but taking full account of relevant material factors (including relative harm), offers the best general theoretical model of proportionality. This approach accords more readily with the genesis and purpose of the right of self-defence and the need for states to respond flexibly to protect themselves in cases of emergency. States may respond legitimately on a retrospective and prospective basis and account for the wider threat comprising past, ongoing and imminent armed attacks. At the same time, this mixed model calls for a balance to be struck such that defensive military action does not result in harm that is completely out of proportion to the attack(s) that prompted it. Going one step further, however, it is clear that proportionality also accounts for wider interests that go beyond both the quantitative and teleological models of proportionality. These interests are considered in the next Section.

\subsection{Applying proportionality and identifying 'excessiveness'}

The balancing exercise described in Section 3.1 is not the end of how we should understand proportionality. States tend to justify the proportionality of their putatively defensive acts primarily by reference to a defensive purpose, and other states focus on such purpose when reviewing the legality of such acts. Yet, it is also clear that the right of self-defence is not absolute, and the review of defensive actions does not operate in a vacuum. Despite what some may regard as the 'superior right' of the defending state vis-à-vis the attacker, ${ }^{179}$ other states do not regard the right of self-defence as a licence to

\footnotetext{
${ }^{178}$ As suggested by Ruys (2010) 117 (emphasis added). On the nature of an armed attack, however, see Section 3.2.1.

${ }^{179}$ Cannizzaro (2006) 785.
} 
harm others, especially civilians. ${ }^{180}$ More generally, when other states, courts and scholars review proportionality and whether or not it is 'excessive' (to quote Webster), they consider a range of issues.

This Section reviews, therefore, factors that are regarded as either permitted, or proscribed, by proportionality. The analysis includes factors that are not relevant to proportionality by way of additional clarification of how proportionality operates in practice and, in certain cases, to confront conclusions made by certain scholars regarding what is relevant to the proportionality calculus. Where this is so, it is highlighted. These factors, inter alia, account for the needs and rights of the defending state, as well as those of the attacker. ${ }^{181}$ They ensure that the purposes of self-defence are achieved, and nothing more. In addition, they restrict the exercise of self-defence so that it does not impinge unduly on the interests of the wider international community and cause excessive harm to those not participating in the conflict. The relevance and relative importance of each factor will vary depending on the circumstances, and they may overlap and interrelate in a manner that is not so neatly delineated as set out below. The subheadings are employed, however, for ease of analysis. ${ }^{182}$

The following review reveals that the pursuit of defensive purpose, whilst operating as the overarching consideration, is not unfettered. Even if a defending state may be regarded as employing no more force than is necessary to achieve a defensive purpose, it may nevertheless be deemed disproportionate if it causes undue harm to other interests, including third-party interests. A defending state cannot prioritise its right of self-defence over the concerns of the international community and pursue such right at any cost. These other interests act as a check on the pursuit of a defensive purpose.

\footnotetext{
180 Tams and Bruckner in Ruys and Corten (2018) 686. See Section 3.2.5.

181 That the attacker has rights under the JAB is, perhaps, controversial. Yet, the following analysis shows that even if it is in breach of Art 2(4) UN Charter, it does not follow that it is subject to unchecked violence in response. In particular, excessive harm to its civilian population risks being regarded as an unlawful act of self-defence.

182 The way in which these different interests relate with each other in the context of armed attacks by NSAs is very different. This is discussed further in Section 4.2.
} 
They constitute additional limitations on the exercise of the right of selfdefence, acting to guard against excessive defensive responses. The result is an overriding teleological approach that balances defences force and its outcomes against a defensive purpose and against these other interests.

\subsubsection{Scale, nature, methods and means}

Section 3.1.1 shows that, on the whole, states do not regard proportionality as confining the amount of defensive force to that employed in the armed attack that provoked it. There is no requirement of parity, ${ }^{183}$ albeit that marked asymmetry might be indicative of disproportionality. State practice against armed attacks by NSAs referred to in Sections 3.1.1 and Chapter 4 most clearly reflects this general premise. Defending states do not match the scale of their defence to those of NSA attacks. This is a natural consequence of the teleological model acting as the primary determinant of proportionality. Proportionality operates to restrain excess and mitigate harm, but it would be illogical that the defending state's ability to protect itself is strictly limited by the capabilities of the attacker and the means and methods the latter adopts in its armed attack. The former should not be required to mirror the latter. This is particularly the case where a series of attacks are expected from the same source. In such cases, as noted, the defensive response needs to take on greater proportions to the armed attack that immediately prompted it in order to counter the threat taken as a whole. ${ }^{184}$ Unreasonable confinement of the defending state, in favour of the attacker, serves only to encourage further violence and prolong conflict. ${ }^{185}$

${ }^{183}$ E.g. O'Connell (1975) 64; Ago (1980) para 121; Gardam (2005) 13; The Chatham House Principles, 969; Schmitt (2007-2008) 153; Greenwood (2011) para 28; Gray (2018) 159-60. ${ }^{184}$ See Section 3.1.1(a).

185 The military capacity of the attacker, including the nature and make-up of its armed forces, is not irrelevant to determining what a proportionate self-defence looks like however. This fact was highlighted, for example, in the UK's justification of the calibration of its role in liberating Kuwait from Iraqi occupation in 1991. The size, nature and make-up of Saddam Hussein's 'military machine' helped to determine what force was needed to liberate Kuwait. UN Doc S/PV.2977 (Part II) (1991) 72. The capabilities of the attacker, therefore, might constitute one of the factors that go to calculating what is required to achieve a defensive purpose. This is a practical consideration for those planning military strategy. Legally, however, such capabilities should not be thought of as an overarching limitation. 
In keeping with this logic, it is further asserted that there is no requirement that the defensive force be of the same nature as the armed attack, ${ }^{186}$ and the defender is not obliged to use the same, or even similar, weapons as used in that attack. ${ }^{187}$ Ground attacks employing one type of weapon, for example, may be met with an aerial response using another, and vice versa. ${ }^{188}$ Judge Schwebel adopted this general position in his dissent in Nicaragua, ${ }^{189}$ and it has occasionally been expressly asserted by states. The Congo, for instance, asserts that 'all means of armed force a victim state had available were lawful, provided they were used only for defence.' ${ }^{190}$ The UK has been emphatic on this point:

[The UN Charter] says nothing whatever about any particular weapon or method which may be used for self-defence. Those who wrote the Charter expected victims of aggression to react as necessary to protect their territorial integrity and political independence, and they were very careful not to say how self-defence could be carried out. ${ }^{191}$

The USA, in quoting this passage in its pleadings before the ICJ in Nuclear Weapons, appears to endorse this approach, ${ }^{192}$ and state practice responding to acts of terrorism clearly reflects it. ${ }^{193}$ Asymmetric conflicts of this kind exhibit

\footnotetext{
${ }^{186}$ Schmitt (2013) 62-3. One exception to this general principle might be the first use of nuclear weapons in response to a conventional armed attack. Given the likely effects of nuclear weapons on other states and the environment and the fact that a first use of nuclear weapons risks a response in kind (thereby escalating the conflict), such first use is only likely to be proportionate in the most extreme cases, where the very survival of the state is threatened (see Nuclear Weapons, paras 96-7). See further Greenwood (1989) 280-1.

187 Ruys (2010) 123; Gray (2018) 159-60. See also IIFFMCG Report, 272. Cf Greenwood (1989) 279-81; Gardam (2004) 171-2.

${ }^{188}$ E.g. respectively, the American strike on the IIS headquarters in 1993, where cruise missiles were used to respond to an attack employing a car bomb; Operation Enduring Freedom, whereby Al-Qaeda's attacks on 9/11 using hijacked aircraft were met with aerial attacks and the eventual ground invasion of Afghanistan.

${ }^{189}$ Nicaragua, diss op Schwebel, paras 212, 237.

190 UN Doc A/AC.134/SR.67-78 (1970) 90 (Congo).

191 UN Doc A/PV.1063 (1961) para 20.

192 Nuclear Weapons, Letter from the Acting Legal Adviser to the Department of State, together with Written Statement of the Government of the United States of America, 20 June 1995,19 . The USA has also reserved the right to respond to cyber armed attacks with conventional means. Speech delivered by Deputy Secretary of Defense William J. Lynn, III, National Defense University, Washington, D.C., 14 July 2011, $<$ http://archive. defense.gov/speeches/speech.aspx?speechid=1593>.

${ }^{193}$ See Chapter 4.
} 
how the methods and means of attack employed by NSAs are not adopted by states in their defensive responses. No state fighting against Daesh would (or should) see itself bound to responding to acts of terror in kind. The methods of defence are therefore incomparable to the modes of attack.

Proportionality, and the JAB more generally, do not prohibit, nor permit, the use of any particular weapon, including nuclear weapons. ${ }^{194} \mathrm{~A}$ distinction should, therefore, be drawn between whether a weapon might be said to be inherently disproportionate from a JAB perspective, and the manner in which it is used. On the first point, it is difficult to argue that any weapon might be deemed disproportionate per se under the JAB. ${ }^{195}$ Such proposition is clearly supported by the ICJ's jurisprudence. In Nuclear Weapons, France maintained that neither necessity nor proportionality could preclude, in abstracto, the use of nuclear weapons in self-defence. ${ }^{196}$ The ICJ accepted this view, adopting the position that even nuclear weapons are not inherently disproportionate. ${ }^{197}$ If the most devastating weapon of all does not automatically breach this requirement, then it is difficult to see why any other weapon, by its nature, would do so. It cannot be the nature of the weapon, therefore, that is determinative of proportionality.

The regulation of weapons used in self-defence (or otherwise) is primarily and better dealt with by the tailored provisions of $\mathrm{IHL}$ and those conventions relating to the use of particular weapons. ${ }^{198} \mathrm{~A}$ summary of the position may be stated as follows:

It is necessary to reiterate here the undoubted right of the State that is attacked to use all the weaponry available to it for the purpose of repulsing the aggressor. Yet this principle holds only so long as such

\footnotetext{
${ }^{194}$ Nuclear Weapons, paras 39, 42, 105.

195 Gardam (2005) 19.

${ }^{196}$ Nuclear Weapons, CR 95/23, 66.

197 'The proportionality principle may thus not in itself exclude the use of nuclear weapons in self-defence in all circumstances.' Nuclear Weapons, para 42.

${ }^{198}$ Certain weapons, such as chemical and biological weapons, are absolutely prohibited by the operation of IHL and specific weapon conventions. See e.g. 'Use of Weapons' ICRC website, <https://www.icrc.org/en/war-and-law/weapons>.
} 
weapons do not violate the fundamental rules of warfare embodied in those rules. Within these constraints, and for the purpose of repulsing the enemy, the full military power of the State that is attacked can be unleashed upon the aggressor. ${ }^{199}$

JAB proportionality instead considers the resulting harm caused by those weapons (and weighs it, primarily, against a defensive purpose). As will be made clear, its remit is the overall defensive response and its outcomes. ${ }^{200}$ Self-defence, as a whole, must be scaled to effect that purpose. The key point when looking at the methods of defence, therefore, is whether a weapon's deployment was restricted to a defensive purpose. Where the use of a particular weapon, or mode of response, significantly escalates hostilities, this serves to counter such conclusion and points to a disproportionate use of force. ${ }^{201}$

Therefore, subject to adhering to the requirements of IHL and international law relating to the use of particular weapons, a state may use whatever force is required, including of scale and/or means to halt, repel or prevent an armed attack, but no more. ${ }^{202}$ In fact, depending on the circumstances, using less force than the armed attack may be sufficient to achieve such aim. ${ }^{203}$ The latter point is crucial. If it is clear in the circumstances that 'less force' (in terms of the nature or scale of the response and/or methods and means of warfare) could have been used to achieve the same result, this suggests that the force used was more than was necessary to achieve the defensive aim. ${ }^{204}$

\footnotetext{
199 Nuclear Weapons, diss op Weeramantry, para 367 (emphasis added).

${ }^{200}$ See, in particular, Section 3.3.2.

201 See O'Connell (1975) 64-5; Ruys (2010) 123; Gardam (2004) 171. Section 2.8.1 UK Military Manual also appears to take this approach. In such cases, it is not the nature of the weapon or mode or response, per se, that results in escalation. It is how the weapon is used, or the results of the mode adopted, that may take a response beyond a defensive purpose. See e.g. the analysis in Section 2.5(a) regarding the sinking of the General Belgrano.

${ }^{202}$ Green (2015) JUFIL, 101.

${ }^{203}$ Ago (1980) para 121; Gardam (2005) 12.

${ }^{204}$ In this regard, Kretzmer (2013) 277, asks whether it was 'necessary in the sense that no less drastic means were available for achieving the same ends?'.
} 


\subsubsection{Timing - a distinct element of proportionality?}

Once a defensive response has achieved the purpose of self-defence (i.e. halting, repelling or preventing an armed attack), or the UNSC has taken effective action, or the situation has otherwise been resolved peaceably, defensive force will no longer be necessary. Whilst it is not this author's position, it might be tempting to say that a use of force beyond this point in time is also disproportionate. That proportionality might impose a time limit on self-defence is suggested in the ICJ's jurisprudence. In Nicaragua, the Court noted, in commenting on proportionality, that the American reaction 'continued long after the period in which any presumed armed attack by Nicaragua could reasonably be contemplated. ${ }^{205}$ The purported defensive response endured after the point in time that the defensive necessity had fallen away. The Court also appeared to view force beyond this point as disproportionate.

Yet, the Court's position on how the timing of a defensive response relates to proportionality is ambiguous. As set out in Section 2.4.2, it considered the timing of the American response principally on the basis of necessity. Having found a lack of necessity, it is unclear why it offered further observations on proportionality or considered temporal factors to be part of this requirement. Even assuming that there had been an armed attack, the fact that the American action continued 'long after' is irrelevant if the response to it was unnecessary and, on that basis alone, unlawful. As such, the weight that should be placed on this observation on proportionality is questionable.

A number of commentators also adopt the view that temporal elements may form part of both necessity and proportionally. ${ }^{206}$ Yet, identifying a clear body of state practice to support such conclusion is difficult. Examples include Argentina's condemnation of Israel's 'punitive expedition' in Lebanon in 1972. This conclusion was reached, inter alia, on the basis that proportion had not

\footnotetext{
205 Nicaragua, para 237.

${ }^{206}$ E.g. Gardam (2004) 167; Ruys (2010) 119; Green (2015) JUFIL, 112-13; Gill in Weller (2015) 745-6.
} 
been respected in terms of the scale of the action or its duration. ${ }^{207}$ Argentina adopted a very strict understanding of proportionality in respect of Israel's action on this occasion. In addition to recognizing a temporal element in proportionality, it also tied its operation largely to the quantitative model. ${ }^{208}$ Its view on immediacy is likewise strict: 'no time must pass in deliberating or reflecting on the desirability of a reaction. This means that the reaction must immediately follow the illegal attack.' ${ }^{209}$ This displays a rigid, and overly simplistic, understanding of both requirements and might be a result of the circumstances of the particular incident. As explored throughout this thesis, states and scholars do not generally share such a narrow view of either necessity or proportionality.

In Armed Activities, the DRC likewise argued that the excessive duration of the Ugandan intervention was indicative of its disproportionate nature. ${ }^{210}$ However, the intervention consisted of Uganda's occupation of Congolese territory. As such, it is the specific factor of enduring occupation that might best explain this negative reaction. A further example, in response to Israel's action in Lebanon against Hezbollah in 1996, is Egypt's insistence that '[t]he scale, duration and objective of military activity must be proportionate to the reason for [selfdefence]. ${ }^{\text {211 }}$ No elaboration was offered, however.

We should not dismiss this state practice, although these incidents highlight how difficult it is to discern analytical clarity regarding the importance (or not) of temporal considerations from the particular context. More often than not, states refer vaguely to the duration of a defensive response, without specifically identifying whether such factor pertains to necessity, proportionality, or any other legally pertinent requirement. For example, Ruys proposes the American intervention in the Dominican Republic in 1965 as a

\footnotetext{
207 UN Doc S/PV.1644 (1972) para 29.

208 ' $[T]$ he measures adopted in self-defence must be of a similar nature or reasonably in keeping with the means used in the illegal act against which action is being taken.' UN Doc S/PV.1644 (1972) para 26.

209 UN Doc S/PV.1644 (1972) para 25.

210 Armed Activities, Reply of the Democratic Republic of the Congo, 29 May 2002, para 3.173-3.177.

211 UN Doc S/PV.3653 (1996) 14.
} 
candidate in support of the contention that proportionality encompasses a temporal element. In such case, France insisted that any operation to evacuate citizens 'should be limited in objective, duration and scale'. ${ }^{212}$ Whilst this is a classical formulation adopted by states when referring to defensive force, France does not specifically mention either necessity or proportionality when noting this as a requirement. Likewise, states may tie the duration of armed conflict explicitly to a defensive necessity. This was the case with the USA during the Vietnam War, for example. ${ }^{213}$ Commentators may, therefore, overstate the case, providing only scant state practice to support the notion that states view timing as a clear and distinct element of proportionality. ${ }^{214}$ The ICJ and states undoubtedly view the duration of self-defence as relevant to its legality, but it is not so clear if and how it operates as an independent indicator of (dis)proportionality.

This blurring of the line between the requirements of necessity and proportionality should be resisted. They should not be used interchangeably, or jointly, as an all-inclusive statement of illegality. Necessity must be applied before proportionality, and proportionality is only meaningful where defensive force is and remains necessary. Unnecessary force cannot conceptually also be disproportionate. There is no defensive purpose against which such measure might be made. It is submitted, therefore, that whilst the ICJ, certain commentators and states might refer (or be understood as referring) to proportionality in terms of the temporal duration of a particular act, in the pursuit of conceptual clarity, this is misleading. ${ }^{215}$ It is not clear from state practice that proportionality, rather than general necessity, imposes a time limit on a defensive response.

\footnotetext{
${ }^{212}$ Ruys (2010) 119-20, citing (1965) UNYB 142 (emphasis added).

213 Office of the Legal Adviser (1972) 837.

${ }^{214}$ Likewise, Gardam (2004) 167, references the American intervention in Grenada in 1983 in support of the same contention, citing to Levitin (1986). Yet, Levitin's comments on the proportionality of the action appear to pertain to the overthrow of the Grenadian government, not the duration of the American response. Ibid, 650. It is unclear, therefore, on what basis Gardam interprets this state practice.

${ }^{215}$ The need to assess proportionality throughout the duration of a defensive act is separate to this issue and is discussed in Section 3.4.
} 


\subsubsection{Geography}

It is often stated that proportionality also imposes a geographical limitation on self-defence, meaning that defensive force 'must generally be confined to the area of the threat which it is designed to meet. ${ }^{216}$ However, whether and how geography factors into the review of the proportionality of self-defence is unclear, particularly in light of recent state practice against NSAs in the context of transnational terrorism. Moreover, where a defensive response is directed might be better thought as pertaining to specific necessity, as proposed in this thesis, rather than proportionality. This is explored further below.

\section{a) ICJ jurisprudence}

In Nicaragua, the Court held that the USA's mining of Nicaraguan ports and attacks on oil installations, in response to Nicaragua's alleged support of Salvadorian rebels who were operating along El Salvador's border, was disproportionate. ${ }^{217}$ Implicit in this determination is a geographical limitation, namely that proportionality takes account of the distance between the target of defensive force and the source of the armed attack. Indeed, the Court questioned whether a strong patrol along the border of El Salvador and Honduras might have been the best way to respond to the attacks by the Salvadorian rebels. ${ }^{218}$ However, it is unclear how this distance factored in the majority's view on proportionality.

As noted, to the extent that the Court considered the necessity and proportionality of the USA's response in Nicaragua, it clearly focused on the former requirement. In fact, the mention of a border patrol as an appropriate response to rebel activity in that area can clearly be interpreted as a reference to the specific necessity of the American action. This is to say that the focus of the Court's concern was the lack of a nexus between the target of the American

\footnotetext{
${ }^{216}$ Greenwood (1989) 277. See also O'Connell (1975) 65; Schachter (1991) 153-4; Gardam (2005) 14, 163; Ruys (2010).

217 Nicaragua, para 237.

$218 \mathrm{Ibid}$, para 156.
} 
response and the source of the purported armed attack. ${ }^{219}$ This is not simply a question of geographical proximity. As such, distilling a firm view from Nicaragua on the ICJ's view of any geographical element of proportionality is not straightforward.

At first glance, Armed Activities presents a clearer jurisprudential position on this issue. In this case, the Court observed that Uganda's taking of airports and towns many hundreds of kilometres from its border would not seem proportionate to the series of transborder attacks Uganda claimed had given rise to the right to use force in self-defence. ${ }^{220}$ The geographical distance between attack and defence appears to form part of the Court's position on proportionality. Yet, putting aside the fact that the Court found that the right of self-defence had not arisen, vague comments contained in three lines of the Court's judgment do not provide a firm and reasoned position on this point.

It is not apparent that distance was the principal factor that led to the Court's conclusion. The nature of the target, i.e. towns and airports, seems equally important. As in Nicaragua, the lack of a nexus between attack and defence is readily apparent. Perhaps it was a combination of both factors that informed the Court's decision, but there is insufficient detail to tell. Furthermore, the Court rendered a view on proportionality before necessity, which is contrary to the logical application of these criteria and its other self-defence jurisprudence. ${ }^{221}$ It is unclear why it did this. Given that it held that the taking of the airports and towns was unnecessary (understood as specific necessity), its views on proportionality are rendered nugatory. ${ }^{222}$ If the targets of the defensive response were unnecessary, for whatever reason, any force used against them was unlawful. Whilst the Court appears to link geography and proportionality, therefore, its position on this relationship remains unsettled.

\footnotetext{
219 See Section 2.5 .

220 Armed Activities, para 147.

221 See Section 1.2.1.

222 Judge Kooijmans in his dissent also appears to characterise such actions as both unnecessary and disproportionate, but it is also unclear how geography factors in his conclusions. Armed Activities, sep op Kooijmans, para 34.
} 
Nicaragua and Armed Activities provide only hints as to whether and how geography relates to proportionality. Moreover, both cases can also be explained on the basis of specific necessity: the object of defensive action was not connected to the armed attacks. Perhaps the best that can be said from this jurisprudence is that geography has featured in the Court's reasoning regarding proportionality on the facts of the cases before it. The pertinent facts, in each case, were purported acts of self-defence against a state in response to, and far from, cross border armed attacks by NSAs. Future jurisprudence is required to elaborate on how important this geographical element is more generally to the requirement of proportionality.

\section{b) State practice}

State practice also indicates a possible requirement of a geographical nexus between attack and defence. When justifying self-defence, states will sometimes emphasize that a defensive action was limited geographically, often in addition to other limitations, such as scope and duration. Examples include Turkey's vindication of Operation Sun in 2008. It asserted that it was confined to the border region where the attacks were occurring. ${ }^{223}$ In a similar incident regarding cross-border raids from Jordan into Israel in 1968, Senegal expressed the view that self-defence was exercisable at the 'actual site of aggression'. ${ }^{224}$ As with the ICJ's jurisprudence, such pronouncements serve to highlight the contextual importance. In these cross-border incidents, states are keen to ensure that self-defence is exercised, and seen to be exercised, within the locality of the armed attack(s) that gave rise to the claim of self-defence. Yet, it is unclear whether these states view this fact as essential to ensure that self-defence is proportionate, or simply as relating to what is necessary to achieve a defensive purpose. ${ }^{225}$

\footnotetext{
${ }^{223}$ UN Doc A/HRC/7/G/15 (2008). See further Ruys (2010) 119, 460-1.

224 UN Doc S/PV.1436 (1968) para 132.

225 O'Connell and Greenwood note, for example, that Portugal did not react to India's seizure of Goa in 1961 by seizing Indian shipping in European waters where Portugal enjoyed naval superiority. O'Connell (1975) 65; Greenwood (1989) 277 . This example of state practice might, however, be better interpreted on the basis of specific necessity: reacting in self-defence
} 
This distinction is evident in Jordan's pleadings before the ICJ in Palestinian Wall. Jordan concluded that the wall was unnecessary for the purposes of selfdefence on the basis that, geographically, it went far beyond Israel's territory, which it was designed to protect. Its conclusion that the wall was also disproportionate, was formed on the basis, not of its geographical location, but on the 'consequences and implications' of its construction. Such effects took the wall beyond a defensive purpose and assumed characteristics of punishment, humiliation and conquest. ${ }^{226}$ Uganda likewise justified its actions, which extended well inside the DRC, on the basis of necessity (understood as specific necessity), rather than proportionality. 227

Another classic example that is often suggested as supporting the requirement of a geographical nexus within the proportionality assessment is that, during the Falklands War, the UK did not engage Argentine warships in areas far removed from the Falkland Islands and, more significantly, did not extend military operations against the Argentine mainland. ${ }^{228}$ Higgins concludes that British bombing of the Argentinian navy or air force while in Argentina or in port would have been regarded as disproportionate. ${ }^{229}$ The same conclusion would apply had Argentina attacked the British mainland. ${ }^{230}$ Such scholarly views on the Falklands incident appear prima facie to be reflected in the UK Military Manual. In accepting that a use of force must be proportionate to the overall objective of self-defence, it gives the following example: 'In the Falklands conflict $(\ldots)$ there were defined and limited goals: to re-take the occupied

\footnotetext{
against targets not connected to the armed attack is unnecessary. In a similar vein, see Office of the Legal Adviser (1972) 837, pertaining to the USA's actions during the Vietnam War. See further Ruys in Ruys and Corten (2018) 91-4, regarding whether the Goa incident should rightly be characterized as an incident of self-defence.

${ }^{226}$ Palestinian Wall, Written Statement of the Hashemite Kingdom of Jordan, 30 January 2004, para 5.275.

${ }^{227}$ Armed Activities, Rejoinder submitted by the Republic of Uganda, 6 December 2002, para 289.

${ }^{228}$ Greenwood notes that it is unclear whether the latter policy was determined by a conclusion that such extension would be disproportionate, or merely reflected political and military considerations. Nevertheless, he concludes that the decision taken by the British not to extend the conflict beyond the Islands and surrounding waters undoubtedly assisted the UK in portraying its actions as being within the boundaries of self-defence. Greenwood (1989) 277. 229 Higgins (1994) 232.

230 Ruys (2010) 119.
} 
territories, not to pursue a war of conquest against Argentina'. ${ }^{231}$ Whilst expressed in the context of proportionality, by assessing the necessity of military action against the mainland first, which is the proper order of application, it could equally be concluded that specific necessity would be absent. State practice, therefore, does not provide a clear account regarding the importance, or otherwise, of geography to considerations of proportionality.

\section{c) Principle and general application}

The above analysis reveals an inconclusive picture regarding whether geographical considerations sit firmly within the purview of proportionality, as some scholars maintain. There is a lack of clarity and consistency on this point. Even if geography is regarded as an element of proportionality, the required proximity between the armed attack and the corresponding defensive force remains unclear. State practice and the ICJ jurisprudence suggests, however, that a geographical connection will be most relevant to border disputes and localised incidents of hostility. Any geographical nexus between attack and defence must, therefore, be considered in light of the specific facts.

Schachter suggests that where a series of attacks in one area requires a defensive response on a larger scale to counter the source of an attack then it does not seem unreasonable to allow a state to retaliate beyond the immediate area of the attack. ${ }^{232}$ Greenwood, along similar lines, notes that force falling short of 'total war' will generally incur a geographical restriction, although in the cases of 'total war' the proportionality requirement would no longer confine defensive measures to a restricted geographical area. ${ }^{233}$ Zimmermann likewise maintains that proportionality might allow for the targeting of command and control centres well away from a trans-border attack. ${ }^{234}$ Again, absent a conclusive position based on state practice, such conclusions might also be

\footnotetext{
${ }^{231}$ Sections 2.8-2.8.2 UK Military Manual.

232 Schachter (1991) 153-4.

${ }^{233}$ Greenwood (1989) 278. See also Ruys (2010) 119. See Section 3.2.6, however, regarding the effect on other states.

234 Zimmermann (2007) 123.
} 
better understood as issues of specific necessity, rather than proportionality. Repeated, or large-scale attacks, may simply require targeting on a larger scale to ensure an effective defensive response.

In any event, a requirement of confining a response to a particular locale must be viewed reasonably. It is contingent on context and flexibility is required. It seems sensible to conclude that any geographical limitation would gradually lose its restraining influence in the case of repeated and/or large-scale attacks that threaten the existence of the state, or where there is reciprocal escalation of an armed conflict. ${ }^{235}$ It is also reasonable to assume that, in an era of advanced weaponry, where intercontinental ballistic missiles can cross the globe, countering the source of an armed attack may require covering great distances. A nuclear missile launched from North Korea against the USA might justify a response in kind. In such circumstances, it would be nonsensical to suggest that geography, as an element of proportionality, acts as an independent limitation on action. Specific necessity, however, would confine the defensive response to the source of the armed attacks, i.e. the launch sites and related infrastructure, rather than anywhere in North Korean territory.

In the context of self-defence against armed attacks by terrorist NSAs, state practice pertaining to combatting organizations such as Al-Qaeda and Daesh suggests that geography, as an element of proportionality or otherwise, constitutes little or no meaningful restraint on state responses. Instead, specific necessity assumes the burden. ${ }^{236}$ Confining a defensive response geographically may, therefore, be increasingly difficult as customary international law adapts to an ever-changing world. The importance of geography is being placed under ever-greater strain. ${ }^{237}$

\footnotetext{
235 Ruys (2010) 119.

${ }^{236}$ See Section 4.2.2.

${ }^{237}$ For an interesting review of a number of 'geography-defying' challenges for international law, see Bethlehem (2014).
} 


\subsubsection{Effect of the use of force on the defending and attacking states - general considerations}

The importance of the armed attack and its effects on the proportionality equation is discussed extensively in Section 3.1.1(c). Whilst strict quantitative equivalence between attack and defence (and their respective outcomes) is not required, state practice shows that defending states and other states may nevertheless refer to the armed attack when considering the proportionality of a defensive response.

\section{a) The defending state}

The scale and gravity of the actual or anticipated armed attack (including its actual or anticipated effects) on the defending state is a prima facie starting point when considering a proportionate defensive response. ${ }^{238}$ This will involve, as applicable, an evaluation of the overall damage, death and/or destruction to the defending state's military apparatus, combatants, civilians, territory, infrastructure and other property. ${ }^{239}$ Also naturally feeding into its defensive reaction is an evaluation by the defending state of whether an armed attack is a one-off, or is likely to be one of a series of attacks from the same source. The history and relations between the defending state and the attacker leading up to the attack, as well as the likelihood of success of the attacks themselves, are all necessarily relevant to this threat assessment. Serious threats need to be distinguished from those that have no chance of realization and will depend on the relative military strengths of the parties involved. ${ }^{240}$ These latter considerations are teleological, going beyond a purely quantitative assessment of harm, to what is required to achieve a defensive purpose. These factors are not exhaustive but are indicative of how the peril faced by the defending state should be quantified in terms of the nature of the armed

\footnotetext{
${ }^{238}$ See Sections 3.1.1(c) and 3.1.2.

${ }^{239}$ For a general discussion of some of these factors, see e.g. Tams in Van den Herik and Schrijver (2013) 390-1.

$240 \mathrm{Ibid}, 389$.
} 
attack(s) it faces and their actual or likely effects. This informs how its defensive response should be conditioned.

\section{b) The attacking state}

The effects, actual or anticipated, of self-defence on an attacker should also be evaluated in similar terms, taking into account many of the same factors. ${ }^{241}$ This Section considers the position of an attacker that is a state. ${ }^{242}$ In general, Gardam describes the major considerations for proportionality being 'the level of destruction of enemy territory and the infrastructure of the State; overall collateral civilian damage and combatant casualties'. ${ }^{243}$ As set out below, the position of the attacking state is clearly identifiable in state practice. This reflects the fact that the defending state's right to protect itself is not unlimited. Appraisal of its defensive response takes into account the effects of its actions on the attacking state, including its citizens, and on the wider international community.

One candidate for establishing the outer limits of a general approach to judging the effects of self-defence on an attacking state is the suggestion that the wholesale destruction of a state's military capability and the overthrow of a hostile regime are not warranted. ${ }^{244}$ This conclusion will be true in the vast majority of cases, as it will tend to go beyond a defensive purpose. However, it is not absolute, and must be viewed in light of the Nuclear Weapons dictum regarding the potential right of states to resort to using nuclear weapons in self-defence when their survival is at stake. As such, in extremis, one might envisage the complete destruction of the attacker. ${ }^{245}$ This again reflects the overriding teleological element of proportionality. Outside of such marginal cases, defensive action may warrant the invasion of the attacking state's

\footnotetext{
241 This Section assumes that the identity of the attacker is known. It is often the case that both sides to a conflict claim a right of self-defence, as well as maintaining that the other side is the attacker. Ultimately, this is a question of fact, depending on the circumstances.

${ }^{242}$ Section 4.2. considers the position of NSA attackers and that of the host state.

${ }^{243}$ Gardam (2004) 17.

${ }^{244}$ Gardam (2005) 16.

${ }^{245}$ With armed attacks by NSAs in the context of international terrorism, this conclusion is easier to reach. See Section 4.2.
} 
territory. ${ }^{246}$ This raises the issue of the proportionality of occupation by the defending state of territory that it has captured as a result of its defensive actions.

Occupation is subject to extensive IHL regulation, principally The Hague Regulations of 1907 and the Fourth Geneva Convention. ${ }^{247}$ For the purposes of the JAB, occupation of territory by a defending state is rarely going to be necessary or proportionate. This is because the essence of self-defence is the protection of a state's own territory, and modern international law prohibits the use of force for the acquisition of territory. ${ }^{248}$ Occupation of part of an attacking state's territory will only be lawful in exceptional circumstances, where the threat to the defending state is so great that it cannot be adequately resisted without occupation. ${ }^{249}$ Prolonged occupation or annexation is never justified, however. ${ }^{250}$ Occupation may only be potentially proportionate whilst the threat to the defending state subsists. Once an armed attack has been successfully halted, repelled or prevented, ongoing occupation will be unnecessary. Proportionality at that point is irrelevant.

\subsubsection{Civilian harm}

The precise impact of overall combatant casualties on proportionality is unclear in state practice. ${ }^{251}$ Conversely, it is uncontroversial that civilian casualties resulting from defensive action are highly pertinent when considering its proportionality. ${ }^{252}$ States purporting to act in self-defence, either

\footnotetext{
246 Gardam (2005) 15-16. Operation Desert Storm is an obvious example.

247 See P. Spoerri in Clapham and Gaeta (2014) 182-205.

248 Greenwood (1989) 282. Greenwood gives the example of Israel's occupation of territories during the 1967 war as a possible example of where occupation was necessary.

249 Ibid. See also Cassese, La Charte des Nations Unies (2005) 1333; Ruys (2010) 117.

250 Cassese, La Charte des Nations Unies (2005) 1333; Gray (2018) 164.

251 Gardam (2005) 20, suggests that there is little evidence of restraint in this area. See also IIFFMCG Report, 272, reaching the same conclusions. Regarding terrorist NSA casualties, see Section 4.2.

252 Gardam (2005) 14, argues that civilian collateral damage is generally not specifically articulated as being relevant to proportionality, yet the state practice referred to in this Section suggests otherwise. Moreover, she accepts elsewhere that compliance with proportionality entails an analysis of whether there has been an 'unacceptable level of civilian losses in order to achieve the legitimate aims.' Gardam (2004) 209. See also IIFFMCG Report, 272, counting collateral civilian damage as a relevant criterion.
} 
against other states or NSAs, frequently stress that they have made every effort to minimise civilian casualties and civilian damage. ${ }^{253}$ Most recently, the American-led Operation Inherent Resolve, consisting of a Global Coalition against Daesh and other terrorist groups ('Coalition') has defended a highly rigorous targeting selection process designed to avoid civilian casualties in Syria. They maintain that more resources go into target analysis and selection than to the airstrikes themselves, and their dedicated assessment team investigates all claims of civilian casualties. ${ }^{254}$ The record of the Coalition on the issue of civilian casualties is controversial, but the fact that states generally regard themselves subject to an obligation to minimise civilian harm when acting in self-defence is not. ${ }^{255}$ In Oil Platforms, in justifying the proportionality of its actions, the USA even argued that it had rejected possible targets because their destruction threated an excessive level of casualties or of damage to civilian property'. ${ }^{256}$

However, whilst undoubtedly recognizing this obligation, it is not apparent that states regard it as deriving uniquely from the JAB. IHL proportionality, focusing as it does on civilian collateral damage, may deflect attention from this factor under the JAB. ${ }^{257}$ States may be referring to either regime, or both, when referencing this requirement. Alternatively, or in addition to constituting a legal obligation, minimising civilian harm might be a consequence of policy, e.g. based on the need to garner support amongst the civilian population and also

${ }^{253}$ E.g. UN Docs S/PV.1106 (1964) para 54 (UK, in respect of its raid on Harib Fort); S/PV.1613 (1971) para 202 (India, in respect of the India-Pakistan conflict); S/PV.2674 (1986) 14-15 (USA, justifying its actions against Libya); S/PV.2977 (Part I) (1991) 43 (USA, in defence of its actions in the first Iraq War); S/PV.2977 (Part II) (1991) 74-5 (UK, in defence of its actions in the first Iraq War); S/26003 (1993) (USA, in respect of its strike on the IIS headquarters); S/1998/780 (1998) (USA, justifying its airstrikes against Al-Qaeda in Sudan and Afghanistan); S/2001/946 (2001) (USA, justifying its actions against Al-Qaeda in Afghanistan); A/HRC/7/G/15 (2008) (Turkey, justifying Operation Sun).

254 'Airstrikes, Civilian Casualties and Investigations', Coalition, 13 November 2017, $<$ http://theglobalcoalition.org/en/airstrikes-civilian-casualties-and-investigations/>. See further Chapter 4

${ }^{255}$ Regarding the reported civilian harm and the proportionality of Coalition action in Syria, see Section 4.2.3(b).

${ }^{256}$ Oil Platforms, Counter-Memorial and Counter-Claim submitted by the United States of America, 23 June 1997, paras 4.34.

${ }^{257}$ Gardam (2005) 14. 
political support for the operation at hand. ${ }^{258}$ Yet, such limitation is a logical consequence of JAB proportionality. Moreover, the fact that states will frequently cite the requirement to minimise civilian harm when justifying their purported acts of self-defence logically suggests that it is (also) part of the JAB proportionality calculus. As such, although it is not an absolute limitation on state action in the JAB, it is one of the most important. ${ }^{259}$

This conclusion is clearly supported in the reactions of other states and international organizations. Where putative self-defence leads to large numbers of civilian casualties, or where civilians are perceived by states to be the main victims of the response, this may form the core of their negative reactions. Israel's invasion of Lebanon in 2006 constitutes one of the most frequently cited examples of disproportionate self-defence based, in particular, on civilian collateral damage. ${ }^{260}$ It was reported that Israel's actions, justified as self-defence, resulted in 1,191 deaths and 4,409 injured. ${ }^{261}$ Most of these were civilians. More than 900,000 people were displaced. In addition, major damage was inflicted on civilian infrastructure, including large numbers of bridges and roads, as well as Beirut International Airport. Private housing, water and electrical facilities, schools, medical facilities, factories, mosques and churches, television and radio transmission stations, historical, archaeological and cultural sites were damaged or destroyed. ${ }^{262}$ Israel also imposed air and naval blockades resulting in significant negative humanitarian, environmental and economic impact. ${ }^{263}$ On the Israeli side, 43 civilians were

\footnotetext{
258 It is argued that part of the rationale for the American desire for a 'zero-casualty standard' in Syria derives from the wars in Iraq and Afghanistan, where winning over the local population was considered critical to success. See e.g. 'US Aim for 'Zero Civilian Casualties' Draws Criticism' The Hill, 24 June 2015, <http://thehill.com/policy/defense/policy-strategy/245932us-aims-for-zero-civilian-casualties-in-war-vs-isis>.

${ }^{259}$ Concern regarding civilians does not equate to requiring a complete absence of civilian harm. Such a position would not be a requirement of either the JAB or IHL. This issue is discussed further below in this Section.

${ }^{260}$ For detailed descriptions of the facts, international reaction and a range of legal opinion, see Cannizzaro (2006); Ruys (2007); Zimmermann (2007); Wettberg (2007) 114-123; Schmitt (2007-2008); Steenberghe (2012); Gray (2018) 213-16; 227-231; Tams and Bruckner in Ruys and Corten (2018) 673-88.

261 UN Doc S/2006/515 (2006). Reported figures vary. See further the references in $n 260$.

${ }^{262}$ Report of the UN Commission of Inquiry on Lebanon, UN Doc A/HRC/3/2 (2006) ('Lebanon Commission Report') paras 11, 20, 76-9.

$263 \mathrm{lbid}$, paras 268-75.
} 
killed and approximately 1,000 injured (75 seriously), 6,000 homes were affected and 300,000 persons were displaced by Hezbollah's attacks on towns in northern Israel. ${ }^{264}$

Putting aside, for present purposes, controversies over the legality of Israel's claim of self-defence against Hezbollah, ${ }^{265}$ most states focused on the scope of the Israeli action. Proportionality was decisive to the assessment of the conflict. It is clear that the principal concern for states that criticized or condemned Israel's response as disproportionate was the overall harm to Lebanese civilians and civilian infrastructure. ${ }^{266}$ This was also true for those states and international organizations that did not go so far as to condemn Israel's action, but which nevertheless called for a proportionate response that avoided civilian damage. ${ }^{267}$ The scale of the harm to Lebanon, most notably the collective impact on the civilian population and infrastructure, was deemed by most states to be out of proportion to both the immediate trigger that led to the Israeli invasion and to the broader threat posed by Hezbollah. ${ }^{268}$ Lebanon had not actively supported Hezbollah's activities, yet the Israeli response led

\footnotetext{
264 Ibid, para 78.

${ }^{265}$ Whilst a majority of states, as well as the UN Secretary General and various international organizations, recognized Israel's right of self-defence against Hezbollah, controversies remain regarding that claim. For details and commentary, see references in $\mathrm{n} 260$.

266 UN Docs S/PV.5489 (2006) 7-8 (Russia); 9 (Argentina); 11 (China); 13 (Congo); 13 (Tanzania); 17 (Greece); 17 (France); S/PV.5493 (2006) 14 (Qatar); S/PV.5493 (Resumption 1) (2006) 4 (Peru); 11 (France); 18 (Switzerland); 19 (Brazil); 20 (Algeria); 24 (Jordan); 25 (Indonesia); 28 (Turkey); 30 (Djibouti); 33 (New Zealand); 34 (India); 35 (Chile); 36 (Venezuela); 41 (Guatemala); 45 (Mexico); S/2006/780 (2006) para 145 (NAM).

267 UN Docs S/PV.5488 (2006) 5 (UK); S/PV.5489 (2006) 12 (UK); 15 (Denmark); S/PV.5493 (2006) 19 (Slovakia); S/PV.5493 (Resumption 1) (2006) 7 (Denmark); 16 (Finland, on behalf of the EU. Bulgaria, Romania, Turkey, Croatia, the former Yugoslav Republic of Macedonia, Albania, Bosnia and Herzegovina, Serbia, Iceland, Ukraine and the Republic of Moldova also aligned themselves with the statement); 23 (Norway).

${ }^{268}$ The immediate trigger occurred on $12^{\text {th }}$ July 2006 . Hezbollah launched several rockets across the Blue Line into Israel. Its forces crossed into northern Israel, killed three Israeli Defense Forces soldiers, injured two and abducted two others. The conflict escalated thereafter, culminating in Israel's invasion. See UN Doc S/2006/560 (2006) and the commentary referred to in $\mathrm{n} 260$. Israel viewed the overall threat posed by Hezbollah and regional terrorism as much broader than this triggering event. See e.g. 'With Israeli Use of Force, Debate Over Proportion', The New York Times, 19 July 2006, <http://www.nytimes.com/2006/07/19/world/middleeast/19israel.html>. The aforementioned response by a majority of states suggests that, even accepting such characterisation of a broader threat, Israel's response remained disproportionate. Gray (2018) 227, agrees that the action was disproportionate, even if Hezbollah's past attacks could be taken cumulatively. For the contrary view, asserting that the Israel action was proportionate, particularly viewed in the context of the broader threat, see Schmitt (2007-2008) in particular, 155-6, 163-4.
} 
to destruction of large parts of Lebanese public and civilian infrastructure. In addition, the aerial and naval blockade targeted not only Hezbollah, but also the entire Lebanese population. ${ }^{269}$ The deleterious effects of the blockade were noted by a number of states. ${ }^{270}$ The European Union criticized Israel's disproportionate use of force, insisting that 'the imposition of an air and sea blockade on Lebanon cannot be justified. ${ }^{271}$ Israel's actions were, therefore, viewed by certain states as a collective punishment of Lebanon's civilians. ${ }^{272}$ The UN Secretary General, ${ }^{273}$ and the UN Commission of Inquiry on Lebanon, ${ }^{274}$ likewise viewed Israel's acts in this way. The NAM went so far as to condemn Israel's use of force against Lebanon as aggression. ${ }^{275}$ Looking at the purported act of self-defence as a whole, therefore, the prevailing view on the overall disastrous effects on civilians of Israel's invasion of Lebanon is clear. $^{276}$

This incident is, therefore, expositive of how states and international organizations focus on civilian harm when assessing whether or not a purported act of self-defence is proportionate. It might be that for some states such harm, in and of itself, is sufficient to reach this conclusion. This would constitute a purely quantitative assessment, based on the asymmetry between attack and defence, including their respective effects. Alternatively, or additionally, such marked quantitative imbalance might be viewed as pointing to excessiveness vis-à-vis a defensive purpose. As noted in the preceding paragraph, a number of states (rightly, or wrongly) adopted this view and

\footnotetext{
${ }^{269}$ Ruys (2007) 292.

270 See e.g. UN Docs S/PV.5489 (2006); S/PV.5493 (Resumption 1) (2006).

271 'Israel Blockades Lebanon; Wide Strikes by Hezbollah', The New York Times, 14 July 2006, $<$ http://www.nytimes.com/2006/07/14/world/middleeast/14mideast.html>.

272 UN Doc S/PV.5493 (Resumption 1) 20 (Algeria); 24 (Norway); 25 (Indonesia); 26 (League of Arab States); 29 (Morocco); 30 (Iran); 32 (Djibouti); 42 (UAE); 44 (South Africa).

273 UN Doc S/PV.5492 (2006) 3, describing Israel's acts as excessive and disproportionate.

${ }^{274}$ Lebanon Commission Report, in particular, para 331.

275 UN Doc S/2006/780 (2006) paras 142-3.

${ }^{276}$ As noted, when reviewing the UNSC debates, it is not possible to separate neatly concerns over IHL proportionality from JAB proportionality. The legality of specific targets, for example, may be debated for the purposes of IHL and also from the perspective of specific necessity. If targeting fails the latter test, then proportionality is irrelevant. Regardless, it is the effect of the combination of all incidents of targeting that is the purview of JAB proportionality. For commentary regarding the targetability of bridges, roads, the Beirut International Airport and other elements of Lebanese infrastructure, see e.g. Zimmermann (2007) 133- 5; Ruys (2007) 290-2. See also Lebanon Commission Report, in particular, paras 319-37.
} 
regarded Israel's acts as punitive, rather than defensive, in nature. This reflects a teleological evaluation. Both material and qualitative elements of proportionality are readily apparent, therefore. It is submitted that, over and above the marked asymmetry in harm between attack and defence, the magnitude of civilian causalities and civilian damage is impossible to reconcile with achieving the defensive aim of combatting Hezbollah. In the words of the Russian delegate, 'the scale of the use of force, the casualties and the destruction demonstrate that the actions (...) go far beyond a counterterrorist operation.' 277

Emphasis placed by other states and international organizations on excessive damage to civilians and civilian infrastructure is a consistent and longstanding theme in state practice. This is so in both interstate conflicts, and action against NSAs operating in foreign territory. Other incidents include the UK's raid on the Harib Fort in Yemen in $1964,,^{278}$ as well as Israel's response to terrorist attacks carried out by the Palestine Liberation Organization in 1978. In the latter case, Israeli action included a large-scale military operation against Lebanon, resulting in the occupation of territory, the death and injury of civilians and the destruction of Lebanese infrastructure. The Israeli action was broadly condemned and resulted in the UNSC calling for a cessation of military action and the withdrawal of Israeli forces from Lebanese territory. ${ }^{279}$ Other Israeli interventions in Jordan and Lebanon over the years have received similar criticism, focusing on the effects on civilians. ${ }^{280}$ The same is apparent when Israel has claimed a right of self-defence against Hamas in the occupied Palestinian territories. ${ }^{281}$ These represent examples amongst a number of

\footnotetext{
277 UN Doc S/PV.5493 (Resumption 1) (2006) 2.

278 UN Docs S/PV.1106 (1964) paras 66-7 (Iraq); S/PV.1106 (1964) para 27 (Morocco); paras 48-50 (Ivory Coast); S/PV.1110 (1964) paras 24-6 (Czechoslovakia).

${ }^{279}$ UNSC Res 425 (1978). See further UN Doc S/PV.2113 (1978) para 116 (USSR); (1978) UNYB 298-311.

${ }^{280}$ E.g. UN Docs S/PV.1320 (1966) paras 79-80 (UK); para 89 (USA); S/PV.1323 (1966) paras 9-11 (The Netherlands); S/PV.1327 (1966) paras 14-15 (Uganda); S/PV.1643 (1972) para 118 (France); para 39 (Italy); S/PV.1644 (1972) paras 162, 168 (Somalia); S/PV.1648 (1972) paras 120-1, 127 (Sudan); S/PV.1650 (1972) paras 9-11 (France); paras 99-100 (Italy); S/PV.2292 (1981) paras 28-30 (Lebanon); S/PV.2377 (1982) paras 34-5 (Ireland); para 41 (Japan); S/PV.3653 (1996) 9 (Germany) 10 (Russia) 23 (Afghanistan).

${ }^{281}$ As an occupying power, Israel's claim of self-defence against NSAs operating in occupied territory is highly questionable. See Palestinian Wall, paras 70-9 for further analysis of this
} 
other such incidents where states have expressed concerns over excessive civilian harm. ${ }^{282}$ Turkey's Operation Sun in 2008 likewise highlights the concern placed by the international community on the need to protect civilians. It stands, however, as an example of proportionate defensive action against NSAs in foreign territory. This is on the basis that, although the PKK incurred heavy losses, harm to Iraq's population and infrastructure was limited, despite the scale of the Turkish intervention. ${ }^{283}$

Collateral civilian harm acts, therefore, as a consistent indicator of excessiveness for states in appraising the proportionality of self-defence. It will often be impossible to avoid such death and destruction, but this practice reveals how civilian harm is frequently the focus of the debate regarding the legality of putative defensive action. It shows that a defensive purpose cannot be achieved at any cost. Other interests, in this case of civilians, must be accounted for. The difficulty is determining where states will draw the line. There is no absolute or mathematical answer to this. Although high levels of civilian casualties may point to a lack of defensive purpose, such levels may be unavoidable if a defending state is to defend itself properly. It must be recognized that the defending state's action will invariably be in defence of its own civilian population. Whilst civilians and civilian objects on the other side of a border may not be directly targeted under the JAB or $\mathrm{IHL}$, therefore, and civilian harm must be kept to a minimum under both regimes, this does not entirely exclude civilian death or injury. Identifying excessiveness in such circumstances will be context dependant. This might be an unsatisfactory

status. Nevertheless, in one incident in 2004 , Russia recognized in principle Israel's claim of self-defence, yet condemned it as disproportionate on the basis of the 'massacre of innocent civilians'. This position was echoed by other states, such as Pakistan. See UN Doc S/PV.5049 (2004) 6 (Israel); 12-13 (Russia); 14 (Pakistan). See also generally UN Docs S/PV.6060 (2009); S/PV.6061 (2009); S/PV.7222 (2014); S/PV.8244 (2018); S/PV.8256 (2018); S/PV.8272 (2018).

282 See e.g. (1979) UNYB 219-20 (USA, in the context of the conflict between Zambia and Southern Rhodesia); (1982) UNYB 311-12, 315 (various states expressing concern over civilian harm arising out of South Africa's actions in a number of neighbouring countries); UN Doc S/PV.2676 (1986) 12 (Ukraine, in respect of American airstrikes in Libya); UN Doc S/PV.2900 (1989) 14-15, 18, 28 (Finland, Algeria and Cuba, respectively, in respect of the USA's invasion of Panama); UN Doc S/PV.5961 (2008) (France, in the context of the 2008 conflict in Georgia); IIFFMCG Report, 272-5; UN Doc S/2011/690 (2011) (Turkey, in respect of Israel's use of force against the Mavi Marmara).

${ }^{283}$ Ruys (2008) 362-3; Tams in Van den Herik and Schrijver (2013) 414. 
conclusion, but states assess proportionality flexibly and in light of the surrounding circumstances. The analysis regarding Coalition action against Daesh and others in Syria indicates that high levels of civilian harm may well be accepted where the threat is perceived to be particularly great. ${ }^{284}$

Although civilian harm is a clear potential indicator of excessiveness, the significance of possible long-term effects on the civilian population, including the creation of large refugee outflow, is less clear from state practice. ${ }^{285}$ Judge Higgins, in her Separate Opinion in Palestinian Wall, considered the general effect of defensive force on the civilian population, over and above death and injury. In so doing, she doubted whether the building of a wall could constitute an act of self-defence. Even assuming it could, she went on to query whether the particular route selected could be necessary or proportionate given the 'attendant hardships for Palestinians uninvolved in these attacks'. ${ }^{286}$ This view was echoed by Judge Kooijmans, ${ }^{287}$ and suggests that the general impact on the lives of those affected by, but not taking part in, the conflict may also be taken into account in concluding whether or not defensive force is proportionate. Logically, this would appear to apply to the civilian population of both the defending state and the attacker.

\subsubsection{Effect on third-party rights}

a) General considerations and state responsibility

Scholars have highlighted that the impact of defensive force on the rights of other states is also relevant to a proportionality evaluation. ${ }^{288}$ This factor speaks to the wider effects of an exercise of self-defence, and how the interests of the international community operate to curtail the pursuit of the right. Undue interference with such interests might be deemed excessive. There are many ways in which other states might be affected by defensive

\footnotetext{
${ }^{284}$ See Sections 4.1.3(b) and 4.2.3(b).

285 Gardam (2005) 20.

${ }^{286}$ Palestinian Wall, sep op Higgins, para 35 (emphasis added).

${ }^{287}$ Ibid, sep op Kooijmans, para 34.

${ }^{288}$ E.g. Gardam (2004) 17.
} 
force, including violations of sovereignty and territorial integrity. Temporary incursions by an aircraft or missile into another state's airspace, or the traversing of its territory by the defending state in order to reach its objective, are obvious examples. These breaches might be deliberate or accidental and will be of varying degrees of gravity. More serious are those violations of territorial integrity that result in physical damage to another state's territory, or injury or death to its civilian population. Additionally, blockades, exclusion zones or other military activity may interfere with economic, trade and other rights of states that have no involvement in the conflict. The potential effects of nuclear weapons have already been referred to and the widespread use of conventional weapons might be equally injurious. Regional instability caused by warfare also produces a range of deleterious consequences.

The issue of third-party rights is clearly relevant to the proportionality equation. This feature goes beyond considerations of a defensive purpose and the material factors referred to previously in this Section. Recourse to principles of state responsibility assist with how third-party rights factor in the proportionality review. As noted in Section 2.1, whilst the ILC recognizes that defensive force might affect other states, including neutral states, it explicitly leaves open the question of whether Article 21 ARSIWA precludes the wrongfulness of selfdefence vis-à-vis other states. ${ }^{289}$ For the purposes of Article 25 ARSIWA, however (and as also noted in Section 2.1), an invocation of a state of necessity takes into account the interests of other states, and the international community as a whole, in addition to those of the acting state. ${ }^{290}$ Competing interests are, therefore, accounted for within the international law of state responsibility, ${ }^{291}$ and parallels may be drawn for the purposes of the present enquiry.

The following analysis indicates that the rights and interests of other states, and of the international community as a whole, also form part of the

\footnotetext{
289 ARSIWA 21 Commentary, para 5.

290 Art 25(1)(b) ARSIWA and related Commentary, para 17.

291 This balancing exercise is objective and based on a reasonable assessment. Ibid.
} 
determination of whether or not a defending state has acted excessively. Where the pursuit of the right of self-defence infringes on other legally protected interests, it may be that such infringement is regarded as proportionate. Employing the justificatory language of circumstances precluding wrongfulness, the act of self-defence might be objectively justifiable as a 'lesser evil', when compared to the infringement of the other right. This is to say that the result achieved, being the defending state protecting itself and its citizens, provides a net benefit. ${ }^{292}$ This will not always be the case, however, and self-defence will not always prevail. The following review suggests that the right of self-defence is not to be regarded as a superior interest that invariably trumps all others. Its exercise might be considered to be excessive, depending on the circumstances. The situation is reviewed as a whole. The right of selfdefence is weighed against other interests affected by the use of military force in light of the particular context. ${ }^{293}$ These conclusions are explored further below.

\section{b) Neutrality and former belligerent rights}

The relationship between defending states exercising their right of selfdefence and how the rights of other states are affected under the UN Charter 'awaits full elaboration.'294 Section 4.2.3 considers proportionality in the context of the effect of defensive action on host states. A related question is whether adhering to proportionality permits incursions into the territory of a neutral state. ${ }^{295}$ Traditionally, the law of neutrality applies only in the context of international armed conflicts between two or more states, not to noninternational armed conflicts between states and non-state actors, transnational or otherwise. ${ }^{296}$ It comprises rights and obligations for both

\footnotetext{
${ }^{292}$ For an overview of the balancing and safeguarding of competing interests in the context of Art 25 ARSIWA, together with commentary on the 'lesser evil' justification in this context, see Paddeu (2018) 400, 415-21.

293 In the context of Art 25 ARSIWA, see ibid.

294 Gardam (2005) 21.

${ }^{295}$ For the purposes of this Section, a distinction is made between states that are unwilling or unable to confront terrorist threats emanating from their territory and states that have no nexus whatsoever with the relevant conflict. This Section relates to the latter type of state.

${ }^{296}$ Seger in Clapham and Gaeta (2014) 253.
} 
belligerents and neutral non-belligerents. Essentially, this means that neutral states must abstain from involvement in the conflict and treat the belligerents impartially. In return, the belligerents are required to respect a state's neutral status. ${ }^{297}$ Most importantly, parties to an armed conflict must respect the sovereignty and territorial integrity of the neutral state and must not use force within neutral territory, including a neutral state's territorial waters and airspace. ${ }^{298}$ The fundamental legal rationale is to guarantee that neutral states will sustain only minimal injury from warfare, so long as they in turn abide by the aforesaid obligations not to participate and not to discriminate. ${ }^{299}$

The law relating to neutrality holds an uncertain position in the post UN Charter world. ${ }^{300}$ In Nuclear Weapons, the ICJ affirmed the continued application of the law of neutrality, 'whatever its content,' to all international armed conflicts, but expressed it to be subject to the provisions of the UN Charter. ${ }^{301}$ This statement leaves its application vis-à-vis the JAB unsettled, including to what extent the rules of neutrality might affect the application of both necessity the proportionality. ${ }^{302}$ As a general proposition, however, given the seriousness of intruding into the territory of a neutral state, it would only be where the need to take action there is 'very great indeed' that necessity and proportionality would be satisfied. ${ }^{303}$ To be regarded as the 'lesser evil' (described in the preceding

\footnotetext{
297 Chinkin (1993) 300. For a general overview of the law of neutrality see Seger in Clapham and Gaeta (2014) 248-70.

298 The general principle of neutrality is reflected in Art 1 Hague Convention V Respecting the Rights and Duties of Neutral Powers and Persons in Case of War on Land, 18 October 1907, 205 CTS 299. It states that '[t]he territory of neutral Powers is inviolable.' See further Seger in Clapham and Gaeta (2014) 254-5. However, a belligerent can take defensive action on a neutral state's territory if such state allows its territory to be used by another belligerent state in violation of its duties of neutrality. Bowett (1958) 167-174; Brownlie (1963) 312-14.

${ }^{299}$ Dinstein (2017) 27.

300 See generally Chinkin (1993) 299-314; Greenwood (1989) 283-6; Neff (2005) 349-56.

${ }^{301}$ Nuclear Weapons, para 89.

302 Within the context of collective security, the laws of neutrality are subject to the operation of Art 2(5) UN Charter. This requires all Member States of the UN to assist the UN in carrying out preventive or enforcement measures under the UN Charter, and to refrain from assisting any state against which such measures are taken. This operates as a 'rigorous caveat' to the law of neutrality. Dinstein (2017) 186-7. Furthermore, were the UNSC to authoritatively determine who is an aggressor in a situation of individual or collective self-defence, the logic of the Charter would suggest that all Member States of the UN must do whatever they can to assist the defending state and to foil the aggressor's designs. This also challenges the entitlement of states to neutrality. Ibid, 177 . Outside of these contexts, however, neutrality remains possible. See further Seger in Clapham and Gaeta (2014) 261-3.
}

${ }^{303}$ Greenwood (1989) 278. 
Section) and not excessive, the context would arguably need to be such that the violation of neutral territory was the only way for a state to defend itself. ${ }^{304}$

The issue is not simply intrusion into a state's territory however. Neutrality is perhaps most problematic in the context of interference with neutral shipping. ${ }^{305}$ The laws of war and neutrality previously allowed belligerents considerable freedom to stop and search ships on the high seas, to seize and condemn in prize contraband, to operate long distance blockades and even to use force against neutral shipping. ${ }^{306}$ Whether such rights remain available under the post UN Charter JAB, and might be compatible with necessity and proportionality, is debatable. On the basis of the targeting analysis in Section 2.5 , it is reasonable to conclude that deliberate attacks on neutral shipping, whether military or civilian, are never justifiable. Targeting them will not satisfy the requirement of specific necessity. Proportionality is therefore irrelevant on this point.

More generally, necessity and proportionality should be viewed as narrowing the scope of former belligerent rights, even if they do not require that they be dispensed with entirely. Blockades are an example of this limitation. Being designed to prevent all vessels and/or aircraft from entering or exiting specified ports, airports or coastal areas belonging to, or under the control of, another state, blockades may clearly impinge on the rights of neutral states. ${ }^{307}$ Specifically, they may affect their freedom of navigation and aviation and, being enforced by military means, may constitute an act of aggression if not

\footnotetext{
304 The ICJ has employed this logic, also in the context of considering necessity as a circumstance precluding wrongfulness. In Palestinian Wall, para 140, the Court rejected the necessity of Israel's construction of the wall along the chosen route as it was not the only way to safeguard Israel's interests from peril.

${ }^{305}$ For state practice examples and commentary, see Chinkin (1993) 305-8.

306 Greenwood (1989) 284; Nevill in Weller (2015) 274-9.

307 See O'Connell 1150-8; Guilfoyle (2011); Von Heinegg in Heller (2015) 927-34 for a general overview of the types of blockades, their history and their current legality, including under IHL. Regarding the controversial issue of whether blockades are lawful in IHL in the context of non-international armed conflicts, see in particular Guilfoyle (2011); Von Heinegg in Heller (2015) 928-32. For further discussion of neutral shipping, including under IHL, see e.g. Klein (2012) 287-300.
} 
justified, e.g. by self-defence. ${ }^{308}$ O'Connell argues that the international community would nowadays not accept the long-distance blockades of the two World Wars. Such widespread interference with neutral shipping would be inconsistent with the theory of self-defence and would arguably constitute an unlawful use of force. He suggests, however, that close blockades, i.e. specific blockades of more limited in scope, restricting ingress and egress of neutral shipping to and from a belligerent port, might be tolerated. ${ }^{309}$ The UK appears to adopt this general approach. ${ }^{310}$ The USA likewise recognized that its claim of self-defence during the Vietnam War in 1972 allowed for more limited action than a traditional blockade. In so doing, it explicitly adopted more restricted naval operations than allowed in a blockade under traditional IHL in order to protect the rights of neutrals. It saw this deference to neutrality as a key factor in justifying its defensive actions. ${ }^{311}$

Von Heinegg also recognizes the potential acceptance of blockades under the JAB, subject to compliance with necessity and proportionality. He argues, however, that there would need to be a clear nexus with the armed attack. This means that a blockade could not block all vessels or aircraft, but only those 'associated' with the self-defence situation. ${ }^{312}$ This also represents a move from previously accepted traditional blockades to more limited interdiction operations. Such action would presumably include vessels transporting arms to, or otherwise supporting, the attacker. Whilst this is not clear from his analysis, this conclusion is consistent with the UK Military Manual and the San Remo Manual. ${ }^{313}$ Iran has also followed the UK in asserting a right of stop and search in the exercise of the right of self-defence, if there are reasonable

\footnotetext{
${ }^{308}$ Art 3(c) Definition of Aggression. They may also be authorized by the UNSC. Their legality also depends on compliance with IHL. See generally Von Heinegg in Heller (2015) 927-34. 309 O'Connell (1984) 1155-6.

310 See Section 13.3 UK Military Manual.

311 Office of the Legal Adviser (1972) 837-8. See further Neff (2005) 353; Nevill in Heller (2015) 278.

312 Von Heinegg in Heller (2015) 931.

313 Section 13.91 UK Military Manual; Arts 67, 118 San Remo Manual. Such action by a neutral state would, however, jeopardize its neutral status.
} 
grounds to suspect a vessel of taking arms to the other side for use in a conflict. ${ }^{314}$ Greenwood concludes this is probably permissible. ${ }^{315}$

Following its investigation into the blockade of the Gaza strip in 2010 and Israeli attacks on the flotilla of ships (including the Mavi Marmara) carrying humanitarian assistance to Gaza, the Human Rights Council's fact finding mission concluded that such action could not be justified on the basis of selfdefence. ${ }^{316}$ This was because the flotilla was making no contribution to the war effort and posed no immediate security threat to Israel. ${ }^{317}$ The Israeli action, therefore, went beyond a defensive purpose. By implication, an objectively identifiable defensive purpose might have rendered such action justifiable. If accepted, the foregoing analysis suggests that, even if 'a right of interference with third States' freedom of navigation should not lightly be presumed', ${ }^{118}$ limited interference with neutral states might be notionally necessary. Proportionality will, therefore, depend on the acceptance of the degree of interference in the particular circumstances. Widespread blockades of previous, pre-UN Charter years, are unlikely to satisfy either requirement however.

A further issue relates to maritime exclusion zones. These might be established by a defending state to prevent the passage through a designated area of vessels and aircraft, including those of neutral countries, during conflict. Prima facie, these zones impinge on an essential principle that neutral shipping is not to be denied the freedom of navigation on the high seas. ${ }^{319}$ During the 1982 Falkland Islands conflict, the UK invoked self-defence to justify its imposition of a 'total exclusion zone' around the Islands, which applied to both Argentine vessels and to any other ships or aircraft operating

\footnotetext{
${ }^{314}$ Hansard, HC Deb 05 February 1986 vol 91 col 278. This assertion by the UK was cited by Iran in support of its case before the ICJ in Oil Platforms. Memorial submitted by the Islamic Republic of Iran, 8 June 1993, para 4.59.

315 See Greenwood (1989) 284.

316 UN Doc A/HRC/15/21 (2010) paras 56-61.

317 Ibid.

$318 \mathrm{lbid}$, para 55.

319 O'Connell (1984) 1109. For examples and further commentary, see ibid 1109-12.
} 
in support of the Argentine occupation. Any such ships or aircraft found within the zone, without authorization, were to be treated as hostile. ${ }^{320}$

Ostensibly, such action constituted an 'arbitrary interference' with the freedom of navigation and over-flight of aircraft and ships of non-parties to the conflict. ${ }^{321}$ Yet, as Fenrick argues, the exclusion zone:

was a reasonable temporary appropriation of a limited area of the high seas away from major shipping routes for self-defence purposes to prevent non-party clandestine participation in the conflict. The appropriation was accompanied by adequate notice, did not result in any casualties to the ships or aircraft of non-parties, and was terminated after a brief period $(. .$.$) once the British consolidated their position in the$ Falklands. ${ }^{322}$

Indeed, other than Argentina, only Russia officially protested against the British exclusion zone. ${ }^{323}$ Therefore, assuming that there is an enduring defensive necessity that requires such a maritime operation, exclusion zones might be regarded as proportionate measures of self-defence, provided that they are limited, states are notified of their existence and the danger to neutral shipping is kept to a minimum. ${ }^{324}$ The imposition of maritime exclusion zones as an act of self-defence nevertheless continues to occupy an ill-defined position under international law. ${ }^{325}$

The position of neutral states also poses a conundrum for proportionality in the context of the use of nuclear weapons. In Nuclear Weapons, the ICJ sidestepped this issue, failing to rule on the legality of the use of nuclear weapons on the basis of the laws of neutrality. It simply noted that the principle

\footnotetext{
320 UN Doc S/15006 (1982).

${ }^{321}$ Fenrick (1986) 116.

322 Ibid.

${ }^{323}$ M. Binyon, 'Moscow Rebukes Britain', The Times (London), 15 May 1982, 1.

324 O'Connell (1984) 1110-1; Greenwood (1989) 285. See further Michaelsen (2003), especially 379-80; Paddeu (2015) 129.

${ }^{325}$ See generally Michaelson (2003).
} 
of neutrality 'has (...) been considered by some to rule out the use of a weapon the effects of which simply cannot be contained within the territories of the contending States.' 326 The issue of the effect of nuclear weapons on neutrality featured more extensively in the separate and dissenting opinions. Judge Shahabuddeen, for example, noted that neutrality was not understood to guarantee neutral states 'absolute immunity from the effects of armed conflict', but it was difficult to justify the use of nuclear weapons given their potentially devastating effects on neutral states. ${ }^{327}$

The consequences for the natural environment, territory, infrastructure and populations of neutral countries would, therefore, seem naturally to factor into any assessment of proportionality. It logically follows that such considerations should also apply to all other weapons (biological, chemical and conventional) that may also affect neutral states in this way. There is no obvious rationale why the nature of the weapon, rather than its effects, should limit how proportionality should be assessed. Nuclear weapons are simply the extreme example of what those effects might be. ${ }^{328}$

The position of other states, including the issue of neutrality and former belligerent rights, ultimately holds an uncertain place in the proportionality equation. ${ }^{329}$ Further elaboration in the practice of states is required in order to draw firm conclusions. Their role in determining proportionality will be contingent on the context, however. Depending on the nature of the incident, other clearer indicators of excess, such as civilian harm, may factor more prominently in the appraisal of defensive action. The foregoing analysis suggests, however, that even if the pursuit of a defensive purpose has unavoidable repercussions for such states, it is not the case that defending states may freely prioritize their own defence above all other interests.

\footnotetext{
326 Nuclear Weapons, para 93.

327 Ibid, diss op Shahabuddeen, 44-6.

328 The likelihood and degree of deleterious trans boundary effects are perhaps more apparent with nuclear, chemical and biological weapons. The effects of such weapons, by their nature, can be devastating and are harder to control. Yet, the invasion or bombardment of neutral territory with conventional weapons might be equally catastrophic.

${ }^{329}$ Gardam (2005) 23, maintains that former belligerent rights are not necessarily inconsistent with the right of self-defence and their legality depends on whether they are proportionate.
} 
Depending on the context, third party rights have the potential to limit defensive action. It is an example of proportionality accounting for how the exercise of self-defence impinges on the wider international community. Drawing on the operation of necessity as a circumstance precluding wrongfulness assists with how we might view the operation of these rights within the proportionality equation. The justificatory notion of a 'lesser evil' reflects the balancing exercise that must be carried out between the right of self-defence and other rights that might be impaired by its exercise. This informs whether defensive action might be viewed as excessive.

\subsubsection{Effect on the environment}

The potential impact on the environment of states using force is potentially significant. ${ }^{330}$ During the 1991 Gulf War, for example, over 500 oil wells were deliberately set on fire and huge quantities of oil were pumped or spilled into the Gulf causing widespread environmental damage. ${ }^{331}$ The type of weapons used might also raise environmental concerns. A notable case was the use of Agent Orange (a herbicide and defoliant) during the Vietnam War. More recently, a UN environmental report examined potential contamination caused by depleted uranium munitions during the Kosovo conflict. ${ }^{332}$ As noted, in Nuclear Weapons, the Court concluded that existing international law does not specifically prohibit the threat or use of nuclear weapons. ${ }^{333}$ It also considered that international environmental law should not be construed as depriving a state of its right of self-defence. ${ }^{334}$ Nevertheless, it did note the "powerful constraints' that IHL and international environmental law have placed on those states regarding environmental protection. ${ }^{335}$ It insisted that such environmental law indicates 'important environmental factors that are properly

\footnotetext{
330 See generally Sands and Peel (2018) 828-40.

${ }^{331}$ Roberts (1992) $540-1$.

332 United Nations Environment Programme, 'Depleted Uranium in Kosovo, Post-Conflict Environmental Assessment' (2001) <http://postconflict.unep.ch/publications/uranium.pdf> .

${ }^{333}$ Nuclear Weapons, para 105(B).

334 Ibid, para 30.

$335 \mathrm{Ibid}$, para 31 . See $\mathrm{nn} 338-9$ and accompanying text regarding $\mathrm{IHL}$ environmental protections.
} 
to be taken into account in the context of the implementation of the principles and rules of the law applicable in armed conflict. ${ }^{3}{ }^{336}$

On this basis, the Court held that:

States must take environmental considerations into account when assessing what is necessary and proportionate in the pursuit of legitimate military objectives. Respect for the environment is one of the elements that go to assessing whether an action is in conformity with the principles of necessity and proportionality. ${ }^{337}$

This paragraph is ambiguous. The reference to 'legitimate military objectives' in the first sentence suggests that environmental considerations relate to an $\mathrm{IHL}$ assessment of military necessity and proportionality, whereas the second sentence appears to refer to the JAB. The position remains unclear.

Furthermore, this assertion does not provide detail regarding how to assess the proportionality of using nuclear weapons. Given the potentially catastrophic and enduring effects that such weapons could have on the natural environment, it is reasonable to conclude that their use can only be proportionate in the most extreme cases, i.e. where the very survival of the state is at stake. Yet, if that is so, it might be questioned to what degree the leaders of a state subject to an existential threat would consider themselves under an obligation to respect the environment. How are they to weigh environmental protection against the necessity of protecting their country and their people from what presumably would need to be annihilation? In such circumstances, we might question whether it is truly meaningful to say that respect for the environment factors into the calculus.

Perhaps environmental considerations, in terms of JAB proportionality, carry greater weight and operate as more meaningful limitations on defensive action

\footnotetext{
336 Ibid, para 33.

337 Ibid, para 30.
} 
in the context of conventional weapons. This is to say in situations where the state is not facing an existential threat. In these cases, employing other types of weaponry might result in devastating environmental consequences, depending on how they are used and to what extent. As a general rule, therefore, in circumstances where the defending state has a choice of weapons to deploy to achieve an effective defence, proportionality logically dictates that those that cause the least harm to the environment are chosen. This accords with the analysis in the previous Section that accounts for the interests of the wider international community that might be affected by a use of defensive force. An act of self-defence is likely to be more easily justified as a 'lesser evil', and not excessive, if the impact on the environment (in which the international community in general has an interest) is minimised.

This approach is also in line with the jus in bello rules that limit the methods and means of warfare. These include the general IHL principle of military necessity, ${ }^{338}$ and API that prohibits methods and means of warfare that are intended, or may be expected, to cause widespread, long-term and severe damage to the natural environment, and that prohibits attacks against the natural environment by way of reprisals. ${ }^{339}$ In the future, identifying where the balance should be struck between one or more states pursuing a right of selfdefence and the wider issue of protecting the environment, the developing law relating to the latter will undoubtedly influence perceptions of what is proportionate. ${ }^{340}$

\footnotetext{
338 See Section 2.1.

${ }^{339}$ Arts 35(3) and 55 API. See further the ICRC Commentary to Art 35(3) paras 1440-62. More generally on IHL protections of the environment, see Sands and Peel (2018) 832-6.

340 Gardam (2005) 24. For ongoing consideration by the ILC of protecting the environment during armed conflicts, see <http://legal.un.org/ilc/summaries/8 7 .shtml>.
} 


\subsection{Proportionality, IHL and JAB necessity - overlaps and distinctions}

In order to formulate a clear conceptual understanding of JAB proportionality, it is imperative to identify both the overlaps with, and distinctions that should be made between, IHL and the JAB. Scholars and states have yet to conquer this difficult challenge. Whilst the former often prefer to refer to the more specific rules of IHL when commenting on proportionality, the latter generally do not distinguish between the two legal frameworks when referencing the term. ${ }^{341}$ Examining the differences and areas of possible, and actual, confusion and conflation allows for an enhanced review of the jurisprudence, academic opinion and state practice.

\subsubsection{JAB proportionality v. IHL proportionality}

$\mathrm{IHL}$ and the JAB both regulate the use of force. However, on the whole, they are distinct and separate branches of international law. The operation of $\mathrm{IHL}$ does not take account of the legality of a state's use of force under the JAB, i.e. whether self-defence is lawfully established. ${ }^{342}$ This autonomy is tholy gospel' ${ }^{343}$ and is '[o]ne of the oldest and best established axiomata of international law'. ${ }^{344}$ That said, the operation of the one regime has the potential to influence the understanding of the other. ${ }^{345}$ For present purposes, both systems share the concept of proportionality, but its role in each is different, as are the variables against which the relevant proportionality is measured.

\footnotetext{
${ }^{341}$ Ruys (2010) 110-1.

${ }^{342}$ The preamble to API reaffirms 'that the provisions of the Geneva Conventions of 12 August 1949 and of this Protocol must be fully applied in all circumstances to all persons (...) without any adverse distinction based on the nature or origin of the armed conflict or on the causes espoused by or attributed to the Parties to the conflict' (emphasis added).

${ }^{343}$ Schmitt (2007-2008) 154.

344 Gill (1999) 614. For examples of more recent commentary on this long debated and controversial topic, see e.g. Moussa (2008); Van Steenberghe (2012); Okimoto (2012). See also paras $215-16$ of the 2016 ICRC Commentary on the First Geneva Convention relating to Art 2 ('ICRC's 2016 Art 2 Commentary').

${ }^{345}$ See e.g. Section 2.5 , including analysis of the meanings of 'military target', 'military objectives', and 'military advantage'.
} 
In the JAB, proportionality measures the defending state's response as a whole, primarily against its defensive purpose. This assessment also takes into account material factors such as civilian harm and wider third-party interests. In contrast, IHL proportionality requires an assessment of whether the expected civilian loss or injury, or damage to civilian objects, in each case resulting from a particular planned attack, would be excessive in relation to the concrete and direct military advantage anticipated. ${ }^{346}$ This rule places an obligation on those planning attacks to assess the proportionality of their individual targeting decisions. Proportionality at this operational level employs different variables to JAB proportionality. Whereas JAB proportionality balances the defending state's total use of force against its overall defensive purpose and wider third-party interests, IHL proportionality balances anticipated collateral damage (being civilians and civilian objects) against the expected outcome of specific attacks (that form part of the overall defensive operation). ${ }^{347}$ The UK Military Manual notes the importance of this distinction between the two regimes. ${ }^{348}$

Proportionality in the JAB operates, therefore, at the macro level. It is concerned with the big picture and the totality of the wider defensive response. It is not concerned with single acts of force, unless such acts constitute evidence of a shift in the overall scale or scope of that response. ${ }^{349}$ Proportionality in the JAB relates primarily to the generalities of self-defence,

\footnotetext{
${ }^{346}$ This core principle of IHL is encapsulated in Art 51(5)(b) API. If collateral damage is expected to be excessive, then an attack is to be cancelled, suspended or re-planned. Arts $57(2)$ (a)(iii) and (2)(b) API.

347 It is generally understood that collateral damage is assessed in relation to the anticipated military advantage from the attack as a whole and not only from isolated or particular parts of that attack. Ten contracting states (Australia, Belgium, Canada, France, Germany, Italy, the Netherlands, New Zealand, Spain and the UK) made formal declarations that the expression 'military advantage' employed in Arts 51, 52 and 57 API (as applicable) has this meaning. See ICRC database, $<$ https://ihldatabases.icrc.org/applic/ihl/ihl.nsf/States.xsp?xp viewStates=XPages NORMStatesParties \&xp treatySelected $=470>$. However, "attack as a whole' is not used as meaning the whole military campaign that may be conducted in self-defence but rather as referring at best to a series of military actions which are part of the individual attack launched in the framework of such a campaign.' Van Steenberghe (2012) 116. See also Dinstein (2010) 94-5.

${ }^{348}$ Section 2.8 UK Military Manual.

349 The Chatham House Principles (2006) 969; Ruys (2010) 110; Lubell (2013) 3; Henderson (2018) 234. See further Section 3.2.1.
} 
operating to protect against 'excessive overall reactions' 350 by states. The logic of this conclusion is based on the fact that uses of force that are uncontained and go beyond what is strictly necessary for states to protect themselves are likely to be disruptive of the international legal order. This goes back to the point made in Section 1.3.1 and this Chapter more generally that proportionality accounts for, and seeks to balance, the interests of a number of different actors, including of the wider international community. It has been suggested, therefore, that the ultimate rationale of JAB proportionality (over and above proscribing excessive uses of force against the attacker) is the maintenance of international peace and security. ${ }^{351}$ This conclusion is supported by the analysis set out in Section 3.2 regarding how essential interests of the international community are accounted for in determining whether defensive responses are excessive.

In contrast, IHL proportionality focuses on the micro level. Its purview is oneoff incidents, being the specifics of individual targeting decisions. It requires a 'concrete and direct military advantage' from each and every military action to ensure that such use of force is not excessive in relation to civilian harm resulting from the particular attack (that forms part of the overall defensive operation). As such, whilst much of the decision making for the purposes of the JAB will be made strategically, at the state level, the majority of the decision making that is relevant to the IHL calculus will happen much lower down the chain of command. ${ }^{352}$

The rationale of IHL proportionality is not, therefore, tied to the international order and the minimization of the use of force between states. Its purview is more localised and short term. Its primary concern is the effect of such force on individuals, not the effect on states in any abstract sense. ${ }^{353}$ It offers

\footnotetext{
350 Simma et al (2012) 1427.

351 Greenwood (1989) 278; Gardam (2004) 16; Van Steenberghe (2012) 118-19.

352 Gardam (2004) 21. See also Lubell (2013) 2, noting the macro/micro distinction between $\mathrm{IHL}$ and the JAB.

${ }^{353}$ An exception that does account for protection of wider interests and international society more generally are the $\mathrm{IHL}$ rules pertaining to protection of cultural property. For an overview of these rules, see e.g. R. O'Keefe in Clapham and Gaeta (2014) 492-520.
} 
humanitarian protection on an equal basis to all sides in a conflict, focusing on minimizing damage and suffering of non-combatants to the greatest degree possible during the exigencies of war. ${ }^{354}$ It seeks at the micro level to balance the two cardinal principles of IHL, being military necessity and humanity. ${ }^{355}$ The function, make up and rationale of proportionality in each regime are, therefore, markedly different. ${ }^{356}$

It is understandable that the distinction between $\mathrm{IHL}$ and JAB proportionality is not always so readily apparent. After all, both govern a state's use of force, acting to constrain it. Yet, whilst a breach of, or compliance with, one regime might lead to the same result in the other, this is not automatic. Starting with the effect of IHL violations on the JAB status, it is perhaps reasonable to conclude that a violation of $\mathrm{IHL}$ proportionality indicates that JAB proportionality is also breached. ${ }^{357}$ This might be the case, but a breach of IHL proportionality will not violate JAB proportionality as a matter of course. It would be illogical to conclude, for example, that a violation of IHL proportionality early on in a long defensive campaign renders the whole operation disproportionate under the JAB. ${ }^{358}$

This conclusion is based on the fact that the rules of IHL and the JAB operate at different levels. As IHL proportionality operates at the micro level of individual decision-making, a one-off, or small number of, IHL disproportionate targeting decision(s) may or may not render the whole defensive operation disproportionate at the macro level, where proportionality in the JAB operates. A 'global calculation' of excessiveness at the JAB level might accommodate

\footnotetext{
354 Greenwood (1989) 278; Van Steenberghe (2012) 118-19; Simma et al (2012) 1427; Okimoto (2012) 49.

${ }^{355}$ See e.g. Nuclear Weapons, para 78.

${ }^{356}$ Van Steenberghe (2012) 115-18, refers to the distinction described in this paragraph as the 'general versus particular' dichotomy. For similar conclusions and further analysis, see further Akande (1998) 191-2; The Chatham House Principles, 969; Cannizzaro (2006) 786; Mousa (2008) 976-8; Okimoto (2012).

357 Van Steenberghe (2012) 117.

358 Greenwood (1983) 231, has suggested that an act that contravenes IHL cannot be a 'reasonable and proportionate measure of self-defence' under the JAB. However, he also accepts that neither body of law is logically dependent on the other. Ibid. Given the logic of the latter conclusion, and the analysis set out in this Section, it is this author's position that a contravention of IHL does not always breach the rules of the JAB.
} 
individual instances of excess at the IHL level. ${ }^{359}$ This will depend on the severity and number of IHL breaches when considered in the context of the overall defensive campaign. Where there are systematic, rather than exceptional, violations of IHL proportionality, these may also result in a breach of JAB proportionality. Consistent violations of IHL proportionality resulting in excessive civilian damage (weighed against a concrete and direct military advantage) will likely indicate that defence is not the aim of the military campaign. ${ }^{360}$ Compliance is, therefore, contingent on the particular circumstances.

Likewise, adherence to the IHL rules of proportionality on all individual targeting decisions during a defensive campaign might indicate JAB compliance, especially where collateral civilian harm is minimized in each case. Yet, such compliance might still breach JAB proportionality if, on an overall assessment, the combination of uses of force is excessive in relation to the defensive purpose. ${ }^{361}$ Everything depends on how a specific act of targeting fits within the bigger defensive picture. This will be decided on a caseby-case basis. The Ethiopia-Eritrea Claims Commission followed this logic when, in adhering to the strict distinction between the JAB and IHL, it concluded that compliance with IHL does not preclude a breach of the JAB. ${ }^{362}$ However, whilst a breach of IHL proportionality might not lead to a breach of JAB proportionality, it still constitutes a breach of IHL. It is, therefore, an unlawful act that must not be carried out or, if in progress, must cease

\footnotetext{
359 This assumes targeting is prima facie lawful under both the JAB and IHL. As noted in Section 2.5(b), a lack of specific necessity is also likely to result in the absence of a 'military advantage' for the purpose of IHL. This denies targeting under both regimes. In such cases, an act of targeting can be neither IHL nor JAB proportionate. It will simply be unlawful under both regimes.

360 Whilst the two regimes are strictly separate, given that the military advantage can be judged by reference to the (defensive) campaign, this constitutes a prima facie bridge between the two regimes. One informs the other. See Section 2.5(b).

361 Greenwood (1989) 279, reaching a similar conclusion. See also Gardam (2004) 11; Okimoto (2012) 58; Kretzmer (2013) 278.

362 'If (...) a State initiating a conflict through a breach of the [JAB] is liable under international law for a wide range of ensuing consequences, the initiating State will bear extensive liability whether or not its actions respect [IHL]. Indeed, much of the damage for which Ethiopia claims [JAB] compensation involves conduct that the Commission previously found to be consistent with [IHL].' Eritrea-Ethiopia Claims Commission - Final Award - Ethiopia's Damages Claims, Decision of 17 August 2009, RIAA Volume XXVI 631, para 316.
} 
immediately. As such, it may, depending on the circumstances, attract both state responsibility and individual criminal responsibility. ${ }^{363}$

Conversely, it has been suggested that compliance with JAB proportionality might prevent an attack on a target that would otherwise be lawful under IHL. Gardam proposes the example of an electricity grid that, she argues, might be targetable under $\mathrm{IHL}$, but the destruction of which might be excessive in relation to achieving the aims of self-defence (thereby constituting a breach of JAB proportionality). ${ }^{364}$ However, as explored in Section 2.5 and in this Section, to be targetable under the JAB, specific necessity must first be satisfied. This requires a connection between the armed attack and the defensive response (in this example, being the destruction of the electricity grid). To be targetable under IHL, there must also be a 'military advantage' to destroying the grid. If the grid is not connected with an armed attack, it is unlikely to offer a 'military advantage' during a defensive operation and, therefore, will not be targetable under IHL or the JAB. It is the bridge between specific necessity and IHL that leads to this result. Gardam's example rightly raises the issue of how the two regimes might influence each other, but proportionality is irrelevant to this targeting analysis.

The instinctive link between the two types of proportionality must, therefore, be approached with caution. A contributor to any potential conflation or confusion is that $\mathrm{IHL}$ and $\mathrm{JAB}$ proportionality share common, ultimately humanitarian, characteristics. Both account for how force affects civilians and civilian objects and, thereby, seek to minimise civilian harm. As noted in Section 3.2.5, states often focus on this point when referring to proportionality and tend not to distinguish between IHL proportionality and JAB proportionality when so doing. This conflation, unhelpfully for those seeking conceptual clarity, leads to 'a sort of global assessment of proportionality'. ${ }^{365}$

\footnotetext{
363 See below regarding the ongoing and concurrent application of the JAB and IHL.

${ }^{364}$ Gardam (2004) 168-9.

${ }^{365}$ Cannizzaro in Clapham and Gaeta (2014) 348.
} 
Yet, whilst civilian harm is the principal variable against which the concrete and direct military advantage anticipated is measured for the purposes of $\mathrm{IHL}$ proportionality, it is only one of a number of factors and interests that go to whether a purported defensive purpose satisfies JAB proportionality. IHL proportionality is not concerned, for example, with broader considerations such as the effect on other states, including a host state where acts of selfdefence are carried out against NSAs within its territory. ${ }^{366}$ Also, whilst IHL incorporates environmental protections, they are not a feature of $\mathrm{IHL}$ proportionality. ${ }^{367}$ Moreover, as noted above, the JAB will review overall collateral civilian damage (and all the other aspects of proportionality discussed above) from the perspective of the defensive military operation as a whole, rather than in respect of each individual part of that operation, which is the purview of IHL.

The ICJ has contributed to the confusion regarding the distinction between the $J A B$ and $I H L$ by potentially suggesting that compliance with JAB proportionality is dependent upon conformity with IHL. In Nuclear Weapons, the Court stated that:

a use of force that is proportionate under the law of self-defence, must, in order to be lawful, also meet the requirements of the law applicable in armed conflict which comprise in particular the principles and rules of humanitarian law. ${ }^{368}$

This may be interpreted to mean that in order for self-defence to be JAB proportionate, it must comply with $\mathrm{IHL}$, including $\mathrm{IHL}$ proportionality. ${ }^{369}$ This unnecessarily conflates the JAB and IHL, however. ${ }^{370}$ The better view is that, in order to be lawful, any use of defensive force must be JAB proportionate

\footnotetext{
${ }^{366}$ This is not to say that these considerations are irrelevant for the purposes of IHL. The point is that they are not relevant to a calculation of IHL proportionality. See further Section 4.2.3.

367 See Section 3.2.7. The environment more generally does not factor as a third-party interest in IHL proportionality, as it might do in JAB proportionality, even though it is a protected interest under separate $\mathrm{IHL}$ prohibitions.

${ }^{368}$ Nuclear Weapons, para 42.

${ }^{369}$ See e.g. Heller in Ohlin (2016) 252.

370 Moussa (2008) 974-7.
} 
and also comply with IHL. The UK adopted this conclusion in its statement to the Court. ${ }^{371}$

On this interpretation, to be a lawful use of force, the requirements of both the $\mathrm{JAB}$ and IHL (including proportionality in each) must be met, but independently. ${ }^{372}$ There is support for this position in the Nuclear Weapons judgment itself. Compliance with the two regimes is set out separately and independently in the dispositif, ${ }^{373}$ and is also considered on this basis in the declaration of President Bedjaoui, ${ }^{374}$ and several separate and dissenting opinions. ${ }^{375}$ As such, the JAB and IHL should be regarded as cumulative obligations, whilst remaining as two essentially separate and independent bodies of international law. ${ }^{376}$ Any suggestion that the JAB is subordinated to $\mathrm{IHL}$, such that compliance with the former depends on adhering to the latter, fails to recognize the fundamental distinction between the two. ${ }^{377}$

\subsubsection{JAB proportionality $\mathrm{v}$. JAB necessity}

Adopting the teleological or 'means-end' model as the primary determinant of proportionality emphasizes the rapport that necessity has with proportionality and explains the risk of conflation between the two. As Kretzmer rightly notes, '[m]eans can only be proportionate when they are necessary to achieve the legitimate ends. ${ }^{378}$ The result is a possible understanding of proportionality

\footnotetext{
371 'Assuming that a State's use of nuclear weapons meets the requirements of self-defence, it must then be considered whether it conforms to the fundamental principles of the law of armed conflict regulating the conduct of hostilities.' Nuclear Weapons, Statement of the Government of the UK, June 1995, para 3.44.

372 Moussa (2008) 975. See also Greenwood (2002) 313-4; Kretzmer (2013) 240; Cannizzaro in Clapham and Gaeta (2014) 347-8; Gill (2016) 369.

${ }_{373}$ Nuclear Weapons, paras 105(C) and (D).

$374 \mathrm{Ibid}$, declaration of President Bedjaoui, para 22.

$375 \mathrm{Ibid}$, sep op Ranjeva, paras 22, 26; sep op Fleischhauer, paras 3, 5; diss op Shahabuddeen, paras 155-7; diss op Weeramantry para 397 (although, see also diss op Weeramantry para 367 , which suggests a less clear separation. See further Section 3.4 regarding the continuing application of both regimes); diss op Koroma, para 14. See also sep op Guillaume, para 8 for some more nuanced views on this issue.

376 Gill (1999) 618, 623; Van Steenberghe (2012) 115, 117; Okimoto (2012) 50, 57, 70. As noted, this is subject to the interaction between the JAB and IHL on the issue of targeting. See Section 2.5(b).

${ }^{377}$ For further discussion of this case and the relationship between IHL and the JAB, see Akande (1998); Gill (1999); Moussa (2008); Van Steenberghe (2012) 121-3.

378 Kretzmer (2013) 239. See also Corten (2010) 488.
} 
that 'the level of force used is not greater than that necessary to end the attack or remove the threat. As such it is another way of looking at the requirement of necessity. ${ }^{379}$ This conclusion brings us back to the conceptual circularity that exists between these two customary requirements.

\section{a) Proportionality and general necessity}

This circularity, and the potential for conflation, is limited however. As initially set out in Section 2.2, understanding necessity and proportionality to be equivalent is only theoretically possible as between specific necessity and proportionality. There can be no conflation between proportionality and general necessity. The two are conceptually distinct. This can be explained as follows. If, following an armed attack, self-defence (in any form) is deemed unnecessary, such conclusion must result from a lack of general necessity. This might be because peaceful alternative means are available to resolve the situation, or the UNSC takes effective action. In such circumstances, where there is no prima facie need for a state to act in self-defence, it is meaningless to say that a use of force is also disproportionate. Absent general necessity, it is simply unlawful. An assessment of proportionality, as against a defensive aim, cannot be made, as such aim is lacking. Consideration of specific necessity is likewise impossible in such circumstances.

If, in the alternative, some form of defensive response is necessary (e.g. because peaceful options are not available and/or were unsuccessfully pursued, and/or the UNSC has not taken effective action), then it is meaningful to assess the proportionality of a defensive operation. This is because, once general necessity is satisfied, a defensive purpose is present. The two concepts function very differently however. General necessity requires an assessment of whether any force is required to respond to an armed attack. Proportionality requires that the total force deployed (as a result of that general necessity) is not excessive. In summary, therefore, a use of force that satisfies

\footnotetext{
379 The Chatham House Principles, 969. See also Ruys (2010) 112; Kress in Weller (2015) 587; Henderson (2018) 237.
} 
general necessity may be proportionate or disproportionate. However, a use of force that does not pass the general necessity test can be neither.

\section{b) Proportionality and specific necessity}

To address the potential conflation issue, we must examine the relationship between proportionality and specific necessity. To understand proportionality, and to identify distinctions between it and specific necessity, it is important to appreciate where any overlap might exist. The principal factor that might lead to a conclusion that defensive force is both necessary and proportionate, or unnecessary and disproportionate, is the nature of the target. As set out in Section 2.5 , this thesis argues that specific necessity requires that the target of self-defence must be military in nature (in line with IHL 'military objectives') and, in addition, connected with the armed attack (thereby establishing a defensive purpose). The question, therefore, is whether the nature of the target also factors in the proportionally equation.

The ICJ in Oil Platforms, in referring to both necessity and proportionality, stated that '[o]ne aspect of these criteria is the nature of the target of the force used avowedly in self-defence.' ${ }^{380}$ Some commentators interpret this to mean that proportionality also requires the target to have a connection with the armed attack. ${ }^{381}$ Others state that proportionality, like necessity, requires the target to be of a military nature. ${ }^{382}$ The result of this approach is to say that both specific necessity and proportionality impose an identical limitation on the choice of targets. Such conclusion requires further examination.

As noted, following an armed attack and the satisfaction of general necessity, specific necessity must be established before a proportionality assessment is possible. ${ }^{383}$ Where specific necessity is absent, e.g. because the target is not

\footnotetext{
380 Oil Platforms, para 74.

381 Okimoto (2012) 64. Ruys (2010) 121, asserts that targeting, as well as forming part of the necessity criterion, 'equally fits into the proportionality framework.'

${ }^{382}$ Etezazian (2016) 284-8. Although, to the extent his analysis relates to proportionality, such conclusion appears to focus largely on the resulting civilian harm.

${ }^{383}$ See Sections 1.3.1 and 2.5(a).
} 
military and/or not connected with the armed attack, ipso facto, a use of force cannot be connected with a defensive purpose. It is meaningless in such cases to say that an unnecessary incident of targeting is also disproportionate. It will simply be an unlawful use of force. As an example, let us consider targets that are prima facie unnecessary for the purposes of the JAB. Obvious candidates are civilians and civilian objects that, by definition, are not (and cannot be) legitimate targets connected to the armed attack. ${ }^{384}$ Targeting them directly is not capable of serving a defensive purpose and will always be unnecessary under the JAB, as well as constituting unlawful acts under IHL. ${ }^{385}$ This conclusion, so far as it relates to the $\mathrm{JAB}$, is not reached on the basis of a particular prohibition under that regime. It contains no such specific rules. It is deduced rather from the general principles that logically flow from the foregoing analysis. ${ }^{386}$ The ensuing question is whether such unnecessary targeting can also rightly be labelled as disproportionate.

Green and Waters suggest that it can be. In asserting that targeting is also inherent in the proportionality requirement, they argue that it is unlikely that a direct attack on a civilian target will be anything other than 'excessive' when measured against the state's defensive need.' 387 There is, therefore, a

\footnotetext{
${ }^{384}$ As set out in Section 2.5, this assumes that civilians are not DPIH and that civilian objects are not being used for military purposes.

${ }^{385}$ As a caveat, Green and Waters (2015) 23-4, argue that the JAB rules on civilian targeting are not absolute in the same way as they are in IHL. The authors highlight that necessity and proportionality are relative criteria, to be assessed by reference to the defensive needs of the state. As such, in extreme situations of defensive need, such as where the very survival of the state is threatened (as recognized by the ICJ in Nuclear Weapons, paras 96-7), then their position is that attacking a civilian target would meet the necessity and proportionality requirements. They accept that such instances would be rare and that targeting in this way would still be unlawful under IHL. This conclusion regarding the JAB seems hard to reconcile with the Oil Platforms decision, however, and the general proposition that targets must be military. The use of nuclear weapons might well be necessary and proportionate in such in extremis circumstances, allowing for the targeting of a military target that leads to high levels of civilian collateral damage (which is a proportionality consideration). However, there is nothing in the ICJ jurisprudence, or the logic inherent in the necessity criterion, that would allow for the deliberate targeting of civilians or civilian objects in these circumstances. Such a position effectively allows the JAB to override one of the cardinal principles of IHL, which is both unwarranted and unwelcome.

${ }^{386}$ As Okimoto (2012) 69, rightly notes, the JAB is silent as to which types of persons and objects may be attacked in self-defence, as well as regarding which weapons can or cannot be used. It is rather IHL that provides these detailed rules. However, such rule is inherent in the requirement that self-defence is both necessary and proportionate.

387 Green and Waters (2015) 11-12. See also Okimoto (2012) 65.
} 
potential argument to be made that targeting decisions might lead to a determination of defensive force being both unnecessary and disproportionate. Yet, this conclusion, whilst true on its own terms, is problematic regarding how proportionality is assessed. The difficulty lies in the order in which the necessity and proportionality evaluations are made. By considering necessity first, as we must do, the requirement of proportionality in such circumstances is rendered inapplicable. On this basis, where specific necessity is absent, as is the case with attacking a civilian target, a use of force cannot be proportionate, but neither can it be disproportionate.

Where specific necessity is present (because the target is military and connected to the armed attack) the applicability of proportionality is clear. The resulting harm caused by attacking a target that is specifically necessary can either be proportionate or disproportionate (when measured against the overarching defensive purpose and accounting for the various factors referred to in this Chapter). ${ }^{388}$ It is unfortunate, therefore, that the ICJ in Oil Platforms was not clearer on how the 'nature of the target' pertains to the requirements of necessity and proportionality separately. It did not offer any analysis regarding what relevance this has in practice for proportionality, or how the two requirements might be applied jointly to issues of targeting. ${ }^{389}$

If the concern that the Court and certain commentators are attempting to address is the result of an act of targeting, this is indeed a matter for proportionality. However, such concern does not relate to the nature of the target per se, but rather the consequence of targeting, including the ensuing collateral damage. ${ }^{390}$ Gardam argues, for example, that proportionality regulates, inter alia, the 'means and methods of warfare' and the 'targets that

\footnotetext{
${ }^{388}$ Cf Gray (2018) 159, who argues that if a use of force is 'not proportionate, it is difficult to see how it can be necessary.'

${ }^{389}$ Even if the taxonomy adopted by this thesis is not accepted, including the distinction between 'specific' and 'general' necessity, it is evident that the nature of the target and its connection with an armed attack is an issue for necessity broadly defined. If there is no rational connection between the act(s) of self-defence and the armed attack, such force cannot be necessary. In the crudest sense, proportionality then considers everything else in assessing the overall defensive response, including the outcomes of that use of defensive force.

${ }^{390}$ Cf Etezazian (2016) 25-8.
} 
are available to States in the exercise of [the right of self-defence]. ${ }^{391}$ Yet, she goes on to argue that, integral to decisions relating to these two factors, are the anticipated scale of the damage and destruction that result from these decisions. ${ }^{392}$ These latter comments reflect the foregoing analysis that shows that proportionality's purview is the overall defensive picture, not the minutiae. As set out in Section 3.2.1, proportionality should not be understood as limiting the methods and means of warfare, nor should it limit the nature of the targets. Proportionality evaluates whether or not the total resulting harm caused by the methods and means of defence and targeting decisions are excessive in relation to the defensive purpose and other affected interests.

As such, whilst both necessity and proportionality are measured against a defensive purpose, and may risk being conflated on this basis, their respective purposes and operation are very different. Specific necessity relates to targeting. Proportionality evaluates the outcomes of all instances of (specifically necessary) acts of targeting and whether or not they are excessive. Determining the specific necessity of an act of targeting comes before, and is separate to, whether the consequences of that act are proportionate. This does not mean that proportionality is limited to a post facto assessment, but rather that both requirements are to be reviewed constantly, and in this order. Along similar lines, IHL sets out rules that relate to the definition of a 'military objective' for the purposes of targeting and separate rules that pertain to proportionality, the analysis of which is a consequence of targeting. For JAB proportionality, the relevance of the choice of weapons, and where they are targeted, is that the ensuing outcome must remain within the confines of a truly defensive response. If the resort to a particular weapon or targeting strategy represents a considerable escalation of hostilities, it is not the choice of weapon and/or target in and of itself that might fail the test of proportionality, but rather the fact of that escalation. ${ }^{393}$

\footnotetext{
391 Gardam (2005) 18.

392 Ibid (emphasis added).

393 See Gardam (2005) 20. See further Sections 2.5, 3.2.1.
} 


\subsection{Overall assessment and enduring application}

In the $\mathrm{JAB}$, proportionality measures the defending state's response as a whole. In Oil Platforms, the Court stated that it 'cannot assess in isolation the proportionality of [a specific defensive act] to the attack to which it was said to be a response; it cannot close its eyes to the scale of the whole [defensive] operation' ${ }^{394}$ Proportionality is, therefore, concerned with the defending state's wider defensive operation. ${ }^{395} \mathrm{It}$ is for this reason, as much as any other, that adherence to proportionality must be understood as an enduring requirement that applies throughout the entirety of a conflict arising out of an exercise of self-defence. ${ }^{396}$ Evaluating the proportionality of a defensive response is only possible by reference to a period of time during which such response is occurring or, if the conflict is over, has occurred. It should not be viewed as relating solely to the initial decision to deploy defensive force, before handing over to IHL to govern the conduct of ongoing hostilities. ${ }^{397}$

Proportionality continues to apply even if the state is facing an existential threat. In Nuclear Weapons, the ICJ reaffirmed its application to acts of selfdefence 'whatever the means of force employed', ${ }^{398}$ specifically stating that proportionality may not exclude the use of nuclear weapons in self-defence in all circumstances. ${ }^{399}$ It did not say that proportionality was inapplicable. ${ }^{400}$ Rather, the Court envisages an extreme situation of self-defence, i.e. where the very survival of the state is at stake, where a defensive use of nuclear weapons might be considered proportionate. ${ }^{401}$ Proportionality may be difficult, or even impossible, to measure or quantify in such circumstances ${ }^{402}$ Yet, the

\footnotetext{
394 Oil Platforms, para 77.

${ }^{395}$ See further Section 3.3.1.

396 Greenwood (1983) 223; Gardam (2005) 5. See further Sections 3.3 and 3.4.

397 See Section 3.3.1 regarding the joint application of $\mathrm{IHL}$ and the distinctions between JAB proportionality and IHL proportionality. Cf Dinstein (2017) 282-7, proposing a right to wage an all-out 'defensive war' against armed attacks of a 'critical character'.

${ }^{398}$ Nuclear Weapons, para 41.

399 Ibid, para 42.

${ }^{400}$ As suggested by Dinstein. See $\mathrm{n} 397$.

401 That both necessity and proportionality continue to apply to an exercise of self-defence using nuclear weapons, see Nuclear Weapons, diss op Shahabuddeen, para 158.

402 Ibid, diss op Weeramantry, paras 371-2.
} 
majority's conclusions in Nuclear Weapons point to an acceptance that a use of such a devastating weapon is permissible in order to fulfill the ultimate purpose of the right of self-defence, being the 'continued existence of its beneficiary'. ${ }^{403}$ Even if one may disagree with the notion that the use of nuclear weapons can ever satisfy proportionality, the judgment reinforces the fact that, even in the most extreme of situations, it still has a role to play. The majority of the Court, and seemingly the states connected with the judgment, all accept that the law continues to regulate conduct. ${ }^{404}$

As an enduring requirement, defensive action must be continuously monitored by the defending state to ensure that it is and remains proportionate and, ipso facto, lawful. 405 This JAB evaluation should run alongside monitoring of IHL compliance. A useful analogy may in fact be drawn with the IHL rules relating to proportionality. These impose an ongoing obligation to appraise potential collateral damage and require the taking of precautions in attack. ${ }^{406}$ It is logical that both regimes impose a similar obligation regarding the need to evaluate proportionality on a rolling basis, even if the meaning of such term in each regime is different. 407 Only when viewed in this way does JAB proportionality have the capacity to constrain defensive action. This enduring obligation means that proportionality in the JAB may operate to capture, at any point in time during an ongoing act of self-defence, 'a snapshot of the big picture'. ${ }^{408}$ This snap-shot necessarily involves retrospective, current and prospective elements. This is to ask what action has the defending state taken up until the point that the snap-shot is taken (i.e. when the assessment of proportionality

\footnotetext{
${ }^{403}$ Steenberghe (2012) 122. Akande (1998) 193, likewise believes that '[i]t is difficult to hold that if the use of nuclear weapons is the only way of repelling an aggressor, that use is disproportionate to the objective of legitimate self-defence.'

${ }^{404}$ Nuclear Weapons, para 22. That states explicitly viewed the JAB, as well as IHL, as regulating their conduct, see e.g. the pleadings referred to in Section 3.1.1(e).

405 Gardam (2005) 5.

406 If collateral damage resulting from an attack is expected to be excessive, or if it becomes apparent that this would be the case, then the attack is to be cancelled or suspended. Arts $57(2)(a)$ (iii) and (2)(b) API.

407 See Section 3.3.1.

408 Lubell (2013) 2.
} 
is being made), what is it currently doing, and what will it need to do prospectively, in each case to meet its defensive objective?

The main importance of the snap-shot approach is likely to be its use as a practical decision-making tool. It can aid the defending state to take stock, assess the current situation, and then look forward and plan its ongoing defensive strategy. It enables, and requires, the defending state to determine what next steps may be taken to halt, repel or prevent an armed attack, whilst still remaining within the boundaries of legality. This cannot be undertaken as an exact science and, because of the changing nature of conflict (see below), it is not meaningful when looked at too far in the future. As such, the idea of a snap-shot should not be understood as a one-off event, but rather as a continuing process of assessment by the defending state that monitors the changing defensive need by reference to ongoing hostilities.

This evaluation is particularly challenging in the context of anticipatory selfdefence. ${ }^{409}$ Establishing what is proportionate to counter imminent armed attacks involves a degree of conjecture. ${ }^{410}$ However, if the imminent armed attack is a threat of specific action, ${ }^{411}$ or there is history between the defending state and the attacker, this might be easier. As noted in Section 2.4.2(b), claims of 'pure' anticipatory self-defence are rare. The prospect of imminent armed attacks tends to arise where there is an ongoing threat to a state that has already been the victim of a prior armed attack. As discussed in Sections 2.4.2, 3.1.1 and Chapter 4, in such cases states might be entitled to respond on a cumulative basis to this threat. Even if difficult, therefore, assessment of

\footnotetext{
${ }^{409}$ See Section 2.4.1(b).

${ }^{410}$ As with all acts of defence, a good faith effort must be made to calibrate carefully a response by reference to the reliable and credible intelligence available at the time such decision is taken. This requirement takes on greater significance with imminent armed attacks, due to the increased uncertainty regarding the defensive need. Ultimately, an assessment of the proportionality of pre-emptive self-defence will be made objectively on a post facto basis. It will be for third parties to judge, after the event, how they view the proportionality of the response. In addition, they will need to form a view on whether an armed attack was in fact imminent and that the right of self-defence was, therefore, available to the defending state. Given the inherent uncertainties pertaining to imminent armed attacks, it might be that the latter issue plays the decisive role in such cases.
}

411 Gardam (2004) 179. 
the threat as a whole, i.e. looking at the entire period during which the threat subsists, must encompass consideration of imminent armed attacks. ${ }^{412}$

Assessing proportionality primarily against a defensive purpose, and on an enduring basis, provides a flexible and pragmatic model that takes into account the changing circumstances on the ground, in conjunction with the other interests referred to in this Chapter that may point to excessiveness and disproportionality. If we take the example of a defensive campaign against an ongoing threat, then there will be moments during this campaign when the level of violence rises and falls. Ruys, for instance, gives the example of the 2006 Israeli intervention in Lebanon where, over time, the circumstances gave rise to a 'mutually reinforcing cycle of violence' that, because of action on both sides, escalated well beyond an initial response to the abduction of two Israeli soldiers ${ }^{413}$ It is not the fact that Israel's campaign developed into an 'all-out war' with Hezbollah that automatically rendered the response disproportionate, however. Rather, it was the imposition of a naval blockade on Lebanon and the widespread targeting of civilian infrastructure and Lebanese military bases that clearly breached the proportionality requirement. ${ }^{414}$

This example serves to highlight why adherence to proportionality is necessarily an enduring requirement and may only be properly assessed as such. Evaluating compliance over the relevant period of time accounts for the vicissitudes of the factual context during that period. This is the case whether

\footnotetext{
${ }^{412}$ Even if forming part of a series of armed attacks, states planning to counter an imminent armed attack are advised to exercise caution. This is because formulating a proportionate response remains precarious. From a quantitative perspective, gauging the magnitude of an attack (and its effects) that has not yet occurred cannot be a precise science. For the purposes of the teleological evaluation, it will also mean establishing what is required to achieve a defensive purpose in relation to such attack. When the armed attack will start and finish is also uncertain. States, and observers of state action, are thereby faced with a laborious undertaking in identifying the precise nature of the threat, how long it will endure, and what a reasonable response looks like. Applying proportionality to defence against an imminent armed attack is, therefore, 'somewhat of a haphazard process.' Gardam (2004) 179. Where the details of the total threat are unclear, therefore, a defending state that is mindful of the legality of its response might be wise to limit the initial stages of a defensive response to a high degree of quantitative equivalence vis-à-vis the anticipated imminent armed attack. Such strategy could serve to avoid a post facto determination that a defensive act was an overreaction and disproportionate.

${ }^{413}$ Ruys (2010) 118.

414 Ibid. See further Section 3.2.5.
} 
a proportionality calculus is made on a snap-shot basis, whilst a defensive act is ongoing, or when looking back at a defensive operation as a whole on a post factum basis. Viewing the requirement in this manner enables an evaluation of the acts of defence in the round. It takes account of the fact that pursuing a defensive object will change over time as the nature and scale of the conflict ebbs and flows. Developments on the ground may mean that what is a proportionate response at one point in the conflict may later become disproportionate. As the threat to the defending state increases and decreases, so long as self-defence remains necessary, the corresponding defence must be calibrated accordingly. Proportionality only makes logical sense both theoretically, and as a matter of practical application, when conceptualised in this manner.

\subsection{Conclusions}

Proportionality is often employed by states as a 'ritual incantation' to identify excess and illegality. State practice does not offer a consistent narrative, and the ICJ jurisprudence likewise presents a varied approach, but the foregoing analysis clarifies proportionality's role in the exercise of self-defence. In response to an actual or imminent armed attack, general and specific necessity respectively determine whether force may be used, and where it must be directed. Proportionality proceeds to govern how much total force is permissible to achieve a defensive purpose. It guards against excessive reactions. It does this by appraising the act(s) of self-defence as a whole, not the specific targeting decisions, which is the domain of specific necessity and IHL. It is, therefore, only relevant when there is an actual or imminent armed attack, and both general and specific necessity have first been satisfied. Like necessity, it is also an enduring requirement that subsists, and must be monitored, throughout the duration of a defensive operation.

State practice indicates that proportionality operates flexibly, is largely context dependant, and accounts for a variety of interests that go beyond those of the defending state. Whilst proportionality balances defensive force and its 
outcomes primarily against a defensive purpose, its application is not the neat binary exercise that is sometimes suggested. It is not simply a question of referring to proportionality as either quantitative or teleological. Material factors arising out of defensive action play an important part in evaluating proportionality. In particular, widespread civilian harm will tend to be condemned by the international community as excessive. Manifest quantitative imbalance will indicate disproportionately, either in and of itself or, more likely, signalling a lack of defensive purpose.

Moreover, states clearly do not view themselves as being able to do 'whatever it takes' to achieve a defensive purpose. Other interests operate to restrict how far states may go to defend themselves. A proportionality analysis, therefore, must account for how much these interests are affected by the act(s) of selfdefence. These factors act as indicia of excessiveness (viz disproportionality). They include the effects of self-defence on third parties, the environment and international peace and security more generally. The respective importance of defensive purpose, material factors and third-party interests varies and is contextual. State practice and jurisprudence suggests, however, that states and the ICJ will point to the most obvious indicator of illegality when considering whether or not self-defence complies with the proportionality requirement. Civilian harm is likely to be the principal factor. 


\section{CHAPTER 4: NECESSITY AND PROPORTIONALITY AND ARMED ATTACKS BY NON-STATE ACTORS}

\section{Introduction}

A right of self-defence against armed attacks by NSAs is controversial, particularly where the NSAs are acting independently and their acts are not attributable to a state. ${ }^{1}$ There remains a lack of consensus on this issue, but an increasing body of state practice and academic literature indicates that states have a right of self-defence against non-attributable armed attacks by NSAs. ${ }^{2}$ This is most clearly evidenced by recent state practice related to combatting transnational terrorism perpetrated by Al-Qaeda, Daesh and similar groups. ${ }^{3}$ For the purposes of the ensuing review, this thesis assumes a right of self-defence against armed attacks carried out by NSAs, regardless of attribution.

The analysis set out in Chapters 2 and 3 relating to interstate self-defence also applies in general terms to defensive acts taken in response to armed attacks by NSAs operating from foreign territory. Yet, armed attacks by NSAs raise further specific issues for necessity and proportionality. In this context, their requirements are adapted and supplemented. NSA armed attacks therefore represent a particularly good medium through which the content and outer parameters of necessity and proportionality may be explored. ${ }^{4}$ As will be made clear, necessity in particular plays a greater role outside of the interstate context, where the requirement is likely to be satisfied more easily. ${ }^{5}$ The

\footnotetext{
1 See e.g. Tams (2009); Ruys (2010) 368-510; Trapp in Weller (2015) 679-96; Gray (2018) 200-61.

${ }^{2}$ See e.g. Lubell (2017) 217-18. Even if accepted, the precise content and parameters of this right are still being worked out in state practice.

3 Such practice is discussed throughout this Chapter.

${ }^{4}$ There are other areas of the JAB that also raise additional issues for these two concepts. These include uses of force in cyber space and in outer space. Consideration of these particular topics is beyond the scope of the present enquiry, however.

${ }^{5}$ Tams in Van den Herik and Schrijver (2013) 399-401.
} 
content and operation of proportionality, however, are much more uncertain, being stretched to the very boundaries of meaningful application.

Much of the following analysis is set against the background of international terrorism. This is principally because the majority of state practice pertaining to NSA armed attacks has taken place in this context. There should be no confusion, however, between a right to respond defensively to armed attacks by NSAs, who happen to be terrorists, and to 'terrorism', howsoever the latter concept might be defined. ${ }^{6}$ There is no right of self-defence against 'terrorism', only against actual or (potentially) imminent armed attacks. ${ }^{7}$ The fact that such attacks are being carried out for terrorist purposes does not affect the trigger of the right. ${ }^{8}$ However, the threat posed by terrorism has consequential effects on how we should understand necessity and proportionality. Universally accepted as one of the most serious threats to international peace and security, ${ }^{9}$ the phenomenon has undoubtedly influenced how states, and the UNSC, view the right of self-defence. As will be made clear, this feeds into what it means for states to comply with necessity and proportionality.

\subsection{Necessity and armed attacks by NSAs}

\subsubsection{The host state and alternative measures}

Where NSA armed attacks are not attributable to a host state, serious implications arise from a defending state using force against the responsible NSAs on the host state's territory. As in the interstate context, whether there are reasonable alternatives to using defensive force is the starting point. ${ }^{10}$ If

\footnotetext{
6 There is no commonly agreed legal definition of terrorism. See e.g. Saul (2005); Trapp (2011) 14-23; Watkin (2016) 180-208.

7 See Section 2.4.1(b). For present purposes, this Chapter also assumes a right of selfdefence against armed attacks that are imminent.

${ }^{8}$ Art 51 UN Charter. See further Ruys (2010) 496-99.

92005 World Summit Outcome Document, UN Doc A/Res/60/1 (2005) paras 81-91. See further Section 4.1.3(c).

10 Ideally, a defending state should request the host state to take adequate measures to forestall or halt (further) terrorist action and, in cooperation with it, to take measures of law enforcement to prevent terrorist acts from being undertaken from that state's territory. Gill in Weller (2015) 744; Tams in Van den Herik and Schrijver (2013) 403, 408-9. This presumption
} 
force is required, the defending state should seek prior explicit consent from the host state to act militarily on its territory. ${ }^{11}$ Absent consent, for action in selfdefence to be necessary, the host state should generally be given the opportunity to comply with its international law obligations to prevent and suppress international terrorism. It might do so by acting on its own, or working in co-operation with the defending state. ${ }^{12}$ If the host state adopts measures against the NSAs within a reasonable time period, and they are effective to combat them, this prima facie renders defending state action unnecessary. ${ }^{13}$

If seeking a viable solution via, or in cooperation with, the host state is an option, and has not been tried, it is unlikely that unilateral force against NSAs can be considered necessary..$^{14}$ Host state action, to use Webster's words, thereby offers a potential additional 'choice of means' to that seen in the interstate context. Alternative measures accordingly have the potential to play a much greater role in combatting NSAs than they do in the interstate context.

is in keeping with the notion that terrorists are first and foremost criminals and, if possible, should be dealt with as such before resorting to force. The Leiden Policy Recommendations, 539-40; Wilmshurst and Wood (2013) 393. If law enforcement measures are capable of dealing with terrorist acts, force will not be necessary. The Leiden Policy Recommendations, 542 .

${ }^{11}$ What constitutes consent, including whether this might be implicit, or intervention by invitation, are much-debated topics. See e.g. Abass (2004); Bannelier-Christakis (2016).

12 In Armed Activities, para 162, the ICJ confirmed as customary international law the Friendly Relations Declaration's requirement that '[e]very State has the duty to refrain from organizing, instigating, assisting or participating in (...) terrorist acts in another State or acquiescing in organized activities within its territory directed towards the commission of such acts, when the acts referred to in the present paragraph involve a threat or use of force.' This is an expression of the general premise that every state has an obligation not to allow knowingly its territory to be used for acts contrary to the rights of other states. Corfu Channel, para 51. This is not an absolute obligation. It is a duty to apply due diligence in preventing harm to other states stemming from actions within the host state's own territory. It constitutes, therefore, an obligation of means rather than results. Ruys (2007) 285. The obligation to combat terrorism and prevent terrorist acts, and to co-operate with other states in so doing, is likewise reflected in various UNSC Resolutions (e.g. UNSC Res 1373 (2001) para 2) and nineteen multi-lateral terrorism suppression conventions (see <http://www.un.org/en/counterterrorism/legalinstruments.shtml>). On the general approach to redressing the situation before force is used on a host state's territory, see further Ruys (2010) 505-6; Deeks (2012) 519-21; Henderson (2018) 324, 326.

${ }^{13}$ For example, prior to Operation Sun in 2008, the Turkish President appeared to accept that if the Iraqi government acted against the PKK, it would not be necessary for Turkey to act in its place: 'We have made it very clear that if the terrorist shelters there are not destroyed, it is our legitimate right to destroy those shelters ourselves. 'Turkey Bombards Northern Iraq after Ambush', The Guardian, 22 October 2007, $<$ www.theguardian.com/world/2007/oct/22/turkey.iraq1>.

${ }^{14}$ Lubell (2010) 46. 
The consequence is that general necessity, at least in theory, acts as a stronger limitation on exercising the right of self-defence. The reality, however, might be somewhat different.

Whether peaceful options and/or host state action are in fact reasonable alternatives to defensive force will depend on the context, particularly the timing of the armed attack. ${ }^{15}$ In terms of resort to peaceful alternatives against the NSAs themselves, it may be that such action proves sufficient over time to counter an enduring threat from a group of NSAs. However, there is no suggestion in state practice that a defending state under direct attack is required to forego its right of defensive response in favour of law enforcement. A distinction must be made, therefore, between long-term responses to degrade the capacity for future NSA armed attacks, and the more immediate needs of the defending state to respond to ongoing violence. ${ }^{16}$

There may also be an understandable reluctance on the part of the defending state to cooperate with a host state, or to rely on host state action, before resorting to force against the NSAs operating on their territory. Deeks notes that whilst defending states tend to point to the fact that they first ask the host state to take steps to supress NSA activities on their territory, before using force against them, this is not always the case. A request for the host state to take action might be considered futile, or as causing tangible harm to the

\footnotetext{
15 See Section 2.4.1.

${ }^{16}$ Peaceful alternatives vis-à-vis the NSAs themselves are not required by the UN Charter's emphasis on peaceful settlement of disputes that applies between states. See Section 2.3.1. Moreover, they are unlikely, on their own, to prove effective in halting, repelling or preventing an armed attack. It is unrealistic, for example, to assume that diplomatic pressure or economic sanctions will be employable against terrorist organizations like Al-Qaeda or Daesh. Likewise, it is doubtful that law enforcement strategies and non-forcible options such as freezing bank accounts and funds will be sufficient alone to halt, repel or prevent armed attacks. This is especially so where the host state will not cooperate. Tams in Van den Herik and Schrijver (2013) 406-7. Domestic terrorism occurring exclusively within the confines of one national legal system is more likely to be countered by traditional law enforcement measures. With cross border armed attacks by NSA terrorists such responses (coupled with other efforts like education and deradicalisation programmes) are essential in dealing with the long-term threat, but they do not necessarily contribute to the immediate defensive needs of a state under attack, or threat of imminent attack. Where armed groups of NSAs have been sufficiently weakened by military force, however, alternatives to force might be sufficient to tackle the long-term threat. See Section 4.1.4(a).
} 
defending state's national security. ${ }^{17}$ For example, prior to the USA's intervention in Afghanistan in 2001, the USA refused to negotiate, let alone cooperate, with the Taliban before launching its airstrikes. ${ }^{18}$ The USA made a number of demands to the Taliban prior to using force, but there was no indication that it felt legally obligated to resolve the issue peaceably, or that such demands were anything other than politically or strategically expedient. ${ }^{19}$ The American approach is likely due to the Taliban's close relationship with AlQaeda and the view that their support made the 9/11 attacks possible. ${ }^{20}$ George W Bush viewed them as an illegitimate and murderous regime and publicly condemned them on this basis. ${ }^{21}$ Despite this refusal to cooperate with the Taliban, the ensuing Operation Enduring Freedom was generally regarded as a lawful act of self-defence. ${ }^{22}$

Likewise, in the context of combatting Daesh and other terrorist groups in Syria since 2014, those states claiming a right of self-defence to justify their military operations within Syrian territory have refused to cooperate with the Assad regime. ${ }^{23}$ This is despite potential initial indications on the latter's part of its ability to combat Daesh and a willingness to do so by coordinating military action. ${ }^{24}$ This raises an interesting question of what it means to satisfy the

17 Deeks (2012) 521-25, noting that such procedural requirement is not, therefore, absolute.

18 'The US Refuses to Negotiate with the Taliban', BBC History, <http://www.bbc.co.uk/history/events/the us refuses to negotiate with the taliban>.

${ }_{19}$ Green (2009) 81.

20 UN Doc S/2001/946 (2001). See further Section 4.1.3(a).

21 'President Bush Addresses the Nation', The Washing Post, 20 September 2001, $<$ http://www.washingtonpost.com/wpsrv/nation/specials/attacked/transcripts/bushaddress 092001.html>.

${ }^{22}$ See 2.4.2(b).

23 States invoking individual and/or collective self-defence to justify their actions against Daesh in Iraq and Syria include: UN Docs S/2014/695 (2014) (USA); S/2014/851 (2014) (UK); S/2015/221 (2015) (Canada); S/2015/563 (2015) (Turkey); S/2015/688 (2015) (UK); S/2015/693 (2015) (Australia); S/2015/745 (2015) (France); S/2015/928 (2015) (UK); S/2015/946 (2015) (Germany); S/2016/34 (2016) (Denmark); S/2016/132 (2016) (The Netherlands); S/2016/513 (2016) (Norway); S/2016/523 (2016) (Belgium). None of these states have cooperated with President Assad, and some have been very public about this fact. The USA, for example, clearly rejected the offer of cooperation and coordination, explicitly stating that it was not looking for the approval of the Syrian regime. 'White House won't commit to asking Congress for Syria strike', The Hill, 25 August 2014, <http://thehill.com/policy/defense/215905-white-house-wont-commit-to-asking-congress-forsyria-strike>.

${ }^{24}$ For commentary on this point, see e.g. Goodman (August 2014); Goodman (December 2014); Goodman (2015); Gray (2018) 241. It later became clear that Syria was strongly opposed to Coalition action on its territory. Before the UNSC, Syria insisted that it was 
necessity requirement in this context. ${ }^{25}$ In particular, it is unclear from practice whether defending states consider themselves to be under a legal obligation to cooperate with a host state that is purportedly willing. The refusal to cooperate with President Assad may have been because his regime had lost control over significant parts of its territory (affecting its ability to counter the threat) or doubts as to whether Assad was acting in good faith regarding any cooperation. ${ }^{26}$ Akin to the USA's view of the Taliban, states may also have had concerns regarding cooperating with, and potentially strengthening, an illegitimate regime that stands accused of crimes against humanity and war crimes. ${ }^{27}$

This latter possibility reflects a regime interaction issue and the need to interpret international law systemically. JAB necessity cannot be interpreted so as to require a defending state to cooperate with, and thereby support, host states that breach IHL and whose officials potentially face international criminal law liability. Indeed, such collaboration by a defending state might engage its own international responsibility for a breach of the obligation to respect, and to ensure respect for, the Geneva Conventions and IHL more generally. ${ }^{28}$ The ICRC maintains that, as a matter of customary international law, this obligation is not limited to the Geneva Conventions, but applies to the entire body of international humanitarian law binding upon a particular state. ${ }^{29}$ Where IHL violations are 'likely or foreseeable', defending sates might be responsible for

combatting terrorism and that any counter-terrorism efforts had to be coordinated with the Syrian government. UN Docs S/PV.7271 (2014) 43; S/PV.7316 (2014) 33. It went on to condemn Coalition airstrikes and complained to the UNSC of aggression against it. E.g. UN Docs S/2015/719 (2015); S/2015/727 (2015); S/2015/851 (2015); S/2015/933 (2015).

${ }^{25}$ See further Section 4.1.2 regarding necessity and the 'unwilling or unable' doctrine.

${ }^{26}$ The USA has since accused the Syrian regime of focusing on combating opposition groups rather than fighting terrorists. UN Doc S/PV.8236 (2018) 7.

${ }^{27}$ See the various reports of The Independent International Commission of Inquiry on the Syrian Arab Republic ('HRC Syrian Commission of Inquiry'): $<$ http://www.ohchr.org/EN/HRBodies/HRC/IICISyria/Pages/IndependentInternationalCommis sion.aspx>. The EU's position, for example, was that policies and actions of the Assad regime meant that it could not be a partner in the fight against Daesh. UN Doc S/PV.7540 (Resumption 1) 14 (EU).

${ }^{28}$ Common Article 1 to the Geneva Conventions. See further the 2016 ICRC Commentary on the First Geneva Convention relating to Art 1.

${ }^{29}$ ICRC Commentary, ibid, para 126. The ICRC's interpretation of this obligation is not without its critics however. It has been described as 'expansive' and 'aspirational'. See e.g. Hakimi (2016); Goodman (2016). 
providing support that could be construed as encouraging breaches of IHL. ${ }^{30}$ If the breaches of IHL also constitute a serious breach of peremptory norms of international law, the laws of state responsibility would likewise prohibit aid or assistance to the responsible state (i.e. Syria) that maintains the situation created by that serious breach. In fact, these rules go further and impose a positive obligation on states to cooperate in order to bring to an end such breaches. ${ }^{31}$

Operation Enduring Freedom and Coalition action in Syria appear to reflect this rationale. ${ }^{32}$ However, the lack of sufficient detail surrounding the relevant states' positions on this topic means that it is difficult to conclude whether cooperation with Assad was a reasonable alternative to using force. After all, Assad did go on to cooperate with other nations, such as Russia and Iran, purportedly in its fight against Daesh. ${ }^{33}$ Ultimately, the USA took the view that the Syrian regime could not, and would not, confront Daesh effectively. ${ }^{34}$ Such inability was arguably confirmed by UNSC Resolution 2249. ${ }^{35}$ Despite the legal controversies involved with intervention in Syrian territory against Daesh, a large number of states have claimed a right of self-defence against Daesh, clearly believing that they are not, as a matter of law, required to cooperate and coordinate with the host state before they do so. ${ }^{36}$

This most contemporary state practice highlights that the particular factual context is crucial when considering necessity and the resort to peaceable alternatives in the context of combatting terrorist NSAs. Whilst emphasis is placed prima facie on the primacy of host state action in dealing with the threat emanating from its territory, it is not always practicable. The necessity of the defending state taking action might instead be established, or at least

\footnotetext{
${ }^{30}$ Nicaragua, paras 220, 256.

${ }^{31}$ See Arts 40 and 41 ARSIWA and related Commentary.

32 On whether cooperating with the Assad regime would amount to illegal assistance, see further Kress (2015).

${ }^{33}$ Whether the purpose of such collaboration was primarily to combat Daesh or Assad's domestic opponents, is highly debatable however. For an overview of Russian and Iranian involvement and objectives, see e.g. Gill (2016) 356-7.

${ }^{34}$ UN Docs S/2014/695 (2014); S/PV.7565 (2015) 4. See further Section 4.1.2.

35 See Section 4.1.3(c).

${ }^{36}$ See further Section 4.1.3(b).
} 
arguable. The main additional considerations for necessity pertaining to crossborder terrorist attacks by NSAs are the nature of the group of NSAs being combatted, and of the regime on whose territory they operate. In particular, the focus is on the relationships between the defending state and the host state, and between the host state and the NSAs. The risk to the defending state of cooperating with a host state, in terms of whether the former's international responsibility might be engaged because of unlawful acts of the latter, is also a feature of more recent state practice. These issues are central to how states view their obligation to pursue (or not) peaceful alternatives and cooperate (or not) with host states. They bring an extra dimension to the contemplation of alternative measures.

\subsection{2 'Unwilling or unable'}

The corollary to the general premise that primacy of action against NSAs lies with the host state is that:

where a state is unable or unwilling to assert control over a terrorist organisation located in its territory, the State which is a victim of the terrorist attacks would, as a last resort, be permitted to act in self-defence against the terrorist organisation in the State in which it is located. ${ }^{37}$

This 'unwilling or unable' doctrine, like the general issue of a right of selfdefence against NSAs, remains highly controversial both conceptually and as a matter of practical application. That putative defending states might abuse any right to use force in the territory of another state is a serious concern. Sands rightly notes that the challenge for international law is to ensure that the rules balance the legitimate interests of those states that feel vulnerable to international terrorism, and those states that feel vulnerable to the response to that threat, especially unilateral responses ${ }^{38}$ Further state practice is required in order to clarify the place, or otherwise, of the unwilling or unable doctrine in

\footnotetext{
${ }^{37}$ The Chatham House Principles, 970. See also The Leiden Policy Recommendations, 540.

${ }^{38}$ Sands (2005) 203, in the context of responding to terrorism more generally.
} 
the lex lata. ${ }^{39}$ As matters stand, however, there is growing support for the view that where there is a 'manifest and persistent unwillingness or inability to prevent non-State attacks', self-defence will be justifiable: a host state cannot perpetually hide behind its sovereign inviolability. ${ }^{40}$

For present purposes, a determination of unwillingness and/or inability on the part of the host state satisfies (if accepted as lex lata) or would satisfy (if lex ferenda) the necessity requirement of self-defence against NSAs carrying out cross-border armed attacks. That there has been an armed attack that requires a defensive response (assuming any gravity threshold is met) is a general necessity issue, i.e. whether there is a need for some form of defensive response. Host state unwillingness and/or inability deny the defending state an alternative means of redress, meaning that force is the only way to remove the threat. Specific necessity accounts for military action taken against NSA targets on host state territory.

If accepted, self-defence against NSAs on the territory of another state, absent its consent, should still be viewed as an exception, exercisable only in cases of the most compelling emergency. ${ }^{41}$ This general premise recognizes the difference between the bilateral situation of interstate self-defence, where defending state(s) respond directly against armed attacks by the attacking state(s), and the situation in self-defence against NSAs, where the host state is essentially a third-party. In the latter situation, the unwilling or unable doctrine has the potential to act as an additional constraint on the exercise of self-defence. In accounting for the position of the host state, it has the capacity

\footnotetext{
${ }^{39}$ For a general discussion of the doctrine (representing a variety of views) and state practice, see e.g. Heller (2011); Deeks (2012); Bethlehem (2012); Kress (2015); Trapp (2015); Corten (2016); Gray (2018) 243-8; Henderson (2018) 322-33.

${ }^{40}$ Ruys (2010) 505-6. '[A] state's territorial integrity should not act, for its own sake, to shield NSAs so as to provide them with the (legal and physical) space within which to violate individual rights to life and physical integrity, even if those threatened are across a border.' Trapp (2015) 211. See also Teitel (2011) 219, noting the increasing acceptance of the compromise or suspension of the Westphalian norms of sovereignty and territorial integrity where human rights are at stake.

41 The Leiden Policy Recommendations, 543.
} 
to constitute a further barrier to be overcome, taking necessity beyond its operation in the interstate context. ${ }^{42}$

If necessity is established as a result of unwillingness or inability, it is argued that the resulting exercise of lawful self-defence against the NSAs excuses a limited breach of the host state's sovereignty and territorial integrity. ${ }^{43} \mathrm{An}$ even more controversial question is whether unwillingness and/or inability on the part of the host state, and the relationship between it and the NSAs, also accounts for a defending state's right of action against the host state itself, including its military personnel and apparatus and civilian infrastructure. The targeting rules discussed in Section 2.5 suggest that specific necessity requires the defensive force to be aimed at, and only at, the NSAs responsible for the armed attack. This includes their personnel, equipment, bases and other resources located in host state territory. Where the host state has not sent, directed or controlled the NSAs, or their acts are not otherwise imputable to it, the host state should not be considered the source of the attack. ${ }^{44}$ Directly targeting that state's infrastructure and apparatus is, therefore, prima facie unnecessary. Recent state practice suggests, however, that important caveats apply to this general rule.

First, a neat distinction between targeting the NSAs on the one hand, and not targeting the host state on the other, may not be easy to make in practice. Unless the NSAs are operating in a remote location, it is unlikely that the host state (including its infrastructure, apparatus and civilian population) will remain totally unaffected by a defending state's military action. This might be by way of collateral damage, where the host state is not directly targeted, but suffers harm. This will be discussed further in Section 4.2.3 in the context of proportionality. Moreover, in order to ensure that the defensive force is effective, the defending state might consider it necessary to target elements of

\footnotetext{
42 The ability of necessity to act as an effective additional constraint on state action in this context depends on establishing a clearer unwilling or unable test. See Deeks (2012).

${ }^{43}$ See e.g. Trapp (2007) 147; Moir in Weller (2015) 730; Henderson (2018) 323. See further Section 4.2.3.

${ }^{44}$ Ruys (2010) 496.
} 
the host state, in addition to the NSAs. Gardam argues that it might be difficult to establish to what degree a host state is complicit in allowing its resources, territory and infrastructure to be used by NSAs. Defending states will inevitably, therefore, regard themselves as requiring a degree of latitude in the selection of targets in such cases. ${ }^{45}$ She maintains that targeting the infrastructure of the host state 'will not be justifiable unless it can be demonstrated that they contribute in some way to the terrorist activities. ${ }^{36}$

Other scholars support the notion that where the host state is unwilling or unable to meet its international law obligations to prevent and suppress international terrorism, then this might have implications for whether the defending state may also direct force against host state targets, in addition to NSA targets. ${ }^{47}$ The authors of The Leiden Policy Recommendations maintain that:

measures of self-defence against suspected terrorists must be directed primarily against the terrorist groups responsible for the armed attack in question or their facilities. Only in exceptional circumstances will selfdefence justify the use of force against the armed forces or facilities of the [host state], for example, in circumstances where the [host state] is supporting suspected terrorists, as in Afghanistan in 2001.48

The state practice reviewed in the next Section is broadly in line with this statement.

\footnotetext{
${ }^{45}$ Gardam (2005) 21.

${ }^{46} \mathrm{Ibid}$. This is set out in the context of her views on proportionality. It is submitted, however, that such analysis is better understood as relating to specific necessity.

47 E.g. Lubell (2010) 47. It is unclear from this analysis, however, whether this conclusion holds despite due diligence on the part of the host state, rather than effective results.

48 Leiden Policy Recommendations, 542. Support for NSAs clearly amounts to an unwillingness to combat them. Whilst expressed as a requirement of proportionality, it is submitted that these views on targeting are also better understood under the rubric of specific necessity.
} 


\subsubsection{Targeting the host state - state practice}

The controversial unwilling or unable doctrine is not universally, or even consistently, referred to by states when justifying their acts against NSAs in foreign territory. ${ }^{49}$ Yet, the view that unwillingness or inability, as a factual matter, might lead to targeting elements of the host state, in addition to the NSAs, does find support in post 9/11 state practice in response to armed attacks by Al-Qaeda (and associated groups) and Daesh. Such practice points to a potential relaxation of the specific necessity requirements within the context of trans-border terrorism.

\section{a) Operation Enduring Freedom}

The first example, referred to in the Leiden Policy Recommendations quote at the end of Section 4.1.2, is Operation Enduring Freedom. This action in Afghanistan, beginning in 2001 as a response to $9 / 11$, is difficult to reconcile with the specific necessity analysis set out in Section 2.5. In this incident, in addition to targeting the source of the armed attacks (namely Al-Qaeda), the American-led coalition also targeted the military installations, personnel and apparatus of the Taliban regime, which was the de facto government of Afghanistan at the time.50 The action led to the overthrow of the Taliban and its replacement with a transitional government supported by UN peacekeepers. ${ }^{51}$ This was despite the fact that whilst the Taliban was considered to have wilfully and unlawfully harboured Al-Qaeda, it had not sent, directed or controlled them, thereby giving rise to attribution.52 The Taliban was not, therefore, regarded as being directly responsible for the 9/11 armed

\footnotetext{
${ }^{49}$ See e.g. Deeks (2012); Chachko and Deeks (2016); Corten (2016); Gray (2018) 240, $243-$ 4.

50 See S/2001/946 (2001); Murphy (2002) 246-7, 250.

51 (2001) UNYB 254; Murphy (2002) 250-1; Gray (2018) 231-3.

52 The Taliban refused the UNSC's demand (acting under Chapter VII UN Charter) to hand over Osama bin Laden. UNSC Res 1267 (1999) para 2. The failure was expressly noted by the UNSC in UNSC Res 1390 (2002) 1. See further Murphy (2002) 243-4, 248; Ruys (2010) 440.
} 
attacks, only for acquiescing in terrorism, ${ }^{53}$ and making the attacks possible. ${ }^{54}$ Yet, despite divided scholarly opinion, states and international organizations, including the UNSC, generally accepted the coalition action in Afghanistan as lawful, encompassing it would seem, the targeting of the Taliban. ${ }^{55}$

There is no definitive interpretation of this incident of state practice, in terms of establishing an agreed justification for targeting the Taliban in addition to AlQaeda. ${ }^{56}$ One option is to say that action against them was simply necessary to achieve the defensive purpose of defeating Al-Qaeda, given the support they received from the Taliban. ${ }^{57}$ Indeed, the USA and the UK appeared to take the view that they could not destroy Al-Qaeda without removing the Taliban..$^{58}$ The Americans justified taking defensive action against the Taliban on the basis that they had made the 9/11 attacks possible by allowing parts of Afghanistan to be used by Al-Qaeda as a base of operation. ${ }^{59}$ This allowed AlQaeda to use Afghan territory to plot and prepare for the attacks and the

\footnotetext{
${ }^{53}$ Whilst not amounting to an armed attack, acquiescence in terrorist acts involving a threat or use of force constitutes an unlawful use of force in breach of Art 2(4) UN Charter. See Friendly Relations Declaration, para 1; UNSC Res 748 (1992). Following 9/11, this general approach was encapsulated in UNSC Res1373 (2001) para 2.

${ }^{54}$ E.g. UN Docs S/2001/946 (2001); S/2001/947 (2001). For arguments over the issue of attribution see references in nn 49, 55, 57.

${ }^{55}$ See Section 2.4.2(b). See further Trapp (2007) 149-56 (including footnoted citations); Ruys (2010) 495, 503-510, including in relation to the question of attribution and the controversies surrounding targeting the Taliban in addition to Al-Qaeda.

${ }^{56}$ On the question of indeterminacy, see Milanovic (2010).

${ }^{57}$ Other arguments focus on establishing a link between the armed attacks and the state of Afghanistan. Such positions include that the Taliban was complicit in Al-Qaeda's actions, with complicity satisfying a lower standard of attribution and giving rise to a right of self-defence directly against it. See e.g. Tams (2009) 385 (albeit not in the specific context of this incident). This approach is conceptually flawed, however. It unnecessarily conflates the primary rules of the JAB with the secondary rules of state responsibility. Trapp (2009); Tsagourias (2016) 8067. Another possible justification is that the Taliban's 'substantial involvement' in Al-Qaeda's activities (per Art 3(g) Definition of Aggression) makes it the author of the 9/11 armed attacks and, therefore, subject to a defensive response. See Tsagourias (2016) 816-19, arguing that substantial state involvement (whether acts or omissions) with NSAs that commit armed attacks might satisfy this requirement, where the state knows that the NSA is willing to commit attacks and such aid or assistance facilitates this. See also Ruys and Sten Verhoeven (2005) 314-17, making a similar argument. Alternatively, sheltering and refusing to surrender AlQaeda might be viewed as endorsement of the 9/11 attacks, thereby constituting the Taliban as accessories-after-the-fact and justifying direct defensive action against them. Dinstein (2017) 243, arguing the incident is, therefore, interstate. This does not appear to be the position of the USA or the UK, however.

58 Greenwood (2002) 309.

59 UN Doc S/2001/946 (2001). As to whether this amounts to a lower 'harbouring' standard of attribution, and analysis of the attribution issue more generally, see Henderson (2018) 31416, 319-22.
} 
Taliban were unwilling to prevent this.$^{60}$ The UK likewise noted the Taliban's support. ${ }^{61}$ The UK Foreign Affairs Committee concluded that the defeat of the Taliban did achieve its major objective, which was to destroy Al-Qaeda's support base in Afghanistan and significantly to weaken the organization. ${ }^{62}$

We might hesitate, however, in accepting this incident as a precedent based on necessity for future action against a host state, absent attribution to it of an armed attack. The particular circumstances of Operation Enduring Freedom mean that it has been viewed as an exception to anti-terrorist self-defence state practice that has been understood as justifying force against terrorists, not against states ${ }^{63}$ Relevant factors include the magnitude of the Al-Qaeda terrorist attacks, the unique symbiosis between Al-Qaeda and the Taliban and the express recognition of the right of self-defence by the UNSC. ${ }^{64}$ This conclusion is explored further in the following Section.

\section{b) Coalition action in Syria}

More recent state practice, in the form of the global response to Daesh, suggests that Operation Enduring Freedom is indeed sui generis, at least in relation to directly targeting manifestations of the host state. Such practice also highlights the potential for specific necessity to act as a restraint on a defending state's actions when responding to NSA armed attacks on the territory of a host state. The American-led Coalition operating against Daesh and other terrorist groups was established in September 2014..$^{65}$ As of July 2018 , it consists of a coalition of over seventy states, in addition to international organisations such as the Arab League, NATO and the EU. Its stated mission is to degrade and ultimately defeat Daesh in Syria and Iraq. ${ }^{66}$ The Coalition

\footnotetext{
${ }^{60}$ Bellinger (2006).

61 UN Doc S/2001/947 (2001).

62 House of Commons Foreign Affairs Committee, Report HC 384, $20^{\text {th }}$ June 2002, para 87.

${ }^{63}$ Tams in Van den Herik and Schrijver (2013) 411.

${ }^{64}$ Ruys (2010) 435, 495.

65 The number of terrorist groups operating in Iraq and Syria is diverse and complex. The main groups, however, are Daesh, Al-Qaeda, and Al-Qaeda-associated forces. See e.g. Gill (2016) 357-9; Gray (2018) 237-48. See also Corten in Ruys and Corten (2018) 873-98.

${ }^{66}$ See <http://www.inherentresolve.mil/>; <http://theglobalcoalition.org/en/home/>. There is controversy regarding the precise ultimate aim of some coalition partners. For example, the
} 
action in Syria represents a factually and legally complex picture for the application of the JAB, as well as IHL and international human rights law. Such action takes place in the same space as a bloody civil war and is further complicated by other non-Coalition actors fighting Daesh and other terrorist groups in the same vicinity. These include Russia, Iranian-back militia groups and the Syrian regime itself.

Measures taken by the Coalition in Syria consist of well-documented air strikes and less detailed action by special forces and other military personnel within Syrian territory. ${ }^{67}$ Given the lack of information regarding ground operations and related troop numbers, it is the former category of action that best assists for the present analysis. ${ }^{68}$ As of 9 August 2017, the Coalition had conducted over 11,000 air strikes in Syria. ${ }^{69}$ Even a cursory glance at the strike release reports quickly reveals the scale of the targeting of public and private apparatus and infrastructure within Syrian territory..$^{70}$ These include bridges, tunnels, factories, 'ISIL-held buildings', 'ISIL headquarters', 'fighting positions', 'storage facilities' and 'supply routes'. Economic targets are also evident, such

USA appears set on regime change. See e.g. 'The Trump Administration Appears to Embrace Regime Change in Syria', The Atlantic, 6 April 2017, $<$ https://www.theatlantic.com/international/archive/2017/04/us-syria-policy/522117/>; 'US envoy Nikki Haley says Syria regime change is inevitable', CNN, 10 April 2017, $<$ http://edition.cnn.com/2017/04/09/middleeast/syria-missile-strike-chemical-attack-

aftermath/index.html>. In and of itself, such goal goes beyond a defensive purpose. Given that the Assad government is also combatting Daesh, it is unlikely to be either necessary or proportionate to achieving that defensive goal. See further Section 1.3.2.

${ }^{67}$ See e.g. 'US Special Forces Carry Out Secret Ground Raid Against ISIL in Syria, 'Killing at Least 25 Jihadists', The Telegraph, 9 January 2017, $<$ http://www.telegraph.co.uk/news/2017/01/09/us-special-forces-carry-ground-raid-againstisil/>.

${ }^{68}$ Regarding the ambiguity regarding troop numbers, see e.g. 'Full Transcript of Media Q\&A with Major General Jones', Coalition Media', 28 June 2017, $<$ http://theglobalcoalition.org/en/full-transcript-of-media-q-a-with-major-general-jones/>;

'There are four times as many U.S. troops in Syria as previously acknowledged by the Pentagon', The Washington Post, 6 December 2017, < https://www.washingtonpost.com/news/checkpoint/wp/2017/12/06/there-are-four-times-asmany-u-s-troops-in-syria-as-previously-acknowledged-by-thepentagon/?utm term=.830a0949682d>. On Turkey's ground operations in Syria, see n 117. ${ }_{69}$ Latest figures provided by the Coalition. See U.S. Department of Defense, Operation Inherent Resolve, Airstrike Updates <https://www.defense.gov/OIR/> [last accessed 23 July 2018].

70 Operation Inherent Resolve Strike Releases, <http://www.inherentresolve.mil/News/StrikeReleases/>. Coalition partners also publish details of their individual activities. E.g. UK Ministry of Defence, British Forces Air Strikes in Iraq and Syria: Monthly List, $<$ https://www.gov.uk/government/publications/british-forces-air-strikes-in-iraq-monthly-list>. 
as oil collection facilities that have provided the necessary funds for Daesh to govern the areas that have been captured and to carry out military operations. $^{71}$

Putting aside, for the moment, the issue of the proportionality of these air strikes and the ensuing collateral civilian damage, ${ }^{72}$ the current issue is whether, as a general matter, targeting Syrian infrastructure and apparatus in this way might satisfy the test of specific necessity. ${ }^{73}$ First, let us consider the Coalition's use of force against the military apparatus and personnel of Syrian and pro-Syrian forces. There are a handful of examples. They include strikes against pro-Syrian forces advancing inside so-called 'de-confliction zones', the shooting down of unmanned aerial vehicles and a SU-22 fighter-bomber ${ }^{74}$ In these cases, it is noteworthy that the reason given by the Coalition for targeting Syrian and pro-Syrian forces directly has been the defence of Coalition and/or partnered forces. ${ }^{75}$ The Coalition has consistently insisted that its mission is to defeat Daesh in Iraq and Syria and that it does not seek to fight the Syrian regime or forces partnered with them. ${ }^{76}$ In fact, the Coalition has gone so far as to publicly admit error in unintentionally targeting Syrian government forces. ${ }^{77}$ This does not explain away all Coalition action in and against Syria

\footnotetext{
${ }^{71}$ For example, 'Operation Tidal Wave II Deprived ISIS of $80 \%$ of its Oil Collection Facilities as well as \$25 Million a Month in Oil Revenue Which Negatively Impacted ISIS Military Operations and Halted Enemy Expansion.' Operation Inherent Resolve History, $<$ http://www.inherentresolve.mil/Portals/14/Documents/Mission/HISTORY 170CT2014JUL2017.pdf?ver=2017-07-22-095806-793>. Regarding whether such economic targets constitute 'military objectives' for the purposes of IHL, see n 147.

72 See Section 4.2.3.

${ }^{73}$ The aim is not to analyze individual instances of targeting, but rather the general policy adopted by the Coalition.

${ }^{74}$ For details of these incidents, see Ruys et al (2017) 391-4. The US airstrike against a Syrian military base in response to a use of chemical weapons is a separate issue. See ibid, 396402. For commentary regarding whether such targeting renders the conflict international or non-international in nature, see e.g., ICRC's 2016 Art 2 Commentary, para 257-64; Akande in Wilmshurst (2012) 70-9; Gill (2016) Just Security; Watkin (2016) Just Security; Haque (2016). See further $\mathrm{n} 93$ and accompanying text.

${ }^{75}$ Ruys et al (2017) 21-24. An analysis of the legality of such claim is beyond the scope of this thesis. See e.g. Haque (June 2017).

${ }^{76}$ See ibid and the documents cited in $\mathrm{n} 23$.

77 'US Military Admits it Mistakenly Targeted and Killed Loyalist Syrian Forces', The Guardian, 29 November 2016, <https://www.theguardian.com/world/2016/nov/29/us-military-airstrikesmistake-syria-assad-deir-ez-zor>. This action was criticized by Russia and Syria and condemned by Venezuela before the UNSC. UN Doc S/PV.7777 (2016) 10 (Russia); 14 (Venezuela); 22 (Syria). See also: 'Syrian War: US Military Strikes Pro-Assad Convoy Amid Clashes with Coalition Forces, Officials Say', ABC News, 19 May 2017,
} 
however. The nature, purpose and justification of the so called 'de-confliction zones' are unclear and reports of the USA occupying a Syrian airfield raise troubling legal issues, not least for necessity and proportionality. ${ }^{78}$

Yet, the general trend implies that the Coalition does not deem it necessary to engage the military of the Syrian regime and its partners in order to carry out its defensive operation against Daesh. ${ }^{79}$ Instead, they will only engage them directly if the defensive operation is threatened by force. This approach accords with previous practice. Over the years, states have consistently asserted, and justified, a right of self-defence against NSAs in foreign territory by expressly stating that they are not using force against the host state itself, rather their targeting is limited to the NSAs..$^{80}$ This was the case, for example, with American action against Al-Qaeda in Sudan and Afghanistan in 1998. ${ }^{81}$

Israel has also consistently made this claim in its fight against the PLO and Hezbollah. ${ }^{82}$ During the 2006 invasion of Lebanon Israel insisted that it was not attacking the government of Lebanon, but rather the military assets of Hezbollah located in that country. It went on to assert that it had avoided striking Lebanese military assets, unless they were used to assist Hezbollah. ${ }^{83}$ Most recently, Turkey, in its claim of self-defence against what it characterizes as Kurdish terrorists operating in Syria, expressly limited its actions to terrorist targets. At the same time, it emphasized its commitment to the territorial

\footnotetext{
$<$ http://www.abc.net.au/news/2017-05-19/us-strikes-syria-convoy-threatening-us-backedforces/8540070>.

${ }^{78}$ Further conclusions are difficult to draw in the absence of additional details. See, however, Horowitz (2016); Bridgeman (2017).

${ }^{79}$ Regarding scholarly support for this general position, Dinstein (2017) 300 , agrees that host state armed forces must not be engaged and host state 'installations' must be exempt from attack. He does not provide reasons for such conclusion however. This author suggests that the best interpretation of state practice is that it is due to specific necessity. Such explanation is supported, e.g. by Tsagourias (2016) 823. Tams and Devaney (2012) 105, however, characterise this as an issue of proportionality.

80 Indeed, up until 2007, Trapp (2007) 155, noted that all invocations of self-defence against terrorists since 2001 had operated on this basis.

81 UN Doc S/1998/780 (1998).

82 In relation to action against the PLO, see e.g. UN Docs S/PV.2071 (1978) paras 52-8 (Israel); S/PV.2611 (1985) paras 65-7 (Israel).

83 'Behind the Headlines: Israel's Counter Terrorist Campaign', Israel Ministry of Foreign Affairs, $15 \quad$ August 2006, $<$ http://www.mfa.gov.il/MFA/ForeignPolicy/lssues/Pages/lsraels\%20counter\%20terrorist $\% 20$ campaign \%20-\%20FAQ\%2018-Jul-2006.aspx>.
} 
integrity and political unity of Syria. ${ }^{84}$ Such practice constitutes a direct expression of what states consider to be the defensive necessity, even if not explicitly characterized in these terms. If the armed attacks and enduring threat originate from NSAs, then defensive targeting should be limited accordingly.

State practice supports the general proposition, therefore, that the governmental and military apparatus and infrastructure of the host state (and its allies) are not to be targeted directly whilst acting in self-defence against NSAs on the territory of the host state. ${ }^{85}$ Absent attribution of the armed attack, it is difficult to argue that targeting such sovereign trappings of 'the state' will ever be necessary to support a self-defence claim. A narrow exception to this general rule, as exemplified by the targeting of the Taliban during Operation Enduring Freedom, might be where there is complicity between the host state and the NSAs, or the former is somehow supporting or protecting the latter. This remains a unique and unclear precedent, however, and is controversial. Absent a very close connection indeed, there can be no defensive purpose served by directly targeting the host state in this manner. ${ }^{86}$

However, the Syria incident does show that states participating in the Coalition action against Daesh accept that certain elements within the host state are targetable. Such targets are reflected in the strike release reports referred to above. They exemplify the difficulties with trying to separate neatly permissible 'NSA targets' from impermissible 'host state targets'. However, prima facie, many of these targets are capable of satisfying the test of specific necessity, regardless of whether we consider such targets to be inherently civilian, or public/state owned. This on the basis that they are either under the control of Daesh and are being used by them to conduct their armed activities (e.g. 'ISILheld buildings', 'ISIL headquarters', 'fighting positions' etc), or directly contribute to such activities and the ongoing threat that such activities pose to

\footnotetext{
84 UN Doc S/2018/53 (2018).

${ }^{85}$ As noted, controversial claims of local force protection might be an exception to this general rule. Further clarity is required on this point, however.

${ }^{86} A$ fortiori if the failure to combat the NSAs is due to inability, rather than unwillingness, on the part of the host state. Directly targeting its military would serve only to further impair that ability. This could not logically be regarded as necessary.
} 
Coalition partners (e.g. bridges, tunnels, factories, oil collection facilities and so forth). Destroying, capturing or neutralizing such targets either directly affects Daesh's capacity to conduct military operations or cuts off the financing that allows them to continue. ${ }^{87}$ Targeting them is, therefore, potentially necessary for the effective exercise of the right of self-defence against the NSAs, which is the primary purpose of such action. Any effect on the assets or persons of the host state is incidental to this necessity. ${ }^{88}$

In attempting to draw a line between permissible 'NSA targets' and impermissible 'host state targets', there is a strong argument to be made that when public property is under the control of NSAs, and not under the effective control of the host state, it can no longer be identified with that of 'the state'. This accords with Coalition action that is, as a matter of policy, limited to targeting Daesh, and only Daesh, in order to counter the threat that they pose. This is the position explicitly adopted by the Coalition, ${ }^{89}$ and separately a number of its partners. ${ }^{90}$ It also reflects the position of the Coalition that their military operations are carried out in areas controlled by Daesh (and, ipso facto, not in control of the Syrian government), in partnership with Syrian allies on the ground and aimed at liberating the local Syrian population. ${ }^{91}$

For the purposes of specific necessity, therefore, where the Coalition targets public or private buildings that have been captured or occupied by Daesh or, in the case of bridges, roads and the like, are being used by them, this is not to be equated with targeting the state of Syria itself. ${ }^{92}$ The Coalition should only

\footnotetext{
${ }^{87}$ See further Section 2.5; n 147 and accompanying text.

${ }^{88}$ Tsagourias (2016) 823, also adopts this position. The permissible extent of such incidental effects is an issue for proportionality. See Section 4.2.3.

89 'Q\&A Session: Transcript of Major General Jones' Opening Remarks', Coalition Media, 26 June 2017, <http://theglobalcoalition.org/en/qa-session-transcript-of-major-general-jonesopening-remarks-june-26-2017/>.

90 See e.g. the reports of self-defence to the UNSC referred to in $n$ 23; USA State Department Legal Adviser Speech 2016, 240-1.

91 'Our Mission', Combined Joint Task Force Operation Inherent Resolve Fact Sheet, $<$ http://www.inherentresolve.mil/Portals/14/Documents/Mission/20170717$\% 20$ Updated $\% 20$ Mission $\% 20$ Statement $\% 20$ Fact $\% 20$ Sheet.pdf?ver $=2017-07-17-093803$ $770>$.

${ }^{92}$ Syria has complained, however, that by striking Syrian service, economic, industrial and productive infrastructure, the Coalition has demonstrated hostile intentions towards it. E.g. UN Doc S/2016/31 (2016).
} 
be regarded as using force against the Syrian state when it engages its armed forces directly, attacks national assets that are under Syrian state control, or occupies its territory. The fact that the Coalition is avoiding doing all of these things, albeit without a perfect success rate, provides support for the general premise. Drawing an analogy with the classification of conflicts under IHL supports this conclusion. Gill argues that where intervening states direct their force solely against the NSAs, albeit without consent on host state territory, the classification is one of a non-international armed conflict between the intervening state(s) and the NSAs, not an international armed conflict between the intervening state(s) and the host state. ${ }^{93}$ Taking the same approach to JAB necessity is logical and accounts for the Coalition state practice in Syria.

This argument is strongest with respect to those areas where the Syrian government has lost effective control of its territory. In these circumstances, the necessity of taking action is greatest, given the inability of the Syrian regime to counter Daesh activities in such areas. ${ }^{94}$ This argument is often a feature of state justifications for cross-border action against NSAs. This is reflected, for example, in the attitude of Coalition states that have referred to ungoverned space and/or a lack of effective territorial control when justifying their actions in Syria. ${ }^{95}$ Likewise, Turkey has relied on Iraq's lack of control

\footnotetext{
${ }^{93}$ Gill (2016) 367-73. In contrast, Akande in Wilmshurst (2012) 70-9, maintains that a use of force on the territory of another state, without its consent, is a use of force against that state. This is the case, he argues, even if such force is directed only against the NSAs and not against the governmental structures of that state. This gives rise to an international armed conflict between the two states. The ICRC's 2016 Art 2 Commentary, paras 224, 260-3, also follows this approach. Akande, ibid, notes however that his is the minority view, with most commentators focusing on the nature of the parties to a conflict (i.e. where the conflict is between a state and NSAs, this renders it a non-international armed conflict). Akande's conclusion also runs contrary to the state practice referred to in this Chapter that suggests that defending states do not consider themselves as being in an armed conflict with the host state, regardless of the latter's lack of consent.

${ }_{94}$ Even if necessary, targeting NSAs in territory in which the host state lacks effective control might still be regarded as breaching that state's sovereignty. Tsagourias (2016) 811. See further Section 4.2.3.

${ }^{95}$ E.g. 'Memorandum to the Foreign Affairs Select Committee, Prime Minister's Response to the Foreign Affairs Select Committee's Second Report of Session 2015-16: The Extension of Offensive British Military Operations to Syria', November 2015, www.parliament.uk/documents/commons-committees/foreign-affairs/PM-Response-to-FACReportExtension-of-Offensive-British-Military-Operations-to-Syria.pdf, 2, 9. See also the reports of self-defence to the UNSC referred to in $n 23$.
} 
over its northern territory when justifying using force there against the PKK. ${ }^{96}$ Israel made a similar claim regarding its actions against Hezbollah in Lebanon in 2006. ${ }^{97}$ In response, the importance of Lebanon extending control over its territory was generally emphasized by states and the UNSC. ${ }^{98}$ The lack of effective control over territory is also a feature of the implicit endorsement of Coalition action in Syria offered by UNSC Resolution $2249,{ }^{99}$ as well as the ostensibly supportive observations made by the UN Secretary General. ${ }^{100}$

State practice arising out of the Syrian incident suggests, therefore, that selfdefence against armed attacks by NSAs might necessarily involve damage to, and destruction of, a host state's apparatus and infrastructure. This points to an increasing acceptance by the states involved of harm to a host state. Yet, in contrast to Operation Enduring Freedom, Coalition action against Daesh does not, as a matter of policy, involve the deliberate targeting of the host state. There are, therefore, limits on how far states will go in the pursuit of a defensive purpose. Whilst there may be any number of explanations for such limits, one of the most obvious is specific necessity. Put simply, it is not necessary to target directly manifestations of the Syrian state in order to defend against the Daesh threat.

This distinction between Operation Enduring Freedom and Coalition action in Syria partly comes down to the relationship in each case between the host state and the NSAs. In the former case, the active harbouring of the Taliban regime, and the refusal to hand over Osama bin Laden, meant that to combat Al-Qaeda effectively it was also deemed necessary to target the Taliban. In contrast, there is no suggestion that President Assad has a positive relationship with Daesh or other terrorist organizations. To the contrary, the

\footnotetext{
${ }^{96}$ E.g. UN Docs S/1996/479 (1996) 2; S/1997/7 (1997) 2. Whilst Turkey did not make an express claim of self-defence in these instances, the language employed comes close to it. Gray (2018) 147-8.

97 UN Doc S/2006/515 (2006).

98 UNSC Res 1701 (2006) para 3; Ruys (2010) 451-3.

99 The Resolution exhorted Member States to take action on the territory of Syria under the control of Daesh. UNSC Res 2249 (2015). See Section 4.1.3(c) for further analysis of this Resolution.

${ }^{100}$ See n 126 and accompanying text.
} 
Syrian government has insisted that it is 'waging a relentless war on the terrorists'. ${ }^{101}$ The issue, therefore, in the latter case is not one of unwillingness, but rather inability (or perceived inability) to deal with the threat effectively. ${ }^{102}$ Coalition action is, therefore, supplementing stated host state policy, rather than conflicting with it. It operates in place of it in territory beyond the control of the Assad regime. Targeting Syrian armed forces is not, therefore, necessary to achieve a defensive purpose. This explains why the Syrian military has not been deliberately targeted as a matter of policy, but rather sporadically by accident or as a result of claims of local force protection. Degrading the Syrian military would only increase the inability of the regime to deal with the Daesh threat.

Regarding the extent of state practice in support of these general propositions, of the approximately seventy states taking part in the Coalition, eleven have publicly claimed to be acting in self-defence against Daesh in Syria and have reported this to the UNSC. ${ }^{103}$ The fact that not all Coalition partners operating in Syria have explicitly made this claim, or made a report, is indicative of the inconsistent state practice in this area. This makes assessing such practice difficult, especially as the absence of a report to the UNSC may speak to whether or not a state genuinely believes itself to be acting in self-defence. ${ }^{104}$ However, the actions of Coalition partners, both those that have explicitly claimed a right of self-defence and those that have not, as well as the reactions of other states, speak directly to the issue of targeting in the course of defensive operations.

A number of Coalition states have taken part in airstrikes in Syria, whilst others have provided weapons, equipment, training and other support as part of the

\footnotetext{
101 E.g. UN Doc S/2016/46 (2016) 2.

102 See further Sections 4.1.1 and 4.1.2. The unwilling and unable doctrine in the context of the fight against Daesh is particularly controversial. This is partly because President Assad has asserted that he is actively fighting Daesh (and has requested the assistance of other states to do so), potentially suggesting that he is complying with the obligation of due diligence to combat terrorist threats originating from Syrian territory. Moreover, only a handful of states have explicitly, or implicitly, invoked the unable or unwilling doctrine in justifying their acts of self-defence against Daesh in Syria. See Corten (2016), in particular 778, 780-5, 791-3.

103 See $\mathrm{n} 23$.

104 Nicaragua, para 200.
} 
military action against Daesh. ${ }^{105}$ In terms of active participation in airstrikes, from North America the USA was assisted by Canada. ${ }^{106}$ European partners have included the UK, 107 France, 108 Germany, 109 Denmark, 110 The Netherlands, ${ }^{111}$ Norway ${ }^{112}$ and Belgium. ${ }^{113}$ From north Africa, Morocco sent warplanes, ${ }^{114}$ and several Arab countries have carried out, or supported, air strikes. The latter include Saudi Arabia, the UAE, Jordan, Bahrain and Qatar. ${ }^{115}$ Australia has also taken part, ${ }^{116}$ with Turkey undertaking both air and ground operations. ${ }^{117}$ Italy and Estonia have materially contributed to these military activities. ${ }^{118}$ Furthermore, a number of states have explicitly supported the

105 See generally 'Military', Coalition website, $<$ http://theglobalcoalition.org/en/category/military/>.

106 UN Doc S/2015/221 (2015). Canada later withdrew its fighter jets following the election of Prime Minister Trudeau in October 2015, but continues to participate in Operation Inherent Resolve. 'Canada's New Approach to Addressing the Ongoing Crises in Iraq and Syria and Impacts on the Region: Promoting Security and Stability', Prime Minister of Canada, 8 February 2016, <http://pm.gc.ca/eng/news/2016/02/08/canadas-new-approach-addressingongoing-crises-iraq-and-syria-and-impacts-region>.

107 UN Docs S/2015/688 (2015); S/2015/928 (2015).

108 UN Doc S/2015/745 (2015).

109 UN Doc S/2015/946 (2015).

110 UN Doc S/2016/34 (2016).

111 UN Doc S/2016/132 (2016).

112 UN Doc S/2016/513 (2016).

113 UN Doc S/2016/523 (2016).

114 'Moroccan F16s Undertake 20 Missions against 'Islamic State': British Magazine', Morocco World News, $3 \quad$ February 2015 , <http://www.moroccoworldnews.com/2015/02/150884/moroccan-f16s-undertake-20missions-islamic-state-british-magazine-2/>.

115 U.S. Department of Defense, 'US Military, Partner Nations Conduct Airstrikes in Syria', 23 September 2014, <www.defense.gov/news/newsarticle.aspx?id=123234>. None of these Arab states have communicated a report to the UNSC or otherwise made explicit the legal basis for their actions in Syria. Prior to the start of the Coalition action, however, the Arab League stressed the right of each member state, in accordance with its wish, to provide all means of self-defense, including military support to back the steadfastness of the Syrian people and the free army.' 24th Arab Summit Issues Doha Declaration, Arab League $24^{\text {th }}$ Summit, 21-27 March 2013, <http://arableaguesummit2013.qatarconferences.org/news/news-details-17.html>

116 UN Doc S/2015/693 (2015).

117 See UN Doc S/2015/563 (2015); 'Ministry: Turkey Joins Coalition Airstrikes against ISIS in Syria', CNN News, 29 August 2015, <http://edition.cnn.com/2015/08/29/europe/turkeyairstrikes/>; UN Doc S/2016/739 (2016); 'Turkish Tanks Roll into Syria, Pushing Islamic State out of Key Border Town', Reuters, 24 August 2016, <http://uk.reuters.com/article/uk-mideastcrisis-turkey-operation-idUKKCN10Z07L>. Turkey's actions in Syria are, however, complicated by the military action it is also taking against Kurdish forces. In respect of the most recent offensive in Afrin, entitled Operation Olive Branch see UN Doc S/2018/53 (2018); 'Airstrikes Pound Syria's Afrin as Turkey Launches 'Operation Olive Branch", Reuters, 20 January 2018, <https://uk.reuters.com/article/uk-mideast-crisis-syria-turkey/airstrikes-poundsyrias-afrin-as-turkey-launches-operation-olive-branch-idUKKBN1F90RS>.

118 UN Docs S/PV.7527 (2015) 38 (Italy); S/PV.7670 (Resumption 1) (2016) 34 (Estonia). 
Coalition's military action in Syria in deliberations before the UNSC, ${ }^{119}$ as has the European Union. ${ }^{120}$ Other states have given implicit backing. ${ }^{121}$

The UNSC gave implicit approval of defensive action against Daesh by way of UNSC Resolution 2249.122 What is more, the UNSC has since reiterated its call to the international community to combat Daesh and other terrorist groups. ${ }^{123}$ Far from condemning Coalition action, the UNSC instead noted the progress made in 2016 in taking back Daesh controlled territory in Syria. In so doing, it expressed grave concern that areas remained under their control, noting the negative impact of their continued presence, ideology and actions in the region. It linked the devastating humanitarian impact on the civilian populations to the acts of Daesh and other terrorist organizations, not to the actions of the Coalition. ${ }^{124}$ It is also significant that the UNGA has avoided criticizing the Coalition. As 'world-wide juries', the reaction of these two bodies is important. ${ }^{125}$

The UN Secretary General has followed this trend. He noted the lack of Syrian consent when the airstrikes began in September 2014 (without further comment on this point) and the need for those involved in the campaign to abide by IHL. He went on to remark, however, that the Syrian government was informed beforehand, that the strikes took place in areas not under the effective control of the government and that 'these extremist groups pose an

\footnotetext{
119 UN Docs S/PV.7281 (2014) 25 (Rwanda); S/PV.7316 (2014) 35 (Iraq); 65 (Albania); S/PV.7527 (2015) 55 (Bulgaria); 73 (Ukraine).

${ }^{120}$ E.g. UN Docs S/PV.7281 (2014) 42; S/PV.7540 (Resumption 1) 14.

${ }^{121} \mathrm{E} . \mathrm{g}$. 'It is incumbent upon individual Member States to take the steps needed to protect the Syrian people - steps that they are legally entitled to take - and to establish a no-fly zone over part of Syria.' UN Doc S/2015/190 (2015) Annex, 2-3 (Lithuania). Japan has called upon Russia to limit its air strikes against Daesh targets in Syria. In so doing, it appears to accept, as a general principle, the legality of targeting Daesh in that country. It goes on to note, however, that targeting non-Daesh targets 'would be a cause for concern.' UN Doc S/PV.7540 (Resumption 1) 19 (Japan). 'We also welcome the broad-based international coalition to fight the so-called Islamic State/Daesh and other terrorist groups.' UN Doc S/PV.7588 (2015) 14 (Angola). See also UN Doc S/PV.8178 (2018) 11 (Sweden); 12 (Kazakhstan).

122 This is discussed in detail in Section 4.1.3(c).

123 UNSC Res 2254 (2015) para 8; UNSC Res 2332 (2016) 2.

124 UNSC Res 2332 (2016) 2.

125 Tsagourias (2016) 824.
} 
immediate threat to international peace and security. ${ }^{126}$ At the very least, such statement shows an acceptance of the necessity of the action taken and, at best, may be interpreted as supportive of it. Since then, the focus of the UN's concern has been on such matters as compliance with IHL and human rights law, as well as peaceful settlement and the humanitarian situation on the ground. The legality, or even the legitimacy, of the Coalition operating within Syrian territory has been noticeably absent from its agenda. ${ }^{127}$

Support has not been universal, however. During the many UNSC meetings held since 2014 that have considered the situation in Syria, a limited number of states expressed general concern for action taken absent UNSC authorization, as well as the effect on the sovereignty, independence and territorial integrity of Syria. ${ }^{128}$ Whilst these pronouncements may point to unease regarding Coalition military action in Syria, they also recognize the threat posed by Daesh and do not go so far as to question the legality of such action. Likewise, Sweden has urged the Coalition to take 'greater care' in order to protect civilians in Syria but stopped short of directly criticizing the military action itself, and Kazakhstan has adopted a similar line. ${ }^{129}$ However, both states have since expressed greater implicit support. ${ }^{130}$

Beyond the UNSC, the NAM has adopted a more nuanced approach. In 2016, they condemned the actions of Daesh and other Al-Qaeda affiliated groups in Syria and elsewhere, recognizing the threat posed by terrorism to the region

\footnotetext{
${ }^{126}$ Ban Ki-Moon, 'Remarks at the Climate Summit Press Conference (including comments on Syria)', 23 September 2014, <https://www.un.org/sg/en/content/sg/speeches/2014-0923/remarks-climate-summit-press-conference-including-comments-syria>.

${ }_{127}$ See e.g. 'Report of the Independent International Commission of Inquiry on the Syrian Arab Republic'. UN Doc A/HRC/36/55 (2017); 'Syria: UN Relief Officials Condemn Targeting of Civilians, Infrastructure as Airstrikes Hit Raqqa', UN News Centre, 22 August 2017, $<$ http://www.un.org/apps/news/story.asp?NewsID=57396\#.WINLuFSFhqd>. See also UNSC Res 2332 (2016) 2.

${ }^{128}$ See e.g. UN Docs S/PV.7271 (2014) 15 (Argentina); 17-18 (Chile); 20 (China); S/PV.7419 (2015) 53 (Pakistan); S/PV.7527 (2015) 48-9 (Brazil); 'South African Ambassador: Syria Is an Independent Sovereign State, Can Handle Its Own Affairs', Syrian Arab News Agency, 22 June 2015, <http://sana.sy/en/?p=45877>. See further Corten (2016) 789, citing a number of state reactions that point to a general concern regarding the infringement of state sovereignty. 129 UN Doc S/PV.7931 (2017) 5-6 (Sweden); UN Doc S/PV.7983 (2017) 6 (Kazakhstan).

130 UN Doc S/PV.8178 (2018) 11 (Sweden); 12 (Kazakhstan).
} 
and the world. ${ }^{131}$ They did not offer any comments on the military actions of the Coalition, however. Their hesitance to condemn Coalition action contrasts with previous incidents where they have unequivocally stated their objections to expansive military interventions. ${ }^{132}$ Without referencing any specific bodies, states or acts, they simply affirmed, under the general heading of terrorism, that they 'totally reject[ed] targeting other States under the pretext of combating terrorism'. ${ }^{133}$ We should be hesitant in drawing firm conclusions from silence regarding particular incidents, and this statement could be interpreted in a number of ways. ${ }^{134}$ However, Daesh, Syria and concern regarding the targeting of states were all referenced by the NAM within the context of combatting terrorism. As such, one might have expected more specific language, had the summit wished to express disapproval of the Coalition action in Syria.

A smaller group of states have been more emphatic in their negative reactions. Despite not initially submitting a complaint to the UNSC regarding Coalition action, Syria was increasingly critical, going on to denounce the intervention as aggression and illegal intervention. ${ }^{135}$ Its closest ally in the conflict, Russia, condemned the airstrikes and questioned their legitimacy. ${ }^{136}$ Iran characterized

\footnotetext{
${ }^{131}$ Final Document of the 17th Summit of Heads of State and Government of the Non-Aligned Movement, 17-18 September 2016, $<$ http://cns.miis.edu/nam/documents/Official Document/XVII-NAM-Summit-Final-OutcomeDocument-ENG.pdf>, paras 258, 258.29.

${ }^{132}$ Following the 1999 NATO bombings of Kosovo, for example, the Group of 77 and China were swift to reject the so-called 'right' of humanitarian intervention. Group of 77 South Summit, 'Declaration of the South Summit' held in Havana, Cuba (10-14 April 2000) para 54. 133 Ibid, para 258.34.

${ }^{134}$ Conclusions are difficult to draw from silence, in particular as to whether it should be construed as acquiescence, or even support. The issue of interpreting silence when attempting to divine normative change (whether by way of customary development or treaty interpretation) is a complex and controversial issue. See e.g. Corten (2005) 817-18; Ruys (2010) 38; Henry (2017); Starski (2017).

135 See e.g. UN Docs S/2015/719 (2015); S/2015/727 (2015); S/2016/745 (2016); S/2015/851 (2015); S/2015/933 (2015); S/PV.7774 (2016) 27-28; S/PV.7785 (2016) 19; S/PV.7882 (2017) 46-7; S/PV.7921 (2017) 18-20.

136 'Russia Condemns U.S. Strikes on Islamic State Without Syria's Approval', The Moscow Times, 25 September 2014, <https://themoscowtimes.com/news/russia-condemns-us-strikeson-islamic-state-without-syrias-approval-39759>.
} 
them as illegal. ${ }^{137}$ Other states followed suit, including Ecuador, ${ }^{138}$ Cuba, ${ }^{139}$ Venezuela, ${ }^{140}$ Egypt, ${ }^{141}$ China, ${ }^{142}$ and Bolivia. ${ }^{143}$ There are, therefore, a number of states that have expressly rejected the right of other states to intervene in Syria, absent consent, in order to combat Daesh. Yet, it is notable that Russia and China have only taken their opposition so far. In their capacity as permanent members of the UNSC and, therefore, as agents of the international community, ${ }^{144}$ they have not vetoed UNSC resolutions (like UNSC Resolution 2249) that are implicitly supportive of anti-terrorist military action within Syrian territory.

Moreover, where states have denounced Coalition action, this has tended to be in general terms. This makes it hard to engage with the legal question of whether and how they relate to claims of self-defence and, more specifically, the necessity of targeting elements of Syria's civilian infrastructure and apparatus controlled or used by Daesh. Yet, given the nature and scale of Coalition action and the fact that it began in 2014 , there has been a relative lack of specific and direct condemnation by other states. This is despite the fact that the Syrian incident has been a constant feature of the UNSC agenda ever since. In that time, only a relatively few states have explicitly characterized Coalition action as unlawful.

\footnotetext{
137 'Syria Air Strikes: Iran 'Says US Attacks on Isis are Illegal", Independent, 23 September 2014, <http://www.independent.co.uk/news/world/middle-east/syria-air-strikes-iran-says-usattacks-on-isis-are-illegal-9751245.html>.

138 'Ecuador Rejects US offensive in Syrian Territory', Ecuadorian Ministry of Foreign Affairs and Human Mobility, <http://www.cancilleria.gob.ec/ecuador-rechaza-ofensivaestadounidense-en-territorio-sirio/> (translation by this author).

139 'We reject unilateral actions and those taken outside the United Nations, such as those of the United States, which is launching air strikes across boundaries of sovereign States in clear violation of international law.' UN Doc S/PV.7281 (2014) 62.

140 'We denounce the current attempt to apply the same formula in Syria as was done in Iraq and Libya.' UN Doc S/PV.7419 (2015) 24.

141 'Egypt Defends Syria's Territorial Unity after Turkey Moves against IS', Reuters, 29 July 2015 , $<$ http://uk.reuters.com/article/uk-mideast-crisis-syria-egyptidUKKCNOQ31AY20150729>.

142 '[The USA's] gross violations of Syria's sovereignty have resulted in the further spread of the terrorist threat.' UN Doc S/PV.7857 (2017) 22.

${ }_{143}$ '[W]e see that completely illegal, unilateral military actions are still occurring, (...) undermining the sovereignty and integrity of the Syrian Arab Republic and Government efforts to combat Da'esh.' UN Doc S/PV.7944 (2017) 7.

${ }^{144}$ Art 24 UN Charter.
} 
In summary, whilst not unequivocal, a careful review of the numerous UNSC deliberations and other sources concerning the situation in Syria since 2014 shows substantial support for the Coalition military action against Daesh within Syrian territory. Crucially, this consists of state backing, as well as implicit support from principal UN organs (or, at least, a lack of condemnation from them). To the extent that this reaction is viewed as a positive endorsement, its precise parameters are still debatable. The position of the unwilling or unable doctrine, for example, is particularly contentious and the legal basis for military action in Syria varies from defending state to defending state. Yet, this incident points to an acceptance of a general right to use defensive force against Daesh in Syria. This is despite a lack of attribution of armed attacks to that state, or substantial involvement by the Assad regime in Daesh's activities (per Article 3(g) Definition of Aggression). This furthers the general trend of state practice since 9/11 on this issue and is part of the international community's stance towards international terrorism as reflected in, and supported by, UNSC Resolution 2249 and subsequent resolutions. ${ }^{145}$

Furthermore, the post $9 / 11$ state practice suggests that where the host state is unwilling or unable to tackle the threat itself (including where it is acquiescing in such threat), defending states may deem it necessary to target non-military elements of a host state being used or occupied by the NSAs that were directly responsible for the armed attack. In such cases, the defending state has no choice of means but to use force both on, and potentially against, the territory of the host state in order to achieve an effective defensive outcome. This necessity is also reflected in UNSC Resolution 2249, where the UNSC unanimously recognized the need to 'eradicate' Daesh safe havens in Syria. ${ }^{146}$ This conclusion sits as a general premise however. At present, firm guidelines are difficult to deduce from the aforementioned state practice regarding what

\footnotetext{
145 Wood (2016) 8, for example, argues that Resolution 2249 reflects the UNSC's unanimous approval of a right of self-defence against armed attacks by NSAs unattributable to a state. See further Section 4.1.3(c).

${ }^{146}$ Wood (2016) 8, notes that the UNSC's reference to taking all necessary measures on Syrian territory under the control of Daesh to eradicate Daesh safe havens 'may be an important statement of what is necessary and proportionate in the circumstances.' See further Section 4.2.1.
} 
particular aspects of the host state's civilian apparatus and infrastructure are viewed by states as lawful targets for the purposes of the JAB. However, a review of the Operation Inherent Resolve strike release reports referred to above suggests that the members of the Coalition carrying out military strikes generally consider that targets must be directly connected to, or supportive of, the military activities of Daesh. ${ }^{147}$ Whether they are also connected with actual or imminent armed attacks, however, and serve an identifiable defensive purpose is unclear. ${ }^{148}$ Further clarification from states on this point would be welcome.

\section{c) UNSC involvement - a limiting factor}

This conclusion is potentially troubling, pointing as it does to an expansive right for states to use force in self-defence, once general necessity is established. Yet, there does appear to be a significant limiting factor on the ability to target elements of the host state in this way. This is the central role played by the UNSC in these specific incidents and in the global response to terrorism more generally. The Coalition action in Syria is a prime example. During 2014 and 2015 , and in line with its previous practice, the UNSC consistently condemned the acts of Daesh and other terrorist groups, whilst calling upon all Member States to act collectively to combat the threat to international peace and security caused by terrorist acts. ${ }^{149}$ The UNSC proceeded to adopt unanimously Resolution 2249 , which reaffirmed that 'terrorism in all forms and manifestations constitutes one of the most serious threats to international peace and security.' It called upon all Member States to 'redouble and

\footnotetext{
${ }^{147}$ As noted, to be lawful targets, they must also constitute military objectives for the purposes of IHL. See Section 2.5. A controversial category of targets includes objects, such as oil facilities and tankers, that contribute to financing Daesh's military activities. If the oil production facilities generate revenue that sustain Daesh's operations, this might make an 'effective contribution to military action' for the purposes of targeting them under Art 52(2) API. This will depend on their precise connection with the military action. On this basis, they are to be contrasted with 'war sustaining' objects that, although a controversial issue, are not generally viewed as targetable under IHL. See further International Law Association Study Group Final Report (2017) 15-16. The USA takes a different approach to 'war sustaining' objects. For commentary in the context of the fight against Daesh, see e.g. Watkin (2014); Van Schaack (2015). As to whether Daesh's money is a legitimate target, see Richemond-Barak (2016).

${ }_{148}$ See Section 2.5.

149 E.g. UNSC Res 2178 (2014); 2195 (2014); 2199 (2015); 2214 (2015).
} 
coordinate their efforts to prevent and suppress terrorist acts (...) and to eradicate the safe haven [that terrorists] have established over significant parts of Iraq and Syria'. 150

Such resolution does not, in and of itself, authorise the use of force against Daesh and other named terrorist groups. ${ }^{151}$ Instead, the UNSC called upon the international community 'to take all necessary measures, in compliance with international law' to respond to the stated terrorist threat. ${ }^{152}$ Yet, such exhortation applies, implicitly at least, to each state employing its right of selfdefence in response to armed attacks. It confers a degree of legitimacy on states making this claim. Wood characterises it as an endorsement of claims of self-defence against Daesh in Syria, ${ }^{153}$ whilst Akande and Milanovic maintain that its constructive ambiguity may provide political cover for military intervention, without endorsing any particular legal basis for such action. ${ }^{154}$ Significantly, following the passing of UNSC Resolution 2249 in 2015, six states invoked it in support of their claims of self-defence against Daesh in Syria, explicitly referencing it in their Article 51 reports to the UNSC. ${ }^{155}$ More specifically, this practice can be interpreted as such states accepting a collective determination of the necessity of action against Daesh in Syria. As a factual matter, the UNSC is confirming the unwillingness or inability on the part of Syria to counter Daesh on its territory. ${ }^{156}$

\footnotetext{
150 UNSC Res 2249 (2015). See further UN Doc S/PV.7565 (2015).

151 The Resolution was not passed under Chapter VII UN, nor does it authorise or decide that force should be used. See further Akande and Milanovic (2015); Wood (2016) 7.

152 UNSC Res 2249 (2015).

${ }^{153}$ Wood (2016) 8, noting that no one at the UNSC meeting that adopted the Resolution suggested otherwise.

${ }^{154}$ Akande and Milanovic (2015).

155 UN Docs S/2015/928 (2015) (UK); S/2015/946 (2015) (Germany); S/2016/34 (2016) (Denmark); S/2016/132 (2016) (The Netherlands); S/2016/513 (2016) (Norway); S/2016/523 (2016) (Belgium). Whilst not unanimous, or necessarily explicit, the views of a number of individual UNSC members of UNSC Resolution 2249 can also be interpreted as it being supportive of military action against Daesh in Syria. See UN Doc S/PV.7565 (2015) 2 (France); 4 (USA); 5 (Nigeria); 6-7 (Jordan); 7 (Angola) 8-9 (UK).

${ }^{156}$ Hakimi and Cogan (2016), along similar lines, argue that the six states are using UNSC Res 2249 to establish, as a legal fact, that the preconditions for defensive force have been met. See also Henderson (2018) 327. For the effect of this resolution on proportionality, see Section 4.2.1.
} 
The UNSC's role in this incident is not unique. In response to $9 / 11$, it explicitly recognized and reaffirmed the right of self-defence, thereby providing implicit support for the ensuing Operation Enduring Freedom. ${ }^{157}$ Prior to this, the UNSC had insisted that the Taliban cease supporting terrorism and take effective action against it, including by cooperating with the international community. ${ }^{158}$ It had also demanded that the Taliban hand over the mastermind of the attacks, ${ }^{159}$ determined that the Taliban was itself a threat to international peace and security, ${ }^{160}$ and condemned the Taliban for allowing its territory to be used as a base for the export of terrorism and for providing a safe haven for terrorists. ${ }^{161}$ There was, therefore, much more than a mere unwillingness or inability on the part of host state giving rise to a necessity of self-defence.

Since 9/11, therefore, there has been an increased acceptance by states of the necessity of taking defensive action against NSAs that results in material harm to the host state. This might even include the direct targeting of elements of a host state. This is conditioned, however. The UNSC's response to the nature of the terrorist threat, and to the particular host state, is significant in each of these incidents. They are not simply cases of unilateral determinations of inability or unwillingness and ensuing actions by a state, or groups of states. First, these incidents of practice arise in the context of international terrorism that the UNSC has reacted to in a very specific manner. Second, they are limited to cases where the host state has failed to take effective remedial action against NSAs at the express behest of the international community, acting through the UNSC. ${ }^{162}$ As Zimmerman notes, where the UNSC requests the

\footnotetext{
157 UNSC Res 1368 (2001); 1373 (2001).

158 UNSC Res 1267 (1999) para 1.

159 UNSC Res 1267 (1999) para 2.

160 This was because the Taliban had failed to respond to demands to 'stop providing sanctuary and training for international terrorists and their organizations, and [to] cooperate with efforts to bring indicted terrorists to justice.' Ibid; UNSC Res 1214 (1998) para 13.

161 UNSC Res 1378 (2001).

162 This is most clearly seen in the case of the Taliban and Al-Qaeda. With Syria, there is an argument that President Assad has been actively fighting Daesh and other terrorist groups and has enlisted the help of its allies, Russia and Iran, to do so. However, Coalition action in Syria suggests that much of the international community view these efforts as being ineffective. UNSC Resolution 2249 confirms this view.
} 
host state to take action against armed groups operating within its territory, and it fails to do so, this constitutes a specific form of qualified inaction on the latter's part. ${ }^{163}$

Third, as noted, in such cases the UNSC has implicitly established as a factual matter the necessity of defending states taking action within the host state's territory. It has expressed a collective view, as agent of the international community, on the unwillingness or inability of the host state and, therefore, a determination of the necessity of defensive action. Such a collective determination of necessity acts as an additional limiting factor on the ability of defending states to take action in and against a host state. Any ensuing harm to the host state is, therefore, the price of repeated failure to live up to the collective demands placed upon such states by international law and the international community. ${ }^{164}$

\subsubsection{NSA armed attacks - timing and imminence}

\section{a) Temporal duration of the right of self-defence}

Identifying the period of time over which the right of self-defence against terrorist NSAs subsists is more complex than in the interstate context. Factually determining when the goals of self-defence are achieved is much less clear. From a temporal perspective, what does the end point look like? In contrast to traditional interstate conflict, terrorists tend not to disarm or sign formal instruments of surrender in order to enter into a political process ensuring peace. Moreover, groups such as Al-Qaeda and Daesh are unlikely

\footnotetext{
163 Zimmermann (2007) 120-1. Whilst Zimmerman does not specify that the failure by the host state is to take effective action against the NSAs at the UNSC's behest, this is the natural implication. A similar pattern occurred prior to Israel's invasion of Lebanon in 2006. On a number of occasions, the UNSC called upon Lebanon to exercise effective control over its territory and to prevent attacks over the Blue Line into Israel. E.g. UNSC Res 1583 (2005) para 4; 1614 (2005) para 6; 1655 (2006) para 8. This may account for the initial widespread support for Israel's actions, which were later broadly condemned as disproportionate due to the scale of the operation. See Section 3.2.5.

${ }^{164}$ As to the proportionality of that harm, see Section 4.2.3.
} 
to renounce their ideology and give up their terrorist activities. ${ }^{165}$ As a general premise, however, even if the eradication of international terrorism is the stated goal of the international community, self-defence cannot stand as the legal justification for it. It is not, lawfully, a basis for a permanent war footing, or for achieving a long-term solution to the threat posed by terrorist NSAs. ${ }^{166}$

Section 3.2.2 posits that general necessity, rather than proportionality, most naturally imposes an independent time limit on the exercise of self-defence. In the context of international terrorism, general necessity's potential as a meaningful JAB restraint on state action is readily apparent. At some point, states will have degraded and dismantled the operational capacity and supporting networks of terrorist organizations like Daesh to such an extent that they will have been effectively destroyed and will no longer be able to attempt or launch strategic attacks. ${ }^{167}$ It is unlikely that it will be possible to identify the precise moment in time when this happens, and the concept of 'defeat' is open to varying interpretations. ${ }^{168}$ However, as the USA has argued, there is likely be a tipping point when the military operation against a particular group of NSAs has had such an effect that a counterterrorist law enforcement operation will be capable of replacing it. ${ }^{169}$

\footnotetext{
165 These issues were noted, e.g., in 'Report On The Legal And Policy Frameworks Guiding The United States' Use Of Military Force And Related National Security Operations', December 2016, <https://www.justsecurity.org/wpcontent/uploads/2016/12/framework.Report Final.pdf> 11 ('Military Framework Report'); Speech by J. Johnson, General Counsel of the U.S. Department of Defense, 'The Conflict Against Al-Qaeda and its Affiliates: How Will it End?', Oxford Union, Oxford University, 30 November 2012, <https://www.state.gov/documents/organization/211954.pdf> ('Johnson Oxford Speech') 8.

${ }^{166}$ Achieving a long-term solution to international terrorism, including a politically stable environment in the countries concerned, should not be viewed as part of the emergency right that is self-defence. Rather, a solution should be sought through collective action via the UNSC and other international bodies, working in conjunction with a host state.

167 Military Framework Report, 11-12.

168 Ibid. Blank (2017), especially 282-316, provides a general overview of the issues surrounding an enduring right of self-defence against terrorist NSAs and what it means to defeat them.

169 Johnson Oxford Speech, 4, 8-9.
} 
This conclusion was reached in the context of whether the USA is in a noninternational armed conflict with Al-Qaeda for the purposes of IHL. ${ }^{170}$ Yet, the same logic is compelling when considering JAB general necessity and the duration of the right of self-defence. When hostilities are reduced to such a level that armed conflict can be replaced by law enforcement, force is not the only reasonable option, and will be unnecessary (other than to counter further imminent armed attacks). This may be in one particular territory or region, or globally. As such, focusing on general necessity has the potential to assuage concerns regarding the (im)possible application of proportionality in these circumstances. ${ }^{171}$ As necessity is the first requirement to be satisfied, it bears the burden of ensuring that a defensive response is temporally limited. Unfortunately, the capacity of general necessity to operate in this way is being put under pressure by how states and the UNSC approach the question of imminence.

\section{b) Imminence}

The fact that armed attacks by terrorist NSAs tend to be one-off, or temporally limited surprise attacks, rather than forming a military campaign with a clear beginning and end, mean that defending state responses are likely to take place after such attacks have ended, or before they have begun. ${ }^{172}$ Where armed attacks form part of an enduring threat, the right to respond defensively depends on whether further armed attacks are imminent. ${ }^{173}$ Imminent attacks by terrorists are often much more difficult to identify than traditional interstate threats, ${ }^{174}$ although the accumulation of events doctrine might assist states to knit together past and imminent armed attacks in order to maintain a right of self-defence against terrorists conducting a campaign over time. ${ }^{175}$ This ability

\footnotetext{
170 On the classification of non-international armed conflicts and applicable IHL, see e.g. 1949 Geneva Conventions Common Article 3; Fleck (2013) 581-610. Regarding identifying the end of such conflicts, see Fleck (2013) 68-71; Lewis et al (2017) especially 51-66, 96-105.

171 See Section 4.2.

172 Tams in Van den Herik and Schrijver (2013) 394.

173 See Section 2.4.1(b).

174 Lubell in Weller (2015) 707.

175 See Section 2.4.2(b).
} 
is controversial, however. Its adoption risks widening the ambit of self-defence to unacceptable dimensions and states abusing this right.

As noted in Section 2.4.1(b), a right of self-defence against imminent armed attacks is not understood to include responses to non-specific, potential, or perceived threats. Yet, in the context of countering NSA terrorist threats, state practice suggests a wide interpretation of imminence. It is noteworthy that UNSC Resolution 2249 stipulates that Daesh 'has the capability and intention to carry out further attacks'. ${ }^{176}$ This reference prima facie pertains to an ongoing threat, comprising possible future attacks. Weller refers to this as recognizing a 'permanent imminence' of armed attacks. He concludes that, in considering Daesh's track record and confirming that it represents a permanent and active threat of further attack, the UNSC appears to relieve individual states from having to fulfil the criteria for self-defence. 'It is no longer necessary to demonstrate that they are acting in response to an actual or imminent armed attack and in a situation of instant and overwhelming necessity leaving no choice of means and no moment of deliberation.' ${ }^{177}$ The UK Parliament has also expressed concerns regarding the notion of permanent imminence in respect of the UK's response to individuals that have been identified as posing a terrorist threat. ${ }^{178}$

On the whole, states intervening in Syria against Daesh and others have been hesitant to rely on imminence alone to justify self-defence. ${ }^{179}$ They have instead opted, in whole or in part, for the more easily established justification of the collective self-defence of Iraq. ${ }^{180}$ Nevertheless, in support of their right of action, such states have also tended to refer to the ongoing 'threat' posed by Daesh. Such threat is identified as being either to that state specifically, and/or to other states, and/or to international peace and security more

\footnotetext{
176 UNSC Res 2249 (2015).

177 Weller (2015) EJIL: Talk!.

178 House of Lords, House of Commons, Joint Committee on Human Rights, 'The Government's Policy on the Use of Drones for Targeted Killing', Second Report of Session 2015-16, HL Paper 141, HC 574, para 3.39.

${ }^{179}$ See Section 2.4.1(b), however, regarding claims made by the USA and the UK. See also UN Doc S/2015/127 (2015) (Turkey).

180 See the reports to the UNSC of self-defence referenced in Section 4.1.1.
} 
generally. ${ }^{181}$ As noted, certain states have explicitly referenced UNSC Resolution 2249 to support such claim. ${ }^{182}$ There may be situations, therefore, where specific future armed attacks against a particular state are not identified, yet NSA terrorists are deemed by states, and the UNSC, as posing an ongoing threat justifying an enduring exercise of self-defence.

Where this is so, imminence and necessity more broadly are stretched to the extremes of their conceptual boundaries. ${ }^{183}$ The concern is that they are being disregarded as requirements for lawful self-defence against the threat posed by terrorist NSAs. Alternatively, and more optimistically, we might say that this state practice points to the continuing general necessity of some form of defensive response against an enduring terrorist threat. Given the particular nature of that threat, and the absence of effective UNSC action and peaceful alternatives, this conclusion recognizes that states simply have no choice of means to counter it. Such a view is still disconcerting, however. It constitutes an extremely broad conception of self-defence, stretching it far beyond a temporary right to respond to a situation of emergency. It also risks ignoring the analysis set out in Section 4.1.4(a), namely that when hostilities are reduced to such a level that they can be replaced by law enforcement, force is not the only reasonable option, and will be unnecessary. Yet, if this expansive view of self-defence is ultimately accepted by states, the burden falls to specific necessity to govern whether a particular defensive response is lawful, i.e. against a particular terrorist group operating in a particular state. This is a very heavy burden for specific necessity to bear. These conclusions are discussed further in the next Section.

\footnotetext{
181 UN Docs S/2014/695 (2014) (USA); S/2015/221 (2015) (Canada); S/2015/563 (2015) (Turkey); S/2015/745 (2015) (France); S/2015/928 (2015) (UK); S/2015/946 (2015) (Germany); S/2016/34 (2016) (Denmark); S/2016/132 (2016) (The Netherlands); S/2016/513 (2016) (Norway); S/2016/523 (2016) (Belgium).

182 See Section 4.1.3(c).

183 Along these lines, Bethlehem (2012) 2, argues that states must be able to act in selfdefence where there is evidence of further imminent terrorist attacks, even if there is no specific evidence of where such attack will take place or of the precise nature of the attack.
} 


\subsection{Proportionality and armed attacks by NSAs}

In extreme situations of abuse of the right of self-defence, states can adopt a near-unanimous view of the disproportionality of a particular action. ${ }^{184}$ However, armed attacks by NSAs pose significant challenges to the interstate conception of proportionality set out in Chapter 3. Proportionality operates in state-on-state self-defence to avoid large-scale wars, yet recent state practice in the context of international terrorism suggests a much more liberal approach to this requirement. As will be seen below, states often act beyond their immediate defensive needs. This might encompass preventing potential future armed attacks by eliminating the NSA terrorists entirely. Customary international law is evolving on this point, and it remains to be seen where it will settle. However, a thorough review of the state practice, coupled with a developed consideration of theory, results in a more clearly articulated description of the content of proportionality in this context.

The ensuing analysis reveals that proportionality, better understood, is not irrelevant to regulating state responses to international terrorism. Yet, it does divulge the deficiencies in the ability of proportionality to control state action against terrorist NSAs, revealing it to be weak. ${ }^{185} \mathrm{~A}$ solution is offered, therefore, that focuses on necessity. As a general premise, the main challenges to the interstate understanding of proportionality relate to measuring the danger posed to the defending state by actual and future NSA armed attacks and whether, in this context, the legitimate purposes of selfdefence are consequently broader. In addition, as with necessity, much of the debate focuses on the host state, in particular how it is affected by a defending state's defensive acts on its territory.

\footnotetext{
${ }^{184}$ E.g. Israel's invasion of Lebanon in 2006. See Section 3.2.5.

185 See Tams and Devaney (2012) 102, reaching the same conclusion.
} 


\subsubsection{A more permissive response vis-à-vis terrorist NSAs}

States will often take extensive action to defend themselves against armed attacks by NSAs that they designate as terrorists. A putative defensive response will often be greatly in excess of the corresponding armed attack(s) and may contain far-reaching aims that might encompass weakening and ultimately eradicating a terrorist group. Such expansive defensive action to counter further threats from the same source has already been referred to in Section 2.4.2(b). One notable example is the American-led response to 9/11. Whilst not authorizing force, the UNSC explicitly recognized and reaffirmed the inherent right of individual and collective self-defence. It also concluded that any act of international terrorism is a threat to international peace and security and should be combatted by 'all means'. ${ }^{186}$ This was the prelude to the invasion of Afghanistan and the removal of the Taliban regime, which was widely supported by the international community. ${ }^{187}$ The analysis in Sections 4.1.3(b) and 4.2.3(b) regarding Coalition action against Daesh in Syria constitutes the most recent example of a defensive response that is, prima facie, vastly in excess of the threat faced by those states purportedly acting in self-defence.

State practice, particularly following 9/11, reflects the fact that states consider that they have much greater flexibility in acting in self-defence against terrorist NSAs than they do in the interstate context. ${ }^{188}$ Irrespective of the objective dangers of terrorism, states consider it legitimate to eliminate the terrorist threat, and to take decisive action against it. ${ }^{189}$ With a few notable exceptions

\footnotetext{
186 UNSC Res 1368 (2001); 1373 (2001).

187 See Section 4.1.3(a).

188 This Section highlights that the 'threat' of international terrorism appears to account for a more permissive attitude to proportionality than is seen in the interstate context. The term 'threat' has been referred to in various contexts throughout this thesis and is discussed further below in this Section. As has been made clear, however, to allow for a lawful defensive response such threat must comprise past, ongoing and/or imminent armed attacks. See further Section 2.4.2(b) regarding the accumulation of events doctrine. As noted in Section 4.1.4, however, the often-sporadic nature of NSA armed attacks makes evaluating the totality of a terrorist NSA threat, and whether it is current or has ended, very difficult.

189 Tams in Van den Herik and Schrijver (2013) 411-12, arguing that the strong international response to terrorism has led to a normative reorientation that means that terrorist threats are invariably considered grave, even where the likelihood of attack or risk to the defending state is realistically not great. The state practice set out in this Chapter, and the thesis more generally, supports this conclusion.
} 
referenced in this Chapter, practice also shows how other states and international organizations will tend to give defending states much greater leeway in their responses to terrorist NSAs, when compared to interstate selfdefence. This is particularly evident in cases where there has been a history of attacks from NSAs and the fear of repeated attacks is well founded. 190 UNSC Resolution 2249 is illustrative of this more permissive attitude. In it, the UNSC determined unanimously that terrorist groups such as Daesh, together with all acts of terrorism, constitute a global and unprecedented threat to international peace and security. ${ }^{191}$ As noted, the UNSC also asserted that the named terrorist groups have the capability and intention to carry out further attacks, which might be read as confirming the 'permanent imminence' of future armed attacks. ${ }^{192}$ Remarkably, the UNSC has also called for the eradication of safe havens that such groups have established over significant parts of Iraq and Syria. ${ }^{193}$

The language adopted by the UNSC leaves states considerable discretion to act in accordance with its exhortation. Its approach also informs an understanding of the nature of the threat and the required response. UNSC Resolution 2249 endorses the view that self-defence might include as a legitimate aim the total elimination of the NSA terrorists or, at a minimum, eradicating all safe havens from which they benefit. The Resolution can, therefore, be read as the unanimous view of the UNSC, acting on behalf of the international community, regarding what is a proportionate response in the circumstances. ${ }^{194}$ This is significant, particularly for those six states that have explicitly referenced UNSC Resolution 2249 to support their claim of acting in self-defence against Daesh in Syria. ${ }^{195}$ The eventual destruction of Daesh is also the common theme amongst the approximately seventy states that are part of the Coalition against it. ${ }^{196}$ This collective view prevails even if it cannot

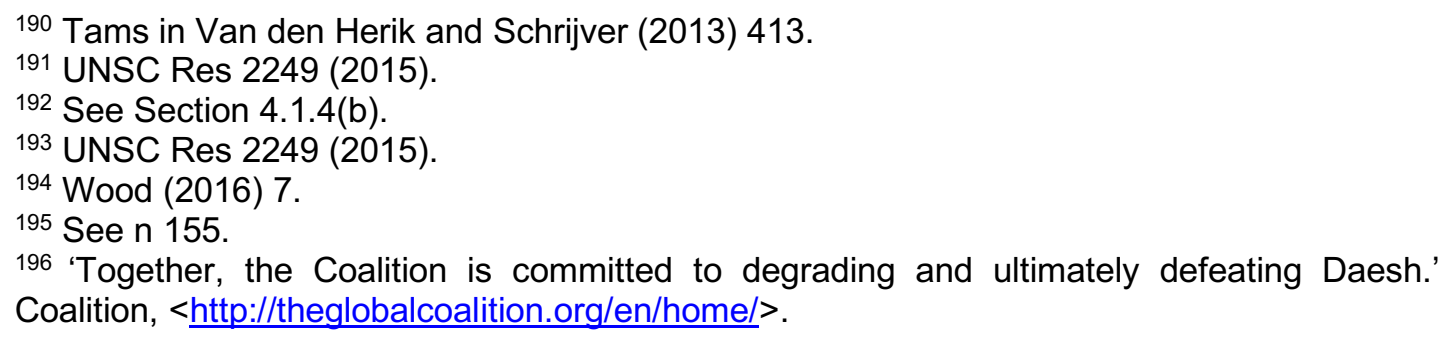


sensibly be concluded that the NSAs are an existential threat to the states that respond defensively against them. Such practice reflects the notion, therefore, that a proportionate defensive response against terrorist NSAs may be greater than a comparable threat in the interstate context. ${ }^{197}$

Whilst it is not this author's position, it is tempting to say that, in the context of transnational terrorism, the aims of self-defence are more broadly defined. ${ }^{198}$ If this view is adopted, such that destroying NSAs is an accepted purpose of self-defence, this pushes the right far beyond the boundaries of an emergency act of protection. A stated purpose of 'destruction' unacceptably blurs the line between lawful self-defence and unlawful armed reprisal. Moreover, it deprives proportionality of meaning. A defensive act cannot be proportionate to 'destruction'. The eradication of NSAs should not, therefore, be viewed as a defensive aim any more than regime change, or occupation. ${ }^{199}$ Destruction is a means, rather than an end. This is to say that it might well be necessary to destroy the group of NSAs, but the necessity arises from a defensive purpose, i.e. halting, repelling or preventing an armed attack. Destruction is potentially proportionate to achieving that purpose, but this will rarely be the case. Only understood in this way, can necessity and proportionality have any meaning and, therefore, the capacity to restrain state action. Otherwise, such action against NSAs is rendered unrestricted.

UNSC Resolution 2249 reflects that fact that defensive action against terrorist NSAs is more permissive, yet it must nevertheless be restrained. The call to Member States in UNSC Resolution 2249 is not to take unlimited action against Daesh and other named groups. The UNSC asks states to take all necessary measures in compliance with international law. Whilst not specified, by implication, this must include the provisions of the UN Charter (most pertinently Article 51), as well as customary international law (including the requirements of necessity and proportionality). Moreover, the objects of the

\footnotetext{
197 In interstate self-defence, absent an existential threat, an equivalent goal would usually be regarded as disproportionate. See e.g. Sections 3.2.4(b) and 3.4.

198 See e.g. Tams in Van den Herik and Schrijver (2013) 412-13.

199 See Section 1.3.2.
} 
defensive response are specified groups, ${ }^{200}$ and the area of operation is geographically confined to the territories of Iraq and Syria. ${ }^{201}$ These limitations accord with the general principles of necessity and proportionality, as they apply to the right of self-defence..$^{202}$

The UNSC approach should not, therefore, be read as an open-ended endorsement of combatting terrorist NSAs or terrorism in an abstract sense. Phrases such as the 'war on terror', the 'fight against terrorism', and the like, are often expressed by states and commentators, but this goes well beyond what is envisaged and permitted by the terms of the UN Charter and applicable custom. States have no right of self-defence against an 'ism', only an actual or imminent armed attack. Fighting terrorism as a concept negates the limitations imposed by necessity and proportionality. It is impossible for these requirements to have any meaningful application in respect of combatting a nebulous abstraction like 'terrorism in all forms and manifestations'. Dispensing with them would be contrary to the exhortation in UNSC Resolution 2249 to comply with the law.

As set out in Section 1.3.2, our understanding of the goals of self-defence should remain limited to the defensive: halting, repelling and/or preventing an armed attack. However, what in the interstate context might be viewed as legitimate to achieve these aims might take on different dimensions in the context of terrorist NSA armed attacks. States and the UNSC undoubtedly recognize greater elasticity in this context. The UNSC's general approach to terrorism is particularly interesting for a proportionality analysis. As noted, international peace and security is part and parcel of the overall balancing of interests that proportionality seeks to achieve. That the UNSC has determined that terrorist NSAs pose a threat to such peace and security perhaps accounts

\footnotetext{
200 Being Daesh, Al Qaida and its associates, and other UNSC designated groups.

201 Para 5 of UNSC Res 2249 (2015) purports to further limit the geographical scope of action to Iraqi and Syrian territory under the control of Daesh.

${ }^{202}$ As noted in Section 4.1.3(c), the Resolution implicitly speaks to this right. Absent UNSC authorization to use force, which this Resolution does not provide, the right of self-defence is the only other lawful alternative to use force under the UN Charter.
} 
for the more permissive attitude that the UNSC and states generally adopt visà-vis those states that combat them.

The nature of the actors, and the perceived harm that they threaten, appear to be determinative of this permissive attitude. States are not considering the threat of harm to only one state, or even a group of states. It is a global threat, faced by all states, and it is viewed as enduring. Moreover, it goes beyond an interstate paradigm to one where non-states are seeking to destabilise, and even destroy, states and the global order more generally. ${ }^{203}$ Such states are victims of actual or imminent armed attacks, and/or are acting in defence of other direct victims, but their defensive action is also potentially in the collective interests of the international community. ${ }^{204}$ They act with its implicit endorsement to counter a threat to that community and to restore international peace and security. ${ }^{205}$

We should hesitate, however, in accepting that a group of defending states, such as the Coalition, may legitimately act in place of the collective security function of the UNSC. ${ }^{206}$ The UNSC's approach to terrorist NSAs, and the steps taken by defending states in support of it, have significant implications for how we might conceive of the proportionality of defensive action against

\footnotetext{
${ }^{203}$ Regarding Daesh, including its partly apocalyptic ideology, see Byman (2016) 136-9. For an overview of the goals of Al Qaeda, see Byman (2015) 47-51.

${ }^{204}$ In contrast, in the context of state responsibility, the ability of 'non-injured states' to respond on an actio popularis basis in the collective interest is circumscribed. There is no clearly recognized right to take collective countermeasures against a wrongdoing state. Commentary to Art 54 ARSIWA, paras 2-6. In any event, countermeasures may not involve the threat or use of force. Art 50(1)(a) ARSIWA. With self-defence against armed attacks by NSA terrorists, however, the target of collective military action is not a state (even if the NSA target operates on the territory of a state) and the implicit support of the UNSC (acting as agent of the international community) means that it is part of the collective response, not excluded from it. 205 The number of states and international organizations involved in the Coalition, coupled with the implicit support of the UNSC, points to this action being in the pursuit of this shared goal. By analogy, see further Henderson (2018) 234-5, noting that proportionality is more permissive in the context of force authorized by the UNSC. Defending state action that goes beyond the bounds of necessity and proportionality of course risks disrupting international peace and security.

${ }^{206}$ Albeit that such state action is perhaps a product of the absence of explicit UNSC authorization to use military force against terrorist NSAs, as well as the UNSC's preference to date for adopting non-military sanctions against terrorist NSAs and employing peaceful measures to counter terrorism on a general thematic basis. See Tams in Van den Herik and Schrijver (2013) 401.
} 
these actors when compared to self-defence against states. Yet, practice suggests that there are restrictions even in this context. The notion of a defending state having greater latitude to respond to a terror threat to it, and the entire world, has been advanced before. Israel adopted this approach, and its role in the 'war on terror', to justify its invasion of Lebanon in $2006 .{ }^{207}$ The majority of the international community refused to allow Israel to stretch the boundaries of proportionality too far, however. They employed proportionality as a rhetorical tool to condemn Israel's actions. ${ }^{208}$ Although there is certainly a more permissive attitude to proportionality in the context of responses to terrorist NSA armed attacks, there are limits to how far defending states can take the notion that they are acting in the collective interest to counter them.

\subsubsection{Geography}

The post $9 / 11$ responses to terrorist attacks by a number of defending states have taken acts of self-defence far beyond their own borders. The objects of defensive force have often been thousands of kilometres away from the defending state and the armed attacks to which they purport to respond. This reflects the fact that terrorist attacks will typically occur on the defending state's territory, but the terrorists themselves may be operating from safe havens in third countries on the other side of the globe. American action against AlQaeda and affiliated groups in Afghanistan and other parts of the world following the 9/11 terrorist attacks on American territory is an obvious example. More recently, the Coalition military action against Daesh in Iraq and Syria is occurring far away from many of the countries that have invoked individual and/or collective self-defence to justify their actions there (most notably the USA, Canada, Australia and the various European Coalition partners). ${ }^{209}$

\footnotetext{
207 UN Doc S/2006/515 (2006).

208 See Section 3.2.5.

209 See Section 4.1.3(b). Assertions of collective self-defence of Iraq may be regarded as geographically proximate to the armed attacks. However, a number of these states are also claiming individual self-defence in relation to terrorist attacks on their own soil.
} 
Proportionality, conceptualised in interstate terms, struggles to accommodate this response and remain consequential to self-defence against terrorist NSAs. ${ }^{210}$ In particular, the response to international terrorism casts doubt on whether proportionality imposes a requirement of a geographical nexus between the armed attack and defensive response, or whether customary international law applicable to self-defence against terrorist NSAs is evolving to accommodate more flexible notions pertaining to the distance between them. Alternatively, are the rules applicable in the interstate context being breached? That the UNSC appears to be encouraging (and certainly not condemning) anti-terrorist action well beyond the borders of the defending states, and that other states have generally supported coalition actions in Afghanistan, Syria and Iraq suggests that geography plays much less of a role in this context, or perhaps no role at all.

This conclusion is reflective of the global reach of international terrorism and is a consequence of the nature of the terrorist organizations themselves. Such groups often function across, and irrespective of, borders. They may be based in, and operate from, a number of different states and work with affiliates and like-minded groups around the globe. ${ }^{211}$ When facing a threat of this nature, one of the fundamental questions for proportionally appears to be whether the defending state may mount a military response in various theatres of operation or countries that, together, constitute the same conflict. ${ }^{212}$ Fulfilling a defensive need might mean that limiting a defensive response to a particular locale makes no sense when faced with a threat of this type. Such limitation might render the defensive response inadequate. Multiple military actions in a number of states may be the only effective way to counter the threat.

If a geographical restriction does exist in respect of armed attacks by NSAs that are disparate and splintered in this way, the challenge for clarifying any role for proportionality is to identify from state practice criteria to establish the

\footnotetext{
${ }^{210}$ See Section 3.2.3.

211 Al Qaeda is the classic example. See Byman (2015) 95-8; 141-61.

212 Lubell (2010) 66.
} 
locale to which the defensive response is to be confined. The question is whether this is possible given the foregoing commentary regarding the global responses to terrorism and, more fundamentally, if it desirable. Arguably, the more meaningful and readily applicable limitation on state action in cases where a defending state is seeking to combat NSAs in a number of different territories is not proportionality at all, but necessity. ${ }^{213}$ Before the proportionality of a response against a group of NSAs as a whole may be evaluated, the general necessity of any forceful response must be first established, followed by the specific necessity of targeting that group within a particular state. The right of self-defence that has previously arisen, or been claimed, in order to fight a group in one territory may not automatically be exported to another part of the world. The USA, for example, appears to adopt this general premise. ${ }^{214}$

Absent host state consent, the right of self-defence must exist independently every time a defending state wishes to use force within the territory of another state. This includes the analysis referred to in Section 4.2.3 regarding the position of a host state, whose right to sovereignty and territorial integrity remains intact unless established otherwise. ${ }^{215}$ If necessity is absent because the 'new' host state is willing and able to combat the NSAs, the right to exercise self-defence is also absent in respect of the particular group of NSAs operating from within that territory. Proportionality is then a moot point. This fact places added emphasis on the unable or unwilling doctrine, which operates as the main gateway to the right of self-defence in this context. ${ }^{216}$

\footnotetext{
${ }^{213}$ Note that targeting members of the same group on a territory without the consent of a host state is an issue for the JAB. It is separate from the question of whether members of the same group are targetable under IHL.

214 '[l]nternational law not only requires a State to analyze whether it has a legal basis for the use of force against a particular non-State actor - which l'll call the "against whom" question but also requires a State to analyze whether it has a legal basis to use force against that nonState actor in a particular location - which I'll call the "where" question.' USA State Department Legal Adviser Speech 2016, 240.

215 On expanding self-defence into new states, see generally Lubell (2015) 222-7.

${ }^{216}$ See Section 4.1.2.
} 


\subsubsection{Effect on the host state and its citizens}

If the necessity of a defending state acting against NSAs on the territory of the host state can be established, ${ }^{217}$ the ensuing question is how, and to what extent, the position of the host state factors in assessing the proportionality of self-defence. The violation of a host state's sovereignty in the pursuit of a defensive purpose is a highly contentious issue. Yet, as with neutral states, recent state practice suggests that host states might be viewed as having to endure, to a degree, defending state action against NSAs on their territory. ${ }^{218}$ Where the line is to be drawn, however, remains unclear. Whilst necessity preserves such acts of self-defence as exceptional measures of last resort, proportionality acts to minimise their effect on the host state.

State practice on this issue is limited, but the investigation below combines what practice is available with an analytical framework that seeks to describe how the effect on the host state (including its civilian population and infrastructure) might point to excessiveness. The analysis set out in Section 3.2.6(a) regarding the justificatory language of circumstances precluding wrongfulness is also helpful in this context. Depending on the circumstances, an act of self-defence might be objectively justifiable as a 'lesser evil' when compared to the infringement of a host state's rights and the effect on its citizens.

\footnotetext{
${ }^{217}$ Whether intrusion into the territory of the host state can ever satisfy the requirement of proportionality is dependent on whether necessity can first be satisfied. The necessity analysis largely depends on the acceptance of the controversial unwilling or unable doctrine to excuse the limited breach of the host state's territory. See Section 4.1.2.

${ }^{218}$ See Section 3.2.6(b). Where a host state violates its international law obligations to prevent and suppress terrorism, this might be equated with the position of a neutral state that violates the laws of neutrality. In such cases, a belligerent can take defensive action on a neutral state's territory if it allows such territory to be used by another belligerent state in violation of its duties of neutrality. Bowett (1958) 167-74; Brownlie (1963) 312-14. See also San Remo Manual Art 22. The propriety of the transposition of this rule into the JAB is debatable (see e.g. Tsagourias (2016) 812), but Coalition state practice in Syria might provide support for such position. See further Deeks (2012) 497-501, considering neutrality in respect of the unwilling or unable doctrine.
} 


\section{a) General considerations}

A number of general propositions that derive from the incidents of state practice referred to throughout this thesis inform the following analysis. The first is that, absent attribution of NSA armed attacks to a host state, defending states do not claim a right to act against the host state when taking action against NSAs operating in that state's territory, although they implicitly assert a right to violate the host sate's sovereignty and territorial integrity. ${ }^{219}$ Instead, defending states tend to justify their acts by emphasising that they limit their targeting to NSAs, and do not target host state military personnel and apparatus. With Operation Enduring Freedom standing as an exception, their actions largely conform to this rule. ${ }^{220}$ Second, it is only where there has been widespread damage to the host state, and harm to its civilians, that other states and international organizations label such putative defensive action as disproportionate. ${ }^{221}$ Finally, the perceived threat from terrorist NSAs invariably informs the how states will respond defensively, and how the proportionality of such response is consequently assessed. ${ }^{222}$

From a proportionality perspective, where defending states limit their defensive actions by only targeting NSAs and their base of operations within the territory of the host state, the use of defensive force nevertheless violates, at a minimum, the host state's sovereignty and territorial integrity. ${ }^{223}$ Whilst not to be readily dismissed, if (and only if) necessity can be established in such circumstances to excuse the harm caused to the host state by way of a limited and temporary breach of its sovereignty and territorial integrity, then the

\footnotetext{
219 Tams in Van den Herik and Schrijver (2013) 410.

220 See Section 4.1.3(a).

${ }^{221}$ See Section 3.2.5. See further Tams in Van den Herik and Schrijver (2013) 410.

${ }^{222}$ See Section 4.2.1.

${ }^{223}$ Trapp (2007) 145. Tsagourias (2016) 822-3, suggests that lawful defensive force does not breach Art 2(4), or constitute unlawful intervention, because it is not targeted at the host state, but rather at the NSAs, and is not interned to coerce the host state. See Section 4.1.3(b) regarding the implications for IHL conflict classification. In terms of state responsibility, the ILC in its Commentaries explicitly left open the question of defensive force on other states. ARSIWA 21 Commentary, para 5.
} 
minimal material effect on the host state is potentially proportionate. ${ }^{224} \mathrm{~A}$ fortiori if the protection of the defending state's own citizens is regarded as an obligation. ${ }^{225}$ Without this resulting outcome, the right of self-defence is nullified and international law would require a state to sacrifice the life of its citizens to the principles of sovereignty and territorial integrity. ${ }^{226}$

On this analysis, proportionality acts in tandem with necessity to restrain the use of force against the NSAs, and to limit the impact on the host state. Adherence to these requirements maintains a balance between two equally foundational principles of international law: sovereignty (and the attendant right of territorial integrity) and the right of self-defence. Schmitt argues that:

International law does not require an either-or resolution of these counterpoised norms. Rather, when principles clash, law seeks that accommodation which best achieves their respective underlying purposes. Although the territorial state need not suffer unconstrained violations of its borders, neither does the victim state have to sit idly by while insurgents and terrorists attack it with impunity from abroad. ${ }^{227}$

The two requirements therefore 'operate as a mediator between the competing security interests of States victim to armed attacks by non-State terrorist actors operating from foreign territory, and States in whose territory terrorists operate.' ${ }^{228}$ State practice, particularly with respect to the operation and

\footnotetext{
${ }^{224}$ Where necessity is not established, proportionality is irrelevant. The use of force, even if targeted solely at the NSAs, will breach Article 2(4). It will be an unlawful use of force against the host state, even though the apparatus or infrastructure of the state is not damaged and none of its armed forces are engaged.

${ }^{225}$ In Palestinian Wall, para 141, the ICJ stated as a general premise that Israel had 'the right, and indeed the duty, to respond in order to protect the life of its citizens' (emphasis added). Trapp (2015) 209, argues that states not only have an obligation to respect rights, but to ensure respect for those rights. As regards the right to life and physical integrity, this obligation means, inter alia, that individuals are entitled to expect that the state that exercises jurisdiction over them will do everything within its capacity to protect them from an existential threat, whatever its source.

${ }^{226}$ Schmitt (2002-2003) 542, argues that 'the unwillingness or inability of one State to meet its legal obligations cannot deprive other States of the most important right found in international law, the right to defend oneself against an armed attack.'

227 Schmitt (2010) 316.

228 Trapp (2007) 146-7.
} 
content of the unwilling or unable doctrine, is yet to provide firm guidelines regarding how this 'mediation' is operationalized on a general basis. Practice suggests, however, that states nonetheless recognize that there is a balance to be struck such that defensive force is exercisable, but not excessive. This analysis reflects the 'lesser evil' justification referred to above. As with Operation Sun in 2008, therefore, where harm to the host state and its citizens is minimal, the conclusion is that defensive action might be regarded as proportionate. 229

This conclusion is most easily reached where the defensive force does not result in any physical harm to the host state's military forces or apparatus, its civilian population, or public infrastructure. An example might be a targeted missile strike by a drone on a desert camp, where only the NSAs and their property are damaged or destroyed. As the state practice referred to in particular in Sections 3.1.1 and 4.1 demonstrates, however, it will not always be the case that the host state and its citizens are insulated from defensive reactions within host state territory. Incidental collateral damage may result from self-defence against the NSAs, or even direct damage if elements of the host state itself are targeted.

The meeting of the two foundational principles of sovereignty and self-defence referred to above also holds true for these cases where the host state and its citizens are materially harmed. However, such material effects mean that the balance might be perceived to shift such that other states and international organizations conclude that the defending state's actions are excessive and, therefore, disproportionate. Israel's intervention in Lebanon in 2006 is the classic example of this. ${ }^{230}$ In such cases, the pursuit of self-defence is not perceived to be the lesser evil. The defensive response must, therefore, be carefully crafted to achieving the destruction of the NSAs, with the minimum impact on the host state, its population and infrastructure. ${ }^{231}$ Moreover, the use

\footnotetext{
229 See Section 3.1.1(d).

230 See Section 3.2.5.

231 Gardam (2005) 17; Ruys (2010) 509.
} 
of defensive force must not amount to punishment for the host state's unwillingness or inability to combat the NSAs. This would go beyond a defensive purpose..$^{232}$

Further state practice is required in order to clarify how far the foregoing analysis might settle in the lex lata, with the issue of necessity (and unwilling or unable in particular) being the key point of controversy. Regarding any assessment of proportionality, the major concern is the death and injury to the host state's civilians resulting from the defensive riposte. Section 3.2.5's review of state practice affirms that civilian collateral damage is the predominant feature of the practice of those states seeking to justify purported uses of defensive force, as well as of the reactions of other states and international organizations that scrutinise them.

Concern over civilian harm sits in stark contrast to the death of the NSA terrorists themselves, however. Terrorist casualties are largely accepted by states, provided that civilian casualties and civilian collateral damage are avoided. ${ }^{233}$ Even the total destruction of terrorist groups appears to be acceptable to the international community. ${ }^{234}$ From the JAB perspective, therefore, terrorist NSA casualties are either not counted as part of the proportionality calculus at all or, alternatively, even very high casualty figures are generally accepted and not regarded as excessive. ${ }^{235}$ In either case, the potential for proportionality to act as a restraining influence is severely reduced. This sits in contrast to the position in interstate self-defence, where

\footnotetext{
232 Likewise, force intended to coerce the host state to abide by its international law obligations to prevent and suppress international terrorism would go beyond the remit of self-defence. Unilateral inducement to abide by international law is the province of countermeasures, which may not involve the threat or use of force. Art 50(1)(a) ARSIWA.

${ }^{233}$ Tams in Van den Herik and Schrijver (2013) 412. Tams cites the example of Turkey's Operation Sun in 2008. Resulting PKK casualties were twenty times the number of Turkish nationals killed in attacks preceding the invasion, yet the invasion generally was not considered excessive and was, in fact, lauded by states. See further ibid 395-6.

234 See Section 4.2.1.

${ }^{235}$ How 'terrorists' are identified and deemed to be targetable for the purposes of the JAB and $\mathrm{IHL}$ determines how this calculus is made. As noted, civilians may not be directly targeted under either regime. See further Section 2.5 .
} 
proportionality accounts for the needs and rights of the attacker, as well as those of the defending state. ${ }^{236}$

Turning to other effects on the host state that are relevant to considerations of proportionality, over and above civilian harm, the 2006 Lebanon incident also demonstrates unease amongst scholars regarding the geographical scope of the Israeli response. For some, the initial Israeli action taken in southern Lebanon appeared to abide by the principle of proportionality, given that Hezbollah's attacks had originated from that area. Later measures taken far beyond this zone, however, were viewed as problematic from this perspective. ${ }^{237}$ Such concerns are in keeping with the argument that actions in self-defence, particularly along a border, should generally be confined geographically vis-à-vis the armed attacks that provoked them. ${ }^{238}$ However, as noted, this is perhaps better understood as an issue of specific necessity. It is difficult to reconcile with a defensive objective the destruction of civilian and military infrastructure well away from, and unconnected with, the armed attack. ${ }^{239}$

Finally, minimising the impact on the host state also requires that any incursion into its territory is temporally limited. As soon as the defensive objective is attained, i.e. once the threat is effectively countered, the cross-border operation must be terminated, and all forces withdrawn. ${ }^{240}$ As with the effects on an attacking state, whilst temporary occupation of parts of the host state might be considered necessary, depending on the circumstances, it must remain proportionate to the defensive objective. Despite the more permissive attitude towards combatting terrorist NSAs, widespread occupation of territory beyond the area of NSA operations is likely to be considered

\footnotetext{
${ }^{236}$ See Section 3.2.

237 Cannizzaro (2006) 784; Zimmermann (2007) 124; Ruys (2007) 290-2.

238 See Section 3.2.3.

$239 \mathrm{Ibid}$. This is a general premise. Depending on the circumstances, command and control centres and other military targets well away from the armed attack might well be legitimate targets that satisfy the requirements of specific necessity. This is most likely in large-scale and enduring conflicts. Regardless, the issue of targeting is still better analysed under the rules of specific necessity and IHL, rather than proportionality.

240 Schmitt (2002-2003) 543.
} 
disproportionate. ${ }^{241}$ Moreover, enduring occupation after the defensive object is achieved will be unnecessary, with proportionality being irrelevant in such cases. ${ }^{242} \mathrm{It}$ is for this reason that statements that America intends to 'maintain a military presence in Syria focused on ensuring ISIS cannot re-emerge', are disconcerting. ${ }^{243}$ Open-ended occupation by the USA long after the threat to it has been significantly diminished, goes well beyond an immediate defensive purpose. ${ }^{244}$ The protection of long-term security interests is not the purview of self-defence. The onus in such instances reverts to the host state, international co-operation and to measures not involving the use of force. ${ }^{245}$

\section{b) Coalition action in Syria}

The Coalition military campaign against Daesh in Syria poses a challenge when considering the effects of defensive action against NSAs on the host state, in particular with respect to collateral civilian damage. Despite the Coalition's insistence that it takes great efforts to minimise civilian harm, their strike reports reveal the extent of the targeting within and against the Syrian state. ${ }^{246}$ Undoubtedly, the campaign has caused considerable damage to the civilian population and infrastructure, including high numbers of reported casualties. It has also contributed to the almost complete destruction of Daesh's self-proclaimed capital, Raqqa. ${ }^{247}$ Syria has accused the Coalition of deliberately destroying 90 per cent of the city and causing widespread civilian

\footnotetext{
${ }^{241}$ As a general premise, Schmitt (2010) 317, argues that it would be 'unlawful to deploy forces into locations void of terrorists or insurgents.'

242 See Section 3.2.4(b).

243 'Remarks on the Way Forward for the United States Regarding Syria', U.S. Department of State, 17 January 2018, <https://www.state.gov/secretary/remarks/2018/01/277493.htm\#https://www.state.gov/secret ary/remarks/2018/01/277493.htm>.

${ }^{244}$ Whilst Daesh is not totally defeated in Syria and elsewhere, at the time of writing it has lost its capital Raqqa and $98 \%$ of territory it once held in Iraq and Syria. 'UK Action to Combat Daesh', UK Government, <https://www.gov.uk/government/topical-events/daesh/about> [last accessed 23 July 2018].

${ }^{245}$ See Sections 1.3.2 and 4.1.4(a).

${ }^{246}$ See Section 4.1.3(b).

247 'The City Fit for No-One: Inside the Ruined 'Capital' of the Islamic State Group' BBC News, $27 \quad$ September 2017, <http://www.bbc.co.uk/news/resources/idtsh/the city fit for no one raqqa syria islamic state group $>$. Regarding reported civilian casualties resulting from Coalition airstrikes, see e.g. Airwars, <https://airwars.org>; The Syrian Observatory for Human Rights, <http://www.syriahr.com/en/>.
} 
harm. ${ }^{248}$ Russia has stated that the Coalition has 'flattened' Raqqa, and has remarked upon the resulting civilian casualties and lack of international concern regarding Coalition action. ${ }^{249}$ An Amnesty International report goes so far as to suggest that Coalition airstrikes indicate possible war crimes. ${ }^{250}$ The Coalition denies this, ${ }^{251}$ and the USA has defended the legality of Coalition action before the UNSC. ${ }^{252}$ How then should we approach assessing the proportionality of the effect of such action on Syria? Given the ongoing campaign, and the continued fight against Daesh globally, it is too early to say whether or not states and international organizations will ultimately conclude that the defensive action is proportionate. Even if one were to attempt to take a 'snapshot' of the proportionality of the ongoing response, it is doubtful, given the particular circumstances of this incident, that a clear answer is discernible. Nevertheless, the following analysis suggests a number of observations and possible conclusions.

The first possibility is to label this incident as a violation of JAB proportionality. This verdict is partly based on what appears to be gross quantitative imbalance between the amount of harm suffered, or anticipated, as a result of Daesh armed attacks and the harm caused by the military response of the Coalition. ${ }^{253}$ Whilst the extent of civilian casualties is debated, it is clear that cities like Raqqa have been decimated and large numbers of its citizens killed and forced to flee. There have even been reports of whole buildings being targeted and destroyed in the pursuit of killing individual Daesh fighters. ${ }^{254}$ Such individual targeting decisions might be $\mathrm{IHL}$ compliant and, therefore, explain the actions

\footnotetext{
248 UN Docs S/PV.8181 (2018) 11; S/PV.8186 (2018) 19; S/PV.8206 (2018) 9.

249 UN Docs S/PV.8186 (2018) 4; S/PV.8217 (2018) 15.

${ }^{250}$ Syria: "War of Annihilation": Devastating Toll on Civilians, Raqqa-Syria', 5 June 2018, <https://www.amnesty.org/download/Documents/MDE2483672018ENGLISH.PDF>

('Amnesty's Syria Report').

251 'Coalition Response to Amnesty Report on Civilian Casualties in Raqqa', 5 June 2018, $<$ http://theglobalcoalition.org/en/coalition-response-to-amnesty-report-on-civilian-casualtiesin-raqqa/>.

252 UN Doc S/PV.8236 (2018) 7.

253 The threat posed by Daesh to states is undoubtedly great, but it cannot be compared to the nature and scale of the defensive response, as clearly articulated in the strike reports of the Coalition.

${ }^{254}$ As reported in: 'The City Fit for No-One: Inside the Ruined 'Capital' of the Islamic State Group' BBC News, 27 September 2017, <http://www.bbc.co.uk/news/resources/idtsh/the city fit for no one raqqa syria islamic state group>.
} 
of Coalition partners. Yet, regardless of whether this is in fact the case, they raise real concerns for JAB proportionality when targeting decisions are reviewed cumulatively. Moreover, if Amnesty's Syria Report is proved correct, the potential violations of IHL set out therein might indicate a breach of JAB proportionality. ${ }^{255}$ Undoubtedly, the overall effect of Coalition action on Syria and its people has been widespread and severe. This is despite the lack of Syria's acquiescence in, or support for, Daesh's activities. Rather, its inability, or perceived inability, to deal with the threat has led to such devastating harm. It is arguable, therefore, that along the lines of Israel's invasion of Lebanon in 2006, the Coalition action goes beyond what is necessary to achieve a defensive purpose.

This conclusion might be too hasty, however. Coalition action against Daesh in Syria sits in marked contrast to Israel's intervention in Lebanon in 2006. First, is the complexity of the Syrian civil war and the sheer number of interlocutors fighting within Syrian territory, all with competing agendas, and all causing death and damage to civilians and civilian infrastructure. ${ }^{256}$ The Assad regime, its allies and Daesh have all been accused of targeting the civilian population directly, as well as causing widespread collateral damage. This is an evidential issue, therefore, of 'who did what'. Even if it were possible to separate the effects of the ongoing civil war from the harm resulting from the purported counterterrorism actions of a number of states acting on claims of self-defence, a proportionality assessment of the Coalition action remains difficult. This is due to the other stark difference between the Syrian conflict and the 2006 Lebanese invasion. The latter was in response to the threat faced by one state (Israel) and was confined to the territory of another state (Lebanon). ${ }^{257}$ In contrast, the Coalition consists of a number of states that are purporting to act in self-defence against a threat not only to such states, but

\footnotetext{
255 Particularly if they are systematic and widespread. See Section 3.3.1.

${ }^{256}$ For a factual overview of the conflict, including the main parties involved in the conflict, see e.g. Gill (2016) 354-362, 373-7.

${ }^{257}$ This is despite Israel's insistence that the threat it faced was also faced by the world. UN Doc S/2006/515 (2006). See Section 4.2.1.
} 
which is characterised by the UNSC as an ongoing threat to international peace and security.

As noted in Section 4.2.1, since 9/11 great latitude has been given by other states and international organizations to states acting in self-defence against terrorist NSAs. Such actions might be regarded as also being in the collective interests of the international community. Despite concern over civilian harm, and regardless of the legality of particular instances of targeting under both IHL and specific necessity, a significant number of states appear to accept that the fight against Daesh necessitates a response of this scale and effect. Such states may be taken as acknowledging that the price to be paid for combatting the NSA terrorist threat to them, and the international community as a whole, includes cities like Raqqa being destroyed and its citizens killed and forced to flee. After all, retaking Raqqa represented one of the milestones in defeating Daesh. The Coalition hailed the 'liberation' of the former capital of Daesh's socalled 'caliphate'. ${ }^{258}$ Russia, whilst blaming the Coalition for Raqqa's 'methodical destruction', has even credited the Coalition with 'smoking out' Daesh from the city. ${ }^{259}$ It also presumably constitutes the eradication of a key safe haven, as per the exhortation of UNSC Resolution $2249 .{ }^{260}$

Ultimately, the tragic humanitarian fallout from the Syrian incident has not prevented the Coalition from pursuing its goal of defeating Daesh, and there has been a paucity of other states labelling the purported defensive action as excessive. Ostensibly, there appears to be widespread recognition that if the ultimate defensive goal is the annihilation of Daesh, then there is no other way to achieve this aim. Although not unequivocal, this suggests the possibility that they consider the harm caused to Syria and its civilian population to be notionally proportionate to that necessity.

\footnotetext{
258 'Syrian Democratic Forces Liberate Raqqa', 20 October 2017, $<$ http://theglobalcoalition.org/en/syrian-democratic-forces-liberate-raqqa/>.

259 UN Doc S/PV.8186 (2018) 4.

${ }^{260}$ Although, it is doubtful whether the UNSC envisaged such an outcome in its call for states to act against Daesh.
} 
This permissive attitude renders the proportionality assessment rather surreal. It also raises the unpleasant prospect of an increased willingness on the part of certain states and international organizations to place issues of security above the human rights and humanitarian protections of those civilians affected by defensive action. It suggests an unfortunate rebalancing of the 'lesser evil' equation, tipping it in favour of self-defence to the detriment of the rights of the host state, and the rights and lives of its civilian population. The result is the prioritisation of the interests of the citizens of the defending state(s) over those of the host state. If this is the case, then self-defence in the NSA terrorist context is conceived of very differently than in the traditional interstate setting. This conclusion is extremely troubling for the humanitarian situation of those innocent civilians caught up in anti-terrorism conflicts.

Determining the (dis)proportionality of Coalition action is no easy task, therefore. It is further complicated by how the Coalition approaches the issue of civilian harm in this context, and what that means for assessing proportionality. As noted above, the Coalition insists that it is not targeting the Syrian state or its people, but only Daesh. The strike reports, taken on face value, confirm that targets are confined to civilian buildings, infrastructure and apparatus that are used or controlled by Daesh, and thus outside of the Syrian state's effective control. ${ }^{261}$ These targets are also justified as military objectives under IHL, ${ }^{262}$ which raises the question of whether IHL is the principal, or only, concern of the military when carrying out these strikes. ${ }^{263}$ The issue for JAB proportionality, however, is whether damage and destruction to such targets should count as harm to Daesh, or harm to the host state (Syria), or both. State practice does not provide a clear answer.

\footnotetext{
261 Gill (2016) 375, agrees that Coalition actions are directed almost exclusively against Daesh, which controlled a significant portion of Syrian territory, population and infrastructure, rather than Syrian government-held territory, population or infrastructure.

262 'Airstrikes, Civilian Casualties and Investigations', Coalition, 13 November 2017, $<$ http://theglobalcoalition.org/en/airstrikes-civilian-casualties-and-investigations/>.

${ }^{263}$ However, see Section 2.5 regarding the need for targeting also to serve a defensive purpose to be compliant with JAB specific necessity.
} 
The distinction is crucial, however. As noted, state practice indicates that states tend not to concern themselves with harm to terrorist NSAs, including buildings, infrastructure and apparatus that belong to them, or that are under their control. Therefore, purported defensive actions are more likely to be characterised as proportionate by states if the harm is viewed as pertaining to the NSAs, rather than the host state. As noted in Section 4.1.3(b), when public property is under the control of NSAs, and not under the effective control of the host state, it should not be identified with that of the host state. This perhaps accounts for the action taken in Syria, as well as the attitude of other states to it. If states view harm, i.e. to buildings, infrastructure and apparatus, principally caused to Daesh in those areas that it controls and (at most) only secondarily to Syria, then Coalition action as a whole is more likely to be regarded as proportionate as the damage to 'Syria' is that much less.

As noted above, the facts regarding the amount of collateral civilian injury and death is a highly contested subject. Regardless of whether the Coalition and other states view the harm caused by Coalition action to relate principally to Daesh, and not Syria, greater clarity is required regarding the extent of such civilian death and injury, and which party to the conflict caused it. Part of the JAB proportionality analysis will then hang on the IHL status issue of whether an individual was in fact a civilian, or DPIH. ${ }^{264}$ The JAB contains no such specific rules to distinguish between them. In addition to $\mathrm{IHL}$ rules governing $\mathrm{DPIH}$, however, it does require that targeting also serves a defensive purpose. ${ }^{265}$ Without further details of the civilian harm, however, it is difficult to conclude whether it will feature as it has in previous incidents, namely as an indicator of excessiveness that other states would normally not accept.

Forming a final view on the proportionality of the ongoing assault on Daesh in Syria and beyond, in order to destroy a threat that the UNSC has deemed to be global and enduring, is akin to being confronted with the Gordian knot. As a starting point, determining the factual elements of the Syrian incident, as they

\footnotetext{
264 See Section 2.5(a).

265 Ibid.
} 
relate to actions of the Coalition, will require further investigation. ${ }^{266}$ Even then, it is highly questionable whether any state, court or international body has the capacity to reach a definitive conclusion regarding the proportionality of the response of a large proportion of the international community to such threat. The permissive attitude of states and international organizations in the context of international terrorism suggests, however, that they are likely to take a more relaxed attitude to proportionality in the case of Syria than they would with an interstate exercise of self-defence. This is despite the disparity between the (relatively minimal) threat that is faced by many of the defending states and their citizens from the NSAs, and the (extensive) harm to the host state and its citizens that results from action to counter that threat.

This conclusion is extremely troubling for the general balance that proportionality seeks to achieve. It also points to the ability of militarily powerful states to intervene in their less powerful neighbours in the name of selfdefence. The Syrian incident showcases, therefore, the need for greater clarity in the law to enable better regulation of such conduct. Pending that development, it demonstrates the emphasis that must be placed on specific necessity and $\mathrm{IHL}$ as potential constraints on state behaviour. These are likely to be more meaningful markers of legality of state action in such complex scenarios. This, perhaps unsatisfactory, conclusion is discussed further in Chapter 5 , together with proposals for legal development.

\footnotetext{
${ }^{266}$ The HRC Syrian Commission of Inquiry was established in 2011 to investigate alleged violations of international human rights law. It has already produced a number of reports. Their work is ongoing and is welcome, not only for the purposes of their mandate, but also as a possible aid to examining the state practice pertaining to the Syrian incident. See: $<$ http://www.ohchr.org/EN/HRBodies/HRC/IICISyria/Pages/IndependentInternationalCommis sion.aspx>.
} 


\subsection{Conclusions}

The content and parameters of a right of self-defence against NSAs is still being worked out in state practice. When compared to interstate self-defence, however, necessity is revealed to have the potential to play a much greater role in the ability of states to act in self-defence against NSAs in foreign territory. Prima facie, the focus is on the primacy of host state action against the NSAs operating on its territory. However, the host state's relationship with both the terrorist group and the victim state is central to whether this represents a reasonable alternative to defensive force in the particular circumstances. The latter association determines whether consent to, or cooperation with, the host state to counter the terrorist threat constitutes a viable option. Whether the host state is seen as a legitimate partner, or cooperation with it will engage the international responsibility of the defending state(s), might also determine the necessity of defensive action.

The contentious unwilling or unable doctrine is central to the ability of defending states to act against NSAs in foreign territory. Debates over its existence in the lex lata, as well as regarding its possible content and practical operation are ongoing, however. If accepted by states, it constitutes an additional barrier to a defending state resorting to military action. Regardless of whether this principle explains state practice against NSAs in foreign territory, such practice suggests that defending states are not to target directly the governmental and military apparatus and infrastructure of the host state (and its allies) whilst acting in self-defence against NSAs on the territory of the host state. This practice highlights the importance of specific necessity in such cases. Drawing on the principles of IHL, it defines what is a permissible NSA target and an impermissible host state target.

How far any defensive action on the host state's territory may ultimately go is an issue for proportionality. The potential for this requirement to operate as a restraint on state action is much more uncertain. In the context of combatting international terrorism, its meaning is stretched, and its review is more permissive. States often act globally, on an enduring basis, and beyond their 
immediate defensive needs. Their responses may receive the blessing of the international community, in whose interests they might also be perceived to be acting. This is a troubling development and makes identifying the lesser evil much more difficult. The law is in flux, but it appears that the right of selfdefence in the context of international terrorism may unfortunately be prioritised above third-party interests and the human rights and humanitarian protections of civilians. 


\section{CHAPTER 5: CONCLUSIONS}

Claims of self-defence are almost ubiquitous when states resort to force beyond their own borders. Although the JAB does not contain absolute and rigid rules regarding what amounts to lawful self-defence, states invariably accept that their conduct is governed by international law and the requirements of necessity and proportionality. Even states that argue for an expansive right of self-defence recognize this fact. As a breach of either requirement transforms lawful acts of self-defence into unlawful uses of force, increased determinacy regarding their scope and substance is crucial to how force might be constrained by operation of international law. Necessity and proportionality are revealed to be flexible, however, with their application and appraisal contingent on the particular facts of each case. Establishing general rules for their application is, therefore, challenging. Despite these challenges, and the fact that the law is in flux, this thesis provides much greater precision regarding the conceptual meaning of necessity and proportionality and its normative content. Their operation is highly contextual, but the analytical framework set out herein allows for a more coherent exposition of both requirements. This increases their potential to exert a normative pull towards compliance.

The Caroline incident of 1837 endures as the locus classicus of international law governing the exercise of the right of self-defence. Webster's formula, whilst not synonymous with the contemporary lex lata, encapsulates its core elements. Once the availability of the right of self-defence is triggered by an actual or (potentially) imminent armed attack, necessity and proportionality condition the exercise of the right. More specifically, necessity determines whether defensive force may be used to respond to an armed attack, and where it must be directed. Proportionality governs how much total force is permissible. Crucially, this thesis contends that the two requirements are conceptually distinct, and must be applied in the foregoing order and on an ongoing basis throughout the duration of an armed conflict prompted by selfdefence. Their operation ensures that the purposes of self-defence are met, 
and nothing more. ${ }^{1}$ At the same time, necessity and proportionality guard against defensive force being unduly disruptive to third party interests and international peace and security more broadly.

The new taxonomy proposed by this thesis of 'general necessity' and 'specific necessity' captures the two distinct elements of the necessity requirement that are reflected in state practice, ICJ jurisprudence and scholarship. Drawing these brighter lines and applying the order of application referred to in the previous paragraph, challenges states, courts and scholars to consider what it is specifically about a purported act of self-defence that is necessary or unnecessary, proportionate or disproportionate. This approach avoids the tendency to determine and describe the legality of resorting to force in a 'catchall' manner, which fails to distinguish between these requirements. It requires a more detailed articulation of the law and its application to the facts. This serves to clarify the JAB's operation and review.

The concept of general necessity reflects Webster's 'no choice of means' formulation and whether resort to peaceable options is reasonable in the circumstances. State practice reveals a nuanced application of this premise, however. Whilst states consider defensive force to be a measure of last resort, they have yet to provide a consistent approach to what this means in practice, beyond this generally accepted hypothetical presumption. The importance of alternatives to force in determining the legality of purported defensive force is highly contextual. Resort or otherwise to peaceable options may stand as evidence of general necessity, but it may not factor at all in either the justification for, or review of, military action.

Ultimately, general necessity will be satisfied where, in the particular circumstances, there is a reasonable need for a defending state to respond to an armed attack using force. This will typically be established per se in the case of an ongoing armed attack, where recourse to peaceable resolution will

\footnotetext{
${ }^{1}$ The purposes of self-defence have been established as halting, repelling and, if a limited right of pre-emptive self-defence is accepted, preventing an armed attack. See Section 1.3.2.
} 
not usually constitute a reasonable alternative to force. The ability of general necessity to act as a meaningful restraint on the exercise of self-defence is, therefore, limited. This is especially so in the context of armed attacks against terrorist NSAs where, in the face of a perceived enduring threat, general necessity is revealed to be a weak limitation on state action.

In contrast, specific necessity operates as a clear restriction on the exercise of the right of self-defence. It confines defensive action to military targets connected with the armed attack, thereby ensuring that their capture, neutralisation or destruction is limited to a defensive purpose. A lack of this nexus suggests that a use of force has a purely punitive and, therefore, unlawful purpose. Specific necessity's importance as a separate and distinct element of necessity has been underappreciated to date. There is potential for future development, therefore, regarding how states conceive of the targeting requirements of the $\mathrm{JAB}$, and how these rules run alongside $\mathrm{IHL}$ to impose parallel and cumulative obligations.

Proportionality is shown, as a general precept, to prohibit excessive uses of defensive force. By operating to restrain the outcomes of a defending state's overall defensive response, it has the potential to contribute to the preservation of international peace and security. It seeks to minimise the disruption of defensive action to the international order and to the rights of those that operate within it. Proportionality is the more complex of the two requirements, however, with its content and outer boundaries lacking detail when compared to necessity. It is also more difficult to apply in practice. Yet, states tend to use this term as their preferred measure of the legality of self-defence. As a rhetorical tool, ${ }^{2}$ it will likely be employed to determine whether or not a state's use of putatively defensive force is deemed excessive by other states. This is so, even if it is not always clear whether the reference to (dis)proportionality is to the JAB, IHL, or both.

2 Gardam (2005) 25. 
Despite this lack of clarity, and the fact that state practice does not offer a consistent narrative, a number of conclusions are apparent regarding how states view JAB proportionality. This thesis shows that states do not commonly require precise equivalence between an armed attack and self-defence in terms of the nature, scale or means of the action taken, or its outcomes. When justifying and appraising defensive action, states primarily balance the defensive response and its outcomes, as a whole, against the legitimate purposes of self-defence. States may, therefore, respond defensively on a retrospective and prospective basis, whilst considering the wider threat comprising past, ongoing and (potentially) imminent armed attacks. Yet, its application is not the neat binary exercise proposed by some academic commentators, but rather involves weighing a diversity of interests. It is not simply a question, therefore, of referring to proportionality as either quantitative or teleological.

A mixed model of proportionality calls for a balance to be struck so that defensive military action does not result in harm that is completely out of proportion to the armed attack(s) that prompted it. There must be a rational connection between the two. In addition, when other states, courts and scholars review proportionality, third-party interests are also accounted for. These constitute potential additional limitations on the exercise of the right of self-defence, although the importance of neutrality and former belligerent rights, as well as the effect of defensive action on the environment, require further elaboration in state practice. What is apparent, is that defending states cannot prioritise their right to self-defence over the rights and interests of other states, and of the international community more broadly, and pursue it at any cost. Civilian collateral harm will typically stand as the principal factor that leads to a conclusion that an act of self-defence is excessive (viz disproportionate).

This thesis has also elaborated on the often-overlooked relationship between $\mathrm{IHL}$ and the JAB. These are essentially separate regimes of international law, but they have the potential to influence the understanding and operation of 
each other. The issue of $\mathrm{IHL}$ and the JAB operating together to regulate targeting is referred to above. In addition, this author has explained that JAB proportionality operates at the macro level of generality, with $\mathrm{IHL}$ proportionality being concerned with the micro level of individual targeting decisions. The exception is where widespread or systematic breaches of IHL constitute evidence of a shift in the overall scale or scope of a defensive response. Crucially, the analysis confirms that the JAB and IHL, whilst remaining as two separate and independent bodies of international law, impose cumulative obligations that apply to the entire defensive operation and must be consistently applied and monitored over that period. A clearer appreciation of this relationship between IHL and JAB provides scope for further theoretical development of how these legal regimes interrelate more generally, as well as contributing to real world decision-making regarding resorting to, conducting, and reviewing acts of self-defence.

Finally, this thesis has examined necessity and proportionality as they apply to self-defence in response to armed attacks by NSAs operating in foreign territory, principally in the context of international terrorism. Against this background, their requirements are adapted and supplemented. This author notes the potential of general necessity to play a greater role outside of the interstate context, where the requirement is likely to be satisfied more easily. This is because the option of seeking a solution via, or in cooperation with, the host state theoretically constitutes an additional limiting factor. However, this potential is not as strong as is sometimes suggested in the literature. Whether it stands as a reasonable alternative to the defending state using force is highly contextual. It is contingent on the timing of the armed attack and the relationships between the defending state and the host state, and between the host state and the NSAs. The risk to the defending state of its international responsibility being engaged by cooperating with a host state is also revealed to be a feature of more recent state practice.

Moreover, the response by states and the UNSC to international terrorism has severely tested the application of both necessity and proportionality as 
conceived of in the interstate context. State practice points to the continuing general necessity of some form of defensive response against what is perceived to be an enduring terrorist threat. This account takes the right of selfdefence beyond being a temporary right to respond to emergency situations. In terms of proportionality, states often act beyond their immediate defensive needs in their responses to international terrorism. They may take preventive action against potential future armed attacks by seeking to totally eliminate the NSA terrorists. It is clear that there is a much more permissive attitude on the part of states and the UNSC when reviewing such action. The law is in flux, but it appears that the right of self-defence in this context might be prioritised above the rights and interests of the host state and its civilians. A clear balance between these rights and interests, and a meaningful role for proportionality, is yet to be worked out in practice. The Syrian conflict stands as a worrying example, however, of potential imbalance and the resulting detriment to humanitarian protections.

Pending clarification of the lex lata through further state practice, this author argues that the burden falls to specific necessity to constrain military action and to determine the legality of a particular defensive response. Where general necessity and/or proportionality are in doubt, specific necessity is the JAB tool that has the greatest determinacy and, therefore, potential to govern whether self-defence is permissible against a particular terrorist group operating in a particular state. It is for this reason that the highly controversial unwilling or unable debate is so crucial. ${ }^{3}$ Whilst the law is unsettled, post 9/11 state practice suggests that where the host state is unwilling or unable to tackle the NSA threat itself, defending states may deem it necessary to target persons and objects on its territory. This ability raises concerns for the effect of defensive action on the host state, and for international peace and security more generally. However, drawing on principles of IHL, specific necessity establishes what is a permissible NSA target and an impermissible host state

\footnotetext{
${ }^{3}$ The unable or unwilling doctrine relates to both general and specific necessity, although it is submitted that the latter position is clearer in the practice of states and, therefore, has the greatest potential at this point in time to regulate conduct.
} 
target. This author's analysis suggests that defending states do not regard themselves as having a licence to target governmental and military apparatus and infrastructure of the host state (and its allies) when acting in self-defence against NSAs on its territory. Targeting is confined to non-military elements of a host state being used or occupied by the NSAs that were responsible for the armed attack. This limits the potential impact on the host state itself.

Normatively, the arguments and conclusions set out herein provide a basis for how future scholarship and jurisprudence might better conceive of, and help to develop, the right of self-defence. This thesis provides a scholastic and judicial tool for tackling some of the long-standing debates in the JAB relating to, inter alia, a right of self-defence against NSAs, responding defensively to imminent armed attacks, and whether there is a gravity threshold that triggers the right. The additional detail and nuance offers scope to move away from the focus to date on the armed attack and the examination of these controversies through that particular lens. The focus of scholars and international courts and tribunals should turn to the elements of self-defence that constitute the most prominent features of state practice and opinio juris: necessity and proportionality.

These requirements best represent how states view their right of self-defence, explain their actions and review the acts of other states. A more coherent and determinate conception of necessity and proportionality speaks directly to this fact and the operation of self-defence. It offers a better practical and theoretical statement of the law and constitutes a more effective determinant of the legality of state responses to armed attacks. The analytical framework set out in this thesis offers, therefore, the opportunity for a doctrinal switch that recognizes necessity and proportionality, and not armed attack, as the core regulating requirements of the exercise of self-defence. ${ }^{4}$ It challenges academics and judges to engage more fully with the detail of state practice and to avoid the conflations and inaccuracies of the past.

\footnotetext{
${ }^{4}$ See further Green (2009) 109, 209, making a similar argument.
} 
It has been suggested that ' $[$ ] he maintenance of world peace and security depends importantly on there being a common global understanding, and acceptance, of when the application of force is both legal and legitimate. ${ }^{5}$ International law provides the independent standard for judging the legitimacy of international actions. ${ }^{6}$ Most importantly, therefore, this thesis argues that the analytical framework set out herein constitutes a tool for states to justify and legitimate more clearly their actions. It also establishes a structure and procedure for other states, courts and international organizations to review more effectively putative acts of self-defence and to assess compliance with the law. Instead of pointing to the most obvious indicator of illegality, as has been the tendency of states and the ICJ to date, this requires consideration of the armed attack, followed by general necessity, specific necessity and proportionality, in that order.

Adopting this systematic approach assists with improved and more transparent decision-making. Such approach, and the greater normative determinacy provided by this thesis, contribute to the clarity, coherency and predictability that underpin the operation of the $\mathrm{JAB}$ and the maintenance and legitimacy of the international rule of law. ${ }^{7}$ Whilst the JAB remains, by its nature, an essentially indeterminate legal regime, this development has the potential to curtail the number of occasions that states resort to using force and to lead to fewer instances of excess where they do so. That this approach allows for more effective resolution of the question of the legality of defensive action, means that it might also reduce how states can abuse their right of selfdefence.

The current endeavour constitutes a greatly clarified and coherent statement of the lex lata. There is scope, however, for necessity and proportionality's

\footnotetext{
5 'A More Secure World: Our Shared Responsibility', Report of the High-Level Panel on Threats, Challenges and Change, UN Doc. A/59/565 (2004) para 184.

${ }^{6}$ Sands (2005) 238.

${ }^{7}$ A degree of indeterminacy will be found in any legal system and, for international law, it is arguable that indeterminacy is central to its acceptability, allowing for the legal rules to fulfill the purposes for which they are adopted. Koskenniemi (2006) 591. However, increased determinacy means a greater potential for law to exert a more powerful pull towards compliance. See generally Franck (1988); Deeks (2012), especially 508-14.
} 
potential to restrain defensive force to be further strengthened and operationalized. Recent efforts by states to engage with JAB issues are very welcome and indicate the potential for future legal development in this direction. ${ }^{8}$ Better articulation by states of their understanding of legal rules benefit the operation of the JAB and promote its advancement. In particular, putative defending states should articulate their reasons for using force, what information and facts these decisions were based on, and what they consider to be the legitimate goals of self-defence in the circumstances. Defending states should explain in detail why their actions are necessary and proportionate and provide data and information to support their claims. Such information should ideally be included in every report of self-defence to the UNSC, as required by Article 51 UN Charter. Other states should actively scrutinize claims of self-defence and, where absent, insist on explanations and available supporting evidence. They need to engage with the detail. Debates before the UNSC are the natural place for this dialogue to happen and should occur as a matter of course following a state resorting to force. Statements in other public fora that relate to the legality of self-defence are also to be encouraged. Such public explanations, or 'legal diplomacy', enable better international cooperation and joint action between states, as well as a common understanding of international law and a way to manage differences in interpreting obligations that are binding upon states. ${ }^{9}$

There is no substitute for better engagement by states with these issues, although this author accepts that such action, and a transparent dialogue, may not be forthcoming, or produce an obvious consensus amongst states regarding the applicable rules. As such, legal development would be aided by work that could build on the framework set out in this thesis. An equivalent of the UNGA Definition of Aggression might be too much to hope for by way of an attempt to codify the principles of necessity and proportionality, but there is

\footnotetext{
${ }^{8}$ E.g. USA State Department Legal Adviser Speech 2016; UK Attorney General Speech 2017; Australian Attorney General Speech 2017.

${ }^{9}$ USA State Department Legal Adviser Speech 2016, 237, 244-5. See further Tams in Van den Herik and Schrijver (2013) 419-21; The Leiden Policy Recommendations, 540-4, considering certain of these issues and the prospect of normative development.
} 
certainly scope for bodies such as the ILC to develop further their meaning and operation. Projects akin to the Chatham House Principles, the Tallinn Manual, ${ }^{10}$ or The Leiden Policy Recommendations could offer states the raw materials to further advance the law. ${ }^{11}$ This thesis represents an important step for our understanding of necessity and proportionality, therefore, but it is not the end of the story. The need for ever greater clarity is clear. As the JAB evolves to meet new challenges, states, scholars and the ICJ must focus on these requirements to enable international law to regulate more effectively how states exercise their right of self-defence.

\footnotetext{
${ }^{10}$ Schmitt (2013).

${ }^{11}$ For a recent example of a state actively engaging with, and recognizing the importance of, such projects (in this case Tallinn Manual 2.0), see e.g. 'Speech by Minister Bijleveld at the Tallinn Manual 2.0 Symposium in The Hague', 20 June 2018, $<$ https://www.defensie.nl/downloads/toespraken/2018/06/20/toespraak-minister-bijleveld-ophet-symposium-tallinn-manual-2.0>. A further example is reliance by states on the Bethlehem Principles. See Section 2.4.1(b).
} 


\section{BIBLIOGRAPHY}

A. Abass, 'Consent Precluding State Responsibility: A Critical Analysis' (2004) 53 ICLQ 211

R. Ago, 'Addendum to the Eighth Report on State Responsibility' (1980) UN Doc A/CN.4/318/Add.5-7

D. Akande, 'Nuclear Weapons, Unclear Law? Deciphering the Nuclear Weapons Advisory Opinion of the International Court' (1998) 68 BYIL 165

D. Akande and T. Liefländer, 'Clarifying Necessity, Imminence, and Proportionality in the Law of Self-Defence' (2013) 107 AJIL 563

D. Akande and M. Milanovic, 'The Constructive Ambiguity of the Security Council's ISIS Resolution', EJIL: Talk!, 21 November 2015, <https://www.ejiltalk.org/the-constructive-ambiguity-of-the-security-councilsisis-resolution/>

M.C. Alder, The Inherent Right of Self-Defence in International Law (Springer 2013)

S.A. Alexandrov, Self-Defense Against the Use of Force in International Law (Kluwer Law International 1996)

All Party Parliamentary Group on Drones Inquiry Report, 'The UK's Use of Armed Drones: Working with Partners', July 2018, $<$ http://appgdrones.org.uk/wp-

content/uploads/2014/08/INH PG Drones AlllnOne v25.pdf>

P. Alston, 'Report of the Special Rapporteur on Extrajudicial, Summary or Arbitrary Executions' (2010) Human Rights Council, UN Doc A/HRC/14/24/Add.6 
A. D'Amato, 'Israel's Air Strike against the Osiraq Reactor: A Retrospective' (1996) 10 Temp. Int'l \& Comp. L.J. 259

A. Aust, Handbook of International Law (Cambridge University Press 2005)

Australian Attorney-General, 'The Right of Self-Defence Against Imminent Armed Attack in International Law', Public Lecture at the T C Beirne School of Law, University of Queensland, 11 April 2017, <https://www.ejiltalk.org/theright-of-self-defence-against-imminent-armed-attack-in-international-law/> ('Australian Attorney General Speech 2017')

K. Bannelier-Christakis, 'Military Interventions against ISIL in Iraq, Syria and Libya, and the Legal Basis of Consent' (2016) 29(3) LJIL 743

J. Bellinger, 'Legal Issues in the War on Terrorism', Speech delivered at The London School of Economics, 31 October 2006, $<$ https://www.state.gov/s///2006/98861.htm>

D. Bethlehem, 'Not By Any Other Name: A Response to Jack Goldsmith on Obama's Imminence', Lawfare, 7 April 2016, $<$ https://www.lawfareblog.com/not-any-other-name-response-jack-goldsmithobamas-imminence>

--'The End of Geography: The Changing Nature of the International System and the Challenge to International Law' (2014) 25(1) EJIL 9

--'Principles of Self-Defense - A Brief Response' (2013) 107 AJIL 579

--'Self-Defense Against an Imminent or Actual Armed Attack by Nonstate Actors' (2012) 106 AJIL 770

L. Blank, 'The Extent of Self-Defence against Terrorist Groups: For How Long and How Far?' (2017) 47 Israel Yearbook on Human Rights 265

D.W. Bowett, 'Reprisals Involving Recourse to Armed Force' (1972) 66 AJIL 1 --Self-Defence in International Law (Manchester University Press 1958) 
--'Collective Self-Defence under the Charter of the United Nations' (1955-6) 32 BYIL 130

J. Boyle, 'Making Sense of Self-Defence in the War on Terror' (2014) 1 Journal on the Use of Force and International Law 55

S.C. Breau and A. Jachec-Neale (eds), Testing the Boundaries of International Humanitarian Law (British Institute of International and Comparative Law 2006)

T. Bridgeman, "About that "Deconfliction Zone" in Syria: Is the United States on Firm Domestic and International Legal Footing?', Just Security, 15 June 2017, <https://www.justsecurity.org/42183/deconfliction-zone-syria-unitedstates-firm-domestic-international-legal-footing/>

J.L. Brierly, 'International Law and Resort to Armed Force' (1932) 4 Cambridge L.J. 308

H. W. Briggs, The Law of Nations ( $2^{\text {nd }}$ ed Appleton-Century-Crofts 1952)

I. Brownlie, International Law and the Use of Force by States (Clarendon Press 1963)

W.E. Butler (ed), The Non-Use of Force in International Law (Nijhoff Publishers 1989)

D. Byman, 'Understanding the Islamic State - A Review Essay' (2016) 40(4) International Security 127

--Al Qaeda, the Islamic State, and the Global Jihadist Movement: What Everyone Needs to Know (Oxford University Press 2015)

E. Cannizzaro, 'Contextualizing Proportionality: Jus Ad Bellum and Jus In Bello In The Lebanese War' (2006) 88 International Review of the Red Cross 779 
E. Cannizzaro and P. Palchetti (eds), Customary International Law on the Use of Force: A Methodological Approach (Martinus Nijhoff Publishers 2005)

E. Castren, The Present Law of War and Neutrality (Academia Scientiarum Fennica 1954)

A. Cassese, International Law (2nd ed Oxford University Press 2005)

--'Article 51', in J.-P. Cot and A. Pellet, La Charte des Nations Unies (3rd ed Paris: Economica 2005)

--(ed), The Current Legal Regulation of the Use of Force (Martinus Nijhoff Publishers 1986)

E. Chachko and A. Deeks, 'Who is on Board with "Unwilling or Unable"?', Lawfare, 10 October 2016, <https://www.lawfareblog.com/who-boardunwilling-or-unable\#UnitedKingdom>

C. Chinkin, Third Parties in International Law (Oxford, Clarendon Press 1993)

A. Clapham and P. Gaeta (eds), The Oxford Handbook of International Law in Armed Conflict (Oxford University Press 2014)

A. Constantinou, The Right of Self-Defence Under Customary International Law and Article 51 of the United Nations Charter (Ant. N. Sakkoulas 2000)

O. Corten, 'The 'Unwilling or Unable' Test: Has it Been, and Could it be, Accepted?' (2016) 29(3) Leiden Journal of International Law 777

--The Law Against War: The Prohibition on the Use of Force in Contemporary International Law (Hart Publishing 2010)

J. Crawford, State Responsibility: The General Part (Cambridge University Press 2013)

--'Second Report on State Responsibility' (1999) UN Doc A/CN.4/498 and Add.1-4 
J. Crawford, A. Pellet, C. Redgwell, 'Anglo-American and Continental Traditions in Advocacy before International Courts and Tribunals' (2013) 2 Cambridge J. Int'I \& Comp. L. 715

A. Deeks, 'Imminence” in the Legal Adviser's Speech', Lawfare, 6 April 2016,

< https://www.lawfareblog.com/imminence-legal-advisers-speech>

--'Multi-Part Tests in the Jus ad Bellum' (2015-2016) 53 Hous. L. Rev. 1035

--'Unwilling or Unable': Toward a Normative Framework for Extra-Territorial Self-Defense' (2012) 52 Virginia Journal of International Law 483

Y. Dinstein, War, Aggression and Self-Defence (6th ed, Cambridge University Press 2017)

--War, Aggression and Self-Defence (5th ed, Cambridge University Press 2011)

--The Conduct of Hostilities under the Law of International Armed Conflict (2nd ed, Cambridge University Press 2010)

--War, Aggression and Self-Defence (4th ed, Cambridge University Press 2005)

--War, Aggression and Self-Defence (3rd ed, Cambridge University Press 2001)

--(ed), International Law at a Time of Perplexity: Essays in Honour of Shabtai Rosenne (Martinus Nijhoff Publishers 1989)

S. Etezazian, 'The Nature of the Self-Defence Proportionality Requirement' (2016) 3(2) Journal on the Use of Force and International Law 260

M.D. Evans (ed), International Law (3th ed, Oxford University Press 2014)

R.A. Falk, The Vietnam War and International Law, Volume 3 (Princeton University Press 2015)

W.J. Fenrick, 'The Exclusion Zone Device in the Law of Naval Warfare' (1986) 24 Can. Y.B. Int'l L 91 
D. Fleck (ed), The Handbook of International Humanitarian Law (3rd ed, Oxford University Press 2013)

T.M. Franck, 'On Proportionality of Countermeasures in International Law' (2008) 102 AJIL 715

--Recourse to Force: state Action Against Threats and Armed Attacks (Cambridge University Press 2002)

--'Terrorism and the Right of Self-Defense' (2001) 95 AJIL 839

--'Legitimacy in the International System' (1988) 82 AJIL 705

--'Who Killed Article 2(4) or: Changing Norms Governing the Use of Force by States' (1970) 64 AJIL 809

J. Gardam, 'A Role for Proportionality in the War on Terror' (2005) 74 Nordic Journal of International Law 3

--Necessity Proportionality and the Use of Force by States (Cambridge University Press 2004)

T. Gazzini, The Changing Rules on the Use of Force in International Law (Manchester University Press 2005)

T.D. Gill, 'Letter to the Editor from Professor Terry Gill on Classification of International Armed Conflict', Just Security, 14 October 2016, $<$ https://www.justsecurity.org/33569/letter-editor-prof-terry-gill-classificationinternational-armed-conflict/> --'Classifying the Conflict in Syria' (2016) 92 Int'l L. Stud. 353

--'The Temporal Dimension of Self-Defence: Anticipation, Pre-emption, Prevention and Immediacy' (2006) 11(3) J. Conflict \& Sec. L. 361

--'The Nuclear Weapons Advisory Opinion of the International Court of Justice and the Fundamental Distinction Between the Jus ad Bellum and the Jus in Bello' (1999) 12(3) LJIL 613 
M.J. Glennon, 'The Fog of War: Self-Defense, Inherence, and Incoherence in Article 51 of the United Nations Charter' (2002) 25(2) Harv. J.L. \& Pub. Pol'y 539

R. Goodman, 'Two U.S. Positions on the Duty to Ensure Respect for the Geneva Conventions', Just Security, 26 September 2016, $<$ https://www.justsecurity.org/33166/u-s-positions-duty-ensure-respectgeneva-conventions/>

--'Assad: Willing to Risk Direct Confrontation with U.S. Over Moderate Rebels

- and Stronger Opposition to US Airstrikes', Just Security, 27 January 2015, $<$ https://www.justsecurity.org/19419/syria-assad-risk-direct-confrontationmoderate-rebels-opposition-airstrikes/>

--'Taking the Weight off of International Law: Has Syria Consented to US Airstrikes?', Just Security, 23 December 2014, $<$ https://www.justsecurity.org/18665/weight-international-law-syriaconsented-airstrikes/>

--'International Law on Airstrikes against ISIS in Syria', Just Security, 28 August 2014, <https://www.justsecurity.org/14414/international-law-airstrikesisis-syria/>

C. Gray, International Law and the Use of Force (4th ed, Oxford University Press 2018)

--'The Limits of Force' (2016) 376 Collected Courses of the Hague Academy of International Law 101

--'President Obama's 2010 US National Security Strategy and International Law on the Use of Force' (2011) Chinese Journal of International Law 35 --International Law and the Use of Force (3rd ed, Oxford University Press 2008) 
J.A. Green, 'Initial Thoughts on the UK Attorney General's Self-Defence Speech', EJIL: Talk!, 13 January 2017, <https://www.ejiltalk.org/initialthoughts-on-the-uk-attorney-generals-self-defence-speech/>

--'The Ratione Temporis Elements of Self-Defence' (2015) 2(1) Journal on the Use of Force and International Law 97

--'The Article 51 Reporting Requirement for Self-Defense Actions' (2015) 55 Virginia Journal of International Law 563

--'Questioning the Peremptory Status of the Prohibition of the Use of Force' (2011) 32 Mich. J. Int'l L. 215

--The International Court of Justice and Self-Defence in International Law (Hart Publishing 2009)

--'Self-Defence: A State of Mind for States?' (2008) 55 NILR 181

--'Docking the Caroline: Understanding the Relevance of the Formula in Contemporary Customary International Law Concerning Self-Defense' (2006) 14(2) Cardozo Journal of International and Comparative Law 429

--'The Oil Platforms Case: An Error in Judgment?' (2004) J. Conflict \& Sec. L. 357

J.A. Green and C.P.M. Waters, 'Military Targeting in the Context of SelfDefence Actions' 84 (2015) Nordic Journal of International Law 3

C. Greenwood, 'Self-Defence' in Max Planck Encyclopaedia of Public International Law (Oxford University Press 2011)

--'International Law and the 'War Against Terrorism' (2002) 78 International Affairs 301

--'Memorandum: The Legality of Using Force Against Iraq' (24 October 2002) Select Committee on Foreign Affairs Minutes of Evidence <http://www.publications.parliament.uk/pa/cm200203/cmselect/cmfaff/196/21 $\underline{02406 . h t m>}$

--'New World Order or Old - The Invasion of Kuwait and the Rule of Law' (1992) 55 Mod. L. Rev. 153 
--'Self-Defence and the Conduct of International Armed Conflict' in Y. Dinstein (ed), International Law at a Time of Perplexity: Essays in Honour of Shabtai Rosenne (Martinus Nijhoff Publishers 1989)

--'International Law and the United States' Air Operation Against Libya' (19861987) 89 W. Va. L. Rev. 933

--'The Relationship Between Jus ad Bellum and Jus in Bello' (1983) 9 Review of International Studies 221

D.W. Greig, 'Self-Defence and the Security Council: What Does Article 51 Require?' (1991) 40 ICLQ 366

D. Guilfoyle, 'The Mavi Marmara Incident and Blockade in Armed Conflict' (2011) 81(1) BYIL 171

M. Hakimi, 'The UK's Most Recent Volley on Defensive Force', EJIL: Talk!, 12 January 2017, <https://www.ejiltalk.org/the-uks-most-recent-volley-ondefensive-force/>

--'US Responsibility Arising From Russian Violations of the Law of Armed Conflict', Just Security, 21 September 2016, $<$ https://www.justsecurity.org/33075/u-s-responsibility-arising-russianviolations-law-armed-conflict/>

M. Hakimi and J.K. Cogan, 'A Role for the Security Council on Defensive Force?', EJIL: Talk!, 21 October 2016, <https://www.ejiltalk.org/a-role-for-thesecurity-council-on-defensive-force/>

M. Halberstam, 'The Right to Self-Defence Once the Security Council Takes Action' (1996) 17 Mich. J. Int'I L. 229

A. Haque, 'On the Precipice: The U.S. and Russia in Syria', Just Security, 19 June 2017, <https://www.justsecurity.org/42297/precipice-u-s-russia-syria/> 
--'Imminence and Self-Defense Against Non-State Actors: Australia Weighs In', Just Security, $30 \quad$ May 2017, $<$ https://www.justsecurity.org/41500/imminence-self-defense-non-stateactors-australia-weighs/>

--'The United Kingdom's "Modern Law of Self-Defence" - Part I', Just Security, 12 January 2017, <https://www.justsecurity.org/36235/united-kingdomsmodern-law-self-defence-part/>

--'Between the Law of Force and the Law of Armed Conflict', Just Security, 13 October 2016, <https://www.justsecurity.org/33515/law-force-law-armedconflict/>

J.L. Hargrove, 'The Nicaragua Judgment and the Future of the Law of Force and Self-Defence' (1987) 81 AJIL 135

K.J. Heller, 'Ashley Deeks' Problematic Defense of the "Unwilling or Unable" Test', Opinio Juris, 15 December 2011, $<$ http://opiniojuris.org/2011/12/15/ashley-deeks-failure-to-defend-theunwilling-or-unable-test/>

C. Henderson, The Use of Force and International Law Challenges (Cambridge University Press 2018)

--'The 2010 United States National Security Strategy and the Obama Doctrine of 'Necessary Force” (2010) J. Conflict \& Sec. L. 403

C. Henderson and J.A. Green, 'The Jus ad Bellum and Entities Short of Statehood in the Report on the Conflict in Georgia' (2010) 59 ICLQ 129

L. Henkin, 'The Invasion of Panama Under International Law: A Gross Violation' (1991) 29 Colum. J. Transnat'I L. 293

E. Henry, 'Alleged Acquiescence of the International Community to Revisionist Claims of International Customary Law (With Special Reference to the Jus Contra Bellum Regime)' (2017) 18 Melb. J. Int'l L. 260 
L. van den Herik and N. Schrijver (eds), Counter-Terrorism Strategies in a Fragmented International Legal Order: Meeting the Challenges (Cambridge University Press 2013)

G.I. Hernández, The International Court of Justice and the Judicial Function (Oxford University Press 2014)

R. Higgins, Problems and Process: International Law and How We Use It (Oxford University Press 1994)

--The Development of International Law Through the Political Organs of the United Nations (Oxford University Press for the Royal Institute of International Affairs 1963)

J. Horowitz, 'Is the US Allowed to Control a Syrian Airfield?', Just Security, 27 January 2016, <https://www.justsecurity.org/28988/allowed-control-syrianairfield/>

International Law Association Study Group on the Conduct of Hostilities in the 21st Century, 'The Conduct of Hostilities and International Humanitarian Law: Challenges of 21st Century Warfare', Final Report (2017) 93 Int'I L. Stud. 322

R. Jennings, 'The Caroline and McLeod Cases' (1938) 32(1) AJIL 82

R. Jennings and A. Watts (eds), Oppenheim's International Law: Volume I, Peace (9th ed, Longman 1996)

J. Kammerhofer, 'Uncertainty in the Formal Sources of International Law: Customary International Law and Some of Its Problems' (2004) 15(3) EJIL 523

T. Kearley, 'Raising the Caroline' (1999) 17 Wis. Int'I L.J. 325

M. Koskenniemi, Apology to Utopia: The Structure of International Legal Argument (Cambridge University Press 2006) 
N. Klein, Maritime Security and the Law of the Sea (Oxford University Press 2012)

C. Kress, 'The Fine Line Between Collective Self-Defense and Intervention by Invitation: Reflections on the Use of Force against 'IS' in Syria', Just Security, 17 February 2015, <https://www.justsecurity.org/20118/claus-kreb-force-isilsyria/>

D. Kretzmer, 'The Inherent Right to Self-Defence and Proportionality in Jus Ad Bellum' (2013) 24(1) EJIL 235

D. Kritsiotis, 'The Legality of the 1993 US Missile Strike on Iraq and the Right of Self-Defence in International Law' (1996) 45 ICLQ 150

E. Kwakwa, 'South Africa's May 1986 Military Incursions into Neighboring African States' (1987) 12 Yale J. Int'I L. 421

A. Laursen, 'The Use of Force and (the State of) Necessity' (2004) 37 Vand. J. Transnat'I L. 485

E. Lauterpacht, 'The Legal Irrelevance of the "State of War"' (1968) 62 Am. Soc'y Int'I L. Proc. 58

M. Lederman, 'The Egan speech and the Bush Doctrine: Imminence, Necessity, and "First Use" in the Jus ad Bellum', Just Security, 11 April 2016, $<$ https://www.justsecurity.org/30522/egan-speech-bush-doctrine-imminencenecessity-first-use-jus-ad-bellum/> --'Speech by State Legal Adviser Egan on International Law and the Use of Force against ISIL', Just Security, 4 April 2016, $<$ https://www.justsecurity.org/30377/asil-speech-state-legal-adviserinternational-law-basis-for-limits-on-force-isil> 
D.A. Lewis, G. Blum and N. K. Modirzadeh, 'Indefinite War: Unsettled International Law on the End of Armed Conflict' (February 2017) Harvard Law Sch. Program on Int'l Law \& Armed Conflict, $<$ https://dash.harvard.edu/bitstream/handle/1/30455582/Indefinite\%20War\%2 0-\%20February\%202017 3.pdf?sequence=4>

M.J. Levitin, 'The Law of Force and the Force of Law: Grenada, the Falklands, and Humanitarian Intervention' 27 (1986) Harv. Int'l. L. J. 621

J. Lobel, 'The Use of Force to Respond to Terrorist Attacks: The Bombing of Sudan and Afghanistan' (1999) 24 Yale J. Int'I L. 537

V. Lowe, 'Clear and Present Danger': Responses to Terrorism' (2005) 54 ICLQ 185

N. Lubell, 'Fragmented Wars: Multi-Territorial Military Operations Against Armed Groups' (2017) 93 Int'l L. Stud. 215

--'Comments on David Kretzmer's "The Inherent Right to Self-Defence and Proportionality in Jus ad Bellum"', EJIL: Talk!, 17 April 2013, $<$ http://www.ejiltalk.org/comments-on-david-kretzmers-the-inherent-right-toself-defence-and-proportionality-in-jus-ad-bellum/>

--Extraterritorial Use of Force Against Non-State Actors (Oxford University Press 2010)

R.St.J. Macdonald, 'The Nicaragua Case: New Answers to Old Questions?' (1986) Can. Y.B. Int'l L 127

C. Michaelsen, 'Maritime Exclusion Zones in Times of Armed Conflict at Sea: Legal Controversies Still Unresolved' (2003) 8 J. Conflict \& Sec. L. 5363

M. Milanovic, 'What is an Imminent Armed Attack? A Hopefully Helpful Hypo', EJIL: Talk!, 12 January 2017, <https://www.ejiltalk.org/what-is-an-imminentarmed-attack-a-hopefully-helpful-hypo/> 
--'Self-Defense and Non-State Actors: Indeterminacy and the Jus ad Bellum' EJIL: Talk!, 21 February 2010, <https://www.ejiltalk.org/self-defense-and-nonstate-actors-indeterminacy-and-the-jus-ad-bellum/>

E. Miller, 'Self-Defence, International Law, and the Six Day War' (1985) Israel Law Review 49

J. Moussa, 'Can Jus ad Bellum Override Jus in Bello? Reaffirming the Separation of the Two Bodies of Law' (2008) 90 International Review of the Red Cross 963

S.D. Murphy, 'Protean Jus ad Bellum' (2009) 27 BERKJIL 22

--'Terrorism and the Concept of "Armed Attack" in Article 51 of the U.N. Charter' (2002) 43 Harv. Int'l L.J. 41

--(ed) 'Contemporary Practice of the United States Relating to International Law' (2002) 96 AJIL 237

E.P.J. Myjer and N.D. White 'The Twin Towers Attack: An Unlimited Right to Self-Defence' (2002) 7 J. Conflict \& Sec. L. 5

S. Neff, War and the Law of Nations (Cambridge University Press 2005)

G. Nolte, 'Multipurpose Self-Defence, Proportionality Disoriented: A Response to David Kretzmer' (2013) 24(1) EJIL 283

D.P. O'Connell, The International Law of the Sea (Oxford, Clarendon Press 1984)

--The Influence of Law on Sea Power (Naval Institute Press 1975)

Office of the Legal Adviser, Department of State, 'Rights and Duties of States' (1972) 66 AJIL 836

J.D. Ohlin (ed), Theoretical Boundaries of Armed Conflict and Human Rights (Cambridge University Press 2016) 
--'The Doctrine of Legitimate Defense' (2015) 91 Int'l L. Stud. 119

J.D. Ohlin and L. May, Necessity in International Law (Oxford University Press 2016)

K. Okimoto, 'The Cumulative Requirements of Jus ad Bellum and Jus in Bello in the Context of Self-Defense' (2012) 11 Chinese Journal of International Law 45

C. O'Meara, 'Should International Law Recognize a Right of Humanitarian Intervention?' (2017) 66(2) ICLQ 441

--'The Relationship Between National, Unit and Personal Self-Defence in International Law: Bridging the Disconnect' (2017) 4(2) Journal on the Use of Force and International Law 273

L. Oppenheim, International Law: A Treatise, Vol. II (H. Lauterpacht (ed), 7th ed, Longmans 1948)

F. Paddeu, Justification and Excuse in International Law (Cambridge University Press 2018)

--'Use of Force against Non-state Actors and the Circumstance Precluding Wrongfulness of Self-Defence' (2017) 30 LJIL 93

--'Self-Defence as a Circumstance Precluding Wrongfulness: Understanding Article 21 of the Articles on State Responsibility' (2015) 85 BYIL 90

J. Paust, 'Use of Armed Force against Terrorists in Afghanistan, Iraq, and Beyond' (2002) 35 Cornell Int'l L.J. 533

J. Quigley, 'The Afghanistan War and Self-Defense' (2003) 37 Val. U. L. Rev. 541

J. Raby, 'The State of Necessity and the Use of Force to Protect Nationals' (1988) 26 Can. Y.B. Int'I L. 253 
W.M. Reisman, 'Self-Defense in an Age of Terrorism' (2003) 97 Am. Soc'y Int'l L. Proc. 141

--'Criteria for the Lawful Use of Force in International Law' (1985) 10 Yale J. Int'l L. 279.

--'International Incidents: Introduction to a New Genre in the Study of International Law' (1984-1985) 10 Yale J. Int'l L. 1

W.M. Reisman and A. Armstrong, 'The Past and Future of the Claim of Preemptive Self-Defense' (2006) 100 AJIL 525

D. Richemond-Barak, 'Is Money a Legitimate Target?', Just Security, 10 February 2016, <https://www.justsecurity.org/29255/money-legitimatetarget/>

A. Roberts, 'Environmental Destruction in the 1991 Gulf War' (1992) 291 International Review of the Red Cross 538

D. Rodin, War and Self-Defense (Oxford University Press 2005)

T. Ruys, 'Armed Attack' and Article 51 of the UN Charter: Evolutions in Customary Law and Practice (Cambridge University Press 2010)

--'Quo Vadit Jus Ad Bellum?: A Legal Analysis Of Turkey's Military Operations Against the PKK In Northern Iraq' (2008) 9 Melb. J. Int'I L. 334

--'Crossing the Thin Blue Line: An Inquiry into Israel's Recourse to SelfDefense against Hezbollah (2007) 43 Stan. J. Int'l L. 265

T. Ruys et al, 'Digest of State Practice: 1 January-30 June 2017' (2017) 4(2) Journal on the Use of Force and International Law 371

T. Ruys and O. Corten (eds) The Use of Force in International Law: A CaseBased Approach (Oxford University Press 2018) 
T. Ruys and S. Verhoeven, 'Attacks by Private Actors and the Right of SelfDefence' (2005) 10 J. Conflict \& Sec. L. 289

C. Ryngaert, 'State Responsibility, Necessity and Human Rights' (2010) 41 NYIL 79

San Remo Manual on International Law Applicable to Armed Conflicts at Sea, $12 \quad J u n e \quad 1994, \quad<\underline{\text { https://ihl- }}$ databases.icrc.org/applic/ihl/ihl.nsf/Treaty.xsp?action=openDocument\&docu mentld=5B310CC97F166BE3C12563F6005E3E09>

P. Sands, Lawless World: America and the Making and Breaking of Global Rules from FDR's Atlantic Charter to George W. Bush's Illegal War (Viking Penguin 2005)

P. Sands and J. Peel, Principles of International Environmental Law $\left(4^{\text {th }}\right.$ ed, Cambridge University Press 2018)

B. Saul, 'Attempts to Define 'Terrorism' in International Law' (2005) 52(1) NILR 57

B. Van Schaack, 'Targeting Tankers Under the Law of War (Part 1)', Just Security, 2 December 2015, <https://www.justsecurity.org/28064/targetingtankers-law-war-part-1/>

O. Schachter (Chair), 'Implementing Limitations on the Use of Force: The Doctrine of Proportionality and Necessity' (1992) 86 Am. Soc'y Int'I L. Proc. 39 --'United Nations Law in the Gulf Conflict' (1991) 85 AJIL 452

--International Law in Theory and Practice (Martinus Nijhoff Publishers 1991) --'Self-Defense and the Rule of Law' (1989) 83 AJIL 259 --'The Extraterritorial Use of Force against Terrorist Bases' (1988-1989) 11(2) Houston Journal of International Law 309 
--'In Defense of International Rules on the Use of Force' (1986) 53 U. Chi. L. Rev. 113

--'The Lawful Resort to Unilateral Use of Force' (1985) 10 Yale J. Int'I L. 291

--'The Right of States to Use Armed Force' (1984) 82 Mich. L.R. 1620

M. Schmitt, (ed) Tallinn Manual on the International Law Applicable to Cyber Warfare (Cambridge University Press 2013)

--'Drone Attacks under the Jus ad Bellum and Jus in Bello: Clearing the 'Fog of Law' (2010) 13 Yearbook of International Humanitarian Law 311

--"'Change Direction" 2006: Israeli Operations in Lebanon and the International Law of Self-Defense' (2007-2008) 29 Mich. J. Int'l L. 127

--'Preemptive Strategies in International Law' (2002-2003) 24 Mich. J. Int'l L. 513

N. Schrijver and L. van den Herik, 'Leiden Policy Recommendations on Counter-Terrorism and International Law' (2010) 57(3) NILR 531

B. Simma, 'NATO, the UN and the Use of Force: Legal Aspects' (1999) 10 EJIL 1

B. Simma et al (eds), The Charter of the United Nations: A Commentary ( $3^{\text {rd }}$ ed, Oxford University Press 2012)

P. Starski, 'Silence Within the Process of Normative Change and Evolution of the Prohibition on the Use of Force: Normative Volatility and Legislative Responsibility' (2017) 4(1) Journal on the Use of Force and International Law 14

R. Van Steenberghe, 'State Practice and the Evolution of the Law of SelfDefence: Clarifying the Methodological Debate' (2015) 2(1) Journal on the Use of Force and International Law 81

--'Proportionality under Jus ad Bellum and Jus in Bello: Clarifying their Relationship' (2012) 45(1) Israel Law Review 107 
--'Self-Defence in Response to Attacks by Non-state Actors in the Light of Recent State Practice: A Step Forward? (2010) 23(1) LJIL 183

S. Talmon, 'Determining Customary International Law: The ICJ's Methodology between Induction, Deduction and Assertion' (2015) 26(2) EJIL 417

C. Tams, 'The Use of Force against Terrorists' (2009) 20(2) EJIL 359

C. Tams and J. Devaney, 'Applying Necessity and Proportionality to AntiTerrorist Self-Defence' (2012) 45(1) Israel Law Review 91

C. Tams and J. Sloan (eds), The Development of International Law by the International Court of Justice (Oxford Scholarship Online 2014)

W. Taft, 'Self-Defense and the Oil Platforms Decision' (2004) 29 Yale J. Int'I L. 295

R.G. Teitel, Humanity's Law (Oxford University Press 2011)

K.N. Trapp, 'Actor-Pluralism, the 'Turn to Responsibility' and the Jus ad Bellum: 'Unwilling or Unable' in Context' (2016) 2(2) Journal on the Use of Force and International Law 199

--State Responsibility for International Terrorism (Oxford University Press 2011)

--'The Use of Force against Terrorists: A Reply to Christian J. Tams' (2009) 20(4) EJIL 1049

--'Back to Basics: Necessity, Proportionality and the Right of Self-Defence against non-State Terrorist Actors' (2007) 56(1) ICLQ 141

N. Tsagourias, 'Self-Defence against Non-state Actors: The Interaction between Self-Defence as a Primary Rule and Self-Defence as a Secondary Rule' (2016) 29(3) LJIL 801

--'Necessity and the Use of Force: A Special Regime' (2010) 41 NYIL 11 
UK Attorney General's Speech at the International Institute for Strategic Studies, 'The Modern Law of Self-Defence', 11 January 2017, $<$ https://www.gov.uk/government/uploads/system/uploads/attachment data/fi le/583171/170111 Imminence Speech .pdf> ('UK Attorney General Speech 2017')

UK Ministry of Defence, The Manual of the Law of Armed Conflict (Oxford University Press 2005)

USA State Department Legal Adviser, 'International Law, Legal Diplomacy, and the Counter-ISIL Campaign', speech to the American Society of International Law, 1 April 2016, available at (2016) 92 Int'l L. Stud. 235 ('USA State Department Legal Adviser Speech 2016')

E. de Vattel, The Law of Nations, Or, Principles of the Law of Nature, Applied to the Conduct and Affairs of Nations and Sovereigns (1797, reprinted Indianapolis: Liberty Fund 2011)

J. Vidmar, 'The Use of Force as a Plea of Necessity' (2017) 111 AJIL Unbound 302

C.H.M. Waldock 'The Regulation of the Use of Force by States in International Law' (1951) 81 Collected Courses of the Hague Academy of International Law 451

K. Watkin, Fighting at the Legal Boundaries: Controlling the Use of Force in Contemporary Conflict (Oxford University Press 2016)

--'The ICRC Updated Commentaries: Reconciling Form and Substance, Part II', Just Security, 30 August 2016, <https://www.justsecurity.org/32608/icrcupdated-commentaries-reconciling-form-substance-part-ii/> --'Sustaining the War Effort: Targeting Islamic State Oil Facilities' Just Security, 3 October 2014, <https://www.justsecurity.org/15890/sustaining-wareffort-targeting-islamic-state-oil-facilities/> 
M.C. Waxman 'Regulating Resort to Force: Form and Substance of the UN Charter Regime' (2013) 24(1) EJIL 151

R. Wedgwood, 'The ICJ Advisory Opinion on the Israeli Security Fence and the Limits of Self-Defense' (2005) 99 AJIL 52

--'Responding to Terrorism: The Strikes Against bin Laden' (1999) 24 Yale J. Int'I L. 559

M. Weller (ed), Oxford Handbook on the Use of Force in International Law (Oxford University Press 2015)

--'Permanent Imminence of Armed Attacks: Resolution 2249 (2015) and the Right to Self Defence Against Designated Terrorist Groups' EJIL: Talk!, 25 November 2015, <https://www.ejiltalk.org/permanent-imminence-of-armedattacks-resolution-2249-2015-and-the-right-to-self-defence-againstdesignated-terrorist-groups/>

G. Wettberg, The International Legality of Self-Defense Against Non-State Actors, State Practice from the U.N. Charter to the Present (Peter Lang 2007)

A.R. Willard, 'Incidents: An Essay in Method' (1984-1985) 10 Yale J. Int'I L. 21

E. Wilmshurst (ed), International Law and the Classification of Conflicts (Oxford University Press 2012)

--'The Chatham House Principles of International Law on the Use of Force in Self-Defence' (2006) 55 ICLQ 963

E. Wilmshurst and M. Wood, 'Self-Defense Against Nonstate Actors: Reflections on the "Bethlehem Principles"' (2013) 107 AJIL 390

R. Wolfrum and C. Philipp (eds), United Nations: Law, Policies and Practice (Nijhoff 1995) 
M. Wood, 'The Use of Force in 2015 With Particular Reference to Syria' (2016) Hebrew University of Jerusalem Legal Studies Research Paper Series No. 1605

A. Zimmermann, 'The Second Lebanon War: Jus ad bellum, Jus in Bello and the Issue of Proportionality' (2007) 11 Max Planck Yearbook of United Nations Law 99 